\title{
UICN
}

\section{Gobernanza para la adaptación basada en ecosistemas}

Alejandro Iza

Editor

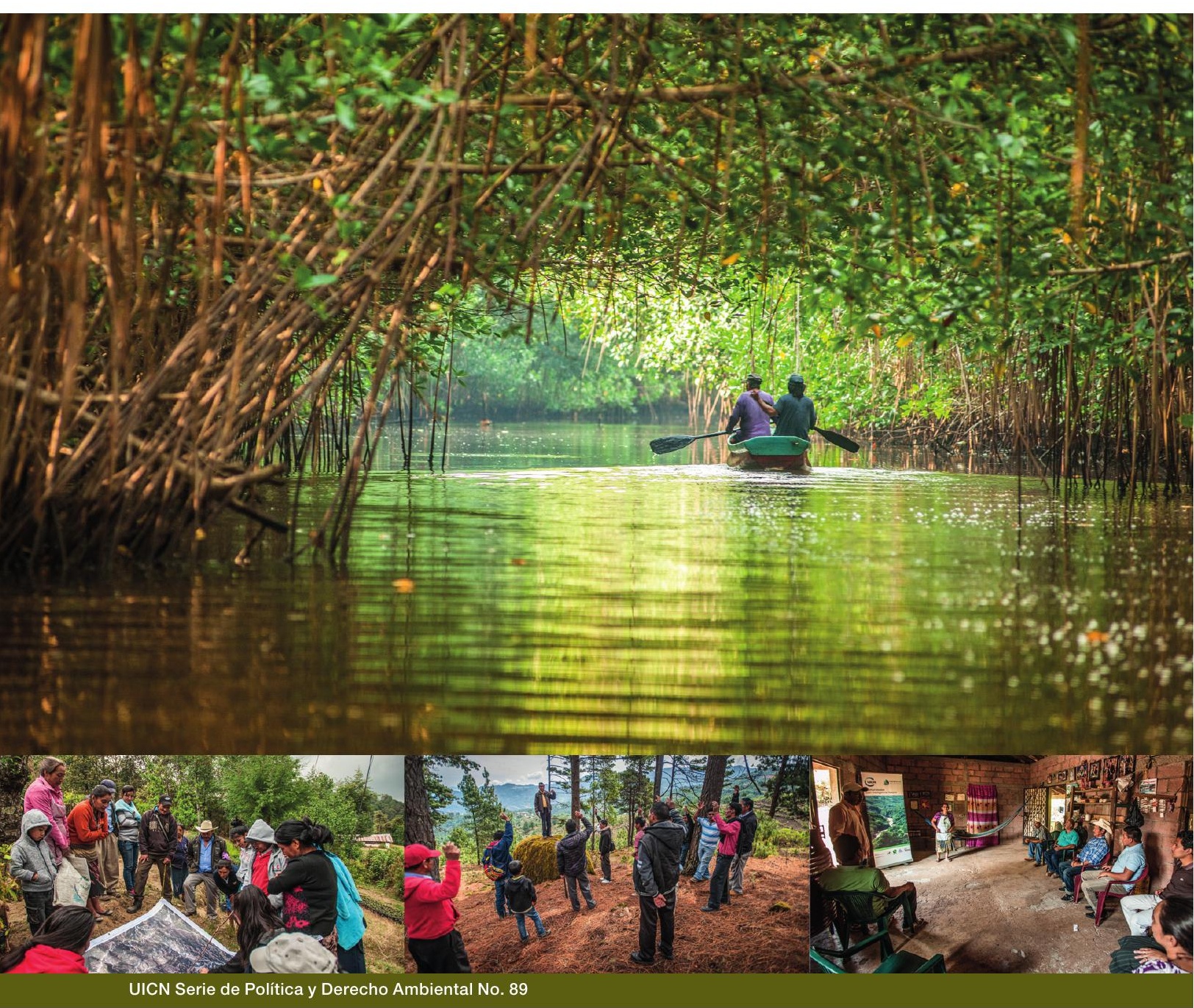

20. $\begin{aligned} & \text { Ministerio Federal } \\ & \text { de Sedio Ambiente, } \\ & \text { y Seguridad Nuclear }\end{aligned}$ 
Gobernanza para la adaptación basada en ecosistemas 



\section{Gobernanza para la adaptación basada en ecosistemas}

Alejandro Iza

Editor 
La presentación del material en esta publicación y las denominaciones empleadas para las entidades geográficas no implican en absoluto la expresión de una opinión por parte de la UICN, de la Iniciativa Internacional del Clima (IKI, por sus siglas en alemán) o del Ministerio Federal Alemán para el Ambiente, la Conservación de la Naturaleza y Seguridad Nuclear (BMU, por sus siglas en alemán) sobre la situación jurídica de un país, territorio o zona, o de sus autoridades, o acerca de la demarcación de sus límites o fronteras.

Los puntos de vista que se expresan en esa publicación no reflejan necesariamente los de la UICN, la IKI o el BMU.

Esta publicación ha sido posible con el amable apoyo de la Iniciativa Internacional del Clima (IKI).EI Ministerio Federal Alemán para el Ambiente, la Conservación de la Naturaleza y Seguridad Nuclear (BMU) apoya esta iniciativa sobre la base de una resolución adoptada por el Parlamento Alemán.

Publicada por:

UICN, Gland, Suiza, en colaboración con el Centro de Derecho Ambiental de la UICN, Bonn, Alemania y la Oficina Regional para México, América Central y el Caribe (ORMACC)

Copyright:

(C) 2019 UICN, Unión Internacional para la Conservación de la Naturaleza y de los Recursos Naturales

Se autoriza la reproducción de esta publicación con fines educativos y otros fines no comerciales sin permiso escrito previo de parte de quien detenta los derechos de autor con tal de que se mencione la fuente.

Se prohíbe reproducir esta publicación para la venta o para otros fines comerciales sin permiso escrito previo de quien detenta los derechos de autor.

Cita bibliográfica: $\quad$ Iza A. (ed.) (2019). Gobernanza para la adaptación basada en ecosistemas. Gland, Suiza: UICN. xx + 156 pp.

ISBN: $\quad$ 978-2-8317-2003-6 (PDF)

978-2-8317-2004-3 (imprenta)

DOI:

https://doi.org/10.2305/IUCN.CH.2019.EPLP.89.es

Fotos de la portada: (C) Paul Aragón

Diseño por:

layout \& more, Bonn, Alemania

Impresión por:

Masterlitho S.A., San José, Costa Rica

Medienhaus Plump, Rheinbreitbach, Alemania

Disponible en: $\quad$ UICN, Unión Internacional para la Conservación de la Naturaleza www.iucn.org/resources/publication

\author{
53175 Bonn, Alemania \\ Tel: $\quad$ + 492282692231 \\ Fax: $\quad+492282692246$ \\ elcsecretariat@iucn.org \\ www.iucn.org/law
}

Programa de Derecho Ambiental

Centro de Derecho Ambiental (ELC)
Oficina Regional para México, América

Central y el Caribe (ORMACC)

San José, Costa Rica

Tel: + 50622838449

Fax: + 50622838472

ormacc@iucn.org

www.iucn.org/ormacc 


\section{Índice}

Prólogo $\ldots \ldots \ldots \ldots \ldots \ldots \ldots \ldots \ldots \ldots \ldots \ldots \ldots \ldots \ldots \ldots \ldots \ldots \ldots \ldots \ldots \ldots \ldots \ldots \ldots$

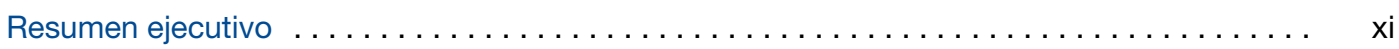

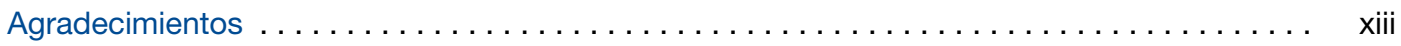

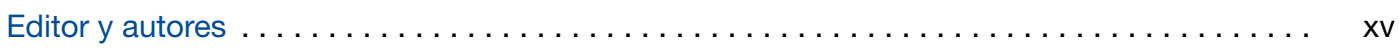

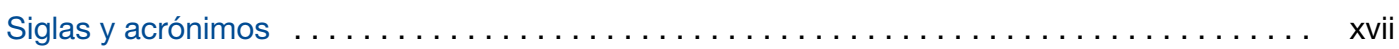

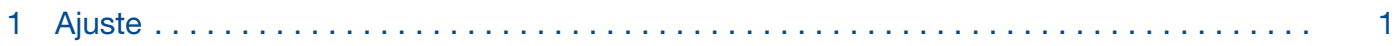

1.1 Introducción: retomando la biodiversidad y los servicios de los ecosistemas como tema esencial para la adaptación al cambio climático $\ldots \ldots \ldots \ldots \ldots \ldots \ldots \ldots . \ldots \ldots$

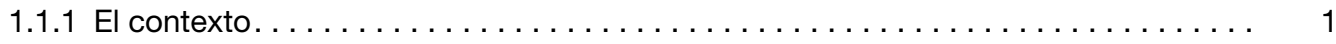

1.1.2 La Adaptación basada en Ecosistemas (AbE) en el contexto actual . . . . . . . . 3

1.2 La buena gobernanza: una propuesta innovadora de valor para la sostenibilidad

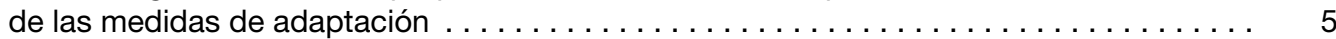

1.3 La articulación necesaria entre la gobernanza y la AbE: una visión futura hacia la sostenibilidad. . . . . . . . . .

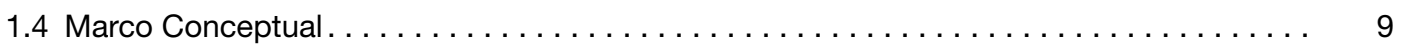

1.5 Contribuciones de la Gobernanza para la AbE a los acuerdos internacionales . . . . . . . 15

1.5.1 Convenio sobre la Diversidad Biológica $(\mathrm{CDB}) \ldots \ldots \ldots \ldots \ldots \ldots \ldots \ldots \ldots \ldots$

1.5.2 Los Objetivos de Desarrollo Sostenible (ODS) $\ldots \ldots \ldots \ldots \ldots \ldots \ldots \ldots \ldots \ldots \ldots$

1.5.3 Acuerdo de París y las Contribuciones Nacionalmente Determinadas (NDC). . . . . 18

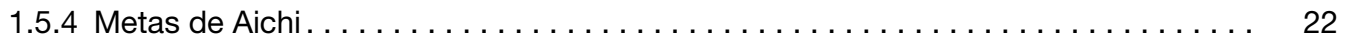

1.5 .5 Protocolo de Nagoya. . . . . . . . . . . . . . . . . . . . . . 23

1.5.6 Marco de Sendai para la Reducción del Riesgo de Desastres 2015-2030 . . . . . 24

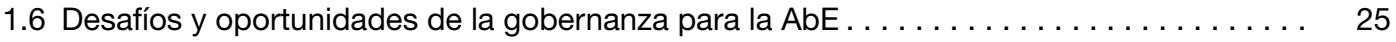

2 Capacidades.................................. 27

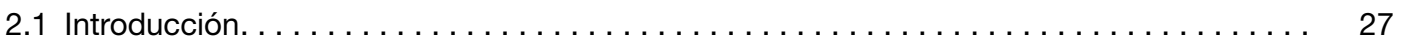

2.2 Capacidad, gobernanza y adaptación $\ldots \ldots \ldots \ldots \ldots \ldots \ldots \ldots \ldots \ldots \ldots \ldots \ldots$

2.3 Actores, habilidades y capacidades para la gobernanza para la AbE . . . . . . . . 29

2.3 .1 Actores. . . . . . . . . . . . . . . . . . . . . . . . . 29

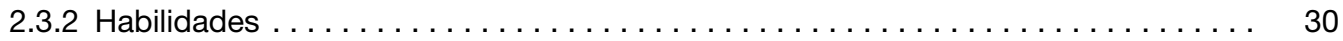

2.3 .3 Capacidades . . . . . . . . . . 30

2.4 Análisis de las capacidades para la gobernanza para la $\mathrm{AbE} \ldots \ldots \ldots \ldots \ldots \ldots \ldots \ldots$

2.4.1 Las capacidades para la gobernanza para la $\mathrm{AbE} \ldots \ldots \ldots \ldots \ldots \ldots \ldots \ldots \ldots$

2.5 Construcción de capacidades para la gobernanza para la AbE . . . . . . . . . . . 41

2.6 Desafíos y oportunidades para las capacidades $\ldots \ldots \ldots \ldots \ldots \ldots \ldots \ldots \ldots \ldots \ldots 4$ 
3 Evidencia

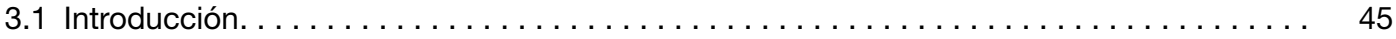

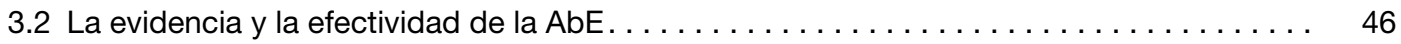

3.3 Tipos de evidencia más comunes y cómo se generan $\ldots \ldots \ldots \ldots \ldots \ldots \ldots \ldots \ldots$

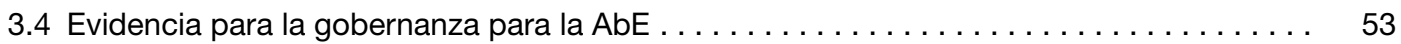

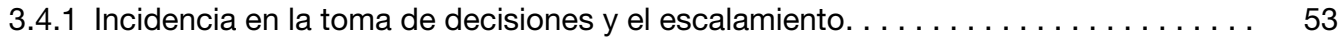

3.4.2 Ambiente propicio para la formulación de políticas y marcos regulatorios

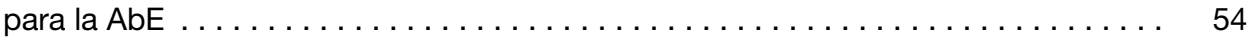

3.4.3 Transferencia de información, conocimientos y comunicación de la gobernanza

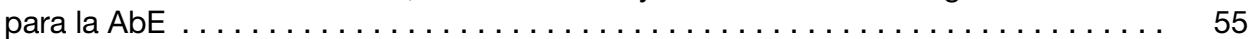

3.4.4 Evidencia generada a través de la gobernanza para la $\mathrm{AbE} \ldots \ldots \ldots \ldots \ldots \ldots \ldots$

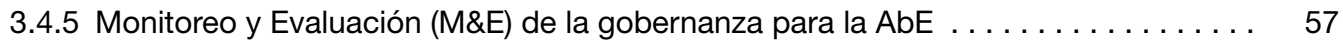

3.5 Desafíos y oportunidades para funcionalidad de la gobernanza para la AbE . . . . . . 59

\section{Politíca}

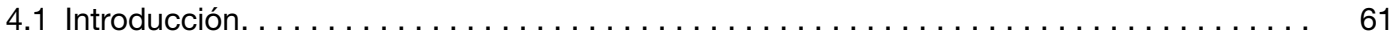

4.2 La Política y la Ley, roles diferentes e interdependientes para la adaptación. . . . . . . . . 61

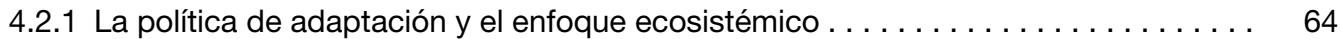

4.2.2 La AbE en los Acuerdos Multilaterales Ambientales (AMUMAs) . . . . . . . . . 65

$4.2 .3 \mathrm{La} \mathrm{AbE}$ en las políticas nacionales $\ldots \ldots \ldots \ldots \ldots \ldots \ldots \ldots \ldots \ldots \ldots \ldots \ldots$

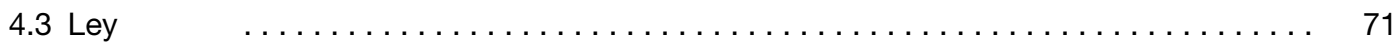

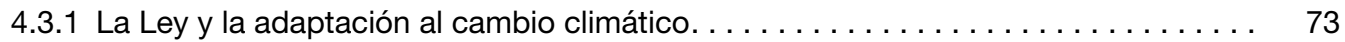

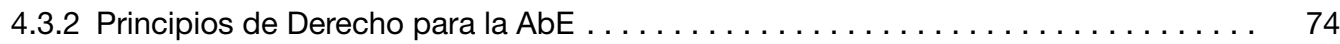

4.3.3 Integración de la AbE en marcos jurídicos ambientales, sectoriales y

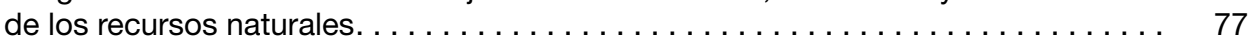

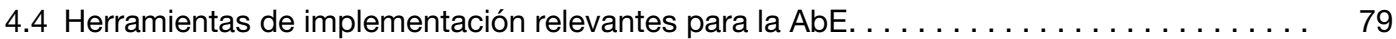

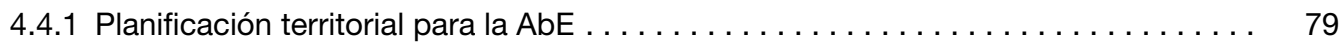

4.4.2 Evaluación Ambiental Estratégica y la Evaluación de Impacto Ambiental . . . . . . 80

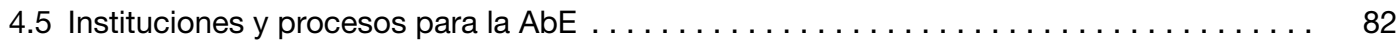

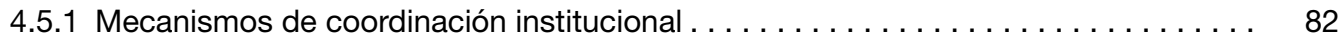

4.5 .2 Coherencia normativa multinivel $\ldots \ldots \ldots \ldots \ldots \ldots \ldots \ldots \ldots \ldots \ldots \ldots \ldots \ldots \ldots \ldots \ldots \ldots$

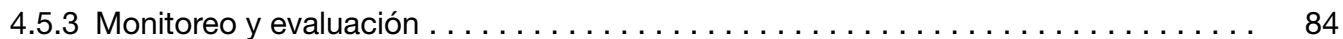

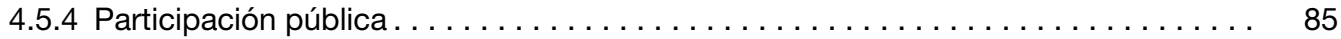

4.6 Mecanismos de financiamiento para la $\mathrm{AbE} \ldots \ldots \ldots \ldots \ldots \ldots \ldots \ldots \ldots \ldots \ldots$

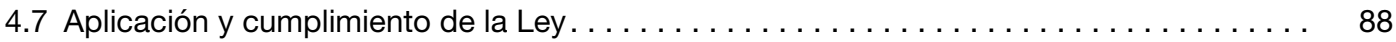

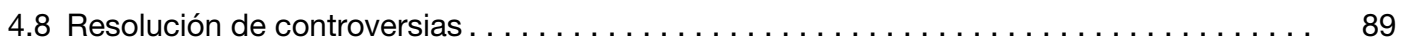

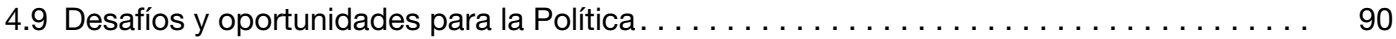

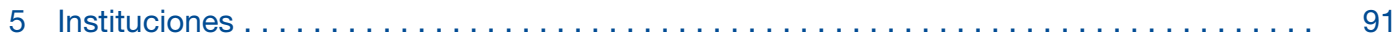

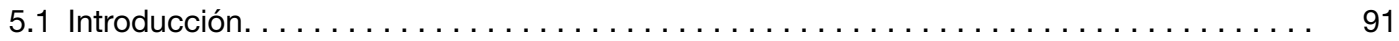

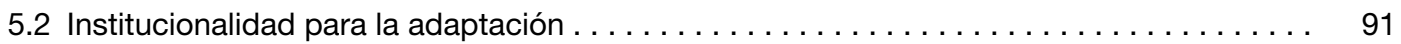

5.3 Tipología de las instituciones para la adaptación $\ldots \ldots \ldots \ldots \ldots \ldots \ldots \ldots \ldots \ldots \ldots \ldots \ldots \ldots \ldots \ldots$ 


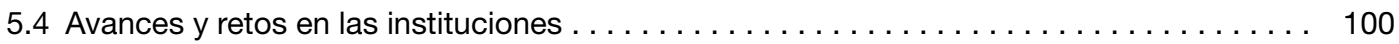

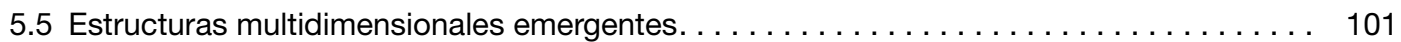

5.5.1 Consejo Consultivo de Cambio Climático del Estado de Chiapas . . . . . . . . . . 102

5.5.2 Consejo Nacional de Cambio Climático de Guatemala (CNCC) . . . . . . . . . . 103

5.5.3 Comité Técnico Interinstitucional de Cambio Climático de Honduras (CTICC) . . . . 104

5.5.4 Consejo Consultivo Ciudadano de Cambio Climático (5C) de Costa Rica . . . . . . . 106

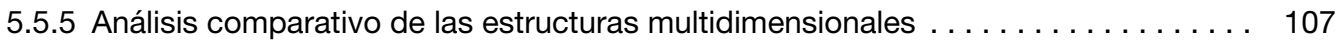

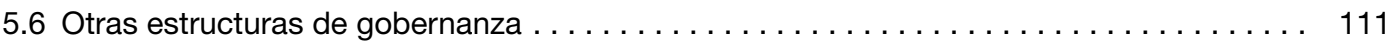

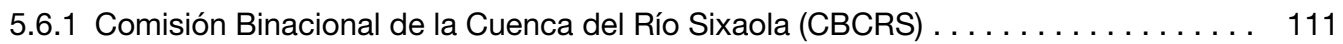

5.6.2 Coordinadora Departamental de Recursos Naturales y Ambiente de

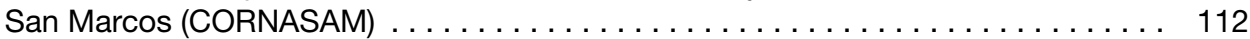

5.7 Implementación de la AbE: características fundamentales de las instituciones. . . . . . . 114

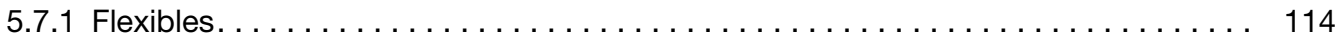

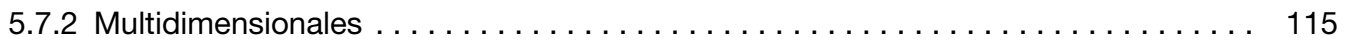

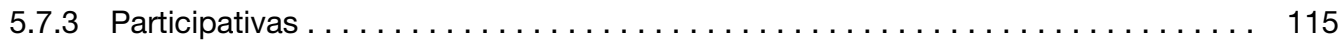

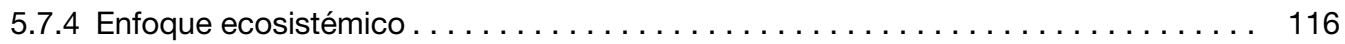

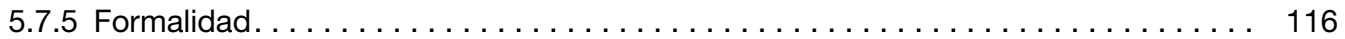

5.8 Desafíos y oportunidades de las institucionales para la $\mathrm{AbE} \ldots \ldots \ldots \ldots \ldots \ldots \ldots \ldots$

6 Negociación ................................... 119

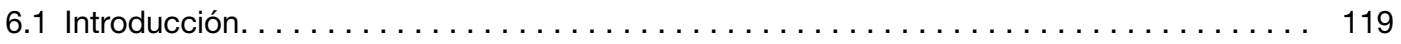

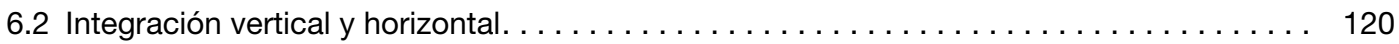

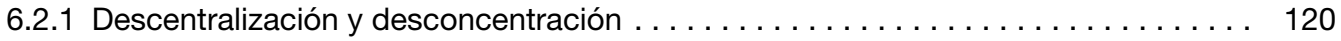

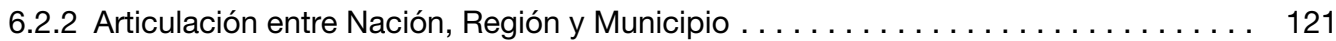

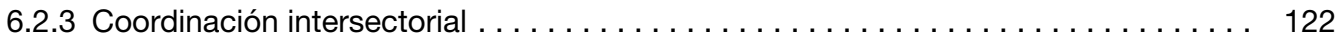

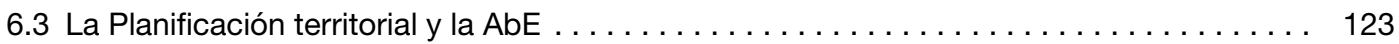

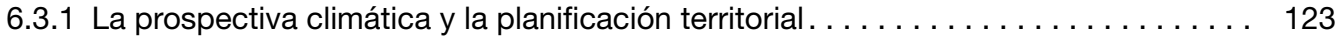

6.3.2 La incorporación de la AbE en instrumentos de ordenamiento territorial . . . . . . 123

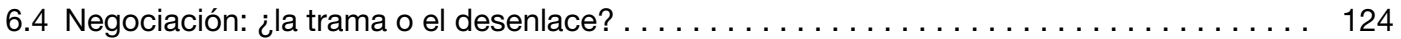

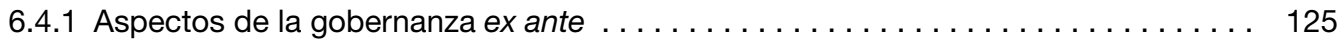

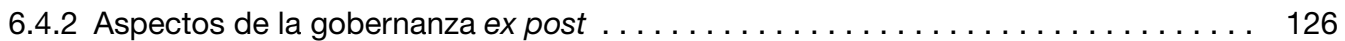

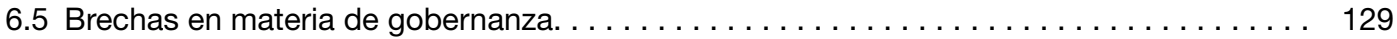

6.5.1 Limitaciones para la participación ciudadana . . . . . . . . . . . . . . . . 129

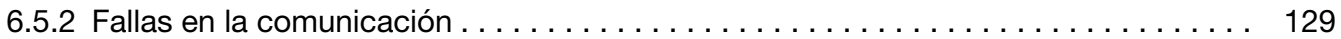

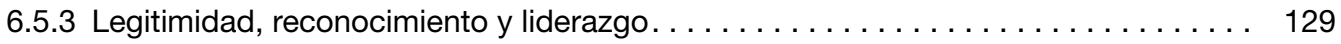

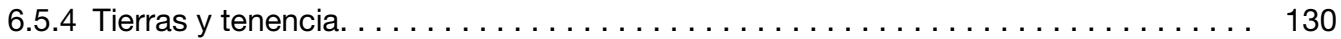

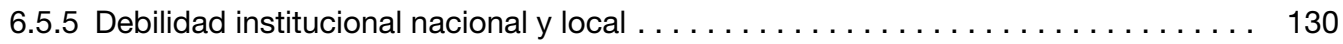

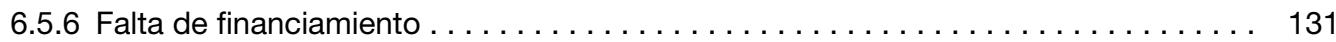

6.6 Desafíos y oportunidades para la negociación $\ldots \ldots \ldots \ldots \ldots \ldots \ldots \ldots \ldots \ldots \ldots \ldots 131$

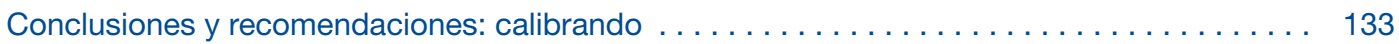

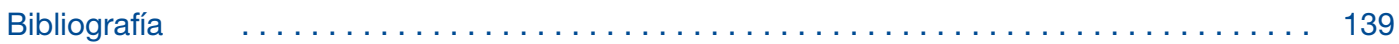





\section{Prólogo}

En las últimas décadas, el planeta ha experimentado transformaciones asociadas a los efectos del cambio climático que han colocado a las sociedades y las personas ante retos importantes a fin de disminuir su condición de riesgo y vulnerabilidad. La región mesoamericana no escapa a esta realidad, la cual depende en gran medida de la provisión de servicios ecosistémicos cada vez más amenazados.

Una de las principales causas de la pérdida de biodiversidad, pilar fundamental de estos servicios ecosistémicos, es precisamente el cambio climático. La Evaluación Global de Biodiversidad y Servicios Ecosistémicos (IPBES por sus siglas en inglés) publicada en mayo de 2019, determinó que la variedad esencial de formas de vida en el planeta continúa en declive. De 8 millones de especies, 1 millón se extinguirá en cuestión de décadas. Tal como lo dijera Robert Watson, Presidente de IPBES: "Estamos poniendo en riesgo las bases de nuestras economías, medios de vida, seguridad alimentaria, salud y la calidad de vida".

Esta situación ha despertado las voces de distintos sectores de la sociedad. Los jóvenes, por ejemplo, se organizan alrededor del mundo en los Fridays for Future para exigir cambios profundos y expeditos que permitan transformaciones políticas inmediatas. En este contexto, existe la responsabilidad de adoptar medidas urgentes que ofrezcan beneficios múltiples, tanto para el uso sostenible de la naturaleza como para las sociedades y las personas.

Dentro de los distintos enfoques disponibles, la adaptación basada en ecosistemas (AbE) invita a considerar a la naturaleza como una respuesta ante los impactos del cambio climático. Permite aplicar conservación, restauración y gestión sostenible de los ecosistemas para reducir los efectos sobre las personas y la biodiversidad; al tiempo que ofrece alternativas para la mitigación y captura de gases de efecto invernadero, la seguridad alimentaria y la seguridad hídrica.

Para cumplir con sus objetivos, la AbE necesita ser anclada en políticas, basadas en la ciencia y la experiencia, que guíen y coordinen esfuerzos de adaptación para el cumplimiento de compromisos y objetivos nacionales y globales. Una gobernanza sólida requiere la coordinación y participación de todos los sectores y niveles de gobierno para implementar medidas de conservación apropiadas a los riesgos climáticos de cada sociedad; así como procesos participativos y transparentes que involucren acciones de ajuste al clima y la conservación de los ecosistemas.

Basado en la experiencia en Mesoamérica, este libro reflexiona sobre los múltiples aspectos y dimensiones de la gobernanza para la AbE y procura ofrecer recomendaciones para estimular los cambios necesarios en políticas, leyes e instituciones que permitan su aplicación efectiva y sostenible en el tiempo.

Dr. Alejandro Iza

Director

UICN Centro de Derecho Ambiental
Viviana Sánchez

Directora Regional a.i.

UICN Oficina Regional para México, América

Central y el Caribe 



\section{Resumen ejecutivo}

El cambio climático es una realidad actual que pone en jaque el bienestar humano y la integridad ecológica de los ecosistemas, sus servicios, su disponibilidad y uso por parte de poblaciones humanas. Las soluciones convencionales (de carácter ingenieril) para enfrentarlo no pueden continuar ocurriendo de manera aislada y reactiva. Es preciso combinar soluciones convencionales con aquellas basadas en la naturaleza que incluyan la biodiversidad y los servicios de los ecosistemas. En este sentido, la adaptación al cambio climático resulta esencial para que tanto los ecosistemas como las poblaciones humanas puedan ajustarse, superar e incluso mejorar su salud y sus condiciones de vida.

El nuevo reto de la Adaptación basada en Ecosistemas (AbE) impone la necesidad, no solo de definir las medidas de adaptación necesarias para poder alcanzarlo, sino también los componentes sólidos de gobernanza para hacerlo efectivo. Una gobernanza para la AbE que debe ser flexible, participativa, multidimensional e inclusiva de los enfoques basados en ecosistemas (mantenimiento de la estructura y función de los ecosistemas para garantizar el bienestar humano). El objetivo de este libro consiste en reflexionar y analizar respecto de las condiciones propicias y necesarias para la gobernanza para la $\mathrm{AbE}$ y su escalamiento en particular en la región mesoamericana, ofreciendo recomendaciones para su implementación tanto en esta región como en otras con características similares. Para poder cumplir con este objetivo, este libro se ha dividido en seis capítulos considerando aquellas condiciones que se estiman más importantes para aplicar la AbE, medidas específicas al respecto y en particular reflexionar en torno a su gobernanza para que sea efectiva, eficiente, funcional, replicable y sostenible en el tiempo.

El capítulo 1 Ajuste pone en escena la gobernanza para la AbE y la sincronización con conceptos relevantes vinculados con ella tales como: Adaptación basada en Ecosistemas (AbE), buena gobernanza, biodiversidad, capacidad adaptativa, infraestructura natural, resiliencia, soluciones basadas en la naturaleza, vulnerabilidad, entre otros. Asimismo, el capítulo contiene información específica en relación con instrumentos de gobernanza a nivel global para la adaptación al cambio climático, la conservación y el uso sostenible de la biodiversidad y los servicios de los ecosistemas. En definitiva, AJUSTE provee las bases conceptuales esenciales para entender el resto del libro incluyendo interrogantes o provocándolos e incitando a la reflexión a lo largo del texto.

El capítulo 2 Capacidad tiene por objeto mostrar cuáles serían las capacidades necesarias para el diseño, la implementación y la evaluación de la gobernanza para la AbE como parte de una estrategia de adaptación más integral y en consonancia con los planes de desarrollo de los países. Este capítulo se explaya respecto de las múltiples capacidades diferenciadas según los actores y que resultan necesarias en un proceso de adaptación al cambio climático y para que éste sea efectivo. Asimismo, reflexiona respecto a los mecanismos necesarios para fortalecer estas capacidades de manera tal que puedan persistir a lo largo del tiempo y permitan la sostenibilidad de las acciones de AbE.

El capítulo 3 Evidencia pretende establecer las pruebas de que la AbE es funcional en el tiempo como herramienta para reducir la vulnerabilidad y aumentar la resiliencia. En particular, analiza la generación y utilización de la evidencia técnico-científica para mostrar la efectividad de la adaptación 
al cambio climático e informar la elaboración e implementación de estructuras de gobernanza que sean eficientes.

El capítulo 4 Política pretende reflexionar en torno al rol de la política y los marcos normativos para implementar una estrategia de adaptación al cambio climático que sea coherente entre los distintos sectores afectados y los niveles de gobierno. Asimismo, y en aras de demostrar su importancia para la gobernanza explora los derechos procedimentales ambientales e identifica las oportunidades necesarias para integrar la AbE en políticas y leyes nacionales.

El capítulo 5 Instituciones analiza aquéllas necesarias para la implementación de una estrategia y medidas de $\mathrm{AbE}$ en distintos niveles (desde el local hasta el transfronterizo). Como componente esencial de la gobernanza para la $\mathrm{AbE}$, este capítulo reflexiona en torno a los arreglos necesarios y adecuados a las realidades nacionales y subnacionales, y se centra en el análisis de aquéllos de carácter formal, poniendo particular atención en los casos de Guatemala, Honduras, Costa Rica y México, con la salvedad de que en ese último caso se centra en el Estado de Chiapas.

El capítulo 6 Negociación realiza y promueve una reflexión integral de aquellos procesos necesarios para armonizar los distintos intereses en juego en la gobernanza para la AbE específicamente para Mesoamérica. Analiza las condiciones necesarias para enfrentar los desafíos derivados de la incertidumbre climática e insiste en la necesidad urgente de la búsqueda de consensos y la cooperación para adoptar acciones de manera inmediata y que sean efectivas.

Al final de cada capítulo se incluyen algunas reflexiones en torno a los principales retos para diseñar, aplicar y mejorar la gobernanza para la AbE y sus distintos aspectos, invitando al lector a plantearse más interrogantes con el afán de enriquecer sus experiencias y continuar así con la búsqueda de soluciones a los múltiples retos y dilemas que plantea el cambio climático y la adaptación al mismo.

Este libro pretende brindar recomendaciones basadas en experiencias reales, proyectos, estudios de caso, que permitan mejorar el diseño y la aplicación de la gobernanza y sus componentes para la $\mathrm{AbE}$ en distintos niveles y brindar ideas prácticas para su escalamiento dentro de la región mesoamericana, con la idea de que estas puedan aplicarse en otros contextos con condiciones ambientales, sociales y económicas similares.

Sin perjuicio del tratamiento específico que se le otorga a cada uno de estos aspectos en los distintos capítulos, conviene destacar que este libro propone una gobernanza para la AbE participativa, es decir, que requiere capacidades, conocimiento e información sólidas; políticas claras ajustadas a dinámicas ecológicas, sociales y económicas; instituciones robustas, inclusivas e incluyentes y con legitimidad, representatividad y apropiación por parte de todos los actores; realista es decir que sea confiable, válida y útil; funcional, es decir, clara en sus objetivos y resultados y alcanzable; y finalmente relevante, vale decir, adecuada al contexto indicado y con sentido de pertenencia por parte de todos los actores interesados.

Para los fines de este libro el término Mesoamérica incluye los siguientes países: México, Guatemala, Belice, Honduras, El Salvador, Nicaragua, Costa Rica y Panamá. Este libro está basado en las experiencias del proyecto: "Transformando Evidencia en Cambio: Un Enfoque Holístico para la Gobernanza para la AbE” (Proyecto AVE) de la UICN, que fue implementado en México, Guatemala, Honduras, El Salvador, Costa Rica y Panamá. 


\section{Agradecimientos}

La presente publicación es el producto del esfuerzo conjunto de expertos en diversas áreas, entre ellas, la gestión de ecosistemas, la adaptación al cambio, la gobernanza y el derecho de aguas, y de un proceso de reflexión respecto de las experiencias recogidas durante casi 10 años seis cuencas transfronterizas en Centroamérica.

Vaya en primer lugar nuestro agradecimiento a todos aquellos que fueron parte de la iniciativa que culmina con esta publicación: a todas las comunidades, individuos, líderes, lideresas y autoridades que nos acompañaron en la búsqueda de soluciones al cambio climático y nos apoyaron con sus esfuerzos en lograr fortalecer las estructuras necesarias para ello.

Un reconocimiento especial merece Rosalía Ibarra Sarlat, Investigadora asociada "C" del Instituto de Investigaciones Jurídicas de la Universidad Nacional Autónoma de México y a Angela Andrade de la Comisión de Gestión de Ecosistemas (CGE) de la UICN y Conservación Internacional-Colombia, por sus aportes, ideas y contribuciones en la revisión del manuscrito de esta obra.

Asimismo, quisiéramos agradecer a Lorena Martínez Hernández, oficial legal del Centro de Derecho Ambiental de UICN por la coordinación de todas las fases de la publicación; a Sarina van der Ploeg, Oficial de Publicaciones de la UICN por su apoyo y guía durante el proceso de edición y publicación; a Anni Lukács, Oficial Senior de Informacion a cargo de la corrección editorial y la supervisión del diseño; Ann DeVoy, Asistente de Proyectos, quien coordinó numerosas tareas en el proyecto que desembocó en la preparación de este libro, Sandra Dalfiume y Juan Carlos Barrientos García, pasantes en el Centro de Derecho Ambiental por su asistencia en la revisión final del texto.

Finalmente, nuestro más profundo agradecimiento a la Iniciativa Internacional del Clima (IKI) del Ministerio Federal Alemán para el Ambiente, la Conservación de la Naturaleza y Seguridad Nuclear (BMU) por su aportación al proyecto Transformando la Evidencia en Cambio: Un Enfoque Holístico para la Gobernanza para la Adaptación basada en Ecosistemas y a este libro que es el resultado de su implementación. 



\section{Editor y autores}

\section{Editor:}

Dr. Alejandro Iza

Director del Centro de Derecho Ambiental

Unión Internacional para la Conservación de la Naturaleza

\section{Autores:}

Rocío Córdoba-Muñoz

Profesional Independiente en Recursos Naturales

Comisión de Gestión de Ecosistemas de la UICN

Pascal Girot

Catedrático

Escuela de Geografía

Universidad de Costa Rica

Mauricio Luna Rodríguez

Asesor Regional para Gobernanza Climática

Deutsche Gesellschaft für Internationale Zusammenarbeit (GIZ)

Programa EUROCLIMA+

Melissa Marín Cabrera

Oficial de Programa en la Asociación Costa Rica por Siempre

Lorena Martínez Hernández

Oficial Legal

Centro de Derecho Ambiental de la UICN

Marta Pérez de Madrid Utrilla

Oficial Regional de la Oficina Regional de México, América Central y Caribe de la UICN 



\section{Siglas y acrónimos}

$4 \mathrm{C}$

$5 \mathrm{C}$

A y $A$

$\mathrm{AbE}$

ACOFOP

ADESCO

AECID

AGAAI

AMHON

AMUMA

ANAM

ANP

ANVCC

ASADAS

ASOREMA

AVE

BRIDGE

C3

CBCRS

CBD

$\mathrm{CC}$

$\mathrm{CCCl}$

$\mathrm{CDA}$

CDB

CENIGA

CEPAL

CES

CGE

$\mathrm{CICC}$

$\mathrm{CICC}$

CLIMA+
Consejo Científico de Cambio Climático (Costa Rica)

Consejo Consultivo Ciudadano de Cambio Climático (Costa Rica)

Instituto Costarricense de Acueductos y Alcantarillados

Adaptación basada en Ecosistemas

Asociación de Comunidades Forestales del Petén (Guatemala)

Asociación de Desarrollo Comunitario (ADESCO)

Agencia Española de Cooperación Internacional al Desarrollo

Asociación Guatemalteca de Alcaldes y Autoridades Indígenas

Asociación de Municipios de Honduras

Acuerdos Multilaterales Ambientales

Asociación Nacional de Municipalidades (Guatemala)

Áreas Naturales Protegidas

Atlas Nacional de Vulnerabilidad ante el Cambio Climático de México

Asociaciones Administradoras de Sistemas de Acueductos y Alcantarillados Comunales (Costa Rica)

Asociación Nacional de Organizaciones No Gubernamentales de Recursos Naturales y Medio Ambiente

Proyecto "Transformando Evidencia en Cambio: Un Enfoque Holístico para la Gobernanza para la AbE"

Proyecto "Construyendo Diálogos de Buena Gobernanza en Ríos" (siglas en inglés)

Consejo de Cambio Climático (México)

Comisión Binacional de la Cuenca del Río Sixaola (Costa Rica-Panamá)

Convención sobre Diversidad Biológica (siglas en inglés)

Cambio Climático

Comités de Coordinación Cantonales Inter-institucionales (Costa Rica)

Centro de Derecho Ambiental de la UICN

Convención sobre Diversidad Biológica

Centro Nacional de Información Geoambiental (Costa Rica)

Comisión Económica para América Latina y el Caribe

Consejo de Educación Superior (Honduras)

Comisión de Gestión de Ecosistemas de la UICN

Comisión Intersecretarial de Cambio Climático (México)

Comité Interinstitucional de Cambio Climático (Honduras)

Secretaría Presidencial de Cambio Climático Clima Más (Honduras) 
CLPI

CME

CMNUCC

CNCC

CNE

COCODES

COHEP

CONRED

COPECO

CORAC

CORNASAM

CP

CTICC

CTICC

DCC

DNCC

DNCC

EAE

ECADERT

Eco-DRR

EIA

ENEE

ENOS

EPANB

FEBA

GmbH-GIZ

ICE

ICF

ICT

ICWL

IHT

IIED

IKI

IMN
Consentimiento libre, previo e informado

Comités Municipales de Emergencia (Costa Rica)

Convención Marco de las Naciones Unidas para el Cambio Climático

Consejo Nacional de Cambio Climático (Guatemala)

Comisión Nacional de Prevención de Riesgos y Atención de Emergencias (Costa Rica)

Consejos Comunitarios de Desarrollo (Guatemala)

Consejo Hondureño de la Empresa Privada

Coordinadora Nacional para la Reducción de Desastres (Guatemala)

Comité Permanente de Contingencia (Honduras)

Consejos Regionales de Áreas de Conservación (Costa Rica)

Coordinadora Departamental de Recursos Naturales y Ambiente de San Marcos (Guatemala)

Conferencias de las Partes de los Acuerdos Multilaterales Ambientales

Comité Técnico Interinstitucional de Cambio Climático (Honduras)

Comité Técnico Interministerial de Cambio Climático (Costa Rica)

Dirección de Cambio Climático (Costa Rica)

Dirección Nacional de Cambio Climático (Guatemala)

Dirección Nacional de Cambio Climático (Honduras)

Evaluación Ambiental Estratégica

Estrategia Centroamericana de Desarrollo Rural Territorial

Reducción de riesgo de desastres basada en ecosistemas

Evaluación de Impacto Ambiental

Empresa Nacional de Energía Eléctrica (Honduras)

El Niño-Oscilación del Sur

Estrategias y Planes de Acción Nacionales para la Biodiversidad

Friends of Ecosystem based Adaptation (Amigos de la Adaptación basada en Ecosistemas)

Deutsche Gesellschaft für Internationale Zusammenarbeit GmbH-GIZ

Instituto Costarricense de Electricidad

Instituto Nacional de Conservación Forestal, Áreas Protegidas y Vida Silvestre (Honduras)

Instituto Costarricense de Turismo

Proyecto: "Mejoramiento de Cuencas Costeras y Medios de Vida" (siglas en inglés)

Instituto Hondureño de Turismo

Instituto Internacional para el Ambiente y el Desarrollo (siglas en inglés)

Internationale Klimaschutzinitiative/International Climate Initiative (Iniciativa Internacional de Protección del Clima)

Instituto Meteorológico Nacional (Costa Rica) 
INAB

INCOPESCA

INDER

INEC

INECC

INVU

IPCC

LCC

LGEEPA

$M \& E$

MAG

MAGA

MARN

MINAE

MIVAH

MOPT

NDC

NCG

ODS

OCDE

OECD

OIT

ONCCDS

ONGs

PEDTT

PINFOR

PINPEP

PNA

PNACC

PROFEPA

PSA

RECOPE

REDD

SEGEPLAN

SEMARNAT
Instituto Nacional de Bosques (Guatemala)

Instituto Costarricense de Pesca y Acuicultura

Instituto de Desarrollo Rural (Costa Rica)

Instituto Nacional de Estadística y Censos (Costa Rica)

Instituto Nacional de Ecología y Cambio Climático de México

Instituto Nacional de Vivienda y Urbanismo (Costa Rica)

Panel Intergubernamental de Cambio Climático (por sus siglas en inglés)

Ley de Cambio Climático del Estado de Chiapas (México)

Ley General del Equilibrio Ecológico y la Protección al Ambiente (México)

Monitoreo y Evaluación

Ministerio de Agricultura y Ganadería (Costa Rica)

Ministerio de Agricultura, Ganadería y Alimentación (Guatemala)

Ministerio de Ambiente y Recursos Naturales (Guatemala)

Ministerio de Ambiente y Energía (Costa Rica)

Ministerio de Vivienda y Asentamientos Humanos (Costa Rica)

Ministerio de Obras Públicas y Transportes (Costa Rica)

Contribuciones Nacionalmente Determinadas (siglas en inglés)

Programa de Gestión Comunitaria de Cuencas en el Río Goascorán, Honduras.

"Nuestra Cuenca Goascorán"

Objetivos de Desarrollo Sostenible de las Naciones Unidas

Organización para la Cooperación y el Desarrollo Económicos (siglas en español)

Organización para la Cooperación y el Desarrollo Económicos (siglas en inglés)

Organización Internacional del Trabajo

Observatorio Nacional de Cambio Climático y Desarrollo Sostenible

Organizaciones no gubernamentales

Plan Estratégico de Desarrollo Territorial Transfronterizo (Cuenca río Sixaola, Panamá-Costa Rica)

Programa Nacional de Incentivos Forestales (Guatemala)

Programa de Incentivos Forestales para Poseedores de Pequeñas Extensiones de Tierra de Vocación Forestal o Agroforestal (Guatemala)

Plan Nacional de Adaptación

Política Nacional de Adaptación al Cambio Climático

Procuraduría Federal de Protección al Ambiente (México)

Pago por Servicios Ambientales o Ecosistémicos

Refinadora Costarricense de Petróleo S.A.

Reducción de emisiones de $\mathrm{CO} 2$ por deforestación evitada

Secretaría de Planificación y Programación de la Presidencia (Guatemala)

Secretaría de Medio Ambiente y Recursos Naturales (México) 
SENARA

SEPLASA

SERNA

SICA

SINACC

SINAMECC

SNICC

UICN

UNDRR

UNESCO

WCMC

WEF

WWAP
Servicio Nacional de Aguas Subterráneas, Riego y Avenamiento (Costa Rica) Secretaría de Planificación del Sector Ambiental (Costa Rica)

Secretaría de Energía, Recursos Naturales, Ambiente y Minas. (Honduras, actualmente denominado MiAmbiente+)

Sistema de Integración Centroamericana

Sistema Nacional de Cambio Climático (México)

Sistema Nacional de Métrica para el Cambio Climático (Costa Rica)

Sistema Nacional de Información sobre Cambio Climático (Guatemala)

Unión Internacional para la Conservación de la Naturaleza

Oficina de las Naciones Unidas para la Reducción del Riesgo de Desastres (siglas en inglés)

Organización de las Naciones Unidas para la Educación, la Ciencia y la Cultura (siglas en inglés)

ONU Medio Ambiente-Centro Mundial de Monitoreo de la Conservación (siglas en inglés)

Foro Económico Mundial (siglas en inglés)

Programa Mundial de las Naciones Unidas de Evaluación de los Recursos Hídricos (siglas en inglés) 


\title{
1 Ajuste
}

\author{
Rocío Córdoba-Muñoz
}

\subsection{Introducción: retomando la biodiversidad y los servicios de los ecosistemas como tema esencial para la adaptación al cambio climático}

\subsubsection{El contexto}

Los efectos negativos del cambio y variabilidad climáticos para el ser humano y sus medios de vida son inminentes y ampliamente demostrados (Mann et al., 2017). Estos impactos negativos se deben principalmente al incremento de gases de efecto invernadero en la atmósfera. El cambio climático provoca además un aumento en la frecuencia, la intensidad y la gravedad de los fenómenos meteorológicos extremos representando una amenaza palpable en términos de inundaciones y sequías, por ejemplo. Aproximadamente el $30 \%$ de la población del mundo, vive en lugares que están expuestos a los impactos de estos fenómenos extremos (WWAP, 2018). Asimismo, la integridad de los ecosistemas sufre los embates del clima, reduciendo sus capacidades para brindar servicios esenciales para los medios de vida de las poblaciones humanas. Como típicos ejemplos pueden citarse la degradación de las costas y sus poblaciones asociadas debido al aumento del nivel del mar, la reducción de la estación lluviosa en lugares como el Corredor Seco Centroamericano y por ende la reducción de la cantidad de agua disponible para consumo humano y para la producción de alimentos, y el blanqueamiento de los corales por el aumento de la temperatura del mar y exacerbado por la sedimentación y contaminación procedente de las actividades no sostenibles que el ser humano lleva a cabo cuencas arriba y en las zonas costeras (Mumby et al., 2014).

La relación entre el potencial de la biodiversidad y de los servicios de los ecosistemas con la reducción de estos impactos del clima sin embargo, ha tardado alrededor de 20 años en ser reconocida por distintos actores clave del desarrollo y algunos tomadores de decisión (Costanza, 2017; Chong, 2014). Si bien en el campo ambiental la importancia de los servicios de los ecosistemas para reducir la vulnerabilidad al cambio climático se entiende cada vez más, falta aún mucho trabajo por hacer para que dichos servicios sean incorporados en forma efectiva, eficiente y responsable dentro de las estrategias y planes de desarrollo en los países de la región mesoamericana.

Este desfase de entendimiento (entre el sector ambiental y el de tomadores de decisión en materia de desarrollo), ha provocado que, ante un proceso de cambio tan apremiante y evidente, se busquen soluciones de carácter urgente para reducir la vulnerabilidad de las poblaciones y sus medios de vida especialmente para reducir las consecuencias de los fenómenos extremos. Estas "soluciones" incluyen por lo general, opciones que se limitan a la infraestructura gris. Por lo general, dichas acciones no son sostenibles en el largo plazo y se concentran en un solo sector de las poblaciones en detrimento de otros (CBD, 2018), eso, sin mencionar que a menudo favorecen a ciertos sectores productivos que cuentan con mayor poder económico y que, generalmente inciden directamente en la toma de decisiones en los países. Las consecuencias de estas decisiones "duras y puras" se reflejan tanto en el aumento de la vulnerabilidad de las poblaciones más pobres como el deterioro de la biodiversidad y los servicios de los ecosistemas que son esenciales para la vida en el planeta (Tickner et al., 2017). A pesar de que la información disponible acerca de los procesos que ocurren 
en los ecosistemas y sus recursos asociados va acrecentándose, la capacidad de estos para brindar los servicios y por ende, los co-beneficios para las poblaciones humanas, sigue deteriorándose en forma alarmante. Para 2005 (Evaluación de los Ecosistemas del Milenio, 2005) se determinó que al menos el $60 \%$ de los servicios de los ecosistemas estaban degradados.

Dehecho el enfoque ecosistémico (CDB, 2000), el cual incluye tanto las dimensiones socioeconómicas como las ecológicas (Guerrero et al., 2006) para la gestión sostenible de los ecosistemas, fue incorporado en el campo ambiental por la CDB en 2000 y en varios instrumentos globales relacionados con el cambio climático años más tarde (CDB, 2009a -adopción de la definición de la AbE-; CDB -Metas de Aichi-, 2010; PNUD, 2015 -Objetivos de Desarrollo Sostenible- y en el Acuerdo de París -CMNUCC, 2015-, entre otros). Anteriormente, la biodiversidad y los ecosistemas y su intrínseca relación con la sobrevivencia humana, seguían ocupando un lugar tangencial (o ningún lugar en absoluto) dentro de los planes de desarrollo y los marcos e instrumentos legales vinculantes de carácter local, nacional y global.

Actualmente esa situación ha mejorado sustancialmente; por ejemplo el $67 \%$ de las Contribuciones Nacionalmente Determinadas (NDC por su siglas en inglés) incluyen acciones para la adaptación relacionadas con los ecosistemas (IIED \& UICN, 2016; Cohen-Shacham et al., 2016). Estas acciones se relacionan con las que han existido desde hace décadas el campo de los recursos naturales y que se han puesto en marcha para la conservación y mantenimiento de los ecosistemas para el bienestar humano. Entre ellas se pueden mencionar las siguientes:

- compensación y pago por bienes y servicios ecosistémicos/ambientales (PSA) (Abell et al., 2017) en donde usuarios de los recursos naturales (especialmente el agua) compensan o pagan a quienes protegen los bosques o el agua de las nacientes

- conservación de recursos naturales, la cual incluye una gama amplia de acciones para mantener los servicios de los ecosistemas y resguardar la biodiversidad en el largo plazo

- fomento de la agroecología, lo cual permite la producción de alimentos a través de prácticas agrícolas sostenibles sin usar insumos químicos

- gestión integral del agua, la cual busca una integración entre la gestión del agua, los suelos y los recursos naturales en general para maximizar el bien social en el largo plazo. El agua constituye para la región mesoamericana uno de los recursos centrales que se afectan por el cambio climático y los fenómenos extremos (sequías e inundaciones)

- gestión comunitaria de áreas protegidas, en la cual participa activamente la comunidad en conjunto con el Estado en la protección de los recursos naturales. Las áreas protegidas constituyen un acervo importante de recursos de biodiversidad y para la conservación de las funciones de los ecosistemas, cuyos beneficios eventualmente llegan al ser humano (MacKinnon et al., 2011)

- protección de fuentes de agua, gestión de cuencas y gestión de paisajes, que incluye un ingrediente importante de coordinación y gobernanza entre actores interesados ubicados en distintas partes de una cuenca hidrográfica por ejemplo. La gestión de cuencas y paisajes reconoce la extensión de los ecosistemas, sus interacciones y por ende las dificultades de gestionar de forma amplia los recursos que se encuentran en dichos espacios

- protección y recuperación de infraestructura natural, como por ejemplo los arrecifes de coral, manglares, costas y bosques como amortiguadores de amenazas naturales, erosión e inundaciones (Chong, 2014), así como la reforestación de zonas de recarga hídrica y en pendientes, 
contribuyendo a la recuperación de suelos, la conservación de la calidad y cantidad de agua y la reducción de la erosión y las amenazas por deslaves

- restablecimiento de sistemas agroforestales tradicionales y no tradicionales, donde se reconocen los conocimientos tradicionales de las poblaciones, su cultura y sus costumbres

- restauración y rehabilitación de ecosistemas para mejorar servicios esenciales tales como disponibilidad de agua de calidad, alimentos, pesca y recursos genéticos.

Cabe mencionar que, a través de estos más de 20 años en que se ha promovido el enfoque ecosistémico, estas acciones se han venido "recuperando del pasado" y se están mejorando al contextualizarlas de forma estructurada y sistemática para hacer frente a los impactos del cambio climático y tomando en cuenta los riesgos ambientales y sociales. Por ejemplo, las acciones agroecológicas y de agro-forestería se están fortaleciendo al utilizar especies que son climáticamente más resistentes ("agricultura climáticamente inteligente") (IIED y UICN, 2016; Cohen-Shacham et al., 2016). Se puede decir que en general la biodiversidad y sus ecosistemas están siendo considerados cada vez más por tomadores de decisión para incluirlos dentro de las estrategias de adaptación a un nivel más integral y en las estrategias y planes de desarrollo. No obstante aún falta mucho por comprender enteramente la relación entre sistemas sociales, los ecosistemas naturales y la interacción entre estos bajo los escenarios de incertidumbre que plantea el cambio climático.

\subsubsection{La Adaptación basada en Ecosistemas (AbE) en el contexto actual}

Como es sabido, la AbE puede clasificarse de diversas formas: como un enfoque, como una iniciativa, como una combinación de ambos o como una serie de estrategias y planes. Incluye acciones que relacionan íntimamente la conservación, el mantenimiento y la restauración de la biodiversidad y los servicios ecosistémicos como medio para mejorar las opciones de adaptación al cambio climático de los seres humanos.

Durante la COP 10 (decisión X/33) del Convenio de Diversidad Biológica (CDB, 2009) se elaboró y se adoptó la siguiente definición de la AbE: "El uso de la biodiversidad y servicios ecosistémicos como parte integrada de las estrategias de adaptación, para apoyar a la gente a adaptarse a los efectos adversos del cambio climático".

Para fines prácticos en este libro la AbE se entiende como "el conjunto de estrategias, políticas y prácticas destinadas a la protección y restauración de los servicios de los ecosistemas para reducir la vulnerabilidad de la sociedad frente al cambio climático".

Esta definición se plantea sin menoscabo de todos los elementos conceptuales que se predican respecto de la AbE de acuerdo con la CDB, FEBA y la UICN ${ }^{1}$ (CBD, 2018). Sin embargo, tiene fines más prácticos y destaca la relación inseparable que existe entre las actividades de conservación de los ecosistemas y sus servicios a la humanidad, la gobernanza de los recursos naturales (tomando en cuenta la equidad y la justicia social) y la adaptación al cambio climático. La gobernanza y la AbE constituyen un binomio inseparable que crea condiciones propicias para que las estrategias, políticas y prácticas para la adaptación al cambio climático sean sostenibles.

La UICN agrega a la definición de la CDB de la AbE lo siguiente: "cualquier iniciativa que reduce las vulnerabilidades del ser humano y mejora la capacidad adaptativa en el contexto de la variabilidad y cambio climático actual y potencial, a través de la gestión sostenible, la conservación y la restauración de los ecosistemas". 
En innumerables publicaciones se ha demostrado la dependencia de las personas y sus comunidades, especialmente de aquéllas más vulnerables (social, cultural y económicamente), al capital o activo natural; no cabe duda que sin ecosistemas sanos la existencia del ser humano está en peligro (Rubio-Scarano, 2017). La AbE genera co-beneficios importantes como resultado positivo de la aplicación de medidas en el largo plazo. Estos incluyen, entre otros, la fijación de carbono, la conservación de la biodiversidad y los servicios ecosistémicos, el aumento de la polinización (favoreciendo la agricultura sostenible), la mejora de la calidad del aire y la regulación local del clima (Cohen-Shacham et al., 2016; Potschin et al., 2014).

La AbE es una solución natural que enfatiza los valores tanto de los servicios ecosistémicos, como del ser humano y busca opciones más integrales para mejorar la resiliencia de ambos (personas y ecosistemas) en el largo plazo dentro de los escenarios climáticos actuales y futuros. Constituye una alternativa de menor costo que las soluciones de infraestructura gris (convencionales) las cuales no consideran permanencia, sostenibilidad y efectos potenciales adversos para las personas y los ecosistemas (UNEP-DHI Partnership/IUCN/TNC, 2014). Sin embargo, resulta necesario incrementar la investigación científica para ir más allá de algunos ejemplos específicos aislados y mostrar hasta dónde la aplicación de un enfoque ecosistémico, por medio de infraestructura verde, puede sustituir al menos en parte la infraestructura convencional, es decir una combinación de soluciones naturales e ingenieriles (Bai, 2018).

Es fundamental además no perder de vista que, para que la AbE pueda ser incorporada dentro de estrategias de adaptación al cambio climático locales y nacionales, debe además articularse con el mejoramiento integral de los medios de vida sostenibles. Estos están constituidos por las capacidades, activos y actividades indispensables para mantener o mejorar las condiciones de la vida humana sin socavar la base de los recursos naturales (DFID, 1999). Por tanto es intrínseco a la $\mathrm{AbE}$, el tomar en consideración los impactos actuales y potenciales de las medidas de adaptación en los "capitales" o "activos" de estos medios de vida: humanos, naturales, sociales, físicos y financieros (Reid et al., 2017).

De acuerdo con Friends of Ecosystem based Adaptation FEBA (2017) con base en los principios esenciales para la $\mathrm{AbE}^{2}$ (Andrade et al., 2011), la $\mathrm{AbE}$ debe incorporar los siguientes criterios de calidad:

1. Reducir las vulnerabilidades de la sociedad y del ambiente.

2. Generar beneficios sociales en el contexto de la adaptación al cambio climático.

3. Restaurar, mantener o mejorar la salud de los ecosistemas.

4. Estar sustentada con normas y leyes a través de múltiples niveles.

5. Apoyar una gobernanza equitativa y aumentar las capacidades para adaptarse.

2 Principios Esenciales para la AbE: 1. Promueve la resiliencia de ambos ecosistemas y sociedades. 2. Promueve enfoques multi-sectoriales. 3. Opera a escalas geográficas múltiples. 4. Integra estructuras flexibles de manejo que permite el manejo adaptativo. 5. Minimiza las compensaciones y maximiza los beneficios con las metas de desarrollo y conservación para evitar impactos negativos sociales y ambientales no intencionados. 6 . Basado en la mejor ciencia y conocimiento local disponible y promueve la generación y difusión del conocimiento. 7. Trata sobre ecosistemas resilientes y sobre el uso de soluciones basadas en la naturaleza, al servicio de los pueblos, especialmente los más vulnerables. 8. Es participativo, transparente, responsable y culturalmente apropiado y, activamente aborda aspectos de equidad y género. 
El presente libro se concentra principalmente en los criterios 4 y 5 relacionados con la gobernanza para la $\mathrm{AbE}$, en el entendido de que esta constituye un medio indispensable para garantizar la sostenibilidad de las acciones en el largo plazo con la participación de todos los actores interesados.

\subsection{La buena gobernanza: una propuesta innovadora de valor para la sostenibilidad de las medidas de adaptación}

En forma simplificada, el término gobernanza alude a la relación entre los gobiernos y los ciudadanos. La gobernanza ha venido ganando espacio dentro de la gestión de los recursos naturales durante los últimos años y se ha transformado en un pilar fundamental en el mantenimiento del bienestar humano. Existe una gran variedad de definiciones; sin embargo todas ellas incluyen objetivos de actores interesados, toma de decisiones y acciones para alcanzar dichos objetivos (Cosens, 2017; Adger et al., 2018).

Para los efectos de la presente publicación, gobernanza se define como: "el medio a través del cual la sociedad define sus metas, prioridades y avanza hacia la toma de decisiones, a nivel global, nacional o local. (Burhenne-Guilmin \& Scanlon, 2004).

La gobernanza posee cuatro elementos o componentes esenciales (Iza \& Stein (eds.), 2011):

- Político: constituye el marco de referencia y los principios orientadores para el gobierno en la gestión de asuntos públicos

- Legal: incluye el conjunto de leyes, decretos, ordenanzas municipales, leyes consuetudinarias (normas y comportamientos no formales que son aceptados por la comunidad y que perduran a través del tiempo)

- Institucional: establecimiento, consolidación y seguimiento de instituciones eficaces con funciones claras

De procesos: conjunto de acciones que se requieren para implementar las políticas y leyes. Deben garantizar los mecanismos de participación pública en donde la sociedad civil organizada forma parte integral de la toma de decisiones en temas que les afectan de forma directa o indirecta y a través de los cuales los actores interesados expresan sus intereses, ejercen sus derechos, cumplen sus obligaciones y resuelven sus diferencias.

Los componentes político y legal de la gobernanza serán tratados en detalle en el capítulo 4 (Política) y el institucional en el capítulo 5 (Instituciones).

Por otra parte la buena gobernanza se refiere al cumplimiento eficaz y efectivo del marco jurídico e institucional con la participación de los distintos actores interesados y bajo una serie de principios esenciales (UICN, 2016). Para que una buena gobernanza (o gobernanza efectiva) pueda existir requiere además de otra serie de características que no se debe perder de vista:

- Transparencia - apertura en la toma de decisiones;

- Acceso a la información - comunicación precisa, efectiva y abierta;

- Acceso a la justicia - mecanismos equitativos de rendición de cuentas y protección de los derechos;

- Participación pública - intervención genuina en la toma de decisiones;

- Coherencia - un enfoque consistente; 
- Subsidiariedad - las decisiones se adoptan en el nivel de base (local) o el que sea procedente;

- Respeto de los derechos humanos - en estrecha relación con una buena gobernanza ambiental;

- Rendición de cuentas - sobre los resultados económicos, sociales y ambientales;

- Imperio de la ley - aplicación de las normas legales de manera imparcial, transparente y consistente a todos los niveles; $y$

- Promoción de la igualdad de género y del empoderamiento de la mujer - como elemento integrante de los principios de la buena gobernanza y tema transversal en toda la labor de la UICN.

La gobernanza es, por tanto un proceso participativo, inclusivo, equitativo, con responsabilidades y derechos. Una buena gobernanza o una gobernanza efectiva se caracteriza por la apropiación de los problemas y sus posibles soluciones por parte de todos los actores interesados, desde el nivel local hasta el nacional y regional (es decir desde las comunidades a nivel de una microcuenca por ejemplo hasta los organismos reguladores de una cuenca transfronteriza).

Para poderalcanzarunabuena gobernanza resulta imprescindible contar con capacidades adecuadas dentro de los distintos contextos y niveles de toma de decisión. En el capítulo 2 -Capacidad- se trata a fondo el tema de la formación y fortalecimiento de capacidades. Así los actores podrán ejercer sus derechos, incidir en las instancias políticas (poder político de toma de decisión), sobre los actores privados (poder económico) y tomar responsabilidades diferenciadas de forma conjunta reconociendo los derechos y deberes de individuos, así como de organizaciones públicas, privadas, niveles de gobierno, unidades provinciales, agencias, empresas públicas, fundaciones, etc. Al mismo tiempo, se requiere contar con la información técnica, científica, social y económica sólida y oportuna para tomar decisiones bien fundamentadas. La academia y los centros de investigación por tanto, son parte fundamental de los actores de la sociedad civil (y el sector privado en algunos casos), que deben tenerse en cuenta a la hora de tomar decisiones adecuadas. Bajo ese mismo esquema de gestión del conocimiento, debe ponderarse adecuadamente el conocimiento tradicional como base para la construcción de una gobernanza para la AbE.

Como fuera mencionado en la sección precedente, existe una relación inherente entre la $\mathrm{AbE}$ y la gobernanza para la adaptación, la cual (para los fines de este libro) incluye, además de los componentes o elementos mencionados, "promover los marcos legales, institucionales y los procesos de participación pública necesarios para mejorar la resiliencia social y ante los retos existentes y potenciales del cambio climático" (Sánchez \& Roberts, 2014).

De esta forma se entenderá como gobernanza para la AbE a las normas, instituciones y procesos que determinan la manera en la que se ejerce el poder, se distribuyen responsabilidades y cómo y qué decisiones se toman e implementan para la conservación, restauración y gestión sostenible de la biodiversidad y servicios ecosistémicos como parte de una estrategia general para ajustarse al clima real o proyectado y sus efectos.

La gobernanza para la AbE implica además una búsqueda de respuestas efectivas y socialmente justas para resolver una serie de procesos complejos que involucran una multiplicidad de actores, relaciones de poder e intereses de diversos sectores relacionados con el desarrollo económico (generalmente no sostenible) (Sieber et al., 2018). Por tanto, alcanzar una buena gobernanza en este contexto, presenta varios retos inherentes: marcos legales e institucionales funcionales y flexibles, articulación entre el desarrollo económico y el mantenimiento de ecosistemas y el respeto a los 
valores del ser humano, la democracia y la equidad social (Colloff et al., 2017). Todos estos, requisitos que permiten la convivencia libre y pacífica de las personas en el mundo.

A la buena gobernanza para la AbE le concierne además, fomentar sistemas dinámicos de toma de decisión capaces de responder oportunamente a la incertidumbre implícita tanto dentro de la variabilidad y como del cambio climáticos. La falta de certeza sobre cuáles serán los impactos del cambio climático constituye una justificación sólida para la construcción de una gobernanza para la AbE. Los componentes propios de la ley, buscan estructuras estabilizadoras que brindan seguridad para esta convivencia en los Estados cualquiera sea la dimensión territorial que se trate. Esta estabilidad podría constituir una barrera para la adaptación (Cosens et al., 2017). Por tanto constituye un requisito en la dinámica actual de la $\mathrm{AbE}$ buscar mecanismos que promuevan combinar esta estabilidad (bajo esquemas de gobierno estables) con herramientas que permitan cambios de marcos políticos, legales e institucionales de acuerdo con las transformaciones de la realidad en cada contexto (Colloff, et al., 2017).

La gobernanza para la AbE por tanto, debe ser flexible (prever mecanismos para adaptar los marcos legales e institucionales); multidimensional (fomentando la coordinación multisectorial, p.ej. agricultura, agua, biodiversidad, industria y multinivel (p.ej. comunitario, local, regional, nacional, internacional) combinando la integración horizontal y vertical; participativa (desde el punto de vista de la justicia social, la participación pública informada permite una mayor equidad en la toma de decisiones que afectan a los grupos más vulnerables al cambio climático, entre ellos, las mujeres, los niños, los jóvenes, los ancianos y las minorías étnicas e indígenas) y ecosistémica (entre las medidas de adaptación más urgente debe estar la búsqueda de mecanismos políticos, legales e institucionales que permitan aumentar la resiliencia de los ecosistemas ante los impactos climáticos y no climáticos) (Martínez \& Luna, 2018).

Aunque ha habido avances significativos en los marcos y arreglos de gobernanza para la AbE, en los instrumentos actuales, predominan las soluciones de infraestructura gris. Por ejemplo, las inversiones directas actuales en soluciones basadas en la naturaleza son menores al $1 \%$ comparadas con las que se hacen en infraestructura convencional (WWAP, 2018). Las escalas y alcances de los instrumentos legales no tienen en cuenta en general, los procesos de cambio y transformación de los ecosistemas en el largo plazo ni las relaciones entre estos procesos, los impactos sobre estos del cambio climático y los medios de vida de las personas (Creed \& van Noordwijk, 2018). Entonces, mantener la biodiversidad y los servicios de los ecosistemas (abastecimiento, regulación, culturales y de apoyo), como parte de las soluciones para la reducción de los impactos negativos del cambio climático, aun no ha permeado de forma clara, efectiva y estructurada en las políticas y marcos regulatorios de los países. Ello no obstante, existen esfuerzos significativos en la región mesoamericana y otras regiones con países en vías de desarrollo orientados a incorporar la gobernanza para la AbE dentro de arreglos de gobernanza que combinan diversas instituciones formales y no formales en instancias que están surgiendo a nivel nacional. Este tema será tratado en detalle en el capítulo 5 (Instituciones). Por otra parte, es a través del aumento de capacidades para la $A b E$ y la gobernanza ejercida por distintos grupos interesados clave, que se puede lograr la incidencia en los tomadores de decisión desde el nivel local (por ejemplo organizaciones de desarrollo, juntas de agua, consejos de microcuenca, grupos de gestión local de áreas protegidas), hasta los niveles nacionales y transfronterizos. En el capítulo 2 (Capacidad) se hace referencia detallada de cuáles son esas capacidades requeridas para gobernanza para la AbE en distintos niveles y grupos interesados. 
La buena gobernanza para la AbE debe propiciar además el desarrollo de un lenguaje común y un entendimiento de los conceptos clave entre todos los actores (Cosens et al., 2017). Los mecanismos legales e institucionales no deben ser percibidos como temas escabrosos e inalcanzables. El fortalecimiento de las capacidades de todos los actores para entender los procesos de gobernanza para la AbE y ejercer los derechos y deberes, incluyendo la incidencia en dinámicas políticas y de toma de decisión, es indispensable para garantizar la ética, equidad y justicia social. Las capacidades humanas e institucionales para la gobernanza para la AbE influyen y determinan el establecimiento y cumplimiento de las políticas y estrategias públicas (UNSTT, 2012).

\subsection{La articulación necesaria entre la gobernanza y la AbE: una visión futura hacia la sostenibilidad}

En las secciones anteriores se ha discutido tanto el concepto de AbE como el de gobernanza. Ahora bien ¿por qué debe existir una articulación entre ambos? Los esfuerzos de mantener la integridad de los ecosistemas y de vincular sus servicios al bienestar de la sociedad, requieren necesariamente de estructuras de gobernanza estables pero con capacidades de adaptación adecuadas, que permitan hacer frente a las variaciones del clima y a las tendencias globales de desarrollo económico.

En este documento se incluyen algunos ejemplos de medidas de adaptación al cambio climático basadas en ecosistemas que se enmarcan dentro de los criterios necesarios de reducción de vulnerabilidad social y de los ecosistemas. Estas acciones solo pueden llevarse a cabo si existe una coordinación efectiva entre distintos actores interesados y arreglos legales e institucionales que las apoyen en el largo plazo.

Las gestiones para la $\mathrm{AbE}$ que se realicen en distintos niveles, serán sostenibles en la medida en que se sustenten en un marco legal e institucional de carácter vinculante. En este sentido, cualquier acción destinada a la conservación de la naturaleza debe estar necesariamente acompañada de arreglos institucionales efectivos y eficientes (OCDE, 2015; OECD, 2018). El Estado debe preocuparse de construir un ambiente propicio político, legal y económico para la adaptación y la reducción de riesgos de desastres (CDB, 2018). No obstante, son los actores de la sociedad civil y otros interesados quienes, de forma organizada y concertada, pueden hacer cumplir los instrumentos políticos y legales. Para tales efectos dichos actores necesitan contar con capacidades de negociación e incidencia política. Asimismo, deberán entender, apropiarse y ejercitar sus derechos y deberes. Las interacciones entre los valores del ser humano, los conocimientos y las regulaciones deben formar parte esencial de la toma de decisiones.

Dado que la gobernanza para la $\mathrm{AbE}$ es un tema poco estudiado y ciertamente de reciente data, no se puede esperar que en los países de Mesoamérica existan estructuras de gobernanza consolidadas para la $\mathrm{AbE}$ que integren todos los sectores e intereses tanto vertical como horizontalmente. Esto es parte de un proceso a largo alcance. Sin embargo, resulta de fundamental importancia contar con un conocimiento adecuado de la legislación, las normativas y los procedimientos que existen relacionados tanto con la conservación del ambiente y los ecosistemas, el cambio climático así como con el desarrollo económico. Identificar los puntos de entrada dentro de las políticas y marcos legales existentes es esencial para plantear y ejecutar acciones de adaptación seguras (evitando la maladaptación) y sostenibles a largo plazo.

Aquí se trata en definitiva de romper paradigmas y ser conscientes que los desafíos de la sociedad relacionados con los servicios de los ecosistemas (seguridad hídrica, seguridad alimentaria, salud 
y medios de subsistencia en general, entre otros) también requieren de marcos legales dinámicos. Entonces, las capacidades de los actores interesados deben permitirles pensar y promover reformas legales necesarias para llenar las brechas y acoplar el desarrollo, los valores de la sociedad y la salud de los ecosistemas, con la adaptación al cambio climático de una forma justa y equilibrada. Esto significa que, la modificación de las leyes y regulaciones son necesarias para la sostenibilidad (a pesar de que tomen mucho tiempo y esfuerzo). Esto es válido en todos los niveles, desde el local (promoviendo ordenanzas municipales específicas por ejemplo) hasta el nacional, transnacional y global.

\subsection{Marco conceptual}

En este capítulo se presenta una serie de nociones fundamentales a ser utilizadas en este libro con el fin de contextualizar los temas a ser tratados. Dichas nociones y conceptos pueden ser encontrados en numerosas publicaciones que a su vez citan las definiciones "oficiales" incluidas en convenios internacionales tales como el Convenio de Diversidad Biológica (CDB, 1992; CDB, 2009b), el CMNUCC (1992) o los glosarios del Panel Intergubernamental del Cambio Climático (IPCC, 2007; 2014). Específicamente para el tema objeto de esta publicación, se ha tomado como marco de referencia el documento de la CBD: Voluntary Guidelines For The design and effective implementation of ecosystem-based approaches to climate change adaptation and disaster risk reduction (Guías voluntarias para el diseño e implementación efectivos de enfoques basados en ecosistemas para la adaptación al cambio climático y para la reducción de riesgos por desastres) (CBD, 2018) por ser uno de los documentos oficiales más recientes.

No es menester de esta publicación efectuar una comparación entre distintas definiciones de un mismo concepto sino, procurar simplificarlas de forma tal que puedan ser comprendidas fácilmente por un grupo amplio de destinatarios. Dado que precedentemente se ha explicado en forma exhaustiva lo que se entiende por AbE, gobernanza y gobernanza para la $\mathrm{AbE}$, estos conceptos no se incluyen en este apartado del documento. Otras nociones relevantes serán expuestas en los capítulos 2 al 6.

\section{Adaptación:}

Constituye un proceso que puede ser interpretado desde el punto de vista social o desde el punto de vista de los recursos naturales. En ambos se trata del ajuste a las condiciones climáticas actuales o esperadas (en el corto, mediano y largo plazo) y sus efectos, con el fin de reducir el daño o deterioro potencial (de las condiciones de vida o de las funciones de los ecosistemas respectivamente) que estas condiciones puedan causar. De acuerdo con el IPCC (2014) también incluye el aprovechamiento de oportunidades beneficiosas que dichos cambios del clima puedan brindar.

\section{Apropiación:}

Proceso por medio del cual los actores interesados asimilan e interiorizan como interés propio las acciones que se realizan en torno al bienestar humano (social) y ambiental. Los temas, acciones, proyectos se vuelven parte integral de la vida de las personas sin necesidad de contar con estímulos o influencias externas de otras personas para continuar con su ejecución. La apropiación permite que grupos organizados se adueñen de estos intereses comunes e incidan en los tomadores de decisión para que estos se cumplan sus acciones de forma eficiente y efectiva. 


\section{Beneficios (co-beneficios):}

Bienes, productos o servicios directos o indirectos que se generan hacia las personas $o$ los ecosistemas, al aplicar medidas de AbE. Estos pueden tener un valor ecológico, social, cultural y monetario. La reforestación por ejemplo puede generar beneficios no tangibles como mejorar la calidad del aire, conservar la calidad del agua, afectar positivamente el clima local y favorecer la polinización de especies importantes para la seguridad alimentaria.

\section{Bienestar humano:}

Es la forma de vivir de las personas o grupos sociales incluyendo los elementos necesarios para la vida. Se refiere al conjunto de elementos que son requeridos para vivir adecuadamente (con calidad) y en paz. Las dimensiones del bienestar humano (Evaluación de los Ecosistemas del Milenio, 2005) comprenden el material básico, la libertad, la salud, las buenas relaciones sociales y la seguridad. Está compuesto además por activos o capitales de medios de vida (humano, natural, social /cultural, físico y financiero) y se encuentra en estrecha relación con la capacidad de participación e identidad para la toma de decisiones.

\section{Biodiversidad:}

Variedad de los organismos vivos de todos los ecosistemas, incluyendo ecosistemas terrestres, marinos y acuáticos y los procesos ecológicos en los que conviven. Incluye la diversidad dentro de una especie, entre especies y entre y dentro de los ecosistemas (variabilidad de los genes, las especies y los ecosistemas). Algunos parámetros para medir qué tan biodiverso es un ecosistema por ejemplo, se relacionan con el número y la abundancia de especies dentro de un espacio geográfico específico.

\section{Cambio climático:}

Es la variación del estado del clima que persiste durante largos periodos de tiempo (decenios o periodos más largos). Puede deberse a procesos naturales o a fuerzas externas como ciclos solares, erupciones volcánicas o cambios causados por el ser humano persistentes en la composición de la atmósfera o el uso del suelo (IPCC, 2014). Para efectos de este libro, este término incluye también la variabilidad climática o variabilidad del clima. Esta se refiere a las modificaciones del estado medio (promedio) y otras características estadísticas, así como fenómenos extremos en todas las escalas temporales y espaciales más amplias que las de fenómenos meteorológicos. El aumento del nivel del mar que está afectando principalmente las zonas costeras de Mesoamérica es un efecto directo del cambio climático, mientras que la concentración de precipitaciones en menos días en ciertas áreas y las sequías son efectos de la variabilidad climática.

\section{Capacidad para la adaptación (capacidad adaptativa):}

Se refiere a la combinación de fortalezas, atributos y recursos (humanos, institucionales y de infraestructura entre otros) que posee una persona, comunidad, sociedad u organización que los faculta para realizar acciones que puedan reducir los impactos adversos del cambio climático y "recuperarse" de ellos (Reid et al., 2017). Esta capacidad incluye los recursos y la autoridad de carácter legal necesarios para responder al cambio como reflejo de un sistema de gobernanza que se ajusta a la incertidumbre. Asimismo se incluye la capacidad para la participación en donde las personas afectadas tienen los derechos, deberes y recursos para jugar un papel en la toma 
de decisiones. En este sentido esta capacidad de participación, reduce los riesgos de que los actores interesados sean marginados o no tomados en cuenta en los procesos de gobernanza relativos al cambio climático (Cosens et al., 2017). La capacidad adaptativa constituye uno de los tres componentes fundamentales de la ecuación de la vulnerabilidad: sensibilidad, exposición y capacidades de adaptación (ver definición de vulnerabilidad), toda vez que es la capacidad el componente que puede ser directamente mejorado a través de diversos mecanismos y herramientas (Capítulo 2).

\section{Capital natural:}

Es la reserva de recursos naturales dentro de los ecosistemas que, combinada con otros capitales o activos de los medios de vida sostenibles produce los servicios de los ecosistemas (Costanza, 2017). Estos recursos incluyen la corteza terrestre, minerales, reservas de energía, suelos, agua, aire, atmósfera, clima y todos los organismos vivos (Creed \& van Noordwijk, 2018). No requieren de actividades humanas para existir como sí lo necesitan los otros capitales (físico o construido, humano, financiero social o cultural).

\section{Ecosistema:}

Se refiere al conjunto de comunidades de plantas, animales y micro-organismos y su ambiente no viviente que interactúan dentro de una unidad geográfica específica. Es un sistema funcional que posee partes físicas (estructura) y procesos dinámicos de transformación de materia y energía (función). Los recursos naturales y la biodiversidad forman parte del ecosistema. El ser humano también forma parte del ecosistema ya que interactúa con los bienes y servicios que estos proporcionan. Estos sistemas se han clasificado de diversas formas siendo las más comunes: ecosistemas terrestres (i.e. bosques), acuáticos (i.e. humedales) y marinos (i.e. arrecifes de coral).

\section{Empoderamiento:}

Se refiere al proceso en el que las comunidades locales y otros grupos sociales desfavorecidos, adquieren el poder y la independencia así como la destreza de darse a conocer, ser escuchados para lograr los cambios que se han propuesto. Significa adquirir seguridad (confianza) en sí mismos (capacidades), legitimidad y reconocimiento por parte de otros actores para ser escuchados e incidir en las estructuras de decisión política.

\section{Funciones del ecosistema:}

Constituyen todos aquellos procesos en los que se transforma la materia y energía (flujo de energía dentro de los ecosistemas). Se refiere a los procesos físicos, químicos y biológicos que ocurren tanto a través de los seres vivos como en su interacción con el entorno (hábitat). Como ejemplos se pueden mencionar todos los ciclos de nutrientes, la producción de biomasa, la fotosíntesis y la polinización los cuales constituyen servicios de los ecosistemas y benefician al ser humano (Creed \& van Noordwijk, 2018).

\section{Incidencia política:}

Es la acción consciente y dirigida de un grupo social para cambiar una determinada realidad. Se predica respecto de un entorno con múltiples actores, proyectos, intereses y perspectivas, de manera que no se trata de una acción unilateral. La incidencia política debe incluir el enfrentarse a 
relaciones de poder y conflictos que se pueden resolver mediante negociaciones, concertaciones y acuerdos pero que a veces pueden llevar también a confrontaciones (UICN, 2006). Las capacidades de incidencia o de influencia a los grupos de poder y de toma de decisiones constituyen un ingrediente importante para las negociaciones y para promover cambios en la política, los marcos legales e institucionales para que sean funcionales ante el cambio climático.

\section{Infraestructura gris:}

Se refiere a las construcciones $u$ obras realizadas principalmente en zonas urbanas para canalizar aguas (diques, muros), proveer servicios de agua potable y saneamiento (redes de abastecimiento, plantas de tratamiento), retener suelos (muros de contención) entre otras, utilizando materiales artificiales tradicionales. Este tipo de obras se realizan generalmente en detrimento de los ecosistemas y sus servicios sin tomar en cuenta sus costos ni su ubicación estratégica.

\section{Infraestructura natural:}

Constituye un enfoque en el que se busca restaurar la estructura, función y composición de los ecosistemas para que mantengan los servicios que brindan. La infraestructura natural es parte importante de la AbE (Cohen-Shacham et al., 2016).

\section{Infraestructura verde:}

Este término está muy relacionado con la infraestructura natural sin embargo, se refiere al mejoramiento de la estructura y función de los ecosistemas para brindar sus servicios. Se usa generalmente cuando se trata de procesos principalmente en áreas urbanas y generalmente se combina con la infraestructura gris (Cohen-Shacham et al., 2016).

\section{Maladaptación:}

Son aquellas acciones diseñadas para la adaptación al cambio climático que por una suma de factores más bien incrementan la vulnerabilidad ecosistémica y social ante los riesgos relacionados con el cambio climático. Se relacionan generalmente con políticas para el desarrollo y medidas que producen beneficios en el corto plazo pero que en un plazo mayor resultan perjudiciales. Incluye además acciones que favorecen a ciertos sectores de la población en detrimento de otros, así como medidas que se aplican en algunas partes de los ecosistemas que perjudican los recursos y sus servicios en otras.

\section{Medidas de AbE:}

Opciones y acciones basadas en el mantenimiento y la restauración de los ecosistemas que a su vez mejoran la calidad de vida de las poblaciones humanas y su capacidad de adaptación al cambio climático.

\section{Negociación:}

Es el proceso de armonización de los diferentes intereses en acuerdos o arreglos en torno a un asunto determinado (Iza \& Stein (eds.), 2011). 


\section{Opciones de adaptación sin arrepentimiento (“low regrets adaptation options"):}

Son acciones que podrían potencialmente producir beneficios socioeconómicos netos a las comunidades locales y ecosistemas independientemente de los escenarios climáticos en el futuro. Consisten en maximizar los aspectos positivos y minimizar los negativos de las soluciones basadas en la naturaleza. Muchas de las opciones convencionales de conservación de ecosistemas, por ejemplo tales como la restauración de ciertos humedales, son beneficiosas social y ambientalmente, con o sin impactos del cambio climático.

\section{Ordenamiento territorial:}

Análisis sistémico de factores físicos, sociales y económicos con el objetivo de seleccionar las opciones más adecuadas que permitan aumentar la productividad, ser sostenibles y satisfacer las necesidades de la sociedad. Busca planificar los usos apropiados de un determinado espacio geográfico sin deteriorar los recursos naturales. Un plan de ordenamiento territorial necesita ineludiblemente, la participación de todos los actores y de una institucionalidad sólida que sea capaz de equilibrar el desarrollo, la conservación y el bienestar de las poblaciones humanas.

\section{Planificación territorial estratégica:}

Se refiere términos generales, a la planificación espacial o del territorio que va más allá de la planificación rural/urbana tradicional, que toma en cuenta impactos e influencias de otras políticas sectoriales, espacios geográficos y el uso de los recursos terrestres y/o marinos, así como otros factores de cambio como el cambio climático y los riesgos de desastres. Su objetivo es planificar las necesidades de desarrollo futuro y las oportunidades en jurisdicciones geográficas particulares, tomando en cuenta las políticas relevantes en el área y sus personas, y crear una distribución más equitativa del desarrollo económico (Lausche, 2011).

\section{Resiliencia:}

Habilidad de un sistema y sus componentes para anticipar, absorber, acomodarse o recuperarse de los impactos negativos del cambio climático mientras conservan su estructura básica y funcionamiento, la capacidad de organizarse y la capacidad de adaptarse al estrés y al cambio (IPCC, 2007). Se suele hacer una distinción entre resiliencia de los ecosistemas la cual hace referencia a su tolerancia a los impactos de factores externos sin sufrir cambios irreversibles (Reid et al., 2017) y la resiliencia humana. En este último caso, la resiliencia es la habilidad de amortiguar los impactos o sobrellevar los cambios. Requiere de resistencia o capacidad de absorber el impacto, recuperación o tiempo requerido para volver al estado de cosas en que estaba antes del impacto, y el aprendizaje para anticipar de mejor manera los potenciales cambios en el futuro. El aumento de la resiliencia de las personas depende de los medios de vida con los que cuenta, su capacidad de adaptación y de una buena gobernanza basada en instituciones sólidas y marcos legales claros e incluyentes.

\section{Restauración de ecosistemas:}

Se refiere a los procesos que se llevan a cabo para recuperar los recursos, las especies, las estructuras de una comunidad, la productividad y los servicios que brindan los ecosistemas que han sido degradados, dañados o destruidos. Esto permite aumentar su resiliencia antes los cambios y conservar su biodiversidad (Creed \& van Noordwijk, 2018). 


\section{Sistemas sociales:}

En forma semejante a los ecosistemas, se refiere al conjunto de personas o grupos de personas que interactúan con funciones y características particulares y específicos. Entre los principales elementos del sistema social se encuentran los valores, las normas, las costumbres, los usos y los acuerdos. Un sistema social tiene como objetivo la búsqueda y mejora de los medios de vida a través de redes y conexiones, la participación en grupos formales y las relaciones de confianza e intercambio (DFID, 1999). La articulación e interacción entre los sistemas sociales y los ecosistemas es un requisito indispensable para el ejercicio de una buena gobernanza para la $\mathrm{AbE}$.

\section{Salud de los ecosistemas (integridad ecológica):}

Se refiere al buen estado de un ecosistema en términos de estructura y funciones que cumple (haciendo una comparación con la salud humana por ejemplo). En otros contextos se utiliza más bien este término para referirse a la integridad ecológica de los ecosistemas donde tanto la estructura (especies y hábitats) como la función (transformación de materia y de energía) se encuentran dentro de ámbitos naturales de variación y pueden soportar y recuperarse de perturbaciones debidas a dinámicas naturales o por intervenciones humanas (Williams et al., 2012).

\section{Servicios de los ecosistemas:}

Son los beneficios que las personas obtienen de la naturaleza. Provienen de las características propias de los ecosistemas (ver definición de ecosistema) tanto de su estructura como de sus funciones. Algunos de estos beneficios son recursos tangibles como los que se obtienen con la pesca, el aprovechamiento de la madera y el agua (servicios de abastecimiento). Otros no son tan tangibles pero existen si los ecosistemas se encuentran en buenas condiciones. Este es el caso de la polinización, el control de la erosión, la regulación de las inundaciones, regulación del clima, la absorción de carbono (servicios de regulación). Los ecosistemas también pueden brindar valores de espiritualidad, culturales o estéticos (servicios culturales). Todos estos servicios no serían posibles sin aquellos necesarios para su producción y mantenimiento (servicios de apoyo) tales como la formación de suelos, el mantenimiento del ciclo de nutrientes, la producción de oxígeno, el hábitat y la biodiversidad entre otros (Layke, 2009).

\section{Soluciones basadas en la naturaleza (soluciones naturales):}

Acciones para proteger, gestionar sosteniblemente y restaurar ecosistemas naturales o modificados para enfrentar los retos de la sociedad de forma eficaz y adaptativa al mismo tiempo que se proporcionan beneficios para el ser humano y para la biodiversidad (Cohen-Shacham et al., 2016). Constituye un concepto nuevo en la ciencia y en la conservación donde se enfatiza el trabajo con los ecosistemas, sus recursos y sus servicios en lugar de usar las soluciones de ingeniería tradicionales para la adaptación al cambio climático. Estas soluciones deben ajustarse a los distintos contextos locales, tomar en cuenta el conocimiento tradicional, local y científico, contar con la participación activa de todos los actores. Además deben ser parte integral del diseño de políticas, legislación e institucionalidad desde el nivel local hasta el nacional y transfronterizo con el fin de ser implementadas de forma transparente y efectiva. 


\section{Vulnerabilidad:}

Se refiere a la propensión o predisposición tanto de un ecosistema como de una persona o grupo de personas a ser afectados negativamente (IPCC, 2014). La vulnerabilidad al cambio climático depende de múltiples factores por lo que debe evaluarse en cada caso particular. En general se definen tres componentes específicos de la vulnerabilidad. El primero, es la exposición que tiene que ver con las variaciones en el clima (temperatura, precipitación, temporadas de eventos extremos o huracanes) y generalmente se refiere a la ubicación geográfica (por ejemplo las personas que viven cerca de cursos de agua están más expuestas a inundaciones). El segundo es la sensibilidad que se refiere al grado en que un sistema se ve afectado por estímulos externos (SINAC, 2013; IPCC, 2007), esto depende de las características particulares de cada sistema. Por ejemplo, un cambio en temperatura o precipitación puede afectar de forma diferenciada a un bosque seco y a un bosque tropical húmedo. Por otra parte, las personas con pocos recursos son más sensibles a estas variaciones. El tercero es la capacidad para la adaptación (ver definición). El grado de exposición a los cambios del clima que tiene la región mesoamericana es muy difícil de modificar. Lo mismo ocurre con la sensibilidad de ciertos ecosistemas (por ejemplo los arrecifes de coral respecto al aumento de temperatura del agua) y comunidades (pueblos originarios en sus territorios). Por estas razones se vuelve cada vez más importante trabajar en pos de la mejora de las capacidades de adaptación de las personas y las comunidades para reducir su exposición y sensibilidad. Esto incluye mejorar las capacidades de las instituciones de gobierno para hacer frente a los desafíos actuales y futuros de la gobernanza para la $\mathrm{AbE}$ ante la incertidumbre de los escenarios climáticos.

\subsection{Contribuciones de la Gobernanza para la AbE a los acuerdos internacionales}

Los acuerdos y tratados internacionales respaldados por la Organización de Naciones Unidas son parte esencial del derecho internacional el cual trabaja sobre la base de valores comunes que ayudan a garantizar la paz y cooperación entre los países a través de una serie de principios.

En términos generales, existen distintos tipos de acuerdos a nivel internacional que pueden o no ser vinculantes. Pueden ser convenciones, convenios, tratados, pactos, cartas, códigos de conducta, memorandos de entendimiento, intercambio de notas por ejemplo (Aguilar \& Iza, 2009) o estar constituidos por la costumbre internacional. Los tratados internacionales vinculantes brindan la oportunidad a los Estados de acordar agendas conjuntas y compromisos que se deben cumplir en un tiempo determinado para mejorar la calidad de vida de los seres humanos. Con este fin, los Estados necesitan contar con arreglos de gobernanza capaces de incorporar los mandatos emanados de dichos acuerdos y traducirlos en políticas, marcos legales e institucionales que garanticen su cumplimiento eficiente, efectivo y oportuno.

En esta sección se incluyen cinco de esos acuerdos relacionados con la adaptación al cambio climático y la conservación de los ecosistemas (Convenio de Diversidad Biológica, Objetivos de Desarrollo Sostenible -ODS-, Acuerdo de París y las Contribuciones Nacionalmente Determinadas (NDC por su siglas en inglés), las Metas de Aichi, el Protocolo de Nagoya y el Marco de Acción de Sendai -reducción del riesgo de desastres-). 


\subsubsection{Convenio sobre la Diversidad Biológica (CDB)}

El Convenio define la diversidad biológica como la "variabilidad de organismos vivos de cualquier fuente, incluidos, entre otras cosas, los ecosistemas terrestres y marinos y otros ecosistemas acuáticos y los complejos ecológicos de los que forman parte; comprende la diversidad dentro de cada especie, entre las especies y de los ecosistemas" (CDB, 1992).

EI CDB es el primer instrumento global que se refiere a todos los aspectos de la diversidad biológica (componentes): recursos genéticos, especies y ecosistemas. Sus principales objetivos están relacionados con la conservación de la diversidad biológica, el uso sostenible de sus componentes y la participación justa y equitativa en los beneficios que se deriven de la utilización de los recursos genéticos. Como se ha mencionado ya dentro de este capítulo, la definición de la AbE fue adoptada en una de las conferencias de las partes del CDB (COP 10, decisión X/33). La AbE se relaciona directamente con este Convenio y sus objetivos, especialmente los relacionados con la conservación y el uso sostenible de los ecosistemas. Del Convenio han derivado numerosos instrumentos y protocolos que están íntimamente relacionados con la $\mathrm{AbE}$. En uno de los más recientes en el contexto del cambio climático y la reducción del riesgo por desastres (COP 14) se vincula la AbE además con la Reducción del Riesgo por Desastres basada en Ecosistemas (CBD, 2018).

Actualmente se discute dentro del CDB el "Marco Mundial de la Diversidad Biológica posterior a 2020" denominado también Marco Post 2020 (CDB, 2019) a raíz de una decisión tomada en la COP14 de la CDB en 2018 para realizar un proceso exhaustivo y participativo para la preparación del marco mundial de la diversidad biológica luego del año 2020. (CDB, 2018a). Los previamente citados documentos hacen mención (entre otros temas) a metas específicas, medibles, ambiciosas, realizables y con plazos que se basen en la ciencia y en los conocimientos. Asimismo, se propone utilizar las Metas de Aichi como base y como mejora para este marco. En general se propone efectuar una revisión exhaustiva del CDB incorporando además de forma explícita los grupos meta tales como la perspectiva de género, el papel de los gobiernos subnacionales, ciudades y otras autoridades locales, la sociedad civil, la juventud y el sector privado.

\subsubsection{Los Objetivos de Desarrollo Sostenible (ODS)}

La ONU define el desarrollo sostenible como "aquel el desarrollo que satisface las necesidades del presente sin comprometer la capacidad de las futuras generaciones para satisfacer sus propias necesidades".

Aunque este ha sido un tema de interés desde hace varias décadas, en setiembre de 2015, 189 Estados Miembros de Naciones Unidas aprueban una nueva visión hacia la sostenibilidad económica, social y ambiental a través de lo que se conoce como Agenda 2030, que cuenta con 17 objetivos de desarrollo e incluye 169 metas (ONU, 2016).

La AbE, como se expuso en secciones anteriores, busca mantener la integridad de los ecosistemas y los servicios que estos suministran lo cual se logra por medio de la conservación y la restauración (entre otros) y al mismo tiempo reducir la vulnerabilidad de las personas. Los ODS definen claramente los retos a los cuales se enfrentan tanto las sociedades como los ecosistemas y combina tanto los temas ambientales como los sociales y económicos por lo que en general se relaciona prácticamente con todos los ODS y muchas de sus metas. Por otra parte muchos de los ODS están sustentados en los servicios que los ecosistemas brindan a la humanidad (y que la AbE busca mantener), por lo 
que es importante comprender la dinámica de estos sistemas para la toma de decisiones en torno al desarrollo sostenible (Wood et al., 2018).

En el cuadro 1.1 se hace una aproximación a la articulación entre cada uno de los ODS y los componentes y principios de la AbE y su gobernanza necesarios para que esta pueda implementarse. No se trata aquí de hacer una revisión totalmente exhaustiva sino de reflexionar sobre los vínculos de la gobernanza para la AbE con cada uno de los ODS. Cabe mencionar sin embargo, que los ODS están planteados de forma independiente (Creed \& van Noordwijk, 2018), por lo que no es fácil ver la interacción entre ellos, lo cual constituye una limitación para este análisis.

\section{Cuadro 1.1 Articulación de la gobernanza para la AbE con los ODS y sus metas}

\begin{tabular}{|c|c|c|}
\hline ODS & Metas & Contribución de distintas iniciativas de AbE y su gobernanza \\
\hline 1. Fin de la pobreza & 1 & $\begin{array}{l}\text { - Medidas de adaptación que ayuden a las personas a mejorar } \\
\text { sus medios de vida sostenibles } \\
\text { - Aumento de la resiliencia y la reducción de vulnerabilidad de los } \\
\text { pobres ante los fenómenos extremos } \\
\text { - Generación de empleos como parte de sus co-beneficios }\end{array}$ \\
\hline 2. Hambre cero & 3,4 y 5 & $\begin{array}{l}\text { - Mejoramiento de las capacidades para la adaptación al cambio } \\
\text { climático y los fenómenos meteorológicos extremos para la se- } \\
\text { guridad alimentaria } \\
\text { - Mantenimiento de la diversidad biológica a través de su uso sos- } \\
\text { tenible respetando la disponibilidad de recursos genéticos y los } \\
\text { conocimientos tradicionales } \\
\text { - Diversificación de la agricultura y provisión de alimentos por } \\
\text { medio de prácticas agroforestales y actividades orientadas a la } \\
\text { agroecología }\end{array}$ \\
\hline 3. Salud y bienestar & 9 y $3 d$ & $\begin{array}{l}\text { - Gobernanza para la AbE afecta directa e indirectamente la salud } \\
\text { - Aumento de capacidades de poblaciones en riesgo a desastres } \\
\text { para hacer frente a fenómenos climáticos extremos }\end{array}$ \\
\hline $\begin{array}{l}\text { 4. Educación de } \\
\text { calidad }\end{array}$ & 7 & $\begin{array}{l}\text { - Fortalecimiento de capacidades para el aprendizaje y aplicación } \\
\text { de nuevos conocimientos sobre AbE y desarrollo sostenible }\end{array}$ \\
\hline 5. Igualdad de género & 5 & $\begin{array}{l}\text { - Promoción de la participación plena, igualitaria y efectiva de to- } \\
\text { dos los actores interesados } \\
\text { - Mujeres con igualdad de oportunidades de liderazgo en todos los } \\
\text { niveles de toma de decisiónes }\end{array}$ \\
\hline $\begin{array}{l}\text { 6. Agua limpia y } \\
\text { saneamiento }\end{array}$ & 5 y 6 & $\begin{array}{l}\text { - Mantenimiento de los ecosistemas, sus bienes y servicios incluy- } \\
\text { endo el agua y su distribución equitativa y sostenible en el marco } \\
\text { del cambio climático } \\
\text { - Relación inseparable con los objetivos } 13,14 \text { y } 15 \text { (cambio climáti- } \\
\text { co, ecosistemas terrestres y ecosistemas acuáticos) }\end{array}$ \\
\hline $\begin{array}{l}\text { 7. Energía asequible y } \\
\text { no contaminante }\end{array}$ & 2 & $\begin{array}{l}\text { - Mantenimiento de ecosistemas saludables y con poblaciones hu- } \\
\text { manas capaces de gestionaros adecuadamente }\end{array}$ \\
\hline $\begin{array}{l}\text { 8. Trabajo decente } \\
\text { y crecimiento } \\
\text { económico }\end{array}$ & 4 & $\begin{array}{l}\text { - Restauración y gestión sostenible de los ecosistemas } \\
\text { - Articulación entre la restauración con medios de vida sostenibles } \\
\text { - Crecimiento económico sin degradación ambiental }\end{array}$ \\
\hline
\end{tabular}




\begin{tabular}{|c|c|c|}
\hline ODS & Metas & Contribución de distintas iniciativas de AbE y su gobernanza \\
\hline $\begin{array}{l}\text { 9. Industria, innovación } \\
\text { e infraestructura }\end{array}$ & 1 & $\begin{array}{l}\text { - Promoción de infraestructura sostenible al largo plazo: infraest- } \\
\text { ructura verde y soluciones basadas en la naturaleza } \\
\text { - Combinación de soluciones naturales e infraestructura tradicio- } \\
\text { nal }\end{array}$ \\
\hline $\begin{array}{l}\text { 10. Reducción de las } \\
\text { desigualdades }\end{array}$ & 2 & $\begin{array}{l}\text { - Aplicación de los principios de la buena gobernanza para la AbE } \\
\text { (inclusión social, económica y política de todas las personas } \\
\text { especialmente aquéllas que son más vulnerables) }\end{array}$ \\
\hline $\begin{array}{l}\text { 11. Ciudades y } \\
\text { comunidades } \\
\text { sostenibles }\end{array}$ & 4 y $11 a$ & $\begin{array}{l}\text { - Mejoramiento de la planificación ambiental en un escenario de } \\
\text { incertidumbre climática }\end{array}$ \\
\hline $\begin{array}{l}\text { 12. Producción } \\
\text { y consumo } \\
\text { responsable }\end{array}$ & 2 y 8 & $\begin{array}{l}\text { Fortalecimiento de conocimientos sobre desarrollo sostenible, la } \\
\text { gestión de recursos naturales, uso racional de los bienes y servi- } \\
\text { cios de los ecosistemas y el uso eficiente de los recursos }\end{array}$ \\
\hline 13. Acción por el clima & 1,2 y 3 & $\begin{array}{l}\text { - Mejoramiento de la gobernanza para el cambio climático } \\
\text { - Inclusión de medidas de AbE en las políticas, estrategias y planes } \\
\text { nacionales }\end{array}$ \\
\hline 14. Vida submarina & Todos & $\begin{array}{l}\text { - Implementación de la gobernanza para la AbE alrededor de los } \\
\text { recursos costeros y marinos } \\
\text { - Conservación y uso sostenible de los ecosistemas }\end{array}$ \\
\hline $\begin{array}{l}\text { 15. Vida de ecosistemas } \\
\text { terrestres }\end{array}$ & Todos & $\begin{array}{l}\text { - Implementación de la gobernanza para la AbE alrededor de los } \\
\text { recursos costeros y marinos } \\
\text { - Conservación y uso sostenible de los ecosistemas y sus servicios }\end{array}$ \\
\hline $\begin{array}{l}\text { 16. Paz, justicia e } \\
\text { instituciones sólidas }\end{array}$ & $\begin{array}{l}3,6,7 \\
16 b\end{array}$ & $\begin{array}{l}\text { - Aplicación de los principios de la Abe tales como la igualdad de } \\
\text { acceso y justicia para todos } \\
\text { - Implementación de la gobernanza para la AbE } \\
\text { - Fortalecimiento de capacidades institucionales } \\
\text { - Participación e inclusión de los intereses de todos los actores } \\
\text { - Coordinación horizontal y vertical entre instituciones, organizaci- } \\
\text { ones y actores interesados }\end{array}$ \\
\hline $\begin{array}{l}\text { 17. Alianzas para lograr } \\
\text { los objetivos }\end{array}$ & 14 & $\begin{array}{l}\text { - Establecimiento de relaciones estratégicas entre distintos acto- } \\
\text { res para mejorar la eficacia y eficiencia de las acciones de ad- } \\
\text { aptación } \\
\text { - Mejoramiento de la coherencia de las políticas de ambiente y ad- } \\
\text { aptación al cambio climático }\end{array}$ \\
\hline
\end{tabular}

\subsubsection{Acuerdo de París y las Contribuciones Nacionalmente Determinadas (NDC por sus siglas en inglés)}

El Acuerdo de París se refiere al conjunto de compromisos asumidos por las partes contratantes de la Convención Marco de las Naciones Unidas sobre el Cambio Climático (CMNUCC) en su XXI sesión celebrada en París en 2015. Este acuerdo constituye un hito en los procesos de negociación entre países para reducir los efectos negativos del cambio climático, no solamente en términos de reducción de gases de efecto de invernadero sino también en temas relativos a la adaptación que fueron señalados como prioridad por varios países en sus planes de trabajo. El acuerdo busca "...reforzar la respuesta mundial a la amenaza del cambio climático, en el contexto del desarrollo sostenible y de los esfuerzos por erradicar la pobreza". A estos efectos propone c: "a) Mantener el aumento de la temperatura media mundial muy por debajo de $2^{\circ} \mathrm{C}$ con respecto a los niveles preindustriales...; b) Aumentar la capacidad de adaptación a los efectos adversos del cambio 
climático y promover la resiliencia al clima y un desarrollo con bajas emisiones de gases de efecto invernadero, de un modo que no comprometa la producción de alimentos...; y c) Elevar las corrientes financieras a un nivel compatible con una trayectoria que conduzca a un desarrollo resiliente al clima y con bajas emisiones de gases de efecto invernadero" (CMNUCC, 2015).

Una de las características más destacables de este acuerdo es la inclusión de la adaptación al cambio climático como uno de los temas esenciales para sus Estados parte. Asimismo, como parte de la adaptación en el Artículo 7 el Acuerdo de París establece que: “las Partes establecen el objetivo mundial relativo a la adaptación, que consiste en aumentar la capacidad de adaptación, fortalecer la resiliencia y reducir la vulnerabilidad al cambio climático con miras a contribuir al desarrollo sostenible y lograr una respuesta de adaptación adecuada en el contexto del objetivo referente a la temperatura". En este contexto, la gobernanza para la AbE tiene un papel importante que cumplir dentro del acuerdo. Entre sus enunciados, el acuerdo resalta la importancia de "garantizar la integridad de todos los ecosistemas, incluidos los océanos, y la protección de la biodiversidad...". Asimismo, reconoce la necesidad de realizar acciones conjuntas para mejorar el entendimiento, las medidas de adaptación y el apoyo para aumentar la resiliencia de las comunidades, los medios de vida y los ecosistemas (artículo 8.4) (CMNUCC, 2015).

Las contribuciones previstas nacionalmente determinadas (INDC por su siglas en inglés) son aquellos compromisos que cada país preparó con el fin de reducir los gases de efecto invernadero y llevar a cabo acciones de adaptación al cambio climático según sus propias realidades. Se los denomina también "planes de acción climática".

El Acuerdo de París incluye un cambio en el estatus jurídico de estos planes de acción climática, transformando lo que eran las INDC en planes concretos de acción, denominados contribuciones nacionalmente determinadas (NDC por sus siglas en inglés) ${ }^{3}$.

Para el caso de Mesoamérica los 8 países han ratificado el Acuerdo de París. En los párrafos siguientes se efectúa un análisis de la gobernanza para la AbE como contribución para alcanzar los NDC de cada uno de los países de Mesoamérica. No pretende ser un estudio exhaustivo sino mostrar cómo la AbE contribuye actual y potencialmente a las acciones propuestas por estos países para el cumplimiento del multicitado acuerdo. En el capítulo 5 (Instituciones) se hará mención de algunos ejemplos específicos del trabajo con estos países en torno a sus NDC.

\section{México}

El tema de adaptación se divide en acciones para tres componentes específicos: Sector Social, AbE e Infraestructura Estratégica y Sistemas Productivos. Para México, se hacen explícitas metas y acciones para la AbE por lo que sus aportes a esta meta están claras. Uno de los más importantes es el compromiso que ha hecho el país de alcanzar una tasa de deforestación cero para el año 2030. Sin embargo, se debe mencionar que la gobernanza para la AbE podría contribuir en la meta referente al Sector Social específicamente en las acciones que se vinculan con la seguridad alimentaria, el fortalecimiento de las capacidades y la participación social, la reducción de la vulnerabilidad a través de la aplicación de herramientas de ordenamiento territorial, la gestión integrada de los recursos hídricos así como en el aseguramiento de las capacidades y la participación social en las políticas de adaptación. 
En tanto que para la meta de Sistemas Productivos, la gobernanza para la AbE también puede contribuir en la incidencia para la incorporación de criterios de adaptación para proyectos de inversión pública, así como en la incorporación de criterios climáticos en los programas agrícolas y ganaderos, por ejemplo (Gobierno de México, 2015).

\section{Guatemala}

La NDC de Guatemala no incluye explícitamente la AbE. Ello no obstante, los ecosistemas marinocosteros, los bosques y sus recursos forestales, los recursos hídricos así como la agricultura, ganadería y seguridad alimentaria son temas prioritarios en materia de adaptación en este país.

La gobernanza para la AbE puede brindar apoyo para la implementación de las agendas de cambio climático especialmente con la implementación de la Estrategia de Biodiversidad y Cambio Climático. Asimismo en el fortalecimiento de las políticas para la gestión integrada de zonas costeras. Por otra parte, en el tema de mitigación uno de los principales recursos que se procura proteger y gestionar sosteniblemente son los bosques. Entre los instrumentos importantes para la protección de estos ecosistemas está la Estrategia de Restauración del Paisaje Forestal en la cual la AbE puede brindar contribuciones importantes (Gobierno de Guatemala, 2015).

\section{Belice}

La primera NDC de Belice se concentra en temas relacionados con la mitigación. Sin embargo, dentro de estas medidas se incluyen como actividad el mejoramiento de áreas protegidas clave. En estas, se compromete a rehabilitar áreas críticas para la conservación a través de la participación de comunidades locales y del uso sostenible comunitario de los ecosistemas y sus servicios (Government of Belize, 2015). Estos temas son componentes importante de la AbE.

\section{El Salvador}

En contraposición con Belice la NDC en materia de adaptación "es de la mayor trascendencia y prioridad para el país". Sin embargo se menciona que se apoyará el tema de mitigación dando énfasis a las acciones que conlleven co-beneficios socio-económicos y el enfoque de mitigación basada en adaptación. Este enfoque está inmerso en los programas de restauración de ecosistemas y paisajes y otras iniciativas relacionadas con los bosques del país. Uno de los programas más importantes para la adaptación en El Salvador es "Paisajes Sostenibles y Resilientes al Cambio Climático" con rehabilitación de zonas boscosas, establecimiento de corredores biológicos, sistemas agroforestales resilientes y actividades de reforestación en zonas críticas (incluyendo las áreas de recarga hídrica). Además, el país se compromete a promover un marco de legislación y arreglos institucionales orientando el desarrollo hacia la adaptación al cambio climático (Gobierno de El Salvador, 2015). Por tanto, la contribución de la gobernanza para la AbE, resulta importante para el cumplimiento de NDC a pesar de no estar explícitamente mencionada.

\section{Honduras}

Considera la adaptación al cambio climático como una prioridad para la reducción de la vulnerabilidad, la promoción de sistemas naturales y productivos así como la protección, conservación y restauración de los ecosistemas costeros marinos y terrestres y su biodiversidad. Las medidas de adaptación de acuerdo con su NDC se concentra en los recursos hídricos, la gestión de riesgos, la agricultura, 
suelos y seguridad alimentaria, los bosques y la biodiversidad, los sistemas costero marinos, la salud humana y la infraestructura principalmente para la energía hidroeléctrica (Gobierno de la República de Honduras, 2015). La AbE puede contribuir al alcance de las acciones relacionadas con el agua, los ecosistemas y la seguridad alimentaria principalmente.

\section{Nicaragua}

Se concentra en la mitigación al cambio climático sin dejar de tomar en cuenta la adaptación en varias secciones del documento. Se divide en dos sectores: energía y el uso y cambio de uso de la tierra. Si bien no menciona explícitamente la $\mathrm{AbE}$ muchas de las acciones propuestas dentro del segundo sector, se refieren explícitamente a acciones prioritarias para la adaptación al cambio climático que pueden formar parte también de medidas AbE. Tal es el caso de la producción agroecológica, incremento de la eficacia en la protección de reservas de la biosfera y otras áreas protegidas, la restauración, conservación y uso racional de humedales, el impulso a la reforestación así como programas de gestión resiliente y restauración de ecosistemas priorizados y sus servicios con enfoque de paisaje (Gobierno de Nicaragua, 2018). Por otro lado también se toma en cuenta la gestión y restauración de cuencas hidrográficas, la protección y conservación de la biodiversidad y la recuperación de los bosques en zonas de recarga hídrica. La gobernanza para la AbE resultará de suma importancia para la implementación de todas las medidas mencionadas así como para la preparación participativa del Plan Nacional de Adaptación, una de las prioridades expresadas en el documento.

\section{Costa Rica}

La AbE se incluye explícitamente en su NDC enfatizándose el aumento de la cobertura forestal del territorio nacional, la promoción de sinergias entre prácticas de adaptación y reducción de emisiones por deforestación evitada mediante la consolidación del Pago de Servicios Ambientales (PSA) y la certificación forestal como mecanismos para lograr un manejo sostenible y la protección de las fuentes de agua. Asimismo, la promoción y consolidación del Sistema Nacional de Corredores Biológicos y el Sistema Nacional de Áreas Silvestres Protegidas. Las acciones de adaptación además están plasmadas en el Plan Nacional de Adaptación al Cambio Climático con los siguientes componentes: agropecuario, biodiversidad, recursos hídricos, zonas costeras y reducción de riesgos por desastres (Gobierno de Costa Rica, 2015). Un tema importante que no está necesariamente incluido dentro de las acciones directas de la AbE en este NDC, consiste en el desarrollo de capacidades para la adaptación, que constituye uno de los más importantes de la gobernanza para la AbE.

\section{Panamá}

Su NDC se concentra en la mitigación y específicamente dentro de dos sectores: "Energía" y "Uso de la Tierra Cambio, de Uso de la Tierra y Silvicultura" en donde se plantean medidas que eventualmente se podrían vincular y mejorar a través de la AbE. Dentro del segundo sector, el énfasis se pone en los ecosistemas forestales, su protección, restauración y gestión sostenible. En torno a la mitigación, promueve la creación de corredores biológicos y la protección de fuentes de agua, además de la incorporación de sistemas agrícolas como parte de la reforestación y restauración de ecosistemas (Gobierno de la República de Panamá, 2015). 


\subsubsection{Metas de Aichi}

En 2010, las Partes al Convenio sobre la Diversidad Biológica (CDB) adoptaron el Plan Estratégico para la Diversidad Biológica 2011-2020, el cual constituye un marco de acción decenal para que todos los países e interesados salvaguarden la diversidad biológica y los beneficios que proporciona a las personas.

El Plan incluye 20 metas conocidas como Metas de Aichi agrupadas dentro de cinco objetivos estratégicos. Las estrategias y planes de acción nacionales en materia de diversidad biológica reflejan de qué manera un país tiene intención de cumplir con los objetivos del CDB. La misión del Plan Estratégico consiste en "Tomar medidas efectivas y urgentes para detener la pérdida de diversidad biológica a fin de asegurar que, para 2020, los ecosistemas sean resilientes y sigan suministrando servicios esenciales, asegurando de este modo la variedad de la vida del planeta y contribuyendo al bienestar humano y a la erradicación de la pobreza. A este fin, las presiones sobre la diversidad biológica se reducen, los ecosistemas se restauran, los recursos biológicos se utilizan de manera sostenible y los beneficios que surgen de la utilización de los recursos genéticos se comparten en forma justa y equitativa; se proveen recursos financieros adecuados, se mejoran las capacidades, se transversalizan las cuestiones y los valores relacionados con la diversidad biológica, se aplican eficazmente las políticas adecuadas, y la adopción de decisiones se basa en fundamentos científicos sólidos y el enfoque de precaución." (CBD, 2010). De esta misión se desprende que, las acciones de gobernanza para la AbE están implícitas en muchas de las Metas de Aichi. Explícitamente el tema de adaptación al cambio climático se encuentra únicamente en las Metas 10, 11 y 15 (mitigación); ello no obstante, todas se relacionan indirecta o directamente con la biodiversidad, por tanto con los ecosistemas.

En el cuadro 1.2 se ha hecho un esfuerzo de valoración de la contribución de la gobernanza para la AbE a los objetivos del Plan Estratégico. Dado que el Plan está vigente hasta el año 2020, sería interesante revisar las Metas mencionadas a la luz de los desafíos que plantea la adaptación al cambio climático.

\section{Cuadro 1.2 Articulación de la gobernanza para la AbE con las Metas Aichi}

\begin{tabular}{|l|c|l|}
\hline Objetivos estratégicos & $\begin{array}{c}\text { Metas } \\
\text { con una } \\
\text { relación } \\
\text { directa }\end{array}$ & Contribución de distintas iniciativas de AbE y su gobernanza \\
\hline $\begin{array}{l}\text { A. Abordar las causas } \\
\text { subyacentes de la } \\
\text { pérdida de la diversidad } \\
\text { biológica mediante la } \\
\text { incorporación de la } \\
\text { diversidad biológica } \\
\text { en todos los ámbitos } \\
\text { gubernamentales y de la } \\
\text { sociedad }\end{array}$ & 1 & $\begin{array}{l}\text { Énfasis en los valores de la biodiversidad como parte del capital } \\
\text { natural }\end{array}$ \\
\hline
\end{tabular}




\begin{tabular}{|c|c|c|}
\hline Objetivos estratégicos & $\begin{array}{l}\text { Metas } \\
\text { con una } \\
\text { relación } \\
\text { directa }\end{array}$ & Contribución de distintas iniciativas de AbE y su gobernanza \\
\hline $\begin{array}{l}\text { B. Reducir las } \\
\text { presiones directas sobre } \\
\text { la diversidad biológica y } \\
\text { promover la utilización } \\
\text { sostenible }\end{array}$ & $5,7,10$ & $\begin{array}{l}\text { - Restauración de ecosistemas degradados } \\
\text { - Implementación de enfoques basados en ecosistemas para la } \\
\text { adaptación al cambio climático } \\
\text { - Reducción de los impactos en ecosistemas vulnerables } \\
\text { - Incidencia en la toma de decisiones para reducir las amenazas } \\
\text { a la integridad de la biodiversidad }\end{array}$ \\
\hline $\begin{array}{l}\text { C. Mejorar la } \\
\text { situación de la } \\
\text { diversidad biológica } \\
\text { salvaguardando los } \\
\text { ecosistemas, las } \\
\text { especies y la diversidad } \\
\text { genética }\end{array}$ & 11 & $\begin{array}{l}\text { - Aplicación efectiva medidas de conservación de servicios eco- } \\
\text { sistémicos en áreas protegidas }\end{array}$ \\
\hline $\begin{array}{l}\text { D. Aumentar los } \\
\text { beneficios de la } \\
\text { diversidad biológica } \\
\text { y los servicios de los } \\
\text { ecosistemas para todos }\end{array}$ & $14,15,16$ & $\begin{array}{l}\text { - Distribución de beneficios de forma justa y equitativa de las pob- } \\
\text { laciones humanas } \\
\text { - Mantenimiento y restauración de la integridad de los servicios } \\
\text { de los ecosistemas (y su biodiversidad) }\end{array}$ \\
\hline $\begin{array}{l}\text { E. Mejorar la } \\
\text { aplicación a través } \\
\text { de la planificación } \\
\text { participativa, la gestión } \\
\text { de los conocimientos } \\
\text { y la creación de } \\
\text { capacidad }\end{array}$ & $17,18,19$ & $\begin{array}{l}\text { - Puesta en marcha de instrumentos políticos y legales } \\
\text { - Participación de todos los actores interesados } \\
\text { - Gestión del conocimiento (incluyendo el tradicional y científico) } \\
\text { - Fortalecimiento de capacidades para la adaptación }\end{array}$ \\
\hline
\end{tabular}

\subsubsection{Protocolo de Nagoya}

El tercer objetivo del Convenio de la Diversidad Biológica se refiere al acceso equitativo a los recursos genéticos (los cuales son parte de la biodiversidad y, por tanto, del capital natural de los ecosistemas) e indica específicamente: "la participación justa y equitativa en los beneficios que se deriven de la utilización de los recursos genéticos, mediante, entre otras cosas, un acceso adecuado a esos recursos y una transferencia apropiada de las tecnologías pertinentes, teniendo en cuenta todos los derechos sobre esos recursos y a esas tecnologías, así como mediante una financiación apropiada." (CDB, 1992). Con el fin de dar mayor impulso a este objetivo se negoció un régimen internacional que promoviera y salvaguardara dicha participación justa y equitativa de los beneficios; es así como se adopta en 2010 el Protocolo de Nagoya sobre Acceso a los Recursos Genéticos y Participación Justa y Equitativa en los Beneficios que se Deriven de su Utilización al Convenio sobre la Diversidad Biológica (Protocolo de Nagoya). El objetivo de este protocolo es "la participación justa y equitativa en los beneficios que se deriven de la utilización de los recursos genéticos, incluso por medio del acceso apropiado a los recursos genéticos y por medio de la transferencia apropiada de tecnologías pertinentes, teniendo en cuenta todos los derechos sobre dichos recursos y tecnologías y por medio de la iniciación apropiada, contribuyendo por ende a la conservación de la diversidad biológica y la utilización sostenible de sus componentes" (CDB, 2011). 
¿Por qué resulta importante enfatizar el Protocolo de Nagoya? La gobernanza para la AbE tiene como uno de sus ejes fundamentales la participación justa y equitativa de los beneficios y el respeto a los derechos de las partes interesadas sobre los recursos de los ecosistemas (i.e. recursos genéticos como parte de los ecosistemas), por tanto toma en cuenta las disposiciones del Protocolo de Nagoya en todas las políticas, leyes y prácticas de AbE que se lleven a cabo en diferentes niveles y con distintas partes interesadas.

\subsubsection{Marco de Sendai para la Reducción del Riesgo de Desastres 2015-2030}

El riesgo de desastres se incrementa debido a los impactos negativos del cambio climático. En Mesoamérica, estos se relacionan estrechamente con los fenómenos hidrometeorológicos. Si bien la $\mathrm{AbE}$ contribuye a reducir la vulnerabilidad de las poblaciones y los ecosistemas frente al cambio climático, puede contribuir también indirectamente a la reducción de riesgos derivados de desastres, fortaleciendo la infraestructura natural (integridad de los ecosistemas) y las capacidades de las poblaciones para hacer frente a estos fenómenos. Por otra parte, otra solución natural que se aplica específicamente en el tema de desastres, es la "Reducción del Riesgo basada en Ecosistemas o Eco-RRD" que también hace uso de los servicios de los ecosistemas para ayudar a las personas a reducir el riesgo por desastres (CBD, 2018). Ambas soluciones naturales están íntimamente vinculadas y contribuyen directa o indirectamente a esta reducción de riesgo de desastres.

El Marco de Sendai para la Reducción del Riesgo de Desastres 2015-2030 se adoptó en la tercera Conferencia Mundial de las Naciones Unidas celebrada en Sendai (Japón) el 18 de marzo de 2015. El objetivo del Marco de Sendai consiste en "la reducción sustancial del riesgo de desastres y de las pérdidas ocasionadas por los desastres, tanto en vidas, medios de subsistencia y salud como en bienes económicos, físicos, sociales, culturales y ambientales de las personas, las empresas, las comunidades y los países". El Marco considera fundamental "prever el riesgo de desastres, planificar medidas y reducirlo para proteger de manera más eficaz a las personas, las comunidades y los países, sus medios de subsistencia, su salud, su patrimonio cultural, sus activos socioeconómicos y sus ecosistemas, reforzando así su resiliencia” (UNISDR, 2015).

Es fundamental enfatizar en este punto que el CDB presenta hoy en día una articulación clara con el Marco de Sendai a través de sus "Voluntary Guidelines For The design and effective implementation of ecosystem-based approaches to climate change adaptation and disaster risk reduction (Guías voluntarias para el diseño e implementación efectivos de enfoques basados en ecosistemas para la adaptación al cambio climático y para la reducción de riesgos por desastres) (CBD, 2018). Estos documentos fueron preparados de forma colaborativa y conjunta entre la CDB y la CMNUCC y la UNDRR (Oficina de las Naciones Unidas para la Reducción del Riesgo de Desastres) e identifica tanto lecciones aprendidas como vacíos y desafíos para la implementación de AbE y la reducción del riesgo de desastres.

En el cuadro 1.3 se ha realizado un resumen de la contribución de la gobernanza para la AbE a las prioridades del Marco de Sendai para la Reducción del Riesgo de Desastres. 


\section{Cuadro 1.3 Articulación de la gobernanza para la AbE con el Marco de Sendai}

\begin{tabular}{|c|c|}
\hline Prioridades & $\begin{array}{c}\text { Contribución de distintas iniciativas de AbE y su } \\
\text { gobernanza }\end{array}$ \\
\hline 1. Comprender el riesgo de desastres & $\begin{array}{l}\text { - Generación de información sobre zonas vulner- } \\
\text { ables al riesgo y el potencial de sus ecosistemas } \\
\text { para reducirlos } \\
\text { - Fortalecimiento de las capacidades de gestión y } \\
\text { adaptación a nivel de comunidades }\end{array}$ \\
\hline $\begin{array}{l}\text { 2. Fortalecer la gobernanza del riesgo de desastres } \\
\text { para gestionar dicho riesgo }\end{array}$ & $\begin{array}{l}\text { - Fortalecimiento de la gobernanza para la AbE en } \\
\text { distintos contextos geográficos y niveles, desde } \\
\text { el local hasta el transfronterizo }\end{array}$ \\
\hline $\begin{array}{l}\text { 3. Invertir en la reducción del riesgo de desastres } \\
\text { para la resiliencia }\end{array}$ & $\begin{array}{l}\text { - Mantenimiento y mejora de funciones de los eco- } \\
\text { sistemas } \\
\text { - Fortalecimiento de la resiliencia de comunidades } \\
\text { - Articulación entre medios de vida sostenibles, la } \\
\text { vulnerabilidad y los servicios de los ecosistemas } \\
\text { dentro de estrategias más amplias de reducción } \\
\text { de riesgos } \\
\text { - Incorporación de medidas para la reducción del } \\
\text { riesgo por desastres en medidas de AbE }\end{array}$ \\
\hline $\begin{array}{l}\text { 4. Aumentar la preparación para casos de } \\
\text { desastre a fin de brindar una respuesta eficaz } \\
\text { y para "reconstruir mejor" en los ámbitos de la } \\
\text { recuperación, la rehabilitación y la reconstrucción }\end{array}$ & $\begin{array}{l}\text { - Fomento de enfoques preventivos y fortaleci- } \\
\text { miento de capacidades }\end{array}$ \\
\hline
\end{tabular}

\subsection{Desafíos y oportunidades de la gobernanza para la AbE}

A lo largo de este capítulo se han analizado los conceptos relativos a la AbE y la gobernanza para la adaptación, así como otros que están íntimamente relacionados con estos dos. En efecto, para que la $\mathrm{AbE}$ sea sostenible en el tiempo tiene, necesariamente que contar con estructuras de gobernanza funcionales desde el punto de vista de políticas, marcos legales, marcos institucionales y procesos. El tema de adaptación al cambio climático es, de por sí, un tema complejo que requiere de una gran diversidad de disciplinas y actores para enfrentar las incertidumbres que conlleva. Si bien no es un tema meramente ambiental, requiere de acciones urgentes para garantizar que los ecosistemas sigan brindando los bienes y servicios indispensables para la sobrevivencia del ser humano.

El horizonte temporal de los procesos no siempre se considera de forma adecuada. Si bien la ejecución de medidas de AbE resulta urgente, sus efectos no pueden ser planificados en un plazo de dos o tres años. Se requiere de un horizonte temporal adecuado que esté de acuerdo con los procesos propios de la naturaleza, de la biodiversidad y de la funcionalidad de los ecosistemas. En este aspecto específico, se podría hablar de décadas. La formación y fortalecimiento de capacidades para la adaptación tanto de los actores interesados como de las instituciones son procesos de largo plazo y necesitan de continuidad para ser efectivos. ¿Cómo planificar con una visión de largo plazo sin dejar de enfrentar la urgencia que impone los impactos negativos del cambio climático? ¿Cómo se mide ese impacto y qué tipo de sistemas de monitoreo y evaluación se requieren? Los procesos e iniciativas de AbE son muy jóvenes aún y requieren de mayor experiencia y capacidades para demostrar sus efectos positivos. 
Se presenta entonces como necesaria una gestión del conocimiento coherente, continua, innovadora, que contemple el conocimiento tradicional y esté científicamente respaldada para demostrar que la AbE funciona, es decir, para crear esa evidencia que es tan urgente demostrar a los diversos actores, principalmente a los encargados de tomar las decisiones y a los actores con poder económico que generalmente influyen sobre dichas decisiones a nivel político. Es imperativo contar con hechos y cifras para poder justificar y convencer a los tomadores de decisión y al sector privado de que las soluciones basadas en la naturaleza, particularmente la $\mathrm{AbE}$, eventualmente brindarán mayores beneficios económicos en el largo plazo. La valoración de los ecosistemas es fundamental para poder lograr este convencimiento. Se requiere de nuevas "métricas" que vayan más allá del ingreso y del poder económico dado que existen otros componentes del bienestar humano (PNUMA, 2011).

La gobernanza para la AbE por otra parte se enfrenta a los mismos retos que la gobernanza de los recursos naturales, con la adición de la incertidumbre climática. Existen todavía varias brechas (especialmente en términos de instrumentos legales y de coordinación interinstitucional) que deben ser resueltas para que los arreglos de gobernanza para la adaptación sean funcionales y sostenibles en el tiempo. Los marcos regulatorios requieren de tiempo para consolidarse de acuerdo con las condiciones necesarias para la aplicación de las medidas de AbE. Hacen falta políticas, planes y lineamientos de apoyo claros y contundentes que sean al menos "neutrales" (es decir que no dañen) al relacionarlos con las soluciones basadas en la naturaleza o soluciones naturales, para que estas puedan ser implementadas (WWAP, 2018). Lo ideal sería contar con todos los elementos necesarios dentro de la planificación, la ejecución, el seguimiento y mejoramiento de las medidas de $\mathrm{AbE}$ en un contexto de buena gobernanza para el cambio climático. Sin embargo, resulta imperioso ir construyendo con las condiciones con las que se cuenta e ir identificando las alianzas estratégicas y los recursos humanos y financieros de diversas fuentes para aprovechar las condiciones propicias para el escalamiento, respetando y favoreciendo a los sectores más pobres.

El financiamiento para la gobernanza para la $\mathrm{AbE}$ es un reto adicional; no obstante es preciso buscar opciones para la movilización de fondos a través de partidas presupuestarias nacionales (para ello se necesita un marco legal sólido y claro) así como del sector privado y empresas que dependen de los servicios de los ecosistemas para sus actividades económicas.

Si bien existen fuentes de financiamiento a nivel internacional para las acciones de adaptación al cambio climático, generalmente los procesos para acceder a estos recursos son engorrosos, consumen mucho tiempo y requieren de capacidades institucionales bien consolidadas y definidas. Estas condiciones no son la norma en los países "en vías de desarrollo" por lo que, generalmente dichas fuentes internacionales de financiamiento son todavía difíciles de alcanzar para muchos de los países de Mesoamérica y otras regiones en vías de desarrollo. 


\title{
2 Capacidades*
}

\author{
Marta Pérez de Madrid Utrilla
}

\section{$2.1 \quad$ Introducción}

La adaptación al cambio climático supone un reto sin precedentes para la sociedad y sus arreglos de gobernanza. Las próximas décadas serán testigo de otros cambios globales (pérdida de biodiversidad, disminución de la seguridad alimentaria e hídrica, aumento de la población en las ciudades, entre otros) que unidos a la incertidumbre asociada al cambio climático, requerirán que los arreglos de gobernanza se adapten, al igual que la sociedad misma y los ecosistemas. Estos ajustes serán necesarios desde el nivel local hasta el global, pasando por el nivel nacional y transfronterizo y en todos ellos serán necesarias las capacidades para la gobernanza para enfrentar dichos cambios.

Los arreglos de gobernanza denominados “de arriba hacia abajo" (top-down), en otras palabras, aquellos que van desde los niveles políticos más altos hasta las comunidades, normalmente no responden a la escala y a la complejidad de los de los sistemas socio-ambientales y a la velocidad del cambio climático (Cumming, 2006), toda vez que los procesos de adaptación son específicos a los contextos locales. Lo anterior requiere una articulación directa y una coordinación con los actores locales y su contexto, un proceso que no siempre se facilita a través de arreglos de gobernanza centralizados. Por otra parte, las consecuencias del cambio climático superan la escala de los Estados, como ocurre con el caso de los ecosistemas compartidos como las cuencas transfronterizas, donde se presentan amplias oportunidades para promover la AbE y su gobernanza en beneficio de los Estados y las comunidades en zonas de frontera.

Los cambios serán necesarios en todos los ámbitos del Estado, a múltiples niveles y por parte de todos los actores de la sociedad, pues se requerirán complejos ajustes a la gobernanza y nuevos arreglos de carácter institucional (IPCC, 2014). De hecho, las instituciones y su propia capacidad de adaptación jugarán un papel clave en el empoderamiento de la sociedad para que lleve a cabo la adaptación en forma efectiva (Gupta et al., 2010)

Más allá de la necesidad de ajustar la gobernanza, lo cierto es que no todos los países cuentan con las mismas capacidades para ello. El Acuerdo de París dentro de la CMNUCC reconoce que los países en desarrollo tienen menor capacidad para aplicar medidas de adaptación y realizar acciones para enfrentar el cambio climático. Para efectos de facilitar el cumplimiento de dichas medidas por parte de estos países la Convención establece un marco que da seguimiento a la construcción de capacidades y fomenta la colaboración entre los Estados con este fin.

En este contexto, se presentan varios interrogantes, entre ellos:

a) ¿Qué se debe entender por capacidad?

b) ¿Qué capacidades serán necesarias de parte de la sociedad y sus instituciones para promover la AbE?

c) ¿Quiénes -individuos o instituciones- requieren dicha (s) capacidad(es)?

d) ¿Qué capacidades se necesitan para la gobernanza para la $\mathrm{AbE}$ ?

\footnotetext{
* Este capítulo contiene aportes sustantivos de Rocio Córdoba Muñoz y Alejandro lza.
} 
Más allá de los interrogantes precedentes, es preciso aclarar algunos conceptos íntimamente relacionados como son la "capacidad adaptativa" (adaptive capacity) o "capacidad para la adaptación", la "gobernanza para la AbE" y la "capacidad para la gobernanza para la AbE".

Siguiendo la lógica de los interrogantes precedentes, este capítulo pretende describir y analizar las capacidades para la gobernanza para la $\mathrm{AbE}$; en otras palabras, aquéllas específicas y necesarias para gobernar los procesos de adaptación que utilizan los ecosistemas y la biodiversidad.

A través de un análisis deductivo de la experiencia del trabajo de la UICN en Mesoamérica, se pretenden identificar las capacidades existentes (o inexistentes) que influyen en la gobernanza y favorecen la implementación de la AbE.

\subsection{Capacidad, gobernanza y adaptación}

El concepto de capacidad adaptativa de las comunidades, las instituciones y los países ha sido analizado en profundad en años recientes. Asimismo, en la última década ha tenido lugar una vasta investigación respecto al concepto de la gobernanza adaptativa. Resulta por ello relevante analizar estos dos conceptos y su interrelación para poder identificar y analizar las capacidades necesarias para la gobernanza de la AbE.

Puede entenderse por capacidad adaptativa a la "combinación de fortalezas, atributos y recursos (humanos, institucionales y de infraestructura entre otros) que posee una persona, comunidad, sociedad u organización que los faculta para realizar acciones que puedan reducir los impactos adversos del cambio climático y "recuperarse" de ellos (Reid et al., 2017). Dicha capacidad incluye los recursos y la autoridad de carácter legal necesarios para responder al cambio como reflejo de un sistema de gobernanza que se ajusta a la incertidumbre. Asimismo incluye la capacidad para la participación en donde las personas afectadas tienen los derechos, deberes y recursos para jugar un papel en la toma de decisiones.

La habilidad de adaptarse a los efectos del cambio climático no es estática sino que puede mejorarse (o empeorarse) si varían los elementos que la influyen o condicionan. Dichos elementos son, entre otros, los recursos económicos, la información, la tecnología, la infraestructura, las instituciones o las habilidades individuales (Smit \& Pilifosova, 2001).

La capacidad se predica respecto de múltiples niveles, es decir, desde el individual hasta el transfronterizo. Existe además una interacción entre los diferentes componentes de la relación Estadosociedad que deben ser tomados en cuenta para la definición de dicha capacidad en el sentido de que cuanto mayor la capacidad del Estado y sus instituciones, mayor la capacidad adaptativa de la sociedad civil (Gupta et al., 2010)" o del sector privado, siempre que el Estado utilice sus capacidades para empoderar a la sociedad y les brinde los espacios necesarios para aprender y resolver algunos de los principales problemas derivados del cambio climático. A su vez, una sociedad que cuente con mayores capacidades, exige a las instituciones del Estado adaptarse más rápidamente.

La gobernanza para la AbE reconoce que hay múltiples actores e interacciones entre el Estado, la sociedad civil y el sector privado y las decisiones usualmente requieren interacción entre diferentes escalas y niveles pudiendo extenderse más allá de las fronteras estaduales, toda vez que los ecosistemas no reconocen fronteras políticas.

La gobernanza para la AbE implica promover las politicas, leyes, instituciones y procesos que facilitan la adaptación y la toma de decisiones en un contexto de incertidumbre. Para ello requiere de 
la coordinación y el aprendizaje entre múltiples actores y niveles para poder implementar y escalar prácticas sostenibles de conservación y procesos de restauración de ecosistemas con la finalidad de mejorar la resiliencia tanto de los seres humanos, como de los ecosistemas mismos. Transformar la gobernanza con esta nueva visión es clave no solo para implementar las soluciones basadas en la naturaleza ante el cambio climático, sino también para alcanzar los Objetivos del Desarrollo Sostenible de la Agenda 2030 (Martínez \& Luna, 2019).

Entonces, para que la AbE sea efectiva y pueda ser escalada se requieren arreglos adecuados de gobernanza.

La capacidad para la gobernanza para la $\mathrm{AbE}$ es aquella relativa a los actores de la sociedad que permite el desarrollo e implementación de políticas, leyes, instituciones y procesos, como la facilitación de la toma de decisiones a diferentes escalas para promover el uso sostenible de la biodiversidad y los servicios de los ecosistemas para hacer frente al cambio climático.

Un ejemplo de las antedichas capacidades se visualiza en el caso del Plan Nacional de Adaptación de Honduras (PNA). El Ministerio de Ambiente (MiAmbiente) desarrolló dicho plan e incluyó como uno de los ejes principales a la AbE. Para operar dicha inclusión, fue necesaria una capacitación a nivel nacional, la organización de espacios de participación y búsqueda de consensos como así también experiencias demostrativas. MiAmbiente contaba con capacidades de liderazgo colectivo e individual para asesorar en el diseño y elaboración del plan, llevar a cabo un proceso participativo de articulación de actores, movilizar fondos y, en definitiva, promover los ajustes de gobernanza necesarios para la implementación del plan tal como un mecanismo de coordinación interinstitucional.

\subsection{Actores, habilidades y capacidades para la gobernanza para la AbE}

\subsubsection{Actores}

La AbE implica procesos complejos de ajuste de la gobernanza en múltiples sectores y ámbitos, en donde interactúan distintos actores. Los actores de la sociedad vinculados con la gestión y la utilización de los recursos naturales, la agricultura, la salud, las ciudades, las empresas y la economía en su conjunto van a requerir adaptarse, promover e internalizar los ajustes de gobernanza necesarios para ello. Esto incluye, entre otros, a mujeres y hombres, jóvenes y adultos, agricultores y pescadores, ingenieros y constructores, comerciantes, empresarios y corporaciones. En lo que al sector público atañe, involucra a todos los poderes del Estado, tanto al ejecutivo, como al legislativo y al judicial, que deberán diseñar, decidir e incorporar modelos de gobernanza participativos, ecosistémicos y más flexibles, cuando fuera el caso.

Por otro parte, desde una perspectiva más global, tanto países desarrollados, como en vías de desarrollo (con mayor urgencia) necesitan adaptarse y poseer las capacidades necesarias para mejorar la gobernanza para impulsar la AbE. Esto no debe entenderse en el sentido de que únicamente los grupos más vulnerables requieren capacidades para la adaptación aunque sí es cierto que se necesitan mayores esfuerzos en los países y poblaciones más vulnerables. Por otra parte, es importante destacar que si las capacidades para la gobernanza para la adaptación no se desarrollan en toda la multiplicidad de actores involucrados, se compromete la implementación efectiva de la AbE. 
Las capacidades de múltiples actores para la adaptación pueden ilustrarse con en el caso del desarrollo de la Política Nacional de Cambio Climático de Costa Rica, adoptada en 2018. Con el objeto de definir las prioridades de dicho instrumento, el gobierno impulsó un proceso multisectorial y multinivel que incluyó la conformación de mesas sectoriales (con representación gubernamental), así como la creación de un comité redactor asesor con representación de expertos del sector académico, de las ONG's y del gobierno. Múltiples actores fueron convocados; desde el sector ambiental y agrícola hasta el de turismo e infraestructura. El borrador de la política fue sometido a consulta para recibir las observaciones de la sociedad civil, tanto a través de redes sociales como por medio de la organización de talleres. Considerando la experiencia de Costa Rica en materia de soluciones basadas en la naturaleza, la política incluyó un eje en materia de AbE.

\subsubsection{Habilidades}

En forma individual las personas requieren contar con las habilidades necesarias para liderar los procesos de transformación y gobernanza adecuados para la promoción de la AbE.

Las habilidades que describe el Foro Económico Mundial (WEF, 2016) para enfrentar la cuarta revolución industrial, son también válidas para los procesos de adaptación. Este informe señala que las habilidades que se requerirán en el futuro serán la resolución de problemas complejos, el pensamiento crítico, la creatividad, el manejo de personas, la coordinación, la inteligencia emocional, el juicio y la toma de decisiones, la orientación al servicio, la negociación y flexibilidad cognitiva.

De acuerdo con la experiencia de UICN en Mesoamérica en materia de adaptación al cambio climático, las habilidades de coordinación, negociación, pensamiento crítico y resolución de problemas complejos resultan indispensables para forjar arreglos de gobernanza efectiva para la adaptación.

En la cuenca del Río Paz, en El Salvador, las mujeres han demostrado habilidades de liderazgo, coordinación y negociación que les han permitido ser parte activa del comité de vigilancia del manglar Garita Palmera y realizar actividades de restauración involucrando a vecinos, ONGs locales así como visibilizar la problemática local a través de medios de comunicación (Pérez de Madrid, 2019). Esto pudo lograrse tras participar en un programa de desarrollo de capacidades en materia de cambio climático, comunicación y liderazgo, mismo que les permitió además de fortalecer conocimientos técnicos, mejorar su autoestima, identificar su propio liderazgo para la acción (Narvaez Marulanda, 2018). El siguiente paso en este proceso constituye el escalamiento de las experiencias a través de instancias tales como un comité de microcuenca con una participación de más amplia de actores. Su meta es el co-manejo del área protegida del Manglar Garita Palmera en conjunto con el Ministerio de Ambiente de El Salvador.

\subsubsection{Capacidades}

Las capacidades para la adaptación al cambio climático pueden clasificarse de la siguiente manera:

- Capacidad social

- Capacidad político/legal

- Capacidad institucional

- Capacidad tecnológica, incluyendo la gestión del conocimiento

- Capacidad financiera 


\section{- Capacidad para la innovación}

- Capacidad para el escalamiento

La innovación no es algo que se considere en las capacidades para la adaptación; sin embargo, habida cuenta de la AbE es novedosa, la capacidad para innovar también debe ser ponderada.

A continuación se incluye una descripción de cada una de las capacidades enfatizando su relación con la AbE:

1. Capacidad social: La capacidad social comprende los lazos sociales, las formas asociativas y las relaciones de confianza entre individuos, organizaciones e instituciones y por tanto es fundamental para la gobernanza para la AbE.

La capacidad social se inicia con los lazos intracomunitarios que se establecen entre los miembros de una comunidad ya sea a nivel de familias, amigos, grupos sociales o asociaciones. A un nivel más alto, se refiere al grado de interacción entre entidades públicas, asociaciones y otras formas organizadas de articulación de intereses. Ejemplos de estas asociaciones son las cooperativas agrarias, los comités de agua, las asociaciones profesionales, las asociaciones de mujeres, asociaciones culturales, sindicatos, asociaciones empresariales y los partidos políticos. Con el objeto de implementar medidas de AbE en forma efectiva, resulta necesario articular los intereses locales, nacionales o sectoriales.

En Chiapas, por ejemplo, las comunidades tienen la estructura del Ejido, que agrupa a propietarios comunales de tierras y promueve un espacio de diálogo para la conservación de los bosques. En Guatemala y en EI Salvador, los Consejos Comunitarios de Desarrollo (COCODES) y las Asociaciones de Desarrollo Comunitario (ADESCOs) permiten el diálogo, el consenso, la priorización de medidas de adaptación y la articulación con las instituciones subnacionales y nacionales.

2. Capacidad político/legal: En materia de adaptación al cambio climático, la política tiene por objeto planificar el proceso de ajuste al clima basado en la información disponible sobre las amenazas y riesgos climáticos que enfrenta la sociedad y los ecosistemas. Idealmente la política en materia de adaptación debería estar plasmada en un instrumento marco que establezca directrices generales para todos los sectores en el corto, mediano y largo plazo. Este instrumento que se implementa por medio de estrategias puede traducirse en acciones concretas a realizar así como criterios e indicadores. Una política puede detallarse en diferentes sectores que contengan sus propias estrategias de adaptación y conjuntamente con una política de adaptación propiamente dicha, contribuir a implementar las acciones concretas para la protección y restauración de ecosistemas, reducción de la vulnerabilidad y aumento de la resiliencia social. La ley, por su parte, debe establecer las instituciones encargadas de coordinar la adaptación en sus múltiples dimensiones, distribuir competencias entre distintos sectores y niveles del gobierno y proveer los mecanismos para gestionar y resolver conflictos entre diferentes demarcaciones administrativas o cuando existan superposición de competencias entre distintas instituciones. En definitiva la función de la ley consiste en proveer un marco estable, claro y obligatorio a la política e institucionalizar los arreglos necesarios para la $\mathrm{AbE}$.

En 2018 Perú dio a conocer su Ley Marco sobre Cambio Climático (Ley No. 30754), cuyo objeto es, entre otros, establecer los principios, enfoques y disposiciones generales para coordinar, diseñar, ejecutar y difundir las políticas públicas para la gestión integral, participativa y transparente de las medidas de adaptación al cambio climático, a fin de reducir la vulnerabilidad. El principio de 
gobernanza climática incluido en la ley apunta a la construcción de procesos y políticas públicas en materia de adaptación (y mitigación) con la participación efectiva de todos los actores públicos y privados en la toma de decisiones, el manejo de conflictos y la construcción de consensos, sobre la base de responsabilidades, metas y objetivos claramente definidos en todos los niveles de gobierno. Dicha ley define un marco institucional para la gestión integral de cambio climático, los instrumentos necesarios para ello, las medidas de adaptación y mitigación, y contiene disposiciones en materia de transparencia, acceso a la información y participación ciudadana, educación, ciencia y tecnología, innovación y financiamiento, integrando a la AbE como parte de dicha gestión.

El Ministerio del Ambiente del Perú explicó que la Ley Marco de Cambio Climático era necesaria, entre otras cosas, para:

- Reforzar la autoridad nacional en materia de política climática, que establece, orienta, dirige, facilita, monitorea y promueve la gestión ante el cambio climático.

- Promover que cada entidad pública a nivel nacional, regional y local defina, priorice y reporte acciones concretas de adaptación y mitigación.

- Impulsar a que los instrumentos de gestión, planificación del desarrollo y de inversión sectorial incluyan acciones de adaptación y mitigación.

- Contribuir a la ejecución de la Estrategia Nacional ante el Cambio Climático, las Contribuciones Nacionalmente Determinadas y los instrumentos de gestión, planificación e inversión sectorial, territorial y recursos hídricos.

- Crear una Comisión Multisectorial de Alto Nivel de carácter permanente conformada en el marco de la normatividad vigente, que actualizará las Contribuciones Nacionalmente Determinadas. ${ }^{1}$

3. Capacidad institucional: En el contexto de la incertidumbre que deriva del cambio climático, las instituciones necesitan evolucionar y flexibilizarse, cuando fuera el caso, de manera tal de atender a los cambios y necesidades de los múltiples actores de la sociedad y sus inter-relaciones. Estas instituciones son las que: 1) tienen las capacidad de estimular el involucramiento de diferentes perspectivas, actores y soluciones; 2) pueden habilitar a los actores sociales a aprender de sus instituciones y a mejorarlas de forma continua; 3) permiten y motivan a los actores sociales a ajustar su comportamiento; 4) establecen las condiciones necesarias para facilitar liderazgos; 5) pueden movilizar recursos para implementar medidas de adaptación y 6) apoyan una gobernanza efectiva.

En el ejemplo del Plan Nacional de Adaptación de Honduras (PNA) citado en la sección anterior, Mi Ambiente conformó un Comité Interinstitucional de Adaptación, cuya función es asegurar la coordinación interinstitucional, la sostenibilidad financiera del PNA, la voluntad política y los recursos técnicos y logísticos, además de un monitoreo formal del cumplimiento del PNA. Este Comité representa una oportunidad para el diálogo, el aprendizaje y la participación en la implementación de dicho plan.

4. Capacidad tecnológica: La tecnología resulta cada vez más importante para la gobernanza para la $\mathrm{AbE}$, toda vez que permite, entre otros, sistematizar la información, facilitar la comunicación oportuna y la participación social. En tanto que la AbE busca implementar medidas de conservación, restauración y gestión sostenible de los ecosistemas, una institución del Estado, u otro organismo como una autoridad de cuenca deben hacer uso de la tecnología y la gestión del conocimiento para 
adoptar y consensuar decisiones, informar a la sociedad para mejorar la implementación de las medidas de AbE.

En 2018, Costa Rica puso en marcha el Sistema Nacional de Métrica para el Cambio Climático (SINAMECC) un mecanismo que aprovecha las tecnologías de la información para cumplir con los requerimientos de medición, reporte y verificación del Marco Reforzado de Transparencia para la Acción y el Apoyo de la CMNUCC y del Acuerdo de París. De forma articulada, la Dirección de Cambio Climático del Ministerio de Ambiente y Energía (MINAE), en coordinación con el Instituto Nacional de Estadística y Censos (INEC), el Instituto Meteorológico Nacional (IMN) y el Centro Nacional de Información Geoambiental (CENIGA) generan información de libre acceso a través de un software que facilita la toma de decisiones basada en datos y rendición de cuentas, tanto a nivel nacional como internacional ${ }^{2}$.

5. Capacidad financiera: La capacidad financiera se refiere a la capacidad de las instituciones u otros organismos para canalizar e invertir recursos para la implementación de la AbE. Dentro de la capacidad financiera deberían considerarse temas tales como las líneas de créditos específicas a nivel local, regional o estatal, la capacidad de gestión financiera y transparente de instituciones locales y nacionales y los mecanismos e instrumentos para la distribución apropiada y equitativa de dichos fondos.

En Costa Rica, México y Guatemala acciones de conservación, priorizadas también como medidas de adaptación, han sido posibles gracias al pago por servicios ambientales gestionados por diversas instituciones del Estado.

En los ejidos La Azteca y Alpujarras en la cuenca del Río Cahoacán, los campesinos se ven obligados muchas veces a realizar acciones de conservación de suelos para evitar la erosión derivad de las intensas lluvias que ocurren en esa región del sur de México. La maquinaria necesaria para estas tareas es costosa y, muchas veces inaccesible para las comunidades campesinas, por lo que las prácticas de conservación (por ejemplo, la construcción de trincheras, zanjas de infiltración y siembra de árboles) terminan siendo de carácter manual. Para la consecución exitosa de estas acciones fue necesario intensificar el empoderamiento local, la coordinación entre distintas instancias, la sensibilización de las comunidades locales y la priorización de ciertas acciones basadas en un análisis de vulnerabilidad comunitario. El financiamiento por medio de fondos estatales procedentes de la Comisión Nacional Forestal dentro de tres programas: el de pago por servicios ambientales, el de restauración integral en zonas de alta prioridad y el de compensación ambiental por cambio de usos del suelo en terrenos forestales (Arrevillaga \& López, 2019). El proceso en sí y sus múltiples resultados son producto de la movilización de la capacidad social, institucional y financiera facilitada por entes públicos.

6. Capacidad para la innovación: La innovación permite identificar soluciones a nuevos problemas o nuevas soluciones a problemas ya existentes. Las soluciones a los problemas derivados del cambio climático deben ser más eficientes, participativas, de largo plazo, y tomar en cuenta la variabilidad y los escenarios climáticos. En el mundo empresarial, la innovación se predica respecto del diseño de nuevos servicios, productos o procesos en el contexto del cambio climático. Por ejemplo, las corporaciones necesitan adaptar sus operaciones (producción, almacenamiento y distribución) para ajustarse a las condiciones cambiantes del clima que afecten la disponibilidad de recursos como el agua (Newborne \& Dalton, 2016). Sin embargo, la innovación no debe limitarse solo al ámbito 
privado, ya que en el sector público puede servir para que los países logren identificar los medios necesarios para mejorar su posición frente a la vulnerabilidad, pasando de una visión de corto plazo a una de largo plazo. Según la OCDE, para facilitar la innovación, los países tienen que fomentar el desarrollo de una economía del conocimiento, la puesta en marcha de políticas de investigación, desarrollo e innovación, así como canalizar inversiones por parte del sector privado.

En Centroamérica, una región con predominancia de la agricultura, innovar en los métodos de producción(talescomoagriculturaregenerativa, conservación desuelos, sistemasagrosilvopastoriles, agricultura de subsistencia sostenible o restauración del paisaje) presenta un gran potencial para la AbE. Honduras, El Salvador, Guatemala y Costa Rica, han analizado las oportunidades de restauración de paisajes a través de un proceso liderado por Mesas Nacionales de Restauración (un espacio interinstitucional y de consenso entre el sector privado y los productores que analiza cómo efectuar la implementación a escala de modelos de producción agrícola y ganadera más sostenibles).

7. Capacidad para el escalamiento: Se refiere a las capacidades necesarias para promover la multiplicación de las medidas de AbE entre distintos niveles y dentro de los mismos (vertical y horizontal). Entre los elementos más importantes para mejorar la capacidad para el escalamiento, corresponde destacar los siguientes:

1. Las existencia de sitios demostrativos

2. La gobernanza local, que permite la apropiación por parte de los actores involucrados

3. La sistematización de experiencias, el monitoreo y evaluación de los resultados y las lecciones aprendidas

4. La existencia de metodologías participativas para replicar acciones

5. La existencia de espacios de aprendizaje y fortalecimiento de capacidades

6. La organización de eventos para el intercambio y reflexión de dicha experiencias

7. La comunicación y la difusión de resultados de las experiencias

8. Las políticas y leyes que reconocen, establecen y promueven la $\mathrm{AbE}$

9. La existencia de financiamiento

La figura 2.1 ilustra el efecto exponencial que tienen los distintos elementos de la capacidad para el escalamiento partiendo de sitios de aprendizaje o sitios demostrativos que podrían considerarse a estos efectos como el punto inicial para la construcción de la capacidad para el escalamiento. Es en estos sitios en donde se logran establecer las bases para el diseño e implementación de medida de AbE y la generación de evidencia. Los actores locales se apropian de las medidas de adaptación y las reflejan o incorporan en los instrumentos y mecanismos de gestión. El empoderamiento de dichos actores opera en un contexto en el cual tienen acceso a información, al asesoramiento técnico para la implementación de acciones para la AbE y cuentan con metodologías para su implementación, además de poder tomar decisiones con base en dicha información. Los espacios de aprendizaje permiten intercambiar experiencias con otras comunidades con medios de vida similares y que sufren los impactos del cambio climático en forma comparativamente similar. Dichos intercambios operan una influencia positiva al motivar a los actores a implementar medidas incluso cuando desconfían de las mismas. La comunicación de los resultados a través de la evidencia generada por la AbE, así como su monitoreo y evaluación, resultan esenciales para difundirlos en un contexto más amplio, incluyendo a los encargados de la toma de decisiones. Por medio de las políticas y 
leyes se logra consolidar las estructuras de gobernanza, estableciéndose las reglas del juego para todos los actores y sectores involucrados. Finalmente, corresponde destacar que el financiamiento resulta indispensable para asegurar no solo la puesta en marcha sino también el escalamiento de las acciones, además de garantizar que las comunidades y sitios más vulnerables cuenten con los recursos necesarios para acceder a los beneficios derivados de las $\mathrm{AbE}$.

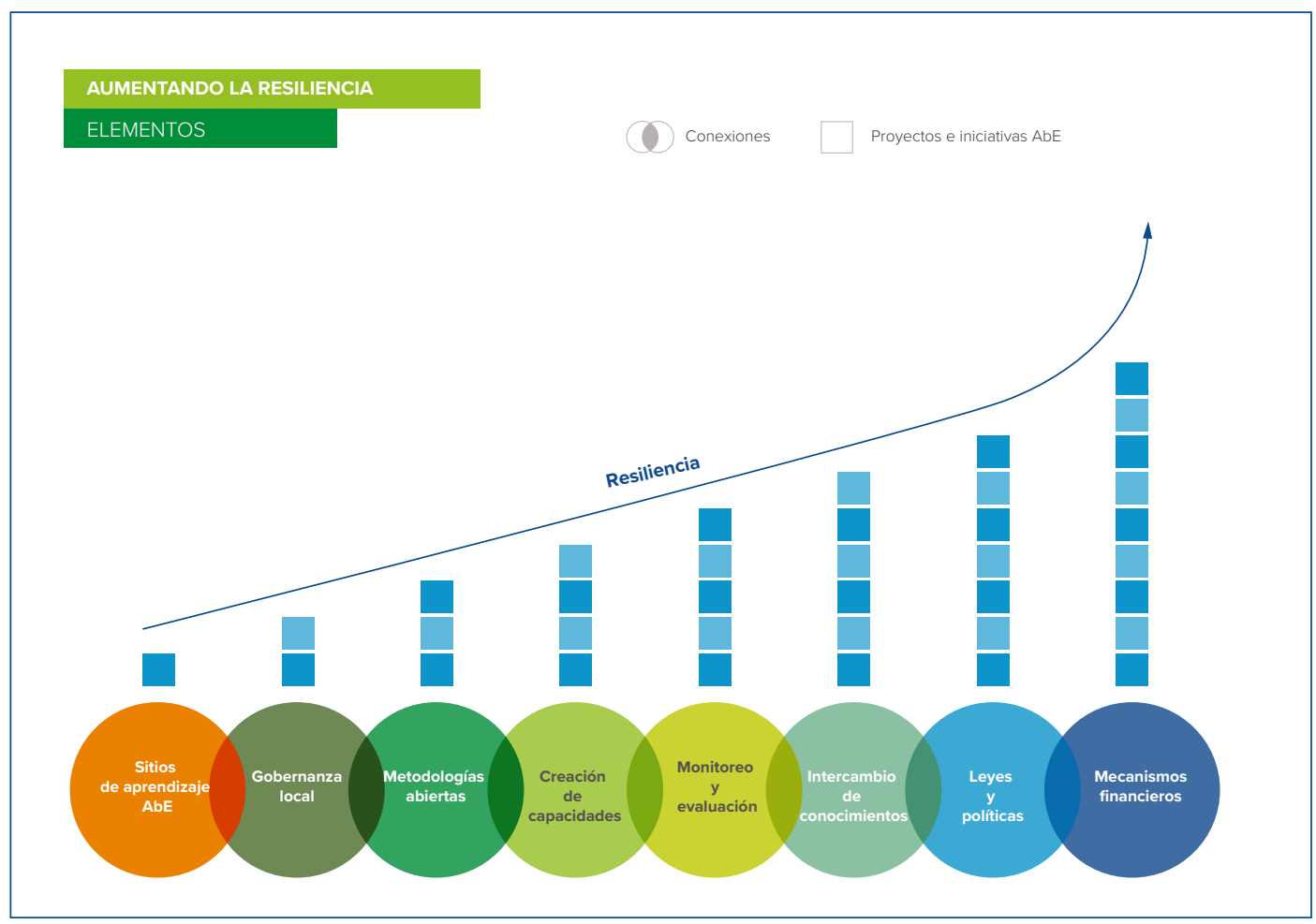

Figura 2.1 Elementos del proceso de escalamiento de la AbE

En el Departamento de San Marcos hay varias comunidades y municipios que desde hace más de una década trabajan junto con organizaciones como la UICN en pos del mejoramiento del medio ambiente. Entre los múltiples esfuerzos que se han impulsado en dicho departamentos se encuentran el fortalecimiento de las capacidades de organización a través de estructuras como los consejos de cuenca y los comités de microcuenca, además de aquellas necesarias para la conservación de los boques en las nacientes de los ríos y manantiales (Pérez de Madrid \& Navarro, 2019). Uno de dichos comités de microcuenca, el de Esquichá, ubicado en el municipio de Tacaná, reunió a 18 comunidades en iniciativas destinadas a mejorar la gestión del agua, el bosque y el suelo. Los resultados y beneficios derivados del accionar de este comité, sumados a su capacidad de incidencia, motivó a que en 2016 el Ministerio de Ambiente y Recursos Naturales (MARN) reconociera a los comités de usuarios del agua y estableciera un proyecto en materia de adaptación al cambio climático en el Altiplano Guatemalteco (Proyecto Fortalecimiento de la Resiliencia de los Medios de Vida ante el Cambio Climático en las Cuencas Altas del Altiplano de Guatemala). Dicho proyecto instituye un fondo para financiar medidas de adaptación gestionando fondos públicos de 
varias fuentes (Instituto Nacional de Bosques, Ministerio de Agricultura y Ganadería y Alimentación, Instituto de Sismología, Vulcanología e Hidrología y MARN).

\subsection{Análisis de las capacidades para la gobernanza para la AbE}

\subsubsection{Las capacidades para la gobernanza para la AbE}

La gobernanza efectiva de la AbE requiere de un fortalecimiento de las capacidades de los actores interesados en los múltiples niveles en los que opera la adaptación, vale decir, local, subnacional, nacional y transfronterizo. Dichas capacidades, o el fortalecimiento de las mismas, deben ser diferenciadas de acuerdo con el nivel y el contexto en el cual se requieren.

En el cuadro 2.1 se identifican los elementos esenciales de las capacidades para la gobernanza para la $\mathrm{AbE}$, distinguiendo entre grupos de actores y niveles. 


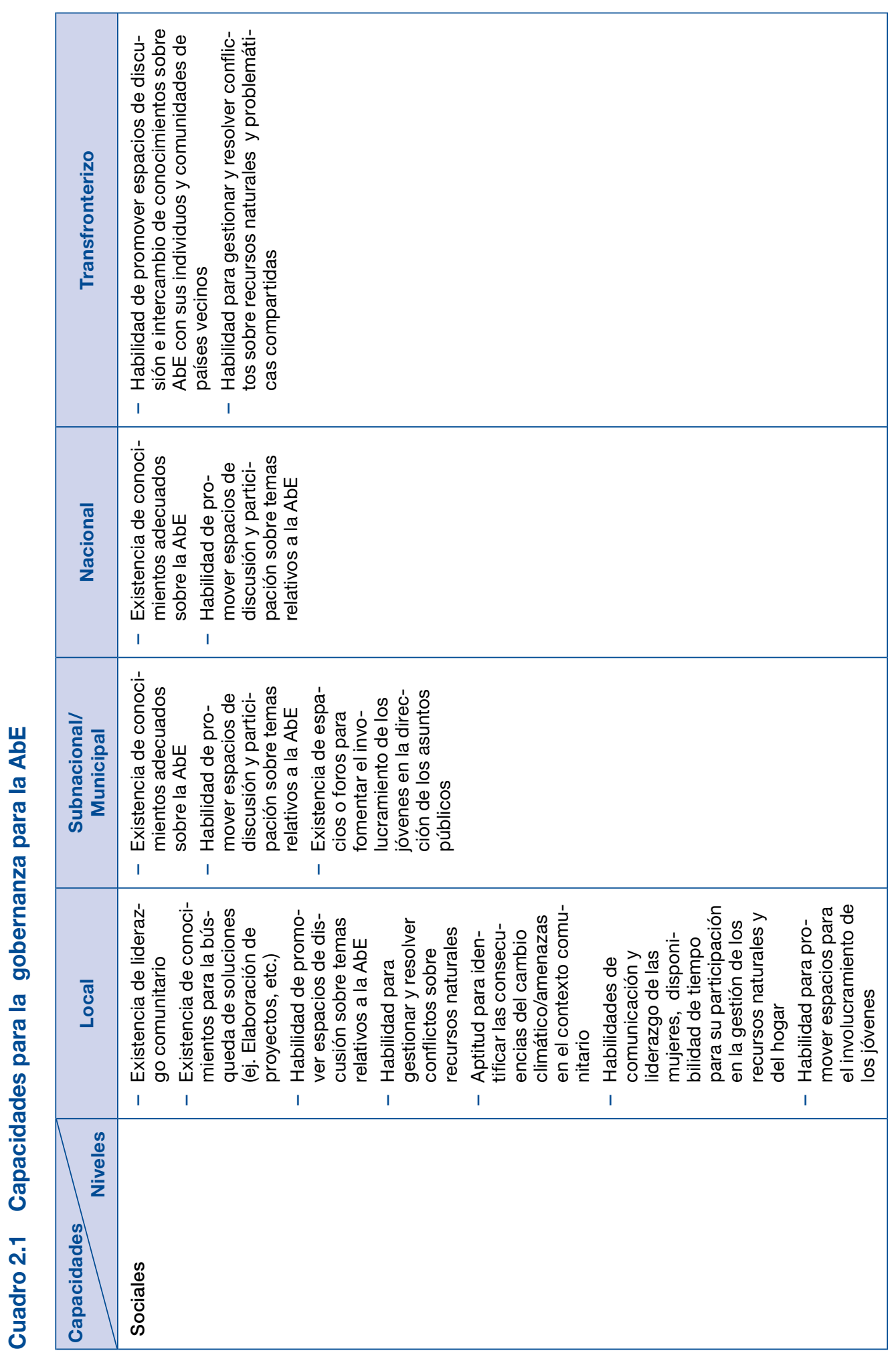




\begin{tabular}{|c|c|c|}
\hline 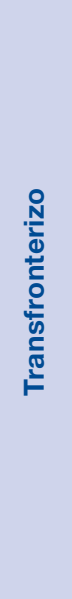 & 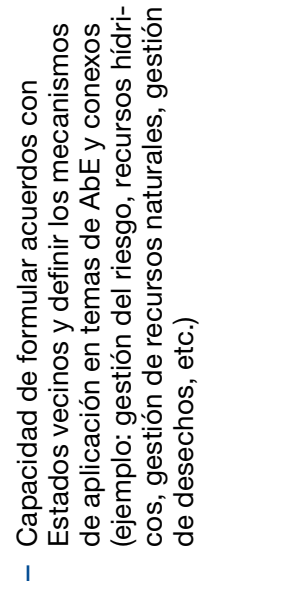 & 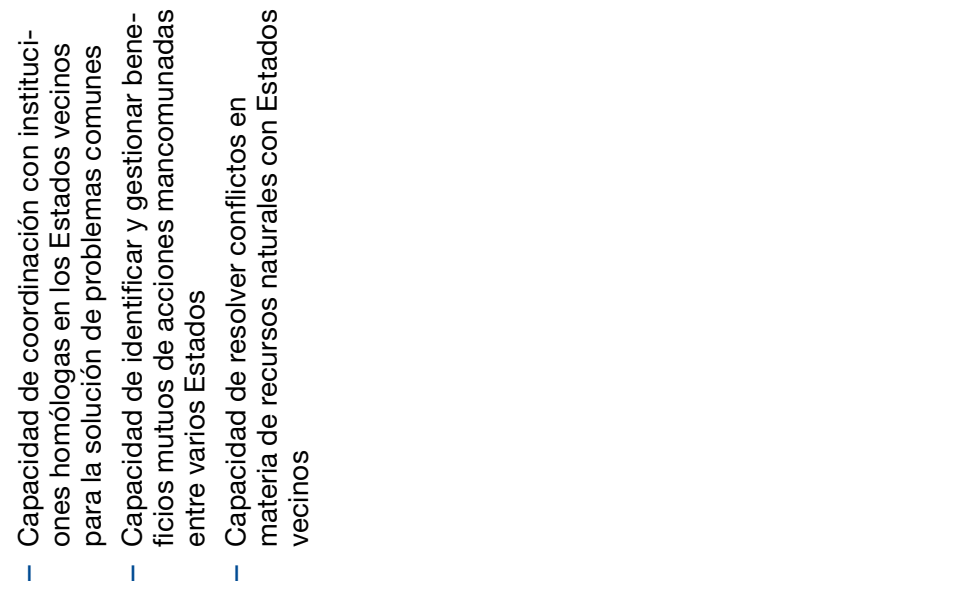 \\
\hline 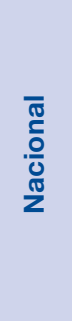 & 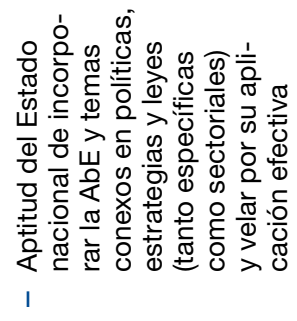 & 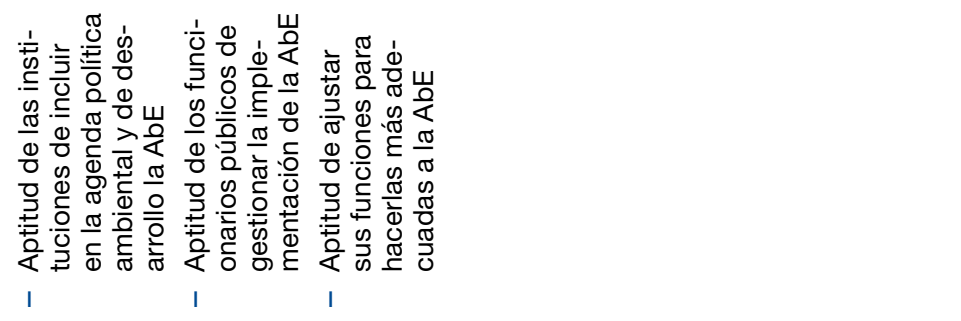 \\
\hline 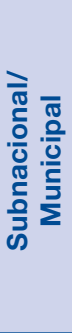 & 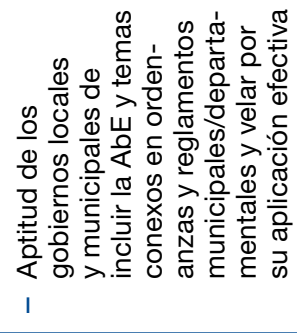 & 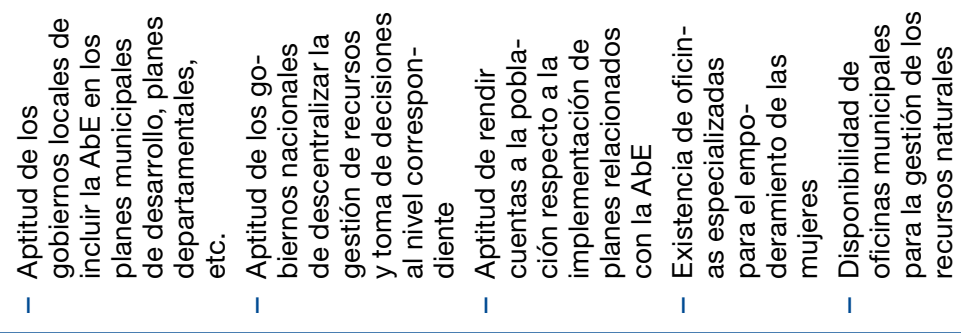 \\
\hline $\begin{array}{l}\bar{\delta} \\
\text { ] }\end{array}$ & 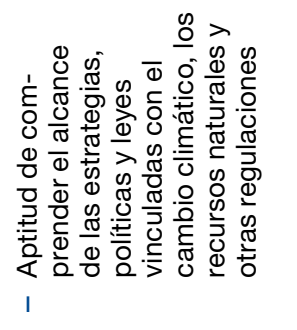 & 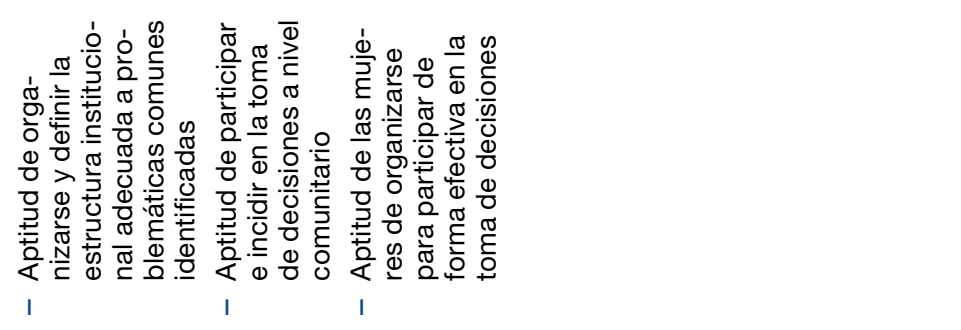 \\
\hline $\begin{array}{l}\frac{0}{0} \\
\frac{0}{2} \\
\frac{2}{z} \\
0 \\
\frac{\pi}{\pi} \\
\frac{\pi}{0} \\
\frac{\pi}{0} \\
\frac{\pi}{\pi} \\
0\end{array}$ & 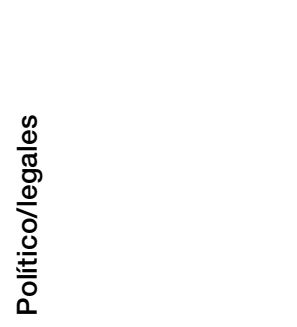 & 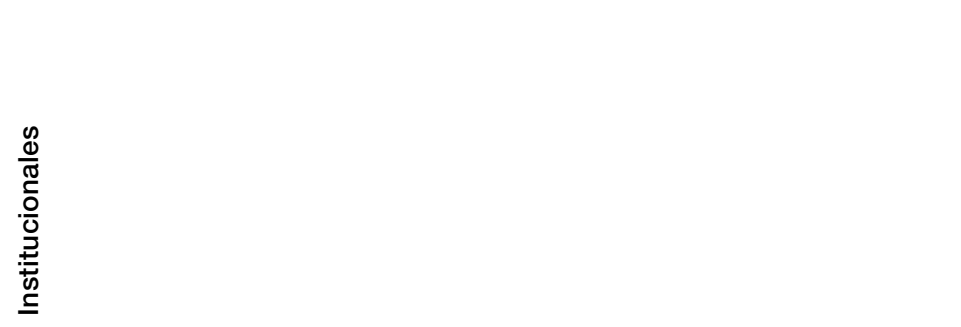 \\
\hline
\end{tabular}




\begin{tabular}{|c|c|c|c|}
\hline 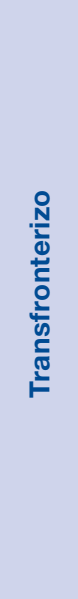 & 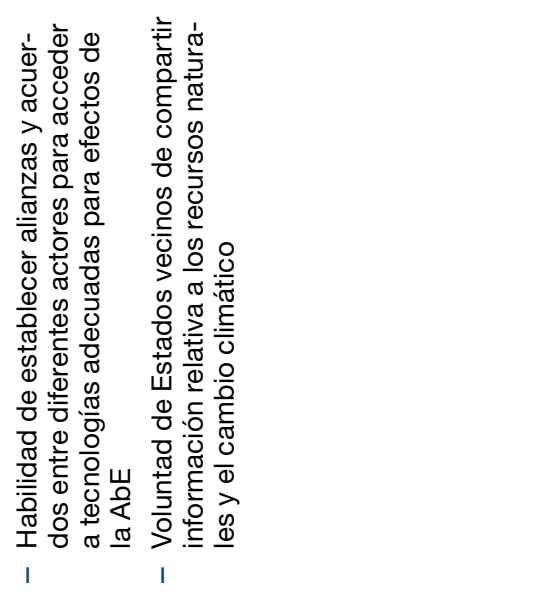 & 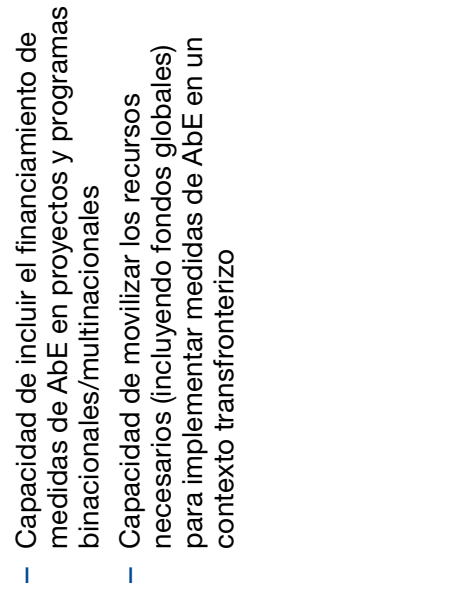 & 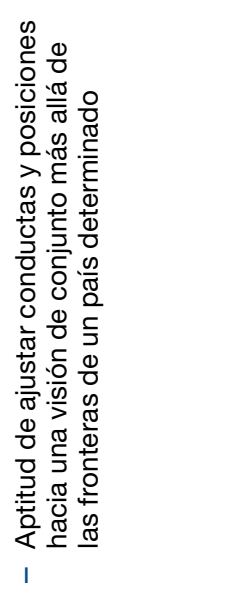 \\
\hline $\begin{array}{l}\bar{\pi} \\
\text { 음 } \\
\frac{0}{0} \\
\text { z }\end{array}$ & 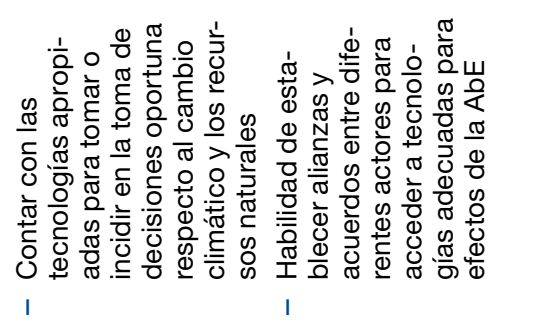 & 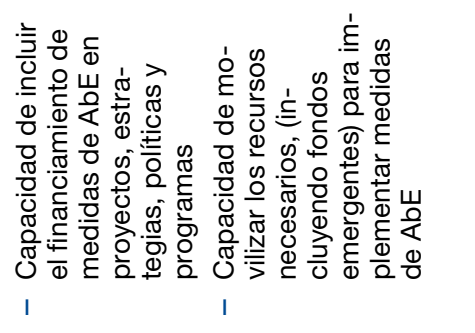 & 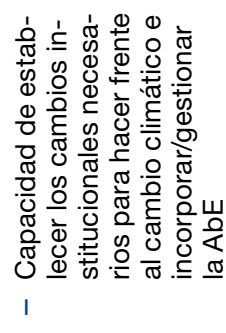 \\
\hline 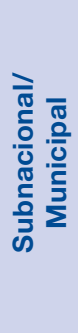 & 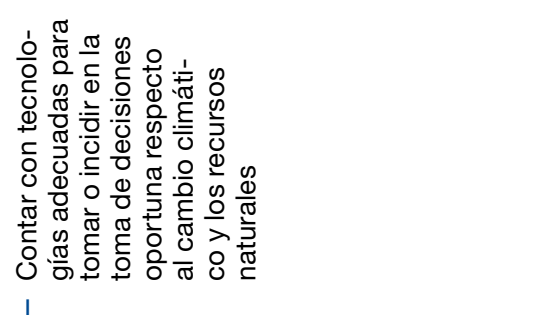 & 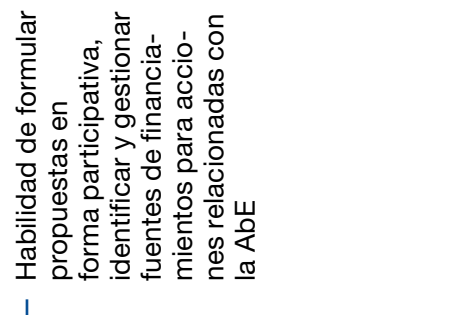 & 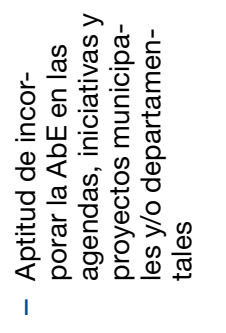 \\
\hline $\begin{array}{l}\overline{8} \\
\text { ㅇ }\end{array}$ & 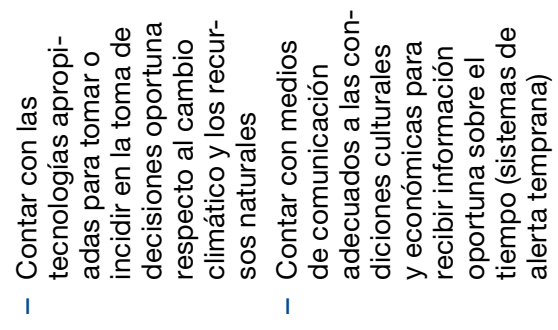 & 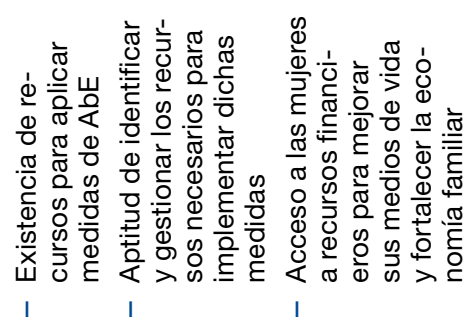 & 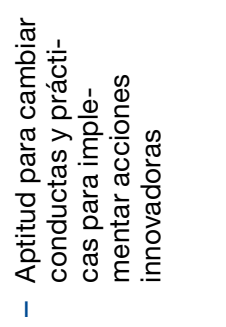 \\
\hline $\begin{array}{l}\frac{9}{0} \\
\frac{0}{10} \\
\frac{2}{z} \\
0 \\
0 \\
\frac{\pi}{0} \\
\frac{0}{0} \\
\frac{\pi}{0} \\
\frac{0}{\pi} \\
0\end{array}$ & 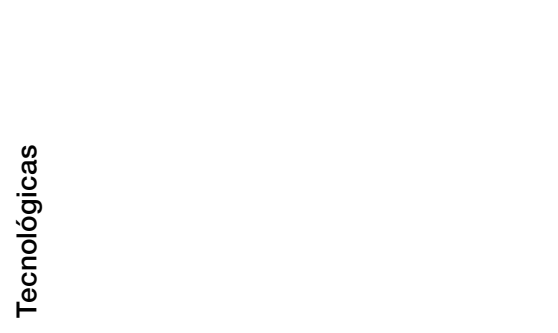 & 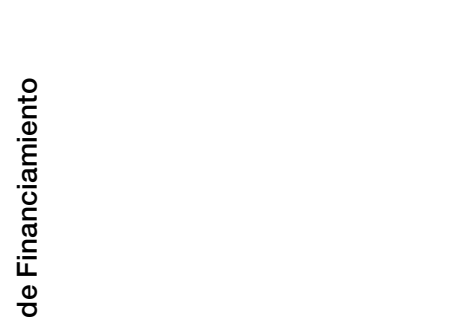 & 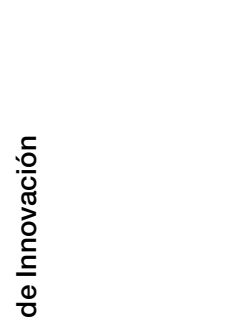 \\
\hline
\end{tabular}




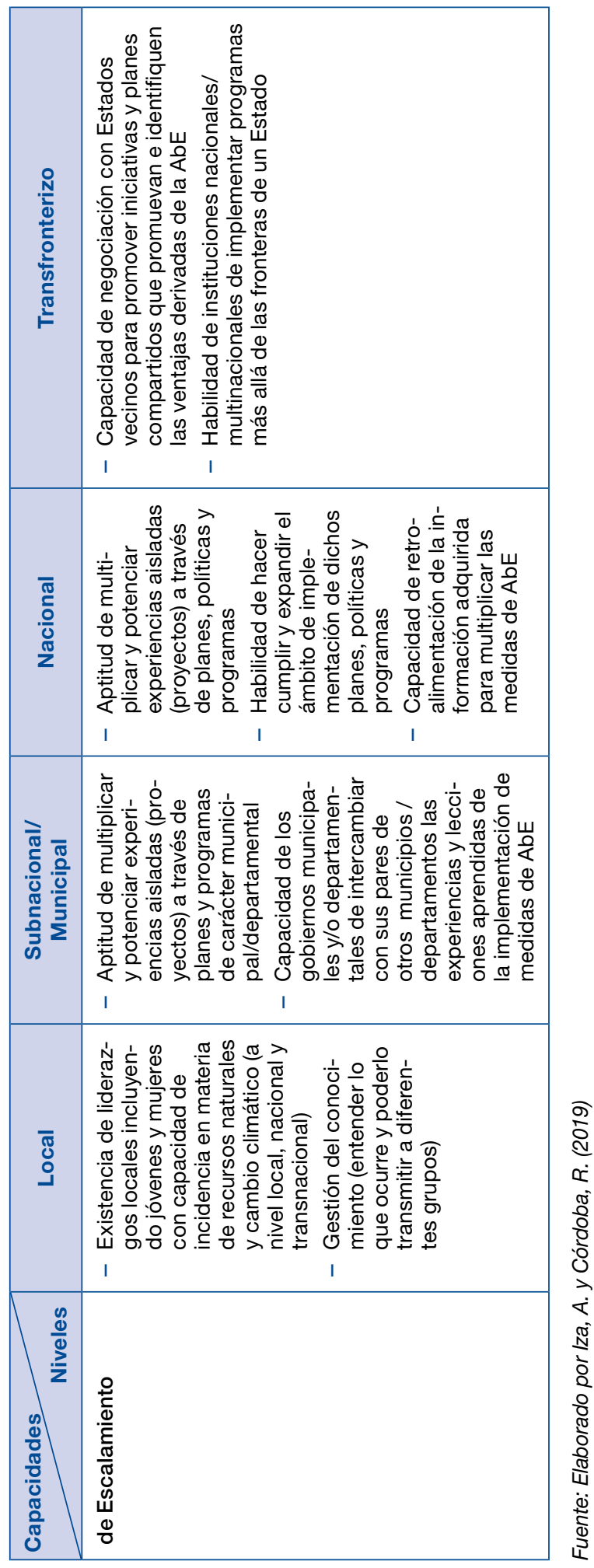




\subsection{Construcción de capacidades para la gobernanza para la AbE}

Para efectos de este libro, si la AbE es el conjunto de estrategias, políticas y prácticas destinadas a la protección y restauración de los servicios de los ecosistemas para reducir la vulnerabilidad de la sociedad frente al cambio climático, la gobernanza para la AbE constituye el conjunto de normas, instituciones y procesos necesarios para la protección y restauración de los servicios de los ecosistemas con el fin de reducir la vulnerabilidad de la sociedad frente al cambio climático.

Para explicar la construcción de capacidades es necesario orientarse a distintos grupos meta para poder discernirlas de manera diferenciada para cada uno de dichos grupos. A los fines de este libro se consideran los siguientes:

Social: se consideran dentro de este grupo a los individuos, las comunidades en general (incluyendo pueblos indígenas y comunidades rurales), las organizaciones no gubernamentales en sentido amplio, asociaciones (incluyendo las comunitarias, las juntas de agua, etc.), la academia e instituciones de investigación, y medios de comunicación

Corporativo: se consideran dentro de este grupo a los productores (de diferentes escalas, incluyendo a la agricultura, la ganadería, minería, pesca y acuicultura), la industria (de diferentes escalas), las instituciones financieras y el sector seguros, el comercio (de diferentes escalas), el turismo, el transporte, la infraestructura (por ejemplo, carreteras, puertos, represas, viviendas, etc.).

Político/institucional: se consideran dentro de este grupo al Estado y sus poderes, es decir, el ejecutivo, legislativo y judicial pero además a las distancias instancias administrativas, es decir, desde las mancomunidades y municipalidades hasta el Estado nacional pasando por los departamentos, cantones y provincias dependiendo de la estructura administrativa de cada uno de los Estados.

Definidos los grupos meta, corresponde entonces explicitar la construcción de cada una de las capacidades de gobernanza necesarias para estos grupos, para lo cual se propone discernirlas de acuerdo con los cuatro componentes fundamentales de la gobernanza, es decir, la política, la ley, las instituciones y los procesos. 


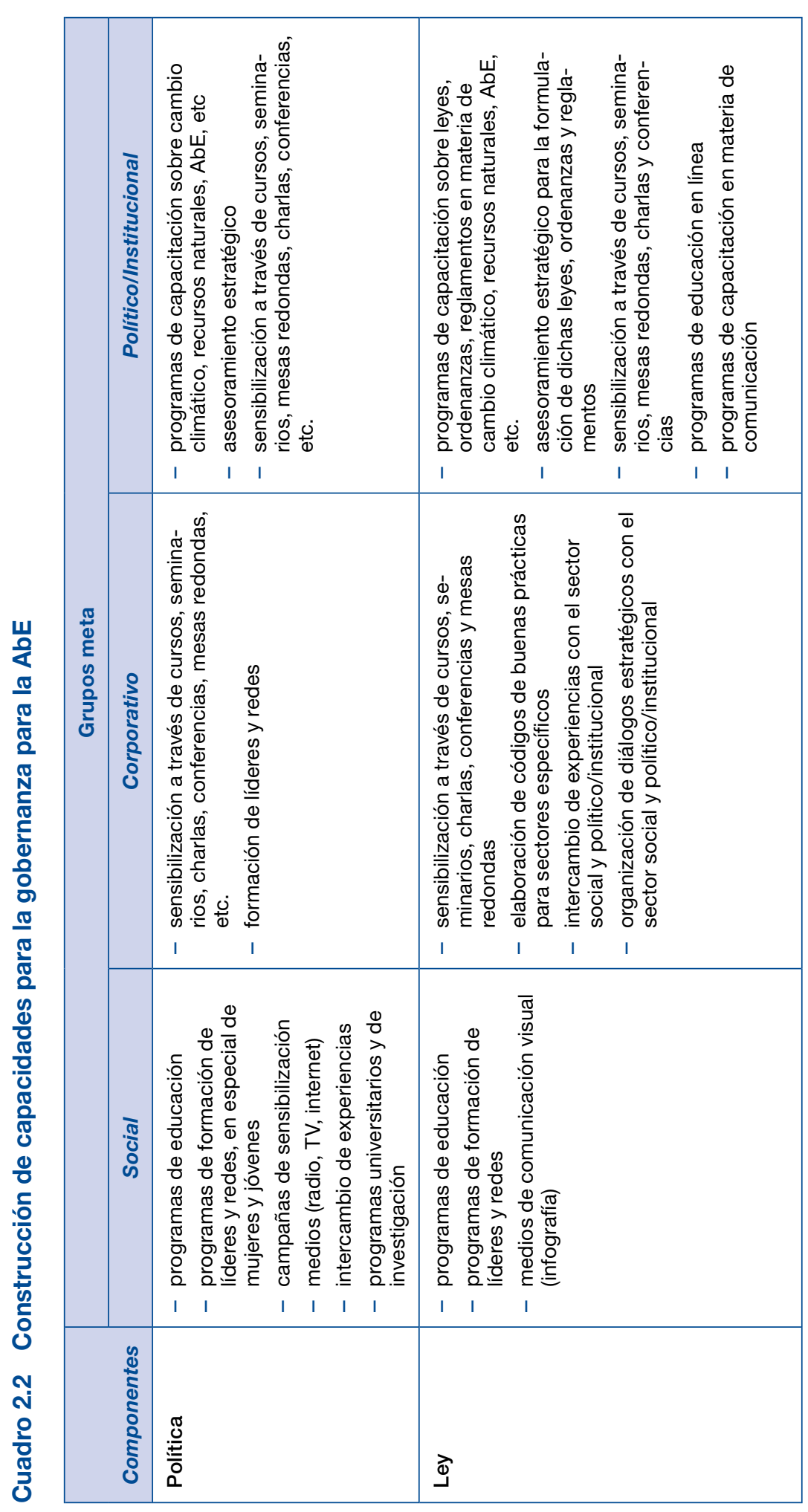




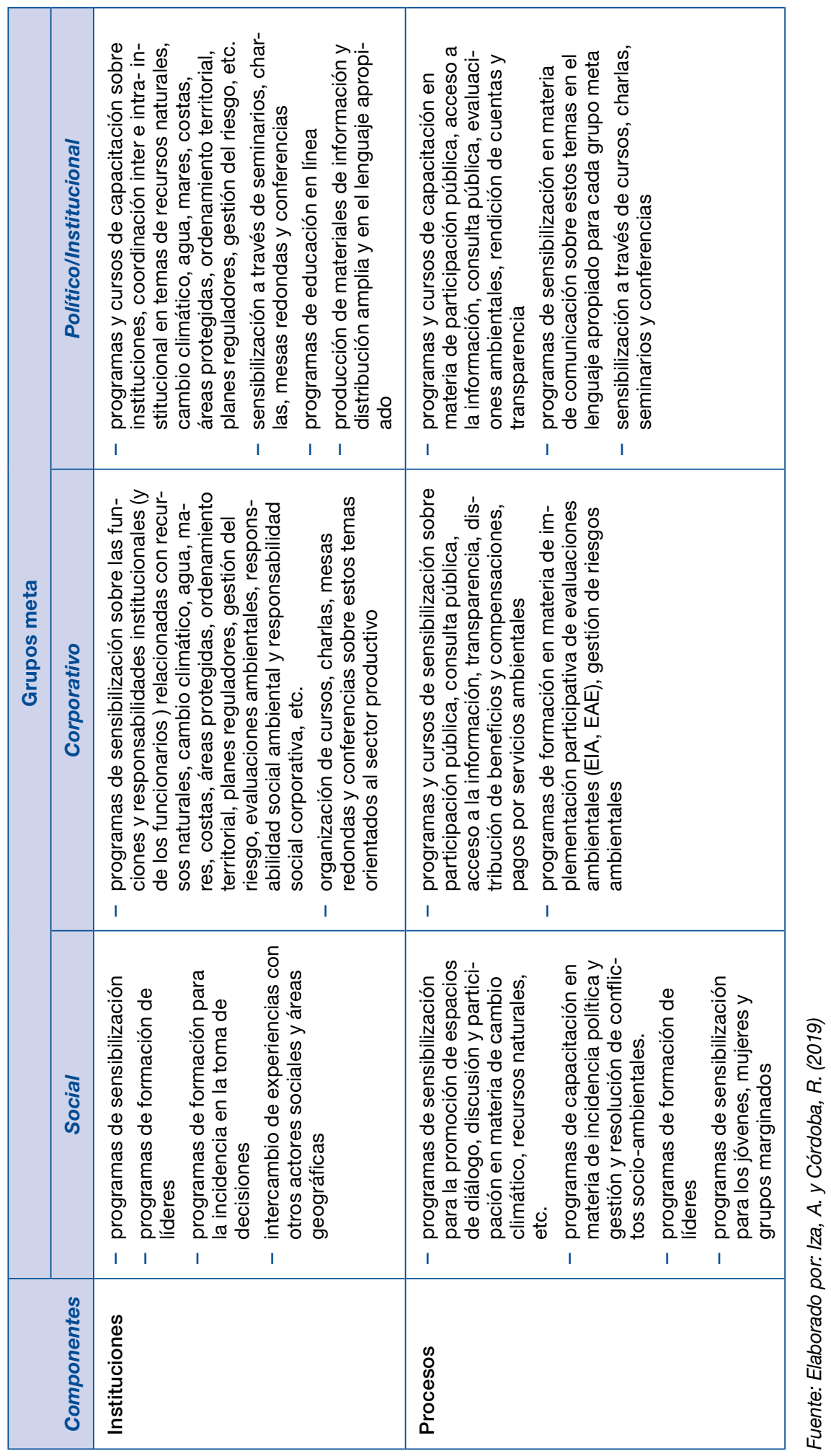


Corresponde insistir en que la construcción de capacidades para la gobernanza para la AbE debe ser adecuada a los contextos de cada país, región y localidad, habida cuenta de que las necesidades son diferenciadas. No obstante, ello, el cuadro anterior pretende brindar un panorama general sobre los principales mecanismos necesarios para la construcción de las apuntadas capacidades aplicables a todos los países. Hay que destacar que las capacidades descritas en los cuadros 2.1 y 2.2, deben ser ponderadas en forma holística e integral y no como componentes aislados en forma compartimentalizada.

\subsection{Desafíos y oportunidades para las capacidades}

Existe un desbalance de capacidades entre países desarrollados y países en vías de desarrollo. Dentro de estos últimos, hay también desbalances de capacidades entre las instancias nacionales y las locales, así como entre los más y los menos vulnerables al cambio climático. Cuanto mayor es la vulnerabilidad de los ecosistemas y de la sociedad menor es la capacidad, en tanto que debería ser al revés puesto que para poder revertir la vulnerabilidad se requiere mejorar las capacidades para la adaptación.

La AbE en sí misma y las múltiples capacidades que requiere para su gestión efectiva constituye un reto dado que necesita tratar temas que van desde cambio climático y sus efectos, la gestión del riesgo, la conservación y el mantenimiento de la salud de los ecosistemas hasta el mejoramiento de medios de vida sostenible y la planificación territorial.

Gran parte de los problemas que se plantean en materia de capacidades para la gobernanza para la $\mathrm{AbE}$ deriva de la multiplicidad de temas a tratar; en otras palabras, de la multidimensionalidad de las capacidades necesarias, toda vez que la AbE abarca desde la capacidad social hasta la innovación.

El cambio climático como ya fuera mencionado requiere de un proceso de ajuste y reajuste permanente, mismo que acarrea consecuencias para la formación y consolidación de las capacidades específicas para gobernar el cambio climático.

Otro desafío importante es el acceso a la información oportuna y adecuada para la toma de decisiones en todos los temas relativos a la AbE y por tanto su inclusión en programas de capacitación y formación en todos los niveles, como así también la limitada asignación de recursos por parte de los Estados para programas de formación, académicos y de investigación y que en el caso de los países en vías de desarrollo dependen en gran medida de la cooperación internacional.

Varios países hicieron explícito el compromiso de implementar acciones relativas a la gestión de los ecosistemas en sus NDCs y en la actualidad se encuentran abocados a desarrollar políticas, leyes y estructuras institucionales para la adaptación al cambio climático, que incluyen la construcción y consolidación de las capacidades necesarias para su implementación. La misma CMNUCC ha reconocido la importancia de este tema.

Los fondos globales o internacionales como el Fondo Verde para el Clima (GCF por su siglas en inglés) y el Fondo de Adaptación en el marco de CMNUCC, constituyen un vehículo propicio no solo para movilizar recursos que se puedan destinar para acciones concretas en materia de AbE sino también para la formación, capacitación y fortalecimiento de múltiples actores. 


\section{Evidencia}

\section{Rocío Córdoba-Muñoz y Melissa Marín Cabrera}

\subsection{Introducción}

Existe una amplia variedad de pruebas de que el cambio y la variabilidad climáticos están exacerbando la degradación de los ecosistemas y la calidad de vida de las comunidades humanas. A pesar de la incertidumbre de los distintos escenarios climáticos, científicamente se han demostrado tendencias en el clima global que desde hace varias décadas tienen consecuencias negativas sobre ecosistemas y seres humanos.

No es el objetivo de este capítulo discutir acerca de estos cambios sino elucidar los elementos necesarios que muestren cómo el adaptarse al cambio climático aplicando el enfoque ecosistémico constituye una mejor opción comparada con otro tipo de acciones. Para demostrar que la AbE es una opción más adecuada esta debe contener necesariamente una serie de pruebas contundentes de que funciona a través del tiempo y presenta ventajas ante otras iniciativas de adaptación. Al mismo tiempo se requiere mostrar que una buena gobernanza para la AbE debe contener suficientes elementos que evidencien que su implementación puede garantizar que los servicios ecosistémicos se mantengan y que las personas tengan una mejor calidad de vida.

De acuerdo con el Diccionario de la Real Academia Española (2018), la palabra evidencia se define como la "certeza clara y manifiesta de la que no se puede dudar". Desde el punto de vista del Derecho, la evidencia constituye una "prueba determinante en un proceso o lo que permite mostrar la verdad de un hecho". La evidencia constituye información y conocimiento confiables que podrían ser utilizados para apoyar el desarrollo, la implementación e incluso la evaluación de políticas y otros instrumentos legales de gobernanza efectiva (Collins et al., 2015).

La evidencia que se produce a través de la implementación de medidas ${ }^{1}$ de AbE constituye un instrumento útil para demostrar que estas acciones poseen un impacto positivo tanto en la salud de los ecosistemas, como en la producción de co-beneficios sociales, económicos y culturales para los seres humanos. Aunque parezca sencillo, idealmente, el proceso de generación de la evidencia requiere de la implementación de sistemas de monitoreo y evaluación, así como de la recopilación y análisis sistemático y permanente de información y de datos (Marín \& Navarro, 2019).

Idealmente, la generación de evidencia debe estar apoyada por datos científicos, investigación y conocimientos de pueblos indígenas y comunidades locales (CBD, 2018); por otra parte, debe provenir de fuentes confiables de información y de conocimientos con datos cuantitativos y cualitativos que permitan incidir en la toma de decisiones (Chong, 2014). Sin embargo, los datos que muestran los efectos positivos de la conservación de los recursos naturales en el bienestar humano suelen ser escasos y provenir de numerosas y muy diversas fuentes, muchas de las cuales no son asequibles para tomadores de decisión u otros actores interesados (McKinnon et al., 2016). La evidencia se puede producir no solamente a través del uso de información científica sólida, sino también de otro tipo de información originada en procesos en donde participan múltiples actores sociales. calidad de vida de las poblaciones humanas que se pueden implementar para mejorar la adaptación al cambio climático. 
La generación de evidencia sobre la efectividad de la AbE articulada con sus respectivos arreglos de gobernanza está apenas dando sus primeros pasos (Reid et al., 2018; Sieber et al., 2018). Por esta razón, actualmente no se puede esperar que los países en desarrollo cuenten con mecanismos claros y suficientes que permitan analizar la factibilidad ecológica, social y económica de la AbE y así construir un argumento sólido que demuestre que las soluciones basadas en la naturaleza son más efectivas que las que usualmente se utilizan para enfrentar los efectos del cambio climático.

En términos generales, la adaptación al cambio climático no cuenta en la actualidad con un sistema consolidado para determinar de manera contundente la eficacia de sus medidas y atribuir la relación causa-efecto en un contexto de proyecciones climáticas con gran incertidumbre (PNUD-INEC, 2017). Por dicha razón, se hace necesario identificar otras fuentes de información y de conocimientos que permitan mostrar cambios y mejoras (o al menos tendencias en este sentido) derivados de la AbE en los servicios de los ecosistemas y la calidad de vida de las personas.

\subsection{La evidencia y la efectividad de la AbE}

La evidencia es la prueba para verificar la efectividad de las medidas de la AbE. De acuerdo con Seddon et al., (2016) una AbE efectiva se refiere a las medidas o acciones que han restaurado, mantenido o incrementado la capacidad de los ecosistemas de brindar servicios. Estos servicios incrementan el bienestar, la capacidad de adaptación o la resiliencia de las personas y reducen su vulnerabilidad. Dichas medidas o acciones contribuyen a que los ecosistemas puedan resistir los impactos del cambio climático y otras presiones y van desde acciones propias en el campo (por ejemplo sistemas agro-forestales, cortinas rompe-vientos u obras de conservación del suelo, protección de nacientes, reforestación de bosques ribereños, entre otros) hasta acciones para fortalecer el capital social (como mejora de los sistemas de coordinación, de capacidades locales, campañas de concienciación).

Según Reid, et al. $(2017,2018)^{2}$ la efectividad de la AbE debe mostrarse a través de la generación de evidencia que se pueda comunicar de manera sencilla y clara a distintos públicos para lo cual desarrollan una guía que propone un proceso basado en un cuestionario para determinar la efectividad de la AbE. Este cuestionario contiene cuatro preguntas principales que, a su vez, se subdividen en preguntas más detalladas vinculadas con:

1. Efectividad para las sociedades humanas: Se refiere principalmente a la capacidad adaptativa, participación, justicia social, distribución de beneficios, co-beneficios para las comunidades y la reducción de la vulnerabilidad.

2. Efectividad para los ecosistemas: Las preguntas se centran en temas tales como la restauración o el aumento de los servicios de los ecosistemas para las comunidades y sobre la resiliencia de los ecosistemas a los impactos del cambio climático.

3. Efectividad financiera y económica: Se centra en el tema de costo-eficiencia, la viabilidad económica a largo plazo y su comparación con otro tipo de inversiones existentes y más convencionales la adaptación.

4. Aspectos políticos e institucionales: Apuntan a los factores sociales, institucionales y políticos para una implementación efectiva de la AbE en el largo plazo.

2 La publicación completa sobre preguntas para evaluar la efectividad puede encontrarse en el siguiente enlace: http://pubs.iied.org/17606SIIED 
Las preguntas se dirigen a distintos tipos de públicos meta involucrados en la implementación de medidas de AbE. De esta manera se generan distintos tipos de evidencia dependiendo de la información y los datos disponibles.

Este cuestionario constituye una iniciativa novedosa y reciente y es un esfuerzo conjunto del Instituto Internacional para el Ambiente y el Desarrollo (IIED, por su siglas en inglés), ONU Medio Ambiente-Centro Mundial de Monitoreo de la Conservación (UN Environment WCMC, por su siglas en inglés) y la Unión Internacional para la Conservación de la Naturaleza (UICN) destinada a orientar a profesionales en la planificación y ejecución de medidas de AbE. Si bien esta serie de preguntas pueden brindar información cualitativa y en algunos casos cuantitativa sobre qué tan efectiva es la AbE comparada con otras alternativas de adaptación, se debe reconocer que cuantificar el éxito de medidas de AbE no es tarea sencilla toda vez que los ecosistemas en sí mismos son dinámicos y no poseen una línea de base estática frente a la cual se pueda medir el cambio (Doswald et al., 2014).

Los procesos ecológicos y sociales tienen su propio ritmo, mismos que generalmente superan los periodos de cambio de las administraciones del Estado en sus distintos niveles. Esto determina la importancia de considerar los beneficios económicos, ambientales y sociales vinculados con la AbE y principalmente con la gobernanza para la AbE de manera tal de convencer a tomadores de decisión y encargados de la formulación de políticas ambientales y de desarrollo respecto a sus beneficios.

La ventaja comparativa de la AbE respecto a soluciones habituales ("business as usual") basadas en la ingeniería, deberá demostrarse a través de evidencia contundente y apropiación de los actores sociales de manera tal que no se prioricen soluciones a corto plazo, como suele ser en caso en países en desarrollo (Calliari et al., 2019; Albert et al., 2019). Resulta imperioso entonces relacionar los actores y partes interesadas con los servicios de los ecosistemas, sus amenazas y vulnerabilidades; así como mapear sistemáticamente sus intereses potenciales en el largo plazo (Raum, 2018).

Respecto a los temas políticos, institucionales y de participación social, la efectividad de las acciones de AbE requiere de la cooperación y comunicación entre múltiples sectores y escalas geográficas que constituyen condiciones sine qua non para la buena gobernanza y su escalamiento (ver capítulos 4 y 5), lo que impone un reto adicional para la obtención de cualquier tipo de evidencia.

\subsection{Tipos de evidencia más comunes y cómo se generan}

La generación de evidencia sobre la AbE debería establecerse desde la etapa temprana de planificación de las acciones de adaptación que se ejecuten dentro de un espacio geográfico limitado y una escala temporal definida acorde con las dinámicas de los ecosistemas y de las sociedades humanas (Raymond et al., 2017). Una planificación adecuada debe por tanto incluir objetivos claros y una hipótesis acerca de lo que se pretende mostrar y mejorar. Es necesario contar con una línea de base exhaustiva de los aspectos que pretenden gestionar (por ejemplo: el área de ecosistemas degradados, la existencia o no de cultivos más resistentes a las variaciones del clima, la capacidad de las personas para mejorar sus prácticas agroecológicas, el nivel de pobreza, la seguridad alimentaria, seguridad hídrica de las comunidades asociadas a los ecosistemas, los distintos grupos interesados, las relaciones de poder entre actores, la presencia o ausencia de estructuras de gobernanza, o el nivel de gobernabilidad del Estado). Requiere además la construcción colectiva con todos los actores involucrados así como la definición de criterios de selección de un conjunto de indicadores que brinden información sobre los cambios que se pretenden influenciar. 
No obstante ello, en diversos estudios que han pretendido analizar proyectos e iniciativas relativas a la $\mathrm{AbE}$, se hace énfasis en la escasez de ejemplos donde se ha construido una línea de base inicial, recolectado y analizado científicamente los datos y procesos en el largo plazo e implementado sistemas completos de monitoreo y evaluación (Raymond et al., 2017; Hills, 2015; McKinnon et al., 2016; Marín et al., 2019). Esta limitación hace necesaria la búsqueda de otras fuentes de información y conocimientos que, aunque no sean resultado de una investigación científica rigurosa, puedan brindar elementos demostrativos de que la $\mathrm{AbE}$ funciona en la práctica.

El cuadro 3.1 pretende clasificar la evidencia dentro de una tipología que va desde la científica hasta aquella recolectada a través de otros procesos (fuentes secundarias) y que muestran tendencias de valor para analizar los resultados de la aplicación de acciones de AbE. Incluye además algunos ejemplos de los distintos tipos de evidencia. 


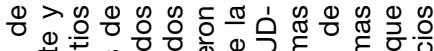
刃

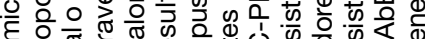
हो סे

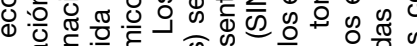

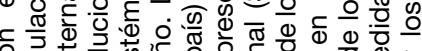

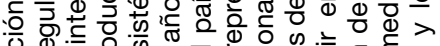

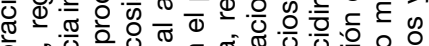
흔.

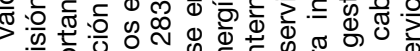

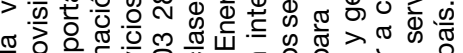

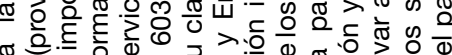

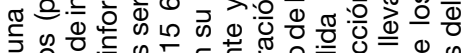
药

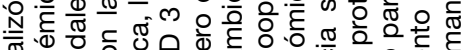
ब.

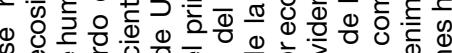

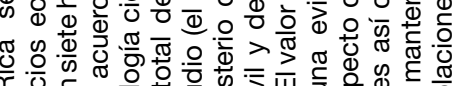

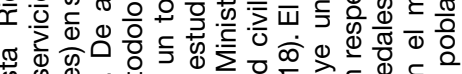

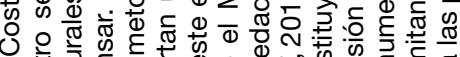

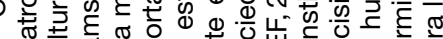

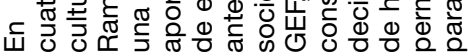

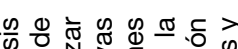

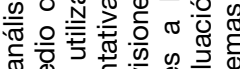

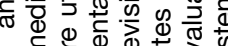

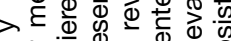

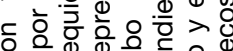

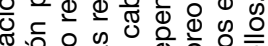

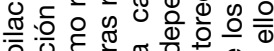

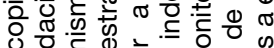
ब.

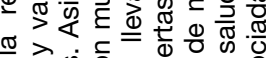
ॠ. 市 要券

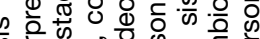

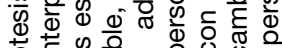

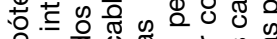
次 的응

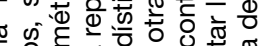
5 $0 \frac{0}{0}$.

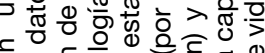
๘

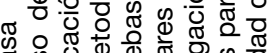
跣

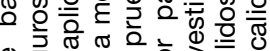

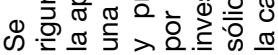

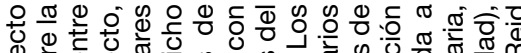

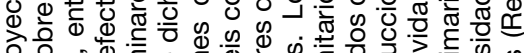

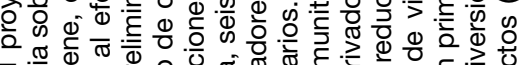

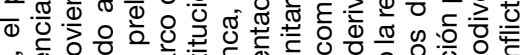

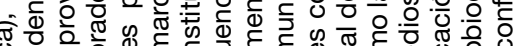

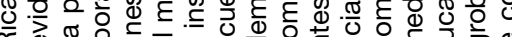

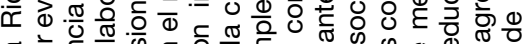

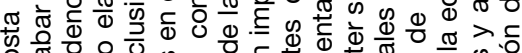

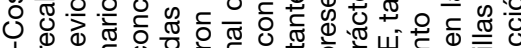

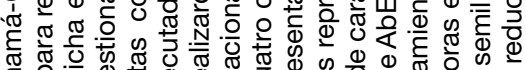

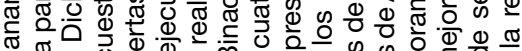

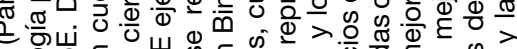
ช 은

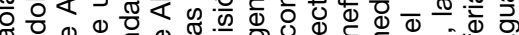
×

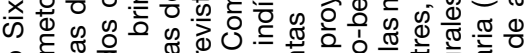

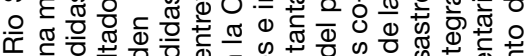
几

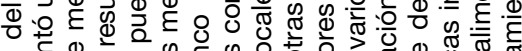
ฮ ब 뜨 $=\frac{1}{0}$

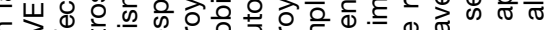

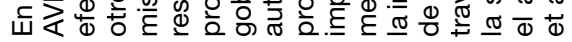

ตீ

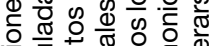

过

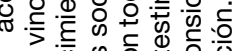
का

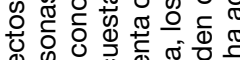

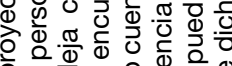

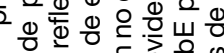

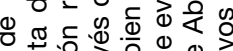
零迸 बै ब

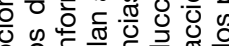

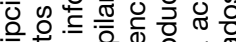

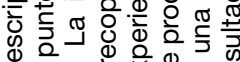
d

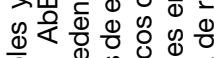

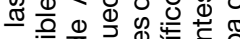

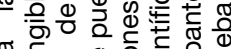

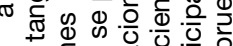
बำ

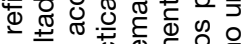

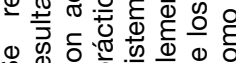




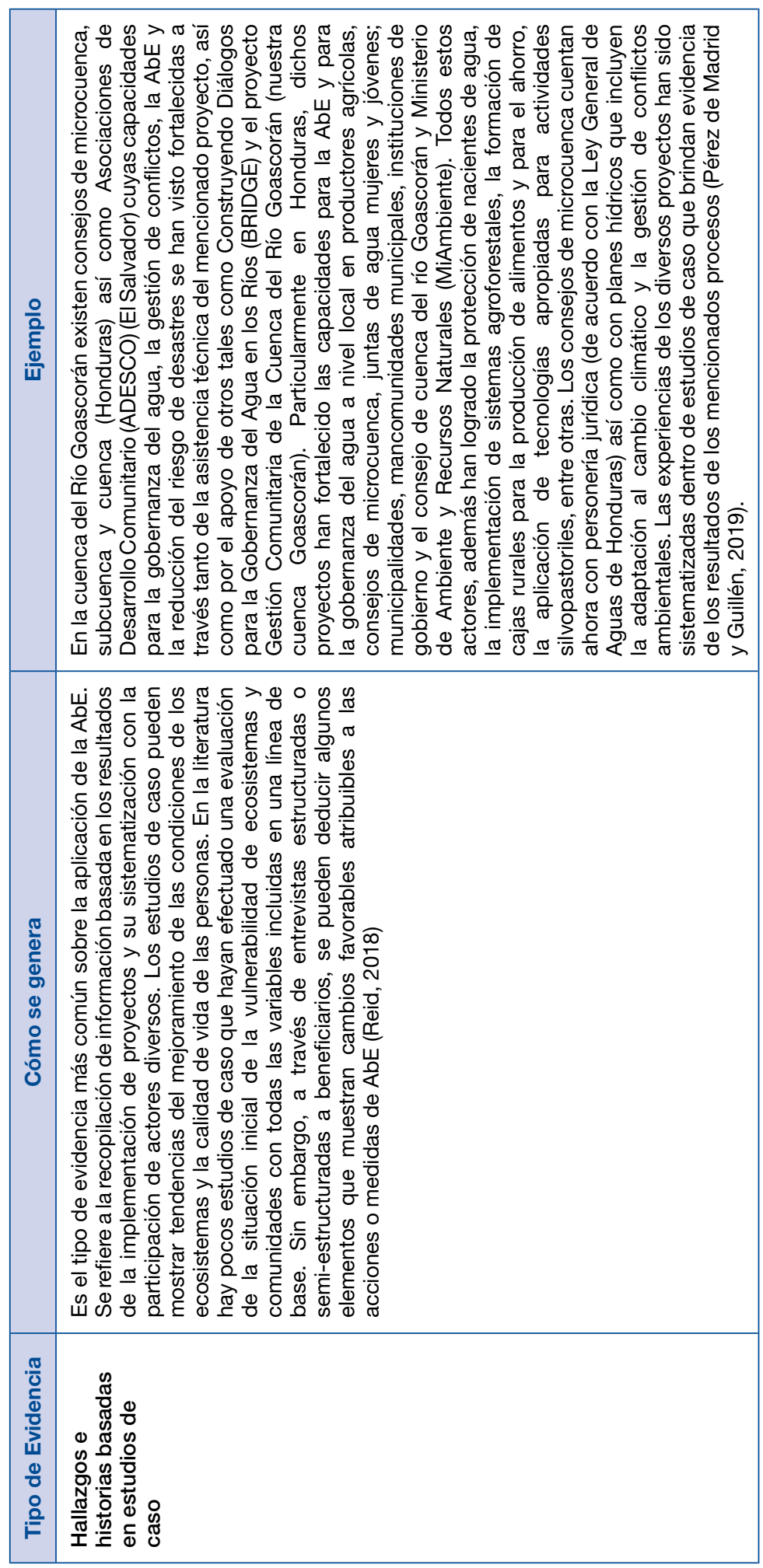




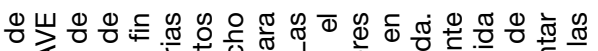

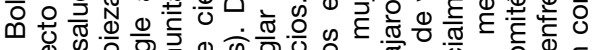

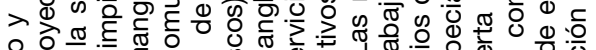

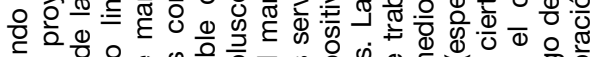
ส

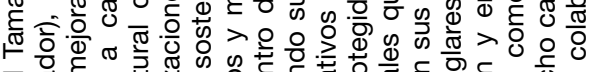

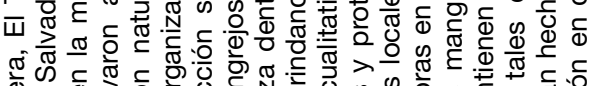
凹

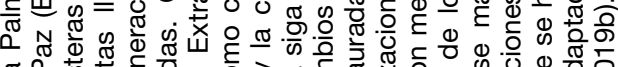

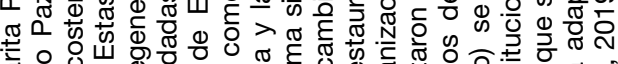

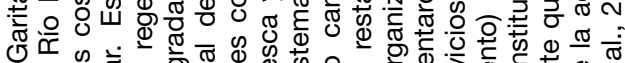

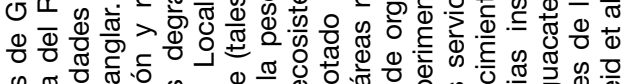

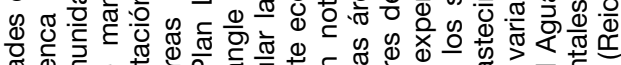
元

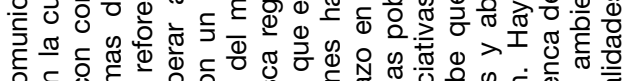

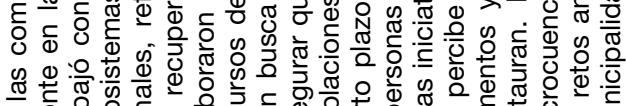

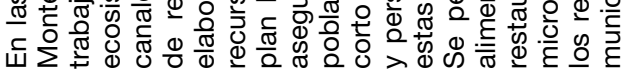

응 응 워

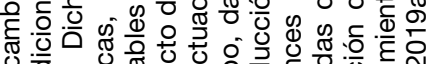

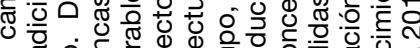
ब

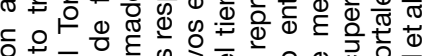
:은

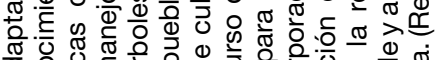

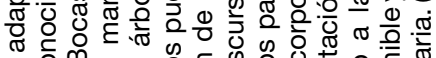

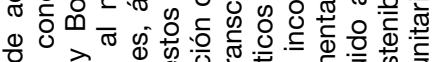

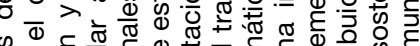
g ब

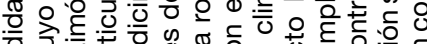
母 $\varepsilon . \leq ₫ 02 \varepsilon$

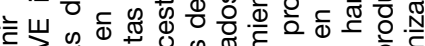

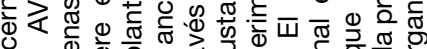

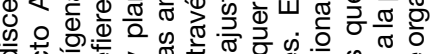

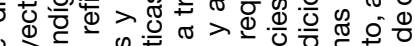
ه

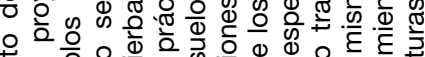

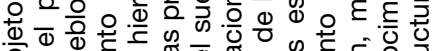

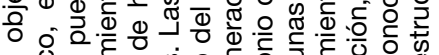
ब. 의의

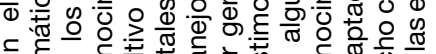

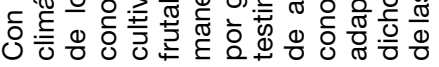

. 匹

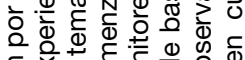

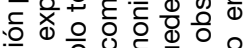

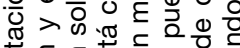

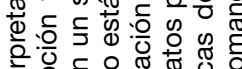

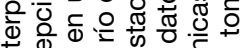

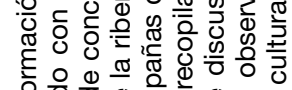

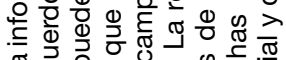

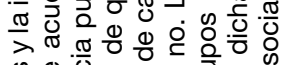

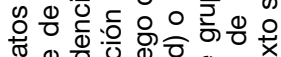
क行

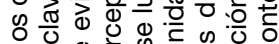
西

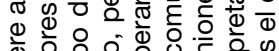
要

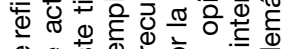

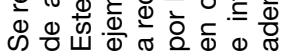

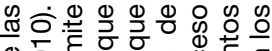

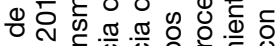

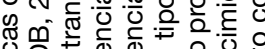
这论

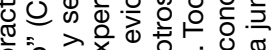

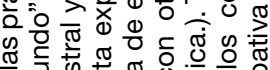

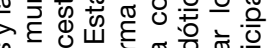

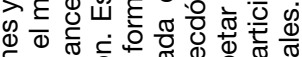

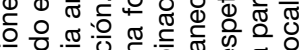

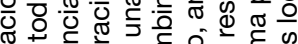

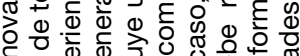

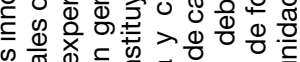

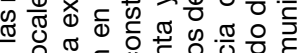

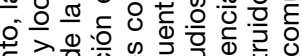

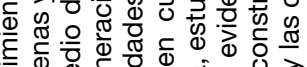

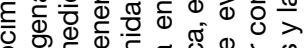

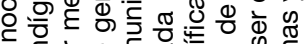

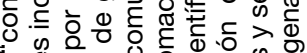
的

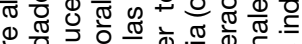

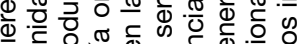

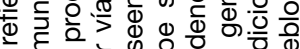

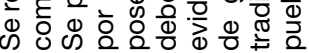




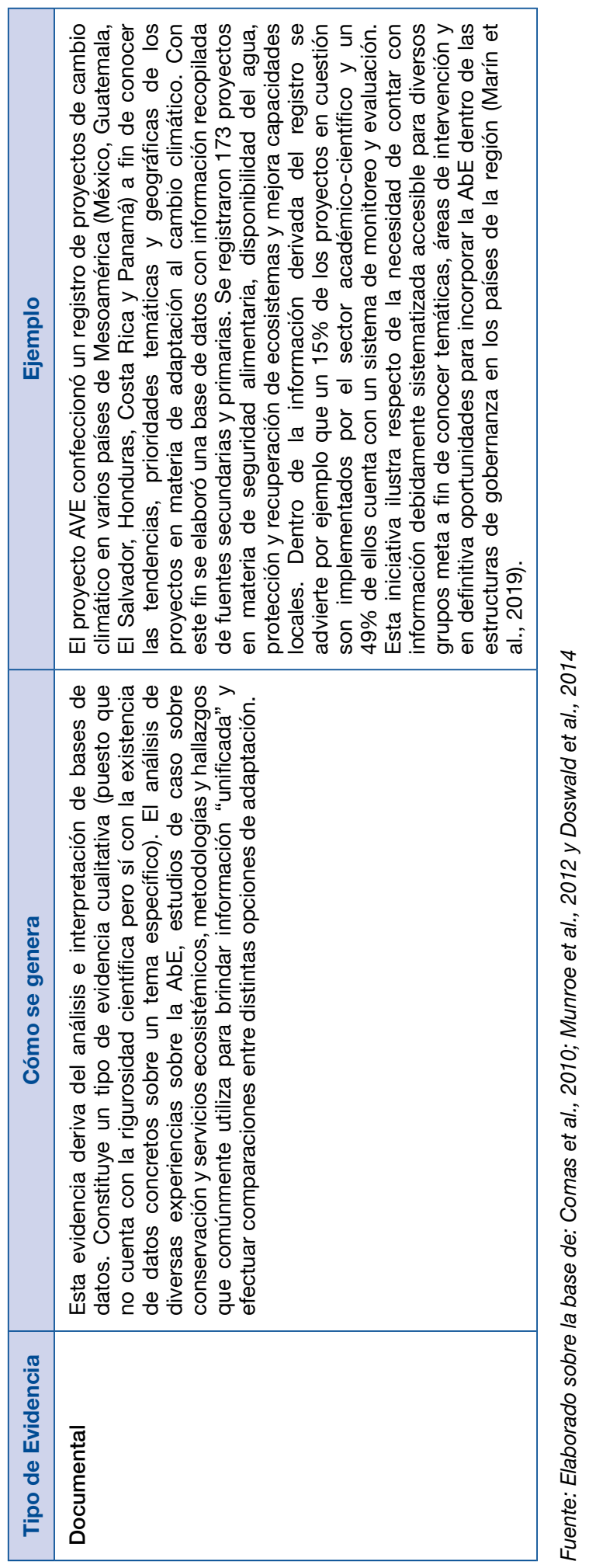


La unificación de todos estos tipos de evidencia (y otros que puedan existir) y sus procesos de generación (de acuerdo con las capacidades y recursos disponibles en cada caso) constituye lo que podría definirse como evidencia integral (Raymond et al., 2017).

La evidencia integral es "transdisciplinaria" es decir, constituye una composición coherente y lógica de los conocimientos de distintos sectores (científicos, tomadores de decisión y representantes de la sociedad civil) para proponer soluciones a un tema de preocupación colectiva basada en la investigación y en la aplicación práctica de conocimientos (Dendoncker et al., 2018).

Lo que se conoce con el nombre de "Investigación-Acción Participativa" constituye una de las propuestas para integrar diferentes actores en procesos de generación de evidencia. Es un método que combina el "conocer" y el "actuar", incluyendo a la población cuya realidad se está atendiendo. Busca comprender mejor la realidad y facilitar una toma de conciencia crítica de la población sobre esta realidad, promover su empoderamiento y acción transformadora dirigida a una mejor planificación. No obstante, una de las preocupaciones de los planificadores de la adaptación y los responsables de la toma de decisiones políticas y de gestión en torno a esta, constituye la falta de estudios cuantitativos y de eficacia en función de los costos (costo-efectividad) que incluyan las medidas de AbE en comparación con otras actividades de adaptación tales como opciones de infraestructura dura (Doswald et al., 2014).

Idealmente, cualquier medida de AbE debería ser diseñada y planificada participativamente para responder de forma objetiva a las preguntas relacionadas con su efectividad (ver sección anterior), identificar claramente un problema, sus causas y efectos. Esto con el fin de poder, a través de la generación de evidencia, identificar cuáles resultados pueden ser atribuibles y hasta qué punto a la implementación de dicha medida. Por otra parte, siendo la gobernanza uno de los elementos esenciales de la $\mathrm{AbE}$, será necesario tener claro el marco legal e institucional existente así como a todas las partes interesadas y su capacidad para escalar los resultados. De esta manera se puede apreciar el potencial de la gobernanza para la $\mathrm{AbE}$, sus vacíos y necesidades de fortalecimiento.

\subsection{Evidencia para la gobernanza para la $\mathrm{AbE}$}

\subsubsection{Incidencia en la toma de decisiones y el escalamiento}

El uso de la evidencia para la AbE debe constituir un vehículo efectivo para influir en la toma de decisiones sobre la adaptación al cambio climático. Para esto, es importante que las experiencias y resultados de las acciones en materia de $\mathrm{AbE}$ reflejen de forma convincente (argumento) los beneficios económicos, ambientales y sociales tanto para los ecosistemas, como para las poblaciones con las cuales se trabaje (Calliari et al., 2019). A través de los años, la preocupación por conocer cómo conservar la salud de los ecosistemas y qué servicios brindan a la humanidad, ha pasado de ser una herramienta de comunicación y concienciación, a una de incidencia para la reflexión y toma de decisiones ambientales y de desarrollo local, nacional, regional y global (Chong, 2014).

Por medio de la evidencia se puede analizar objetivamente la efectividad y el costo-beneficio de las medidas de adaptación implementadas, valorar las oportunidades de los diferentes modelos de reducción de vulnerabilidades climáticas, así como sus alcances y resultados como "pruebas" contundentes de los co-beneficios (Raymond, 2017). Dichos argumentos constituyen, en términos de gobernanza, el instrumento que da sentido a la toma de decisiones sobre el cambio climático. Asimismo contribuye a la concienciación de la sociedad civil, del Estado y del sector privado 
respecto a la necesidad de adoptar prácticas y políticas, a través de un trabajo en redes (Montaña, 2015; Vignola et al., 2019). Por medio de la evidencia se puede mostrar la efectividad y eficiencia (relación costo-efectividad) de los propios mecanismos de cooperación y del trabajo en redes entre diferentes actores. Puede además brindar indicios de la capacidad institucional o local para escalar y transformar los requerimientos de la sociedad en relación al cambio climático, en acuerdos comunales, reglamentos (formales o informales), políticas públicas y leyes.

La generación de evidencia busca obtener información imparcial y objetiva. Su uso, sin embargo, depende de la capacidad de las estructuras y mecanismos de gobernanza para involucrarla a los diferentes contextos sociales, políticos y económicos, así como plasmarla en acuerdos que den sostenibilidad jurídica a las acciones de adaptación. La gobernanza y la evidencia entonces están íntimamente vinculadas, en el entendido de que la gobernanza para la AbE requiere de evidencia como herramienta de negociación y, a su vez, la generación de evidencia no tendría los efectos deseados si las estructuras de gobernanza no existieran o bien fueran ineficientes para producir el cambio social esperado.

Además de la producción de información y de un acervo de conocimientos acerca de los servicios de los ecosistemas, la generación de evidencia pretende establecer, nutrir y enriquecer una base de datos confiable en materia de actores, tomadores de decisión y sus capacidades de adaptación dentro de arreglos de gobernanza efectivos a una escala geográfica y temporal específica. Cualquier proyecto o iniciativa en materia la AbE necesariamente debe incluir un análisis de los desafíos que representa su implementación y sostenibilidad para grupos interesados (Nalau \& Bekens, 2018). En este contexto la gestión del conocimiento ${ }^{3}$ debe ser parte de las acciones de AbE desde su planificación.

A fin de que esta evidencia pueda servir para escalar la AbE dentro de la toma de decisiones estratégicas en los Estados sobre desarrollo, es imperioso concienciar y capacitar a los responsables de esta toma de decisión para que se comprometan a planificar con una visión de largo plazo (Calliari et al., 2019). Esto forma parte de las capacidades de adaptación que deben tomarse en cuenta para garantizar una gobernanza efectiva para la AbE (ver capítulo 2, Capacidades).

\subsubsection{Ambiente propicio para la formulación de políticas y marcos regulatorios para la AbE}

La carencia de información estructurada respecto a la efectividad de la AbE constituye una de las brechas más importantes para la formulación de políticas y marcos regulatorios (OECD, 2018). Asimismo, la debilidad de las instituciones del Estado especialmente en los países en vías de desarrollo impone una limitación importante para contar con una base legal sólida que ayude a garantizar la buena gobernanza. La evidencia que proveen las experiencias y medidas de AbE en la práctica (estudios de caso, investigaciones científicas, etc.) pueden brindar los elementos necesarios para construir las herramientas para garantizar la sostenibilidad de dichas acciones (ver capítulos 4 y 5 ).

Como ha podido apreciarse a lo largo de este capítulo, la generación de evidencia debe responder no solo a la necesidad de buscar la efectividad de la AbE en términos ecosistémicos y de coorganizar, filtrar y presentar la información con el fin de mejorar la comprensión de las personas en un área específica de interés. 
beneficios en el largo plazo, sino también a la solidez de las instituciones, las capacidades de los actores interesados y las condiciones que permitan la participación ciudadana.

La evidencia sobre la $\mathrm{AbE}$ es también necesaria para fomentar el interés de los tomadores de decisión para facilitar procesos participativos de formulación de políticas y leyes que garanticen la continuidad y la mejora de las acciones de AbE. Una vez más, esto depende de las capacidades de gestión y de incidencia que tengan dichos actores para convencer respecto de las ventajas comparativas de la AbE a quienes elaboran las políticas. Las políticas deben ser socialmente aceptables para los diversos actores y sectores interesados, incluyendo al corporativo que demanda información precisa y científica (evidencia) que demuestre las ventajas económicas y sociales de las medidas de AbE en relación con otras alternativas (Cvitanovic et al., 2016).

En la medida en que exista mayor información y evidencia científica (cuantitativa) respecto de los costos, la distribución social y ambiental de los beneficios de las medidas de AbE, habrá más oportunidad de incidir en la formulación de políticas y marcos regulatorios en el largo plazo (Munroe, 2012). Es por ello que la construcción de capacidades resulta esencial para generar, analizar y transmitir la evidencia a distintos grupos y niveles: local, nacional, regional e internacional. Las políticas, estrategias y planes de adaptación en los países en desarrollo, están basados en diversos tipos de evidencia (Vignola, et. al., 2019). Aun en países desarrollados, la base de evidencia se encuentra en construcción y requiere todavía aún de más tiempo para consolidarse (PNUD-INECC, 2017).

\subsubsection{Transferencia de información, conocimientos y comunicación de la gobernanza para la AbE}

La comunicación efectiva (es decir aquella que se logra a través de un mensaje claro y entendible) y dirigida a públicos meta específicos debe considerarse como una herramienta para mejorar la AbE y por tanto su gobernanza en el sentido de que a través de esta es posible generar concienciación, sensibilización, persuasión y motivación. La comunicación estructurada de evidencia, propicia el cambio de actitudes, la interacción social, el intercambio de opiniones, los procesos de retroalimentación y cambios en el comportamiento humano (Encalada, 2005). La comunicación requiere de una planificación adecuada toda vez que una acción caótica en esta materia, puede producir confusión o retrasos en estimular la creación de capacidades o enviar mensajes equivocados a aquellos a cargo de elaborar políticas y leyes sobre AbE.

Para que la comunicación de la evidencia sea objetiva, debe reflejar la realidad derivada del análisis de datos e información y no de las aspiraciones de los que comunican. Aun cuando el análisis de la información generada a través de la evidencia debe ser idealmente un proceso participativo, se requiere que una persona o institución con experiencia lideren dicho proceso para evitar el uso inadecuado de dicha información o posibles malas interpretaciones de la misma.

Al momento de planificar un proceso de comunicación sobre la evidencia de la AbE, hay una serie de puntos que se deben ponderar:

1. Las características de la audiencia (grupos de actores involucrados), sus formas de intercambiar información y los contextos locales que influyen en el cambio climático.

2. La capacidad de los que comunican la información para llevar el mensaje de forma correcta a la luz de las necesidades locales de adaptación y de los compromisos de los Estados en relación con la política y los marcos jurídicos e institucionales. 
3. El "lenguaje" con que se muestra el contenido. Para ello es importante considerar que el lenguaje en la materia es complejo e integra múltiples conceptos; una misma palabra puede tener varios significados generan entonces distintas interpretaciones y finalmente que es fundamental ajustar el lenguaje para facilitar la comprensión por parte de sus destinatarios.

4. El acceso a la información por parte de actores interesados.

Finalmente, dentro de las capacidades necesarias para una comunicación efectiva de la evidencia se deben promover las habilidades de comunicación, la motivación y el liderazgo para comprometer a otros respecto de las necesidades de la gobernanza para la AbE. Las decisiones que se toman con base a la evidencia requieren de un intercambio de conocimientos de doble vía: por un lado, entre beneficiarios/usuarios y científicos y por el otro, entre beneficiarios/usuarios y tomadores de decisión.

\subsubsection{Evidencia generada a través de la gobernanza para la AbE}

La evidencia de la efectividad de las políticas, estrategias, leyes y regulaciones en materia de AbE debe generarse, analizarse y comunicarse; en otras palabras debe existir evidencia respecto de efectividad de la AbE para gestionar su buena gobernanza y a la vez evidencia sobre la efectividad de esta para garantizar que se continúen implementando acciones de AbE.

La sostenibilidad de las soluciones basadas en la naturaleza, incluyendo la AbE requiere de una retroalimentación de doble vía. Los arreglos de gobernanza para la AbE (multidimensionales, participativos, ecosistémicos y flexibles), deben proporcionar información a los proyectos e iniciativas y viceversa. Los responsables del cumplimiento y la implementación de políticas, leyes y regulaciones que mejoran las condiciones propicias para la AbE tienen el deber de rendir cuentas respecto de los resultados de dichas políticas a los actores interesados. Por otra parte, es necesario monitorear y evaluar la transparencia, la capacidad institucional, el control y cumplimiento de la ley con el fin de retroalimentar a la ciudadanía y construir participativamente los cambios necesarios a los marcos legales específicos.

Las capacidades institucionales y humanas para una buena gobernanza determinan, en última instancia, la efectividad de las estrategias y políticas públicas (UNSTT, 2012). Estos temas se profundizan dentro del capítulo 4 de este libro.

En la figura 3.1 se ilustra esta dinámica descrita de doble vía entre la generación de evidencia a partir de la AbE para incidir en su gobernanza y la evidencia de la efectividad de la gobernanza necesaria para la sostenibilidad de la AbE.

Como se ha mencionado la implementación de medidas de AbE debe planificarse de forma participativa y contar idealmente con líneas de base sobre la vulnerabilidad de las poblaciones beneficiaras así como de los ecosistemas asociados a estas. El análisis de esos datos y la interpretación de resultados a través del tiempo es fundamental para la generación de evidencias y lecciones aprendidas para la efectividad de la AbE a través del tiempo, incluyendo el entendimiento de parte de los grupos interesados de los procesos ecológicos. Asimismo, la gobernanza para la $\mathrm{AbE}$ requiere de la construcción de herramientas adecuadas a los diferentes contextos sociales, políticos, económicos y ambientales; así como contener objetivos claros y arreglos institucionales innovadores y flexibles que respondan a las necesidades de las poblaciones y los ecosistemas. La implementación de dichas herramientas permitirán medir la efectividad de la gobernanza para la $\mathrm{AbE}$, así como retroalimentar y mejorar la implementación de las medidas de adaptación. 


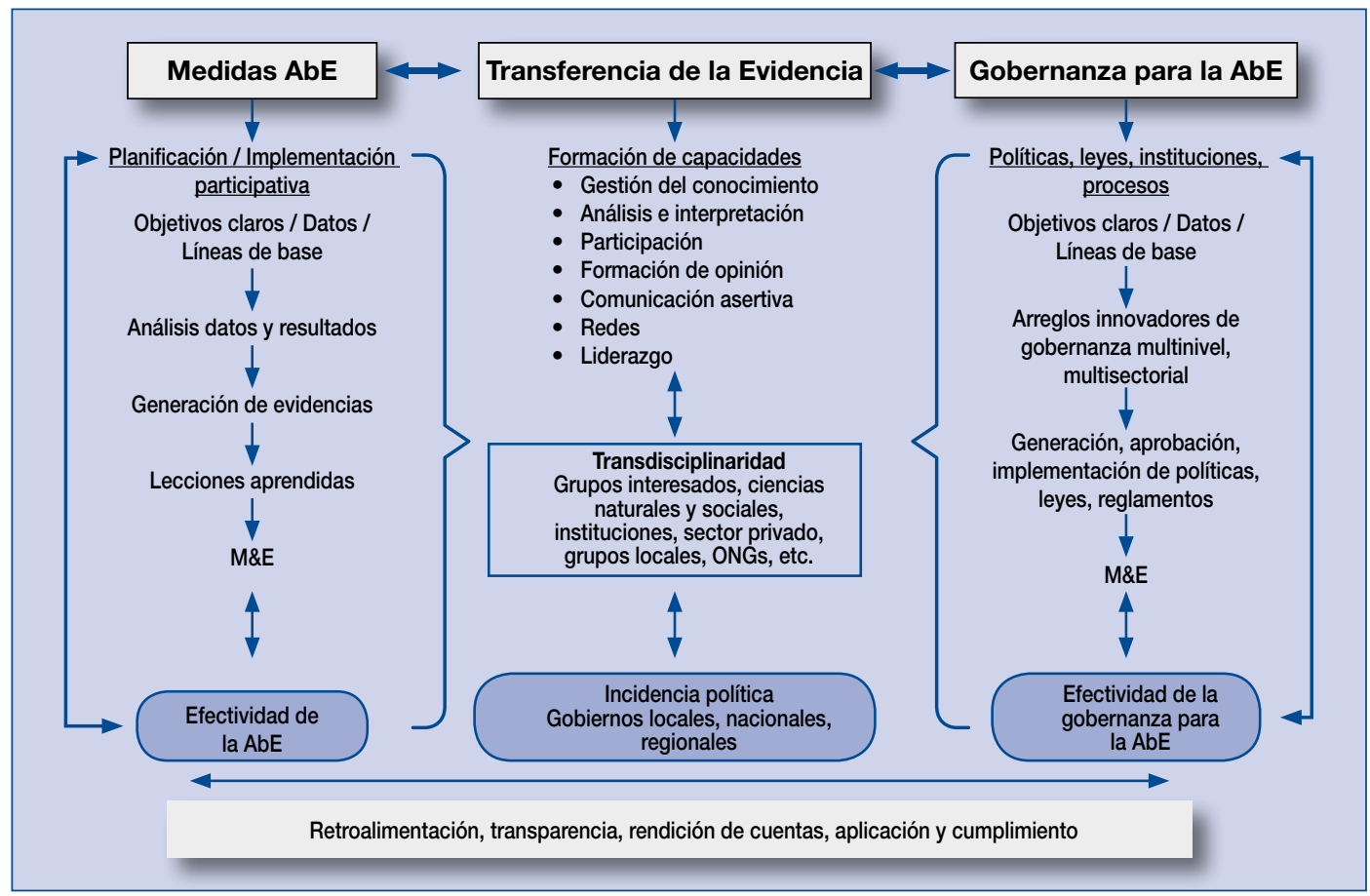

Figura 3.1 Articulación entre la evidencia generada desde la AbE y evidencia de la gobernanza efectiva para la AbE

Habida cuenta de la retroalimentación entre la evidencia generada por la AbE con la evidencia generada por la gobernanza para la $\mathrm{AbE}$, es esencial enfatizar la relevancia que para esto tiene la comunicación y transferencia de información (conocimientos) para sustentar arreglos innovadores y eficientes para la gobernanza para la AbE. Los tomadores de decisión y responsables de la elaboración de políticas, leyes y demás instrumentos también deben responder a los grupos interesados brindando información respecto de la aplicación y el cumplimiento de los marcos legales y así, continuar enriqueciendo la implementación de la AbE. Dentro de esta dinámica, los sistemas de monitoreo y evaluación son un instrumento a tener en cuenta.

\subsubsection{Monitoreo y Evaluación (M\&E) de la gobernanza para la AbE}

Los efectos de las acciones de AbE se ponen de manifiesto principalmente en el mediano o en largo plazo. Dependiendo de la complejidad de la relación costo-efectividad que se quiera demostrar, en ocasiones los resultados esperados pueden no visualizarse de manera clara o quedar integrados en otros cambios producidos. Es por ello que la generación de evidencia debe incluir la implementación de sistemas de Monitoreo y Evaluación permanentes que permitan medir el progreso de una medida de AbE y su gobernanza a través del uso consciente, explícito y racional de datos válidos y disponibles.

El monitoreo se refiere a los productos, al progreso alcanzado durante la implementación de una acción e identifica medidas correctivas en tanto que la evaluación se centra en describir el proceso, el 
cómo y por qué se obtuvieron los resultados y los impactos a mediano y largo plazo, proporcionando con ello una base para el aprendizaje.

Cuando se trata de acciones con efectos acumulativos (como los de AbE o conservación de la biodiversidad, que se pueden considerar más como procesos que proyectos puntuales) la evaluación es clave para medir sus impactos en el largo plazo. Sin embargo, la realidad muestra que tanto las entidades financieras como implementadores de medidas de AbE, suelen priorizar solamente el monitoreo. Esto disminuye las posibilidades de enriquecimiento de otras iniciativas y de planificación a largo plazo basada en información veraz.

En términos de gobernanza para la $\mathrm{AbE}$, los Estados deben monitorear no solo las condiciones cambiantes de los ecosistemas sino también la implementación y el cumplimiento de leyes y normas en la materia. Con este fin deben fijar estándares de calidad basados en métodos aceptados de medición científica, de procesamiento de datos y de análisis (Iza \& Stein (eds.), 2011).

La selección de indicadores ${ }^{4}$ que brinden datos cualitativos y cuantitativos para generar la evidencia sobre la funcionalidad de la Abe son parte de un sistema efectivo de monitoreo y evaluación.

Específicamente para la gobernanza para la $\mathrm{AbE}$ es preciso establecer indicadores desde del inicio de la implementación de las medidas para de esta manera identificar las oportunidades para la elaboración de políticas y leyes y reglamentos para la AbE.

Los indicadores para la gobernanza para la AbE deberán construirse con la participación de los grupos interesados y ser relevantes para los aspectos políticos, legales, institucionales y de procesos en cada caso específico, además deberán brindar evidencia rigurosa respecto de la capacidad, la funcionalidad y el desempeño de estos elementos en el tiempo (Bennett \& Satterfield, 2018).

Habida cuenta de la complejidad inherente a los ecosistemas, sus servicios y las dinámicas sociales relativas a ellos, demostrar la viabilidad de la $\mathrm{AbE}$ y su gobernanza constituyen gran desafío en relación con aquellas soluciones más convencionales o habituales. De allí que, se recomiende monitorear, por ejemplo, un solo servicio ecosistémico y no abarcar todos al mismo tiempo. La experiencia demuestra que en la mayoría de los proyectos de AbE el monitoreo y la evaluación se posponen hasta el final de dichos proyectos y no brindan por tanto información realmente útil para la toma de decisiones (Raymond et al., 2017). Ello no obstante, sí es conveniente seleccionar al menos una actividad de forma participativa que ejemplifique los beneficios tangibles para la calidad de vida a fin de contar con el compromiso, la apropiación y el empoderamiento de los actores locales que son los que en última instancia van a incidir en base a su experiencia en la formulación de políticas, leyes y otro tipo de regulaciones.

Corresponde destacar que a nivel nacional, los sistemas de monitoreo para las políticas de adaptación al cambio climático son complejos, toman tiempo y están apenas en proceso de elaboración por lo que todavía no hay resultados que evidencien los avances respecto del cumplimiento de estos instrumentos (PNUD-INEC, 2017). Por otra parte la mayoría de los indicadores que se incluyen en la mayoría de estos sistemas tienen que ver con los temas de desarrollo social y económico así como con los servicios de los ecosistemas. Es por ello que se hace necesario definir formas de articular

$4 \quad$ Un indicador puede ser definido como "una expresión cualitativa o cuantitativa observable que permite describir características, comportamientos o fenómenos de la realidad a través de la evolución de una variable o el establecimiento de una relación entre variables, la que comparada con periodos anteriores o bien frente a una meta o compromiso, permite evaluar el desempeño y su evolución en el tiempo" (DANE, 2013). 
estos con la aplicación y el cumplimiento de las políticas, leyes y procesos relacionados con la AbE y así contar con un monitoreo y evaluación integrado, coherente y holístico.

Finalmente, debe destacarse que los costos para el establecimiento e implementación de sistemas de monitoreo y evaluación de la gobernanza para la AbE implican una inversión importante de recursos, toda vez que incluyen la capacitación de los diversos actores asociados a su implementación (Iza \& Stein (eds.), 2011).

\subsection{Desafíos y oportunidades para funcionalidad de la gobernanza para la $\mathrm{AbE}$}

El mayor desafío actual para que la evidencia práctica contribuya a construir la gobernanza para la AbE es la generación de información científica y técnica rigurosa (tanto respecto de los servicios de los ecosistemas como de los capitales sociales y políticos así como de los co-beneficios para las poblaciones) que sirva para nutrir sistemas de gobernanza efectivos y eficientes.

En la literatura, las estimaciones cuantitativas son todavía muy escasas, en especial en países en vías de desarrollo donde los datos sobre impactos físicos y la valoración económica de estos resultan difíciles de obtener. La mayor parte de los estudios de caso no cuentan con una evaluación científica que proporcione evidencia confiable y sólida que indique cuán eficientes han sido los enfoques de AbE (Munroe et al., 2012).

Las dificultades para generar datos y conocimientos están normalmente asociadas con los limitados recursos financieros y las capacidades para la adaptación, en especial de las poblaciones locales, mismas que generalmente son las que más dependen de los servicios de los ecosistemas (Mehvar et al., 2018). Aunado a lo anterior, los beneficios de las medidas de conservación, restauración y gestión sostenible de los ecosistemas para la adaptación son visibles en, aproximadamente, diez años, por lo que si bien se están desarrollando metodologías para monitorear y evaluar dichos beneficios, sólo se podrá contar con información científica rigurosa en el mediano plazo. Estos factores condicionan la falta de planificación participativa adecuada, así como una pobre o inexistente elaboración de líneas de base claras respecto de aquellos aspectos que se pretenden mejorar (servicios de los ecosistemas, medios de vida sostenibles, sistemas políticos e institucionales) a través de las medidas de AbE.

Está claro que, si no se generan beneficios ecosistémicos que puedan ser traducidos en términos económicos, las personas no se comprometen con la AbE ni se motivan a mejorar sus opciones de organización y búsqueda de arreglos de gobernanza que les permita continuar adaptándose al cambio climático y en última instancia, mejorar sus calidad de vida. En este sentido hay otro gran desafío que se relaciona con los cambios a largo plazo de los ecosistemas y de la sociedad que interactúan de una forma compleja de predecir en el contexto de la incertidumbre propia de los escenarios climáticos.

Si la evidencia proporciona insumos en términos de beneficios económicos y sociales, los tomadores de decisión y los que elaboran las políticas, no podrán mejorar la gobernanza para la AbE. Actores bien informados y que comprendan bien la evidencia pueden construir argumentos sólidos para mejorar las estructuras de gobernanza y los mecanismos necesarios para implementarlas.

Los conocimientos tradicionales o locales respecto al funcionamiento de los ecosistemas y la interacción de la naturaleza con la sociedad, deben ser siempre adecuadamente ponderados e 
incorporados en la planificación e implementación de medidas de AbE y su gobernanza (WWAP/ ONU-AGUA, 2018). Los pueblos indígenas y comunidades locales son los que generalmente cuentan un panorama histórico de largo plazo respecto de los cambios y comportamientos de los ecosistemas, mismo que puede contribuir a la construcción de distintos tipos de evidencia.

La sistematización y diseminación de estudios de caso sobre la $\mathrm{AbE}$, donde se pongan claramente de manifiesto las lecciones aprendidas y los retos para su diseño e implementación, constituye una buena oportunidad de incidir en las agendas políticas respecto al cambio climático (Nalau \& Becken, 2018).

Las capacidades para la AbE son esenciales para analizar la evidencia y trasladarla a políticas y marcos regulatorios. Los grupos interesados deben poseer la habilidad de percibir y sistematizar las tendencias de cambio en términos de vulnerabilidad y resiliencia, así como las herramientas que permitan monitorear estas tendencias a lo largo del tiempo.

En tanto que los Estados están abocados a elaborar los planes y políticas nacionales de adaptación al cambio climático de acuerdo con sus compromisos asumidos globalmente, existe una oportunidad para incorporar la AbE y consecuentemente mejorar los instrumentos políticos y legales para su implementación y sostenibilidad. Para ello, es necesario contar con evidencia derivada de proyectos de índole diversa (acciones concretas sobre gobernanza para la AbE) que permitan dimensionar y construir de manera lógica y mesurada, los sistemas de monitoreo, indicadores y evaluación para el cumplimiento de los compromisos internacionales (por ejemplo Acuerdo de París).

Son todavía pocos los países en desarrollo que cuentan con estos sistemas y aquellos que ya existen son aún un tanto ambiciosos y complejos. La formulación de dichos sistemas con la participación de todos los actores interesados ha llevado su tiempo y por tanto no existe aun evidencia tangible que demuestre la efectividad de políticas de adaptación al cambio climático (PNUD-INECC, 2017).

Ello no obstante, el aumento de fuentes de financiamiento especialmente para países en vías de desarrollo destinadas a establecer los multicitados sistemas de monitoreo y evaluación constituye una coyuntura que debe ser adecuadamente aprovechada para fortalecer las medidas de adaptación y consecuentemente su gobernanza efectiva. 


\section{Politíca}

\section{Lorena Martínez Hernández}

\subsection{Introducción}

La gobernanza es el medio a través del cual la sociedad define sus metas, prioridades y avanza hacia la toma de decisiones, a nivel global, nacional o local. Incluye: a) las políticas, b) los marcos jurídicos c) las instituciones; y d) los procesos y mecanismos mediante los cuales los actores interesados expresan sus intereses, ejercen sus derechos, cumplen sus obligaciones y resuelven sus diferencias (Burhenne-Guilmin \& Scanlon (eds.), 2004). La gobernanza incluye instituciones y procesos formalese informales a través de los cuales los ciudadanos y las comunidades se organizan y toman decisiones (Martin, Boer \& Slobodian (eds.), 2016). Es importante destacar que la gobernanza va más allá del gobierno, pues reconoce los roles específicos para la sociedad civil y el sector privado (CDB, 2018).

Este capítulo pretende reflexionar respecto del rol de los marcos políticos y normativos para implementar una estrategia de adaptación al cambio climático que integre soluciones basadas en la naturaleza de manera coherente entre diversos sectores, niveles de gobierno y demarcaciones administrativas o políticas en el territorio. Asimismo, procura describir los derechos procedimentales ambientales y su importancia dentro de la gobernanza para la AbE. Las instituciones quedan excluidas del alcance de este capítulo, toda vez que son objeto de un tratamiento específico en otro capítulo de esta misma obra. ${ }^{1}$

En este capítulo, se elucidan los roles de las políticas y de las normas para integrar la AbE en una estrategia de adaptación nacional, se identifican las oportunidades de integrar este enfoque en diversas políticas y leyes, y, finalmente, se apuntan las principales áreas de reforma y se hacen algunas recomendaciones.

\subsection{La Política y la Ley, roles diferentes e interdependientes para la adaptación}

La Política y la Ley pueden diferenciarse fácilmente, al menos en teoría. La Política establece visiones, estrategias, planes y un conjunto de directrices sobre cómo debe tratar el gobierno un asunto público. Su rol es el de guiar la creación o reforma legislativa para alcanzar un objetivo social. También promueve la coordinación de las acciones y de las actividades de otros organismos de gobierno que son relevantes para dicho fin. A diferencia de la Ley, la Política no es vinculante ni crea derechos ejecutables, sino que es dinámica y flexible (Iza \& Stein (eds.), 2011).

La Política resulta ser fundamental para la elaboración o reforma de los marcos jurídicos porque ofrece una oportunidad para la participación de expertos, investigadores y el público en general en la formulación de las directrices sobre lo que debe incluir la nueva legislación (Iza \& Stein (eds.), 2011).

La Política necesita de la Ley² para:

- Crear instituciones: Establecer órganos de gobierno para gestionar los distintos asuntos públicos.

2 Entendida como el conjunto de normas en un ordenamiento jurídico. 
- Distribuir competencias y facultades: Determinar quién tiene la facultad de tomar decisiones, quién tiene la competencia para implementarlas y quién es responsable si las decisiones no se implementan.

- Definir procesos: Definir cómo se toman las decisiones, cómo se deben implementar y cómo los tomadores de decisiones deben rendir cuentas por sus actos.

La Ley también crea derechos y obligaciones y establece mecanismos para la resolución de conflictos entre actores. Brinda la estabilidad y la seguridad a los sistemas para la gestión de asuntos públicos. La gobernanza se beneficia de un marco jurídico funcional que provee directrices concretas y obligatorias (Greiber \& Schiele, 2011).

La adaptación al cambio climático es el proceso de ajuste a las condiciones climáticas actuales o esperadas (en el corto, mediano y largo plazo) y sus efectos, con el fin de reducir el daño o deterioro potencial (de las condiciones de vida o de las funciones de los ecosistemas respectivamente) que estas condiciones puedan causar. De acuerdo con el IPCC (2014) también incluye el aprovechamiento de oportunidades beneficiosas que dichos cambios del clima puedan brindar.

La adaptación puede ser espontánea o planificada. La primera constituye una respuesta inconsciente a los estímulos climáticos, que responde a cambios en los sistemas ecológicos o en los sistemas humanos o los mercados. (Verschuuren, 2013a). La segunda es una respuesta proactiva, que intenta anticiparse a los impactos del cambio climático y busca prevenir la adaptación equivocada (Verschuuren, 2013a).

Las políticas y las leyes en materia de adaptación pretenden dirigir e institucionalizar el proceso iterativo de ajuste de la sociedad y los ecosistemas al clima de manera proactiva e informada. Tiene como finalidad generar decisiones incluyentes e implementar acciones, en los diferentes niveles administrativos y sectores, para gestionar de manera intencional e integrada los impactos del cambio climático.

Desde una perspectiva de la Política, la adaptación es compleja porque no se puede planificar con un instrumento "sectorial" o específico, sino que es transversal y necesariamente debe abarcar todos los sectores afectados por el cambio climático, lo que implica retos adicionales de coherencia y coordinación multisectorial. Otro elemento adicional de complejidad es que la vulnerabilidad al cambio climático depende de muchos factores específicos de cada contexto, y una política de adaptación efectiva necesita nutrirse del conocimiento de las condiciones locales y de su capacidad para responder a los cambios (Flatt, 2012). De tal forma, la adaptación demanda una cercana coordinación de los diversos sectores afectados y los distintos niveles de gobierno, desde el local hasta el nacional y el internacional (Verschuuren, 2013), así como nuevos mecanismos para involucrar a sectores de la sociedad que históricamente han permanecido al margen de la toma de decisiones.

Idealmente, la política para la adaptación debería estar plasmada en un instrumento marco que estableciera directrices generales para los diversos sectores y niveles de gobierno a corto, mediano y largo plazo. Asimismo, una serie de instrumentos de política como las estrategias y programas especiales de cambio climático, así como las sectoriales detallan más la estrategia de implementación (hoja de ruta) y acciones concretas a realizar en cada uno de los sectores.

La política para la adaptación también debería procurar la coherencia de las políticas y las acciones concretas de adaptación desde los niveles locales hasta el global, para lo cual debería definir espacios de participación y canales de comunicación en los procesos de toma de decisiones e identificar los mecanismos o instrumentos de implementación. 


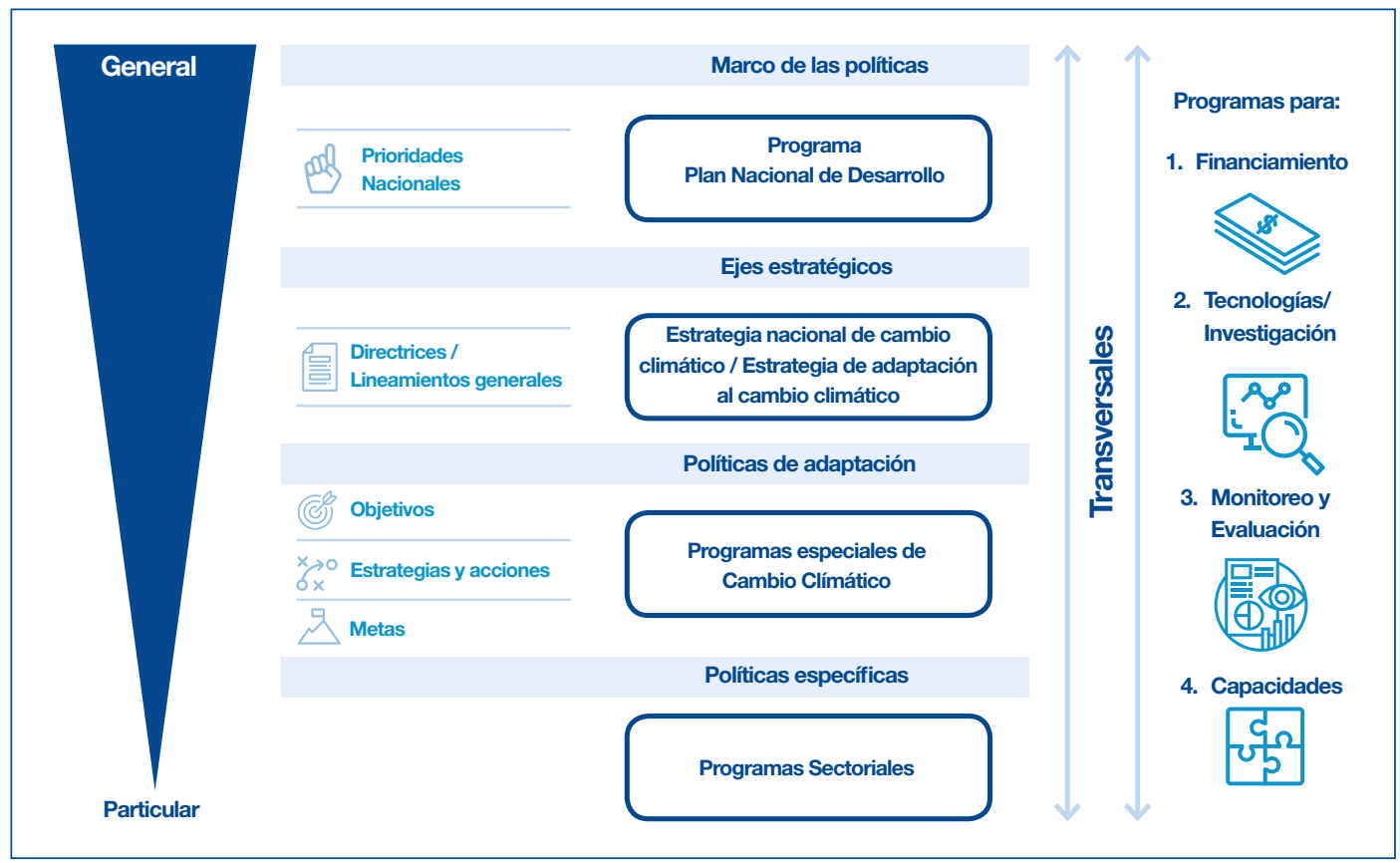

Figura 4.1 La transversalización de la adaptación en la regulación jurídica sectorial Fuente: Adaptado de Ascencio, 2019, p.104

Además, la política de adaptación debería establecer metodologías e indicadores medibles, verificables y reportables para su monitoreo y evaluación en el corto y mediano plazo a fin de poder gestionar la incertidumbre sobre el momento, la intensidad, el lugar en que el cambio climático impactará los sistemas humanos y naturales. Los criterios e indicadores deberían a cumplir la función de evaluar no sólo los avances en la implementación de la política marco, sino, sobre todo, la efectividad de la adaptación (OECD, 2015; Vallejo, 2017). Esto debería incluir la reducción de la vulnerabilidad, la mejora de la resiliencia y de las capacidades adaptativas de las personas, los ecosistemas, los sectores y las instituciones. Si bien la importancia de los indicadores y criterios para medir el progreso en términos de adaptación es ampliamente reconocida, no existen sistemas de medición que integren todos estos elementos, ni la idoneidad y la eficacia de la adaptación (CMNUCC, 2018).

Por su parte, la Ley debería crear las instituciones que están a cargo de la coordinación del proceso de adaptación, distribuir las competencias entre las instituciones al frente de diversos sectores y entre los distintos niveles de gobierno. Por otra parte, debería establecer arreglos o mecanismos tanto para lograr acuerdos como resolver diferencias cuando las competencias o demarcaciones administrativas entre dichas instituciones entran en conflicto o tienen competencias que se sobreponen. La Ley, en definitiva, institucionaliza y da claridad, estabilidad y seguridad jurídica al proceso de coordinación para la adaptación al cambio climático.

Además, la Ley debería establecer obligaciones y derechos de las personas físicas y jurídicas, públicas y privadas, en relación con la adaptación al cambio climático a fin de involucrar a todos los sectores de la sociedad. Probablemente los derechos más fáciles de identificar en esta temática sean 
los de acceso a la información, participación pública en la toma de decisiones y el acceso a la justicia en asuntos ambientales, comúnmente conocidos como derechos procedimentales ambientales. De igual manera, deben destacarse los derechos de los pueblos indígenas al consentimiento libre, previo e informado (CLPI) sobre su territorio y los recursos naturales que se encuentran en él, así como los derechos de las mujeres a participar en la toma de decisiones. Existen otros derechos que son menos evidentes, pero igualmente importantes para la adaptación, por ejemplo, los derechos de propiedad, los derechos de parentes, derivados de los contratos de seguros, entre otros (Greiber, 2010).

La Ley también instaura mecanismos y procedimientos para: garantizar la implementación de las políticas de adaptación, ${ }^{3}$ señalar las autoridades competentes para vigilar su cumplimiento y establecer sanciones.

Finalmente, la Ley tiene también la función de prever conflictos entre derechos e intereses y diseñar los mecanismos de solución de conflictos tanto judiciales como extra-judiciales. Asimismo, la Ley establece los preceptos o fórmulas que utiliza el juez en la ponderación de los derechos o intereses en conflicto.

\subsubsection{La política de adaptación y el enfoque ecosistémico}

Los seres humanos somos completamente dependientes de los ecosistemas y sus servicios (Millenium Ecosystem Assessment, 2005; UNEP, 2019; IPBES, 2019), por lo que la intervención humana para reducir su vulnerabilidad y aumentar la resiliencia ante los efectos del cambio climático debe ser un pilar de la política de adaptación (Preámbulo, Acuerdo de París, 2015).

La intervención humana para el ajuste de los ecosistemas al cambio climático se ha resumido en "acciones de conservación, restauración y gestión sostenible de los ecosistemas y sus servicios" (CDB, 2009), presumiblemente, con el fin de facilitar su comprensión y su traducción en acciones concretas por diversos actores con capacidades técnicas diversas. Sin embargo, una de las limitaciones comunes de esta estrategia es que dichas acciones se consideran como una preocupación ambiental, sin llegar a permear la planeación del desarrollo en general, en la actuación de todos los entes estatales y en la regulación y actuación de los actores de la sociedad (por ejemplo, en el sector privado).

La integración del enfoque ecosistémico en la estrategia de adaptación es, en la realidad, más amplia que la promoción de acciones de conservación y/o restauración en las políticas y leyes correspondientes. Se trata de alinear los procesos económicos, productivos y sociales a los ciclos naturales y desarrollarlos dentro de la capacidad de carga de los ecosistemas, tomando en cuenta las presiones adicionales del cambio climático sobre estos.

Ello implica, por un lado, reducir la vulnerabilidad de los ecosistemas asociada a actividades humanas (por ejemplo, las distintas formas de contaminación, la sobre-explotación de los recursos naturales, la deforestación, la urbanización, los modelos de producción y de consumo, etc.) y, por otro lado, aumentar su resiliencia a través de acciones de conservación y restauración, en paralelo. En este sentido, empieza a haber ejemplos de países que identifican y valoran los servicios ambientales de sus ecosistemas terrestres a escala nacional (TEEB-Rusia, 2018), identificando los servicios ambientales

3 En este capítulo se entiende por política de adaptación a toda aquella que hace referencia explícita a la adaptación al cambio climático, por ejemplo, la Contribución determinada a Nivel Nacional (NDC), las políticas, planes y estrategias de cambio climático, los Planes Nacionales de Adaptación. 
en los distintos sectores económicos y productivos (por ejemplo, proyecto ECOVALOR en Cuba). A partir de aquí, la integración de la AbE podría ser posible si también se evaluara la vulnerabilidad de los ecosistemas y sus servicios y se diseñaran medidas de conservación y restauración acordes con las capacidades de carga de los ecosistemas, con el fin de aumentar su resiliencia ${ }^{4}$ (ver CLIMA- Guía para el fortalecimiento de la gobernanza para la $\mathrm{AbE}$ ).

Mientras la ciencia y la Política van desarrollándose para hacer frente al reto que supone la gestión sostenible de los ecosistemas en el contexto del cambio climático, ya es posible tomar acción haciendo uso de la amplia gama de herramientas regulatorias que ofrece el derecho ambiental, por ejemplo, las evaluaciones ambientales estratégicas (EAE), las evaluaciones de impacto ambiental (EIA), los planes de desarrollo territorial, los planes de desarrollo urbano, las áreas protegidas, las certificaciones ambientales, las cuotas de aprovechamiento en el sector de la pesca, entre otras muchas. La integración de la AbE supone alinear estos instrumentos con la información obtenida de las evaluaciones de vulnerabilidad al cambio climático y la implementación de medidas necesarias para la conservación y restauración de los ecosistemas acordes a las presiones humanas y climáticas.

En resumen, la gobernanza para la adaptación, integrando el enfoque ecosistémico tiene aún un largo camino por recorrer para facilitar la consecución de los objetivos nacionales y globales de adaptación y las necesidades de adaptación a nivel local. Entre las primeras acciones concretas que aquí se identifican se encuentran la inclusión de medidas de conservación y restauración en las políticas y leyes de adaptación marco y sectoriales, por un lado; y la integración de evaluaciones de vulnerabilidad y mecanismos de flexibilidad en las políticas y leyes de carácter ambiental, social y económico, por el otro (Ruhl, 2010; Yazykova \& Bruch, 2018).

\subsubsection{La AbE en los Acuerdos Multilaterales Ambientales (AMUMAs)}

Los efectos del cambio climático sobre los ecosistemas y la biodiversidad fueron reportados por primera vez por científicos en evaluaciones globales tales como el primer informe del Panel Intergubernamental sobre Cambio Climático (IPCC) de 1990. De ahí que las Conferencias de las Partes (CP) de los Acuerdos Multilaterales Ambientales solicitaran a sus respectivos grupos de expertos que analizaran los efectos del cambio climático sobre los ecosistemas o especies que protegen.

El enfoque de $\mathrm{AbE}$ se ha integrado progresivamente en los tratados multilaterales ambientales en el transcurso de la última década, principalmente a través de las recomendaciones de sus órganos permanentes y las decisiones de las Conferencias de las Partes (CP) de los AMUMAs. Las CP recomiendan a los Estados Parte de dichos tratados incorporar la AbE como pieza clave de sus estrategias de adaptación e integrarla en sus políticas ambientales y sectoriales relevantes. Estas recomendaciones son generales, a fin de proveer el espacio suficiente para que los Estados desarrollen sus políticas internas conforme a sus propias vulnerabilidades, condiciones, circunstancias y contextos (Acuerdo de París, art. 7.5).

Las CP reconocen que tanto los ecosistemas como el cambio climático son, por naturaleza, transnacionales, por lo que promueven la cooperación internacional para la adaptación de los ecosistemas y de las personas. Asimismo, tomando en cuenta la transversalidad de la adaptación, las CP han solicitado a sus Secretarías que cooperen con las homólogas de otros tratados ambientales

4 Se recomienda consultar CLIMA, una guía para el fortalecimiento de la gobernanza para la AbE desarrollada por el Centro de Derecho Ambiental de la UICN. Disponible en: www.SolucionesAbE.org 
a fin de hacer recomendaciones coordinadas a las Partes y asistirles en el cumplimiento de sus compromisos internacionales.

A continuación, se detalla el tratamiento de la AbE a nivel global, por orden de relevancia.

Cuadro 4.1 Tratamiento de la AbE

\begin{tabular}{|c|c|c|}
\hline Materia & Tratado & Recomendaciones relativas a la $\mathrm{AbE}$ \\
\hline \multirow[t]{4}{*}{$\begin{array}{l}\text { Cambio } \\
\text { climático }\end{array}$} & \multirow{2}{*}{$\begin{array}{l}\text { Conventión Marco } \\
\text { de las Naciones } \\
\text { Unidas sobre el } \\
\text { Cambio Climático } \\
\text { (CMNUCC) }\end{array}$} & $\begin{array}{l}\text { Estabilizar las concentraciones de gases de efecto invernadero en } \\
\text { un nivel que impida la interferencia antropogénica peligrosa, en un } \\
\text { tiempo que permita la adaptación de los ecosistemas al cambio } \\
\text { climático. }\end{array}$ \\
\hline & & $\begin{array}{l}\text { Acuerdos de Cancún: Las acciones de adaptación deberían de } \\
\text { tomar en consideración los ecosistemas vulnerables, con vista } \\
\text { a integrar la adaptación en las políticas y acciones sociales, } \\
\text { ambientales y económicas relevantes (UNFCCC, 2013). }\end{array}$ \\
\hline & \multirow[t]{2}{*}{ Acuerdo de París } & $\begin{array}{l}\text { Reconoce la importancia de proteger la integridad de los ecosistemas } \\
\text { y la biodiversidad tanto para la mitigación como para la adaptación al } \\
\text { cambio climático (Preámbulo). }\end{array}$ \\
\hline & & $\begin{array}{l}\text { Los principios para la adaptación toman en cuenta los ecosistemas; } \\
\text { y llama a la integración de la adaptación en las políticas y acciones } \\
\text { ambientales relevantes, así como a aumentar la resiliencia de } \\
\text { los ecosistemas a través de la gestión sostenible de los recursos } \\
\text { naturales (art. 7). }\end{array}$ \\
\hline \multirow[t]{4}{*}{ Biodiversidad } & \multirow[t]{3}{*}{$\begin{array}{l}\text { Convenio de } \\
\text { Diversidad } \\
\text { Biológica }\end{array}$} & $\begin{array}{l}\text { Integrar consideraciones sobre la diversidad biológica en todas las } \\
\text { políticas, programas y planes nacionales pertinentes, en respuesta al } \\
\text { cambio climático, y de desarrollar rápidamente herramientas para la } \\
\text { ejecución de actividades de conservación de dicha diversidad que } \\
\text { contribuyan a la adaptación del cambio climático (CBD, 2006; CBD } \\
\text { 2014). }\end{array}$ \\
\hline & & $\begin{array}{l}\text { Meta de Aichi } 15 \text { establece un compromiso específico de } \\
\text { restauración de por lo menos } 15 \% \text { de las tierras degradadas, } \\
\text { contribuyendo a la adaptación. }\end{array}$ \\
\hline & & $\begin{array}{l}\text { Hacer uso de las Voluntary Guidelines for the design and effective } \\
\text { implementation of Ecosystem-based Approaches to Climate Change } \\
\text { Adaptation and Disaster Risk Reduction (Guías voluntarias para el } \\
\text { diseño y la implementación efectiva de un enfoque de AbE para } \\
\text { la adaptación al cambio climático y la reducción del riesgo de } \\
\text { desastres) (CDB, 2018) }\end{array}$ \\
\hline & $\begin{array}{l}\text { Convención sobre } \\
\text { la Conservación } \\
\text { de las Especies } \\
\text { Migratorias } \\
\text { de Animales } \\
\text { Silvestres }\end{array}$ & $\begin{array}{l}\text { Incorporar acciones para la adaptación de especies migratorias } \\
\text { en el Plan Estratégico para las especies migratorias (CMS, 2017) } \\
\text { y en las estrategias nacionales sobre el cambio climático, entre las } \\
\text { que figuran las Estrategias y Planes de Acción Nacionales para la } \\
\text { Biodiversidad (EPANB), con carácter prioritario (CMS, 2017b). }\end{array}$ \\
\hline
\end{tabular}




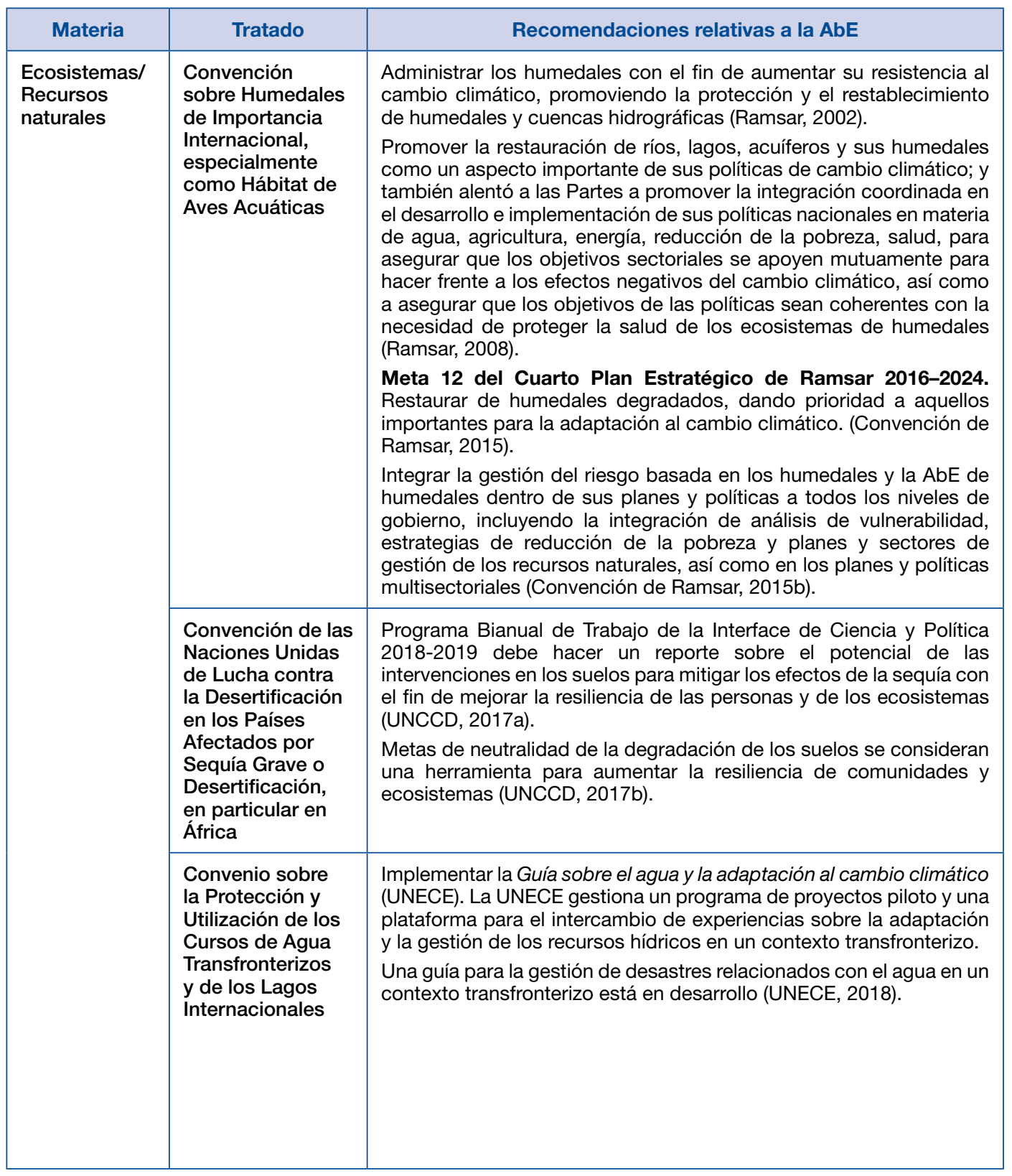

Resultan también relevantes los Objetivos de Desarrollo Sostenible (ODS 13 en relación con los ODS 1, 2, 3, 6, 14 y 15) ${ }^{5}$; el Marco de Sendai para la Reducción de Riesgos de Desastres (Prioridades 2 y 3$)^{6}$; la Nueva Agenda Urbana de Hábitat III (Compromisos de transformación en pro del desarrollo

5 Ver: Anexo de la Decisión 14/5 de la Convención de Diversidad Biológica, sobre Biodiversidad y cambio climático, para una representación visual de la contribución de la AbE a los ODS.

6 En el capítulo 1 (Ajuste) se podrá encontrar un análisis detallado sobre los aportes potenciales y concretos que la AbE puede brindar o brinda en los marcos de los ODS y Sendai, entre otros. 
urbano sostenible, párrafo 80); y el Desafío de Bonn de restaurar 150 millones de hectáreas de bosques degradados y deforestados para el 2020 y 350 millones de hectáreas para el 2030, este último que ha generado un interés creciente por parte de diversos países de adoptar la restauración de paisajes forestales gracias a sus beneficios para mejorar la adaptación al cambio climático (UICN, 2017).

En la práctica, la necesidad de adaptarse al cambio climático ha ido favoreciendo la cooperación transnacional impulsada por las comunidades locales que comparten un mismo ecosistema (Sánchez \& Roberts, 2014). En Centroamérica existen varios ejemplos de este tipo a nivel de cuenca o subcuenca. Uno de ellos, es el de la subcuenca alta del Río Sumpul, compartido entre Honduras y El Salvador, donde las comunidades conformaron en 2017 el Comité Binacional de la Cuenca del Río Sumpul con representación de diversos interesados a ambos lados de la frontera para gestionar los recursos hídricos e implementar medidas de $\mathrm{AbE}$ a fin de mejorar la calidad y cantidad de agua y reducir los riesgos de deslaves e inundaciones. El recientemente instaurado comité cuenta ahora con un Plan de Acción Estratégica que incluye medidas de AbE. Esta cooperación "micro" es importante no sólo para las comunidades que comparten un ecosistema, sino también para los Estados y para la gobernanza global. Para los Estados porque podría servir de ejemplo e impulso para una cooperación más amplia entre vecinos en relación con la gestión de ecosistemas compartidos, y para la gobernanza global porque la sumatoria de estos casos podría contribuir a alcanzar las metas globales (UICN, 2019).

\subsubsection{La AbE en las políticas nacionales}

El orden internacional recomienda a los Estados integrar la AbE en sus políticas internas relativas al desarrollo, la adaptación al cambio climático, la biodiversidad, la gestión de ecosistemas o recursos naturales, la gestión de riesgos de desastres y protección civil, el desarrollo urbano y/o la planificación territorial.

La integración de la AbE en políticas nacionales, regionales o locales puede seguir un enfoque desde las bases, es decir, desde proyectos piloto o experiencias de gobernanza de los recursos naturales con base a nivel comunitario que, a través de diversas estrategias, logran anclar las acciones de $\mathrm{AbE}$ en políticas sectoriales concretas ("bottom-up approach") o desde las instancias nacionales hacia las bases ("top-down approach").

Hasta ahora, el enfoque más común ha sido el "bottom-up", mismo que consiste en la planificación e implementación de proyectos de AbE a nivel local los cuales han contribuido a generar evidencia sobre los beneficios de la AbE e identificar ventanas de oportunidades para incluir aspectos de los ecosistemas en los objetivos, estrategias y políticas de adaptación a distintos niveles del gobierno. En ellos se hace un análisis de las políticas y planes nacionales de adaptación, ambientales, de uso del suelo, entre otros, para buscar oportunidades para la promoción de la AbE y se pretende que gradual y eventualmente esas acciones de $\mathrm{AbE}$ formen parte de las políticas regionales, nacionales y globales relevantes (proceso descrito como "mainstreaming EbA and Eco-DRR" en CBD, 2018).

En parte, la prominencia de este enfoque se debe a que la complejidad de la interdependencia entre los sistemas sociales y ecológicos, junto con las incertidumbres del cambio climático, desafían soluciones simples y lineales replicables con éxito en todos los contextos (Vasseur, 2017). Otra razón ecosistemas. 
podría ser que la $\mathrm{AbE}$ ha tenido que demostrar su costo-eficiencia y su efectividad para competir con otras medidas de adaptación, por ejemplo, aquellas de infraestructura gris. En cualquier caso, la diversidad de soluciones y la innovación asociada al intercambio de experiencias es un elemento fundamental de la respuesta al cambio climático, por lo que no sólo se debería promover dicha innovación, sino que se deberían sistematizar cuidadosamente las experiencias de los proyectos de AbE para poder informar o moldear el contenido de políticas de más alto contenido.

El enfoque "top-down" se inicia con una evaluación de los riesgos climáticos y las vulnerabilidades a nivel nacional, para identificar los principales ecosistemas, sectores económicos y sociales afectados por el cambio climático. Dentro de esta evaluación es importante identificar los servicios ecosistémicos clave y los grupos interesados, comprender la relación entre estos servicios y los diversos actores y sectores a niveles nacional y subnacional, e identificar procesos sociales clave dentro de las instituciones que gobiernan (Andrade et al., 2012).

Sobre la base de la evaluación de la vulnerabilidad, la política marco puede incluir la conservación y restauración de los ecosistemas como uno de sus lineamientos, haciendo referencia al "enfoque ecosistémico", al "manejo y conservación de los ecosistemas" u otro similar. Los lineamientos van acompañados de líneas de acción más concretas, que pueden incluir la formulación de planes regionales y locales de adaptación con un enfoque ecosistémico. Los planes regionales y locales deben abarcar escalas temporales y espaciales adecuadas a las dinámicas de los ecosistemas y sus servicios, garantizando su funcionalidad, y los principales actores y sectores que se benefician de dichos servicios (Andrade et al., 2012).

Los enfoques descritos son complementarios, el "bottom-up" debería ofrecer información relevante para las políticas nacionales, diseñar acciones de adaptación de manera participativa e involucrar a diversos sectores de la sociedad en el proceso de adaptación. El enfoque "top-down" debería coordinar las acciones de los distintos sectores de la sociedad y alinearlos para alcanzar los objetivos nacionales de adaptación, contribuir a la identificación de los factores de vulnerabilidad en las relaciones entre ser humano y naturaleza en los contextos locales, por ejemplo, a través de atlas nacionales de vulnerabilidad que faciliten a los actores locales diseñar planes locales con acciones de $\mathrm{AbE}$ y, sobre todo, debería canalizar recursos financieros e implementar programas de capacitación de los actores locales (públicos y privados) para la implementación de la AbE (Austin et al., 2019). El rol de este último enfoque es coordinar, garantizar la coherencia entre las distintas respuestas para lograr sinergias y prevenir la adaptación equivocada. En resumen, la intregración de la AbE en la Política debería ser un ejercicio de doble vía.

\section{Ejemplo: Política Nacional de Adaptación al Cambio Climático de Costa Rica (PNACC)}

La Política Nacional de Adaptación de Costa Rica forma parte de un conjunto de instrumentos de planificación estratégica en el marco del proceso de formulación de su Plan Nacional de Adaptación La Política se plantea como el marco rector que orientará las acciones del país en materia de adaptación. Asimismo, es un paso concreto hacia el cumplimiento con el compromiso de formular el Plan Nacional de Adaptación, adquirido en el marco de sus Contribuciones Nacionalmente Determinadas (NDC, por sus siglas en inglés) dentro del Acuerdo de París.

La PNACC tiene 6 ejes, que se desarrollan en su respectivo Plan de Acción. Para cada eje se define un objetivo de política y los lineamientos que la integran. Algunos ejes son estratégicos y otros son sustantivos. 


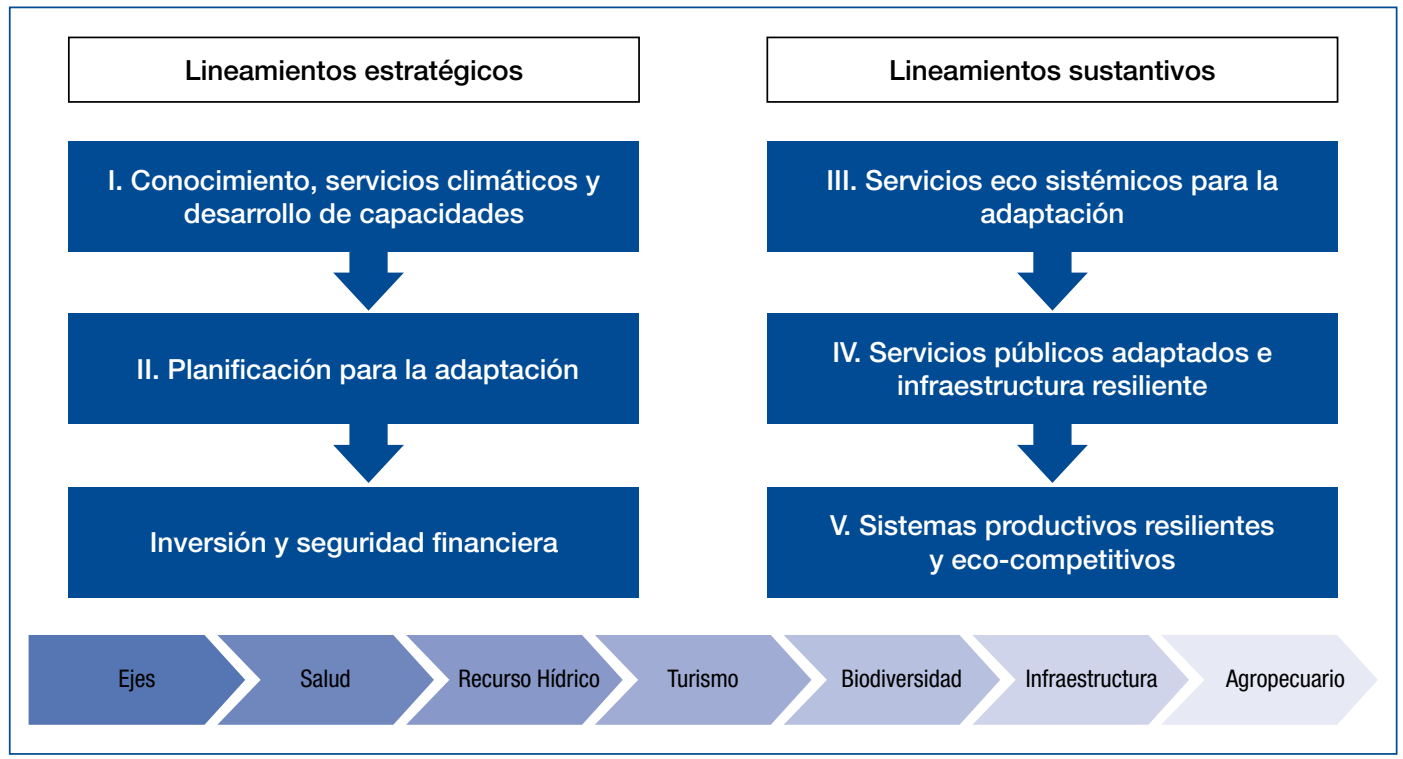

\section{Figura 4.2 Lineamientos instrumentales y sustantivos de la Política y los ejes del Plan Nacional de Adaptación \\ Fuente: Elaboración propia, adaptado de PNACC (2018), Costa Rica, p. 60}

Todos estos ejes y lineamientos desarrollan los elementos necesarios para un entorno propicio para la gobernanza para la AbE, tales como la creación y fortalecimiento de capacidades; la generación, recolección y difusión de información y evidencia de cambio climático, servicios ambientales, entre otros. Específicamente en relación a la $\mathrm{AbE}$, se destaca el eje 2, que reconoce que el punto de partida para fomentar la resiliencia de los sistemas humanos y naturales, es la planificación territorial, marina y costera. Asimismo, reconoce que el punto de partida del ordenamiento territorial debe ser la adaptación al cambio climático. Se hace un fuerte énfasis en los instrumentos de planificación municipal y comunal.

Por otra parte, es importante integrar la AbE en planes sectoriales, la capacitación de las instituciones ambientales para implementar la política, además de promover la conservación y restauración de ecosistemas terrestres y marino-costeros que proveen servicios ambientales que favorecen la adaptación.

Cabe recordar que la participación pública constituye un requisito para la legitimidad y la calidad de las políticas, por lo que se deben crear espacios y mecanismos de participación desde las etapas más tempranas posibles, es decir, desde la etapa de preparación para la evaluación de vulnerabilidad.

Uno de los grandes retos para implementar una política marco de adaptación en relación a la elaboración de planes regionales y locales que incorporen medidas de $\mathrm{AbE}$ es la incertidumbre sobre los impactos del cambio climático en los ecosistemas y la complejidad que involucra entender los sistemas socio-ecológicos. En muchas ocasiones la información no está disponible a escalas locales y, de estarlo, los modelos de escenarios climáticos son insuficientes para entender los 
impactos que la variabilidad climática tendrá sobre los sistemas socio-ecológicos. En este contexto, es importante que los gobiernos nacionales desarrollen instrumentos que faciliten la toma de decisiones y la planificación de la adaptación a escalas locales.

\section{Ejemplo: Atlas Nacional de Vulnerabilidad al Cambio Climático de México}

El Instituto Nacional de Ecología y Cambio Climático (INECC) elaboró el Atlas Nacional de Vulnerabilidad ante el Cambio Climático (ANVCC) con el fin de desarrollar, consolidar y modernizar los instrumentos necesarios para la reducción de la vulnerabilidad ante el cambio climático.

El ANVCC es una herramienta para la toma de decisiones e incidencia en política pública que contribuye en la identificación de acciones de adaptación que se pueden implementar para disminuir la vulnerabilidad al cambio climático, además de ser una guía para cumplir con las Contribuciones Nacionalmente Determinadas (NDC por sus siglas en inglés) en los tres órdenes de gobierno. Tiene como objetivo establecer un conjunto estructurado y sistemático de mapas que muestren la vulnerabilidad territorial ante el cambio climático y orienten la realización de estrategias dentro del proceso de adaptación. El ANVCC tiene un alcance a nivel nacional y la resolución máxima de la información es a nivel municipal. ${ }^{8}$

\subsection{Ley}

La Política debe identificar las diversas leyes o normas que permiten su puesta en marcha, o que requieren una modificación para alinearse a los objetivos sociales establecidos en la política de adaptación. De hecho, muchos planes nacionales de adaptación al cambio climático presentan como uno de sus objetivos generales la inclusión explícita de la adaptación al cambio climático en la normativa sectorial (Boer \& Clarke, 2012; Plan Nacional de Adaptación al Cambio Climático del Reino de España).

Dicha integración debería ser transversal en todas las fuentes del derecho, entre otras, los tratados internacionales, las constituciones nacionales, las leyes, los reglamentos, las decisiones judiciales, los principios generales de derecho, los instrumentos y actos administrativos, los acuerdos, estándares, usos y costumbres, y prácticas tradicionales obligatorias (Martin, Boer \& Slobodian (eds.), 2016).

Además de las leyes de cambio climático (cuando las hay), las ambientales y las sectoriales, son relevantes las leyes de la administración pública y otras normas indirectas que se relacionan o tienen impactos en los ecosistemas y sus servicios; por ejemplo, las leyes fiscales y de finanzas -que pueden crear incentivos o efectos disuasivos en la gestión de los ecosistemas y sus servicios-, la planificación para el desarrollo y la recolección de datos -que es la base para el desarrollo de instrumentos para la gobernanza de los ecosistemas-. También se resaltan las leyes sobre los derechos de propiedad de la tierra -que puede influir sobre el acceso a los servicios ecosistémicos-; y las leyes relativas a la participación pública (Greiber \& Schiele, 2011).

8 SEMARNAT; INECC. Atlas Nacional de Vulnerabilidad al Cambio Climático México. Disponible en: https:// atlasvulnerabilidad.inecc.gob.mx/page/fichas/marcoConceptual.pdf 


\begin{tabular}{|c|c|c|}
\hline \multicolumn{2}{|l|}{ Materia } & Ejemplos de normativa \\
\hline & $\begin{array}{l}\text { Leyes y programas en materia } \\
\text { de planeación y cambio } \\
\text { climático }\end{array}$ & $\begin{array}{l}\text { - Constitución } \\
\text { - Contribuciones Determinadas a Nivel Nacional (NDC) } \\
\text { - Estrategia y Plan de Acción Nacional para la Biodiversidad } \\
\text { - Planes/estrategias nacionales de planeación } \\
\text { - Planes y estrategias de cambio climático/adaptación } \\
\text { - Leyes de planeación } \\
\text { - Leyes de protección ambiental o recursos naturales } \\
\text { - Leyes de cambio climático } \\
\text { - Planes y estrategias sectoriales }\end{array}$ \\
\hline & $\begin{array}{l}\text { Leyes y programas en materia } \\
\text { de gestión de riesgos de } \\
\text { desastres }\end{array}$ & $\begin{array}{l}\text { - Ley de asentamientos humanos } \\
\text { - Leyes humanitarias } \\
\text { - Ley de ordenamiento territorial y desarrollo urbano } \\
\text { - Leyes de protección civil }\end{array}$ \\
\hline & $\begin{array}{l}\text { Leyes y programas en } \\
\text { materia de medio ambiente, } \\
\text { recursos naturales } \mathbf{y} \\
\text { biodiversidad }\end{array}$ & $\begin{array}{l}\text { - Leyes agrarias } \\
\text { - Leyes de aguas } \\
\text { - Leyes de biodiversidad } \\
\text { - Leyes de bioseguridad } \\
\text { - Leyes de desarrollo rorestal } \\
\text { - Leyes de desarrollo rural } \\
\text { - Leyes de pesca y acuacultura } \\
\text { - Leyes de responsabilidad ambiental } \\
\text { - Leyes de sustentabilidad ambiental } \\
\text { - Leyes de vida silvestre } \\
\text { - Leyes de la calidad del aire y protección a la atmósfera } \\
\text { - Ley para la conservación y restauración de las tierras } \\
\text { - Ley para la gestión integral y sustentable de las costas/bosques }\end{array}$ \\
\hline 青囯 & $\begin{array}{l}\text { Leyes y programas con } \\
\text { incidencia en el marco } \\
\text { institucional }\end{array}$ & - Leyes de la administración pública \\
\hline W19 & $\begin{array}{l}\text { Leyes y programas } \\
\text { con incidencia en la } \\
\text { financiación }\end{array}$ & $\begin{array}{l}\text { - Leyes financieras del sector privado (por ejemplo, bancos, casas de } \\
\text { bolsa, aseguradoras, afianzadoras, arrendadoras financieras, } \\
\text { sociedades de objeto múltiple) } \\
\text { - Leyes de finanzas públicas (leyes de ingresos/ejercicios fiscales; } \\
\text { presupuesto de egresos del año fiscal; código fiscal; leyes de } \\
\text { impuestos; fondos gubernamentales; leyes relativas a la deuda pública) } \\
\text { - Leyes de instituciones de seguros, fondos y fideicomisos } \\
\text { - Leyes sobre el contratos de seguros }\end{array}$ \\
\hline & $\begin{array}{l}\text { Leyes y programas con } \\
\text { incidencia en la rendición de } \\
\text { cuentas }\end{array}$ & $\begin{array}{l}\text { - Ley de contabilidad gubernamental } \\
\text { - Leyes de fiscalización y rendición de cuentas } \\
\text { - Leyes de ingresos } \\
\text { - Leyes de presupuesto y responsabilidad hacendaria } \\
\text { - Leyes de responsabilidades de los servidores públicos } \\
\text { - Leyes de transparencia y acceso a la información pública }\end{array}$ \\
\hline$\Rightarrow$ & $\begin{array}{l}\text { Leyes y programas } \\
\text { transversales }\end{array}$ & $\begin{array}{l}\text { - Códigos civiles } \\
\text { - Códigos penales } \\
\text { - Leyes relativas a los derechos de los pueblos indígenas } \\
\text { - Leyes sobre la igualdad de género } \\
\text { - Leyes sobre responsabilidad ambiental }\end{array}$ \\
\hline
\end{tabular}

Figura 4.3 Identificación de la normativa relevante para la Abe 


\subsubsection{La Ley y la adaptación al cambio climático}

En la última década se ha venido observando una tendencia hacia el desarrollo de leyes específicas en materia de cambio climático, ${ }^{9}$ ya que como dijo la exsecretaria Ejecutiva de la CMNUCC "Nothing is going to be agreed internationally until enough is legislated domestically" (Figueres, 2013). Se considera que las leyes de cambio climático no sólo apoyan sino también facilitan la implementación del Acuerdo de París (Nachmany \& Setzer, 2018).

En ocasiones, la Ley también es vista como una barrera para la adaptación al cambio climático dado que tiene que tratar con la complejidad derivada de los siempre cambiantes, impredecibles y no lineales efectos del cambio climático en los ecosistemas y sus servicios. Por ello, una ley para la adaptación no debe ser conservacionista en el sentido de preservar el status quo actual, ni de cambiar a otro nuevo y estable status quo, sino que debe ser dinámica y adaptable en sí misma (Craig, 2010).

Aunque pudiera parecer contradictorio, la Ley también tiene un rol fundamental en la eliminación de barreras a los procesos de gestión adaptativa, al establecer las condiciones para la integración de sectores que hasta ahora han operado de manera aislada y asegurar que los procesos de planificación sean participativos. Asimismo, la Ley puede dar estabilidad a las instituciones a la vez que garantiza que los objetivos sustantivos de los instrumentos regulatorios permanezcan flexibles y sustentados en la información relevante sobre el cambio climático. Finalmente, la Ley también permite establecer normas para la creación de capacidades para la adaptación (Cosens et al., 2017).

El cambio climático puede alterar las características de los ecosistemas, por lo que las leyes que los regulan deberían contar con instrumentos que les permitan ajustarse a las transformaciones ecológicas, en vez de intentar congelar la composición de los ecosistemas al estado en que se encontraban al momento de regularlos. El nuevo paradigma de las leyes ambientales y de los recursos naturales debería de ser el de aumentar la resiliencia y la capacidad adaptativa de los humanos, de las especies, de la sociedad y de los ecosistemas (Craig, 2010). Esto es precisamente lo que la AbE procura realizar.

Craig presenta cinco recomendaciones generales para que las leyes puedan promover la capacidad adaptativa de los ecosistemas:

1. Promover y canalizar fondos para la investigación y el monitoreo de los impactos del cambio climático a todas las escalas y en todos los sectores. Ello con el fin de contar con mayor información y conocimiento sobre los efectos del cambio climático sobre ecosistemas concretos. Dicha información brinda orientación importante para evitar la implementación de medidas de adaptación demasiado simplistas que comprometan las capacidades adaptativas futuras. Asimismo, el contar con información robusta y oportuna, puede ayudar a superar los impedimentos o barreras políticas o sociales para implementar medidas de adaptación.

\section{Eliminar o reducir el estrés no climático sobre los ecosistemas y promover su resilien-} cia. Se refiere a la adopción inmediata de medidas que reducirán los impactos negativos de las actividades humanas sobre los ecosistemas, mejoren la salud ambiental y humana, y contribuyan a la sostenibilidad. Entre dichas medidas se puede mencionar:

9 El Grantham Research Institute on Climate Change and the Environment tiene un repositorio de 1522 leyes de cambio climático de diversos niveles de gobierno en todo el mundo. Ver: http://www.lse.ac.uk/ GranthamInstitute/climate-change-laws-of-the-world/ (Consultado el 1 de abril de 2019). 
a. Aumentar los estándares ambientales para reducir la contaminación, la degradación de los suelos, la destrucción de hábitats y la pérdida de biodiversidad, promover la innovación científica, y aumentar el aporte de recursos económicos públicos para estos fines.

b. Reevaluar las cuotas de aprovechamiento de recursos naturales para hacerlas sustentables.

c. Eliminar los subsidios que alientan medidas de adaptación equivocada (mal-adaptación) y crear incentivos para aumentar la capacidad adaptativa.

d. Proteger y expandir los espacios abiertos y la conectividad entre los ecosistemas, con el propósito de permitir que las dinámicas entre especies y dentro de los ecosistemas encuentren sus propias respuestas de adaptación al cambio climático.

3. Planificar a largo plazo con una mayor coordinación entre sectores, gobiernos e intereses. Las leyes para la adaptación al cambio climático deben incluir mecanismos que permitan y promuevan la planificación para la adaptación y su implementación en una variedad de escalas temporales y espaciales simultáneamente. Los siguientes sub-principios pueden facilitar la incorporación de los aspectos multidimensionales:

a. Incorporar el cambio climático en los instrumentos de planificación de todos los niveles de gobierno.

b. Ponderar una gama de posibles escenarios climáticos futuros a largo plazo durante el proceso de planificación.

c. Aumentar la coordinación regulatoria entre las diversas leyes sectoriales.

d. Mejorar la coordinación regulatoria entre órganos gubernamentales.

e. Dar mayor peso a la función ecológica de la propiedad para balancear los intereses públicos y privados.

4. Promover la flexibilidad basada en los objetivos de regulación y la gestión de los recursos naturales. Esto incluye flexibilizar la gestión de los recursos naturales, incorporando los procedimientos de la gestión adaptativa. Algunas recomendaciones para flexibilizar los marcos jurídicos son, por un lado, establecer un principio para preferir las medidas de adaptación "sin arrepentimiento" (como las descritas en la recomendación 2, párrafos arriba) y, por otro lado, establecer procesos sólidos de toma de decisiones para estrategias de adaptación que impliquen inversiones importantes de recursos.

5. Aceptar que algunas pérdidas serán inevitables. Las leyes para la adaptación deben reconocer que algunas pérdidas son inevitables, pero deben prevenir la inacción ante pérdidas evitables.

De lo anterior se puede rescatar que dada la complejidad y la incertidumbre relacionada con la adaptación al cambio climático, la adopción de medidas que ayudarán a mejorar la capacidad adaptativa de los ecosistemas y de las personas en cualquier escenario, deberían ser un imperativo en las leyes relacionadas con la adaptación.

\subsubsection{Principios de Derecho para la AbE}

Los principios son los postulados básicos que ayudan a interpretar las leyes y a orientar la toma de decisiones en casos de conflicto, al establecer directrices y prioridades al momento en que un juez, por ejemplo, se enfrenta con la necesidad de ponderar entre intereses y derechos excluyentes 
entre sí. Algunos principios de derecho ambiental son especialmente importantes para fomentar e implementar medidas de AbE.

Entre los más relevantes corresponde mencionar los siguientes:

- Principio de precaución, también conocido como in dubio pro natura. Cuando haya peligro de daño grave o irreversible, la falta de certeza científica absoluta no deberá utilizarse como razón para postergar la adopción de medidas eficaces en función de los costos para impedir la degradación del medio ambiente (Sands, 1995). La característica más distintiva de este principio es que se refiere al buen gobierno y la toma de acción ante un riesgo incierto o dudoso.

La complejidad de las interrelaciones de los ecosistemas, aunado a la incertidumbre asociada al cambio climático, hacen del principio de precaución la piedra angular de la toma de decisiones en relación a planes, programas y proyectos de desarrollo con el fin de evitar acciones que lleven a una adaptación equivocada y aumenten la vulnerabilidad de los ecosistemas y las personas al cambio climático.

- Principio de prevención. El principio de prevención implica la utilización de mecanismos, instrumentos y políticas con el objetivo de evitar daños serios al ambiente y la salud de las personas. A diferencia del principio de precaución, este principio atiende a la debida diligencia y al riesgo cierto.

Este principio favorece la aplicación de todas las herramientas disponibles para prevenir y evitar daños a los ecosistemas y sus servicios, por ejemplo, las EAE y las EIA. Su aplicación para la $\mathrm{AbE}$ es importante porque dicta la necesidad de valorar los impactos de las actividades económicas y productivas, tomando en cuenta la variable del cambio climático al diseñar y decidir sobre planes, programas y proyectos de desarrollo.

- Principio de proporcionalidad. Este principio dicta que, si existen varias alternativas de acción razonables, deben elegirse las menos dañinas para el medio ambiente (Proyecto de Pacto Internacional sobre Medio Ambiente y Desarrollo).

Puede darse el caso en que la construcción de alguna infraestructura, por ejemplo, un parque eólico tenga más impactos sobre los ecosistemas, dependiendo del sitio donde se ubique o la tecnología que se utilice. Habiendo varias opciones de dónde ubicar el parque, este principio facultaría a los tomadores de decisiones a elegir la opción que menos impactos produzca sobre el equilibrio ecológico, con el fin de prevenir la degradación de los ecosistemas.

- Principio de no regresión. El principio de no regresión determina que la normativa y la jurisprudencia ambiental no deberían retroceder respecto a los niveles de protección alcanzados con anterioridad. Tiene como finalidad evitar la supresión normativa o la reducción de sus exigencias por intereses contrarios que no logren demostrar ser jurídicamente superiores al interés público ambiental.

Este principio es de suma relevancia para la gobernanza para la AbE, pues sirve como candado para evitar retrocesos durante los procesos de ajuste de los marcos normativos al momento de alinearlos a nueva información disponible sobre el cambio climático, la salud de los ecosistemas y el impacto de las acciones implementadas hasta el momento.

- Principio de la soberanía permanente sobre los recursos naturales. De acuerdo con este principio se entiende que los pueblos y las naciones tienen derecho a decidir sobre el 
uso de los recursos naturales en interés del desarrollo nacional y del bienestar del pueblo del respectivo Estado.

Un aspecto de este principio de la relevancia para la gobernanza para la AbE en que el uso de los recursos naturales debe hacerse tomando en cuenta el bienestar el pueblo. Ello podría indicar a un juez o un tomador de decisiones que considere los servicios ambientales como un elemento central del bienestar humano, al momento de decidir sobre el uso de los recursos naturales.

- Utilización equitativa y razonable de los recursos naturales y la biodiversidad. Este principio tiene una dimensión interna y una dimensión internacional. En la dimensión interna supone el deber del Estado y de las personas de proteger las riquezas naturales de la nación para garantizar su desarrollo sostenible, su conservación o restauración, junto con un deber de intervenir en la explotación de los recursos naturales para racionalizar la economía con el fin de mejorar la calidad de vida de los habitantes, la distribución equitativa de las oportunidades, los beneficios del desarrollo y la protección de un medio ambiente sano (art. 8 y 334 de la Constitución Política de Colombia (Amaya, 2002). En su dimensión internacional supone un límite a la soberanía territorial y manda a los Estados a tomar en cuenta las necesidades y uso de los bienes y servicios ambientales por parte de los Estados que comparten un mismo ecosistema, por ejemplo, en una cuenca hidrográfica. Al analizar el uso equitativo y razonable de los recursos compartidos, los Estados deben tomar en cuenta las condiciones geográficas, los usos de los recursos, la población que depende de ellos, las necesidades económicas y sociales actuales y futuras, y cómo los factores climáticos y ecológicos pueden afectar la disponibilidad del recurso (Art. 6 de la Convención sobre el derecho de los usos de los cursos de agua internacionales para fines distintos de la navegación).

Ambas dimensiones son importantes para la $\mathrm{AbE}$, ya que establecen directrices sobre los distintos factores que se deben de tomar en cuenta al momento de decidir sobre el uso de los recursos naturales y sientan las bases para una cooperación internacional para la gestión compartida de los recursos naturales.

- Principio de subsidiariedad. La idea central de la subsidiariedad es que la gestión de los ecosistemas debe ser al nivel más directo posible y cuando ello no sea posible o requiere de apoyo o coordinación con otros gobiernos del mismo nivel, se debería involucrar un gobierno de mayor jerarquía. Algunas directrices para su implementación en el contexto del cambio climático podrían incluir:

- Las localidades toman la iniciativa y tienen autonomía para liderar las acciones de adaptación, sin afectar otras localidades estados o departamentos (Flatt, 2012).

- Los estados/departamentos intervienen, en calidad de coordinador, cuando: i) un ecosistema o una medida de AbE requiere la participación de dos o más localidades; ii) cuando una localidad no ha tomado la iniciativa para tomar medidas de adaptación o de restauración de ecosistemas; iii) a solicitud de la localidad.

- El gobierno federal/central interviene, en calidad de coordinador, cuando: i) el ecosistema de intervención es transfronterizo; ii) un ecosistema o una medida de AbE requiere la participación de dos o más estados/departamentos; iii) el gobierno local y estatal no han intervenido para la adaptación; iv) a solicitud de uno o más estados/departamentos.

Es un principio que promueve el fortalecimiento de las iniciativas locales, de manera coordinada para alcanzar objetivos globales, como los del ODS y la adaptación (Vasseur, 2017). 
- Principio de solidaridad. Implica que los Estados deberán cooperar con espíritu de solidaridad mundial para conservar, proteger y restablecer la salud y la integridad de los ecosistemas.

Su importancia para la $\mathrm{AbE}$ es que se trata de un deber amplio de cooperación que puede incluir todas sus formas, la investigación, la recolección de información climática, la financiación, el fortalecimiento de capacidades, entre otros.

- Principio de transparencia y rendición de cuentas. Implica el deber de las autoridades públicas de proveer información a la ciudadanía sobre la dirección de los asuntos públicos.

Es de especial importancia en relación al combate a la corrupción asociada a la gestión de los recursos naturales o al erario público (ver capítulo 6, Negociación).

- Principio de responsabilidad ambiental. Implica que la persona, física o jurídica, que haya dañado el medio ambiente, tiene la obligación de restaurar al estado en que se encontraba y compensar por el daño causado.

Además, la propiedad privada es un derecho fundamental en la mayoría de las Constituciones nacionales que faculta para usar, disfrutar y disponer del bien libremente, sin otra limitación que las establecidas por la ley propiamente dicha o un contrato. Como derecho fundamental la propiedad goza de garantías constitucionales y sólo puede ser limitado por motivos de interés público o utilidad social (tales como la expropiación), mediante sentencia judicial e indemnización previa. Algunas Constituciones nacionales, tales como la alemana y la colombiana, establecen límites a la propiedad en razón de su importancia para la consecución de fines sociales, entre ellos, la salud de los ecosistemas de los cuales depende el bienestar de las personas. Si bien no se trata de un principio internacionalmente reconocido, constituye un ejemplo importante del papel que cumple la Ley para la protección de los ecosistemas, especialmente cuando resulta necesario ponderar entre el interés público y los derechos individuales.

\subsubsection{Integración de la AbE en marcos jurídicos ambientales, sectoriales y de los recursos naturales}

\section{Ecosistemas terrestres}

Entre los principales mecanismos para aumentar la resiliencia de los ecosistemas terrestres se pueden mencionar los siguientes (Boer \& Clarke, 2012):

- Áreas naturales protegidas (ANP). Se definen como "un espacio geográfico claramente definido, reconocido, dedicado y gestionado, mediante medios legales u otros tipos de medios eficaces, para conseguir la conservación a largo plazo de la naturaleza y de sus servicios ecosistémicos y sus valores culturales asociados" (Lausche, 2011). Las ANP son esenciales para la conservación de la biodiversidad y el mantenimiento de los servicios ecosistémicos en un contexto de cambio climático.

El cambio climático modifica la composición de los ecosistemas y hace que el reto principal de este mecanismo legal sea el de flexibilizar sus límites geográficos (Tanner-McAllister et al., 2017). Para dar respuesta a este reto se propone la adopción de la gestión adaptativa en los planes de gestión de áreas protegidas, así como el fortalecimiento de la conectividad ecológica.

Ejemplo: Las áreas naturales protegidas (ANPs) en la Ley de Cambio Climático del Estado de Chiapas (LCC) 
La LCC de Chiapas, en México incluye las ANP como el principal instrumento para la adaptación al cambio climático (art. 29) en la entidad federativa, haciendo expresa mención de su importancia para aumentar la capacidad adaptativa de las personas y de los ecosistemas y para el mantenimiento de los servicios ecosistémicos (Art. 30). Establece también el mandato de incorporar los componentes de la adaptación y la mitigación al cambio climático en el decreto de creación y en el programa de manejo de las ANP (Art. 31).

Al incorporar la adaptación, esta ley promueve que tanto el decreto de creación como el programa de manejo incluyan, para su diseño, una evaluación de vulnerabilidad de los ecosistemas, asegurando sus servicios.

- Bosques. Los ecosistemas de bosque juegan un papel esencial en el ciclo del agua, albergan una gran diversidad de especies y funcionan como sumideros de carbono. Para mantener la función de sumidero de carbono de los bosques y la provisión de servicios ecosistémicos, Boer y Clarke recomiendan que las leyes tengan por objetivo prevenir la pérdida de cobertura forestal a través de la introducción de disposiciones que obliguen a la elaboración de inventarios forestales, la preparación de planes de recolección sostenible, el establecimiento de sanciones disuasorias por infracciones a las leyes forestales, la creación de obligaciones de reforestación en áreas deforestadas, y el diseño de fianzas para la rehabilitación ambiental. (Boer \& Clarke, 2012).

- Gestión de recursos hídricos. Las leyes de agua deben incluir mecanismos efectivos para la protección y gestión de las fuentes, incluyendo restricciones en la tala de bosques en zonas de recarga hídrica. En cuanto a la calidad del agua, como ya se indicara, se deben aumentar los controles para la contaminación; las leyes deben garantizar restricciones en el uso del agua para garantizar la protección de los ecosistemas al mismo tiempo que se asegura el agua potable para las poblaciones humanas (Boer \& Clarke, 2012).

\section{Ecosistemas marinos y costeros}

Los manglares y otros ecosistemas costeros cumplen roles significativos en la adaptación al cambio climático. Estos prestan servicios de estabilización de áreas costeras, litorales y la regulación de las tormentas, protegiendo asentamientos humanos.

1. Gestión de costas. Entre las recomendaciones para promover la $\mathrm{AbE}$ en las leyes que regulan las costas se destacan: protección de los manglares de usos insostenibles tales como recolección indiscriminada de fauna y flora asociadas, deforestación y cambios en la línea costera; control de la escorrentía de nutrientes y de los sedimentos que fluyen hacia las aguas costeras; entre otras.

2. Gestión de la pesca. Las herramientas de gestión de la pesca requieren incorporar el enfoque de AbE para evitar la sobre-explotación de los recursos pesqueros y mantener la salud de los ecosistemas costeros y los medios de vida de las comunidades locales. Las leyes de este sector podrían mejorar la salud de los ecosistemas por ejemplo por medio de la prohibición de métodos destructivos de pesca, la protección de zonas de desove, establecimiento de controles para el otorgamiento de las licencias donde existan zonas de prohibición, la protección de determinadas especies de peces, entre otras.

3. Áreas Marinas Protegidas. Con el objeto de maximizar la resiliencia de los ecosistemas marinos, las áreas marinas protegidas deberián poseer, entre otras, las siguientes características: ser áreas amplias con configuraciones simples; representar y replicar múltiples hábitats 
y parámetros físicos, dispersos en amplias áreas geográficas para minimizar los riesgos; protección de las características ecológicas que promuevan la resiliencia y la recuperación ante eventos meteorológicos extremos; y el mantenimiento de la conectividad de los hábitats y los procesos ecológicos (Boer \& Clarke, 2012).

\subsection{Herramientas de implementación relevantes para la AbE}

La Ley debe proveer los instrumentos, mecanismos, procesos y responsabilidades para la implementación de la Política. Los mecanismos de implementación para la AbE deben incluir, entre otros, esquemas de pago por servicios ambientales, incentivos para la reforestación, proyectos de reducción de emisiones de $\mathrm{CO}_{2}$ por deforestación evitada (REDD), establecimiento de áreas protegidas. Podría decirse que todo instrumento de conservación o restauración que tenga por objeto aumentar la resiliencia de los ecosistemas y de las personas, podría considerarse como un mecanismo de implementación para la AbE.

Los principales mecanismos para incrementar la resiliencia de los ecosistemas existentes y que los marcos jurídicos para la AbE podrían fortalecer son los siguientes:

1. La planificación territorial estratégica,

2. Las evaluaciones ambientales estratégicas y evaluaciones de impacto ambiental.

\subsubsection{Planificación territorial para la AbE}

La planificación territorial estratégica es, en términos generales, un instrumento para el ordenamiento espacial del territorio que va más allá de la planificación rural/urbana tradicional, y que tiene en cuenta impactos e influencias de otras políticas sectoriales, espacios geográficos y el uso de los recursos naturales tanto terrestres como marinos, así como otros factores como el cambio climático y los riesgos de desastres. Su objetivo es planificar las necesidades de desarrollo futuro y las oportunidades en jurisdicciones específicas, teniendo en cuenta las políticas relevantes en el área de manera tal de promover una distribución más equitativa del desarrollo económico (Lausche, 2018; Rozas-Vásquez, et al., 2018).

Definir la escala espacial adecuada de intervención paraasegurar el funcionamiento de los ecosistemas es una de las principales dificultades de la integración de la AbE en instrumentos de planificación territorial integral. Esto se debe al hecho de que la provisión y demanda de servicios ecosistémicos varía en los niveles local, regional y global, afectando a una amplia gama de actores interesados. Para hacer frente a este reto, los diferentes niveles de gobierno que tienen competencias para adoptar decisiones sobre temas vinculado con ecosistemas, actividades económicas, relaciones entre áreas rurales y urbanas, y demarcaciones político-administrativas deberían coordinarse para implementar medidas de AbE.

La planificación territorial estratégica presenta el potencial de incorporar los servicios ecosistémicos en múltiples niveles de gobernanza ya que surte los efectos de una plataforma para coordinar distintos instrumentos de política de manera estratégica y articulada y para tomar decisiones respecto a cambios futuros en los sistemas terrestres, costeros y marinos.

La planificación, como proceso, es expresa a través de los planes de ordenamiento territorial, mismos que se elaboran conforme a los procesos y las herramientas establecidos por la ley (generalmente la ley de uso de suelo). 
Una vez que los planes son adoptados, estos tienen implicaciones legales al regular las actividades que se pueden desarrollar en el área cubierta por el plan, es decir, son instrumentos reguladores. Por lo general hay una jerarquía de planes, a nivel nacional, regional y local, y la ley obliga a que aquellos de menor jerarquía mantengan coherencia con los de mayor jerarquía, asegurando así una coordinación normativa vertical (Lausche et. al., 2013).

La integración efectiva de la resiliencia climática en la planificación territorial requiere el posicionamiento de las comunidades locales en el centro de los procesos de toma de decisiones sobre los futuros usos de la tierra. Asimismo resulta importante que se reconozca a la AbE como una respuesta costo-eficiente para hacer frente a los efectos del cambio climático; y que se implementen los planes haciendo el mejor uso posible de los limitados recursos humanos y financieros.

La integración del enfoque de AbE en los instrumentos de planificación territorial requiere que se evalúen los impactos actuales y potenciales del cambio climático sobre los usos de tierra, y los ecosistemas marinos y costeros.

La planificación territorial debería integrar medidas de AbE coherentes con los distintos usos de suelo, garantizando la conectividad entre los ecosistemas y haciendo visibles los servicios ecosistémicos que crean relaciones de interdependencia entre las áreas rurales, urbanas e industriales.

Uno de los retos asociados a todo este proceso consiste en la necesidad de usar una combinación de sistemas de información geográfica y otra información espacial, pues en ocasiones las tecnologías o las capacidades necesarias no están disponibles. Otro reto tiene que ver con el involucramiento de todos los actores clave, pues en definitiva, la planificación territorial es, ante todo, un proceso de negociación.

\subsubsection{Evaluación Ambiental Estratégica y la Evaluación de Impacto Ambiental}

La evaluación ambiental estratégica (EAE) y la evaluación de impacto ambiental (EIA) son dos instrumentos de gestión ambiental que persiguen prevenir y controlar los impactos negativos de origen antropogénico sobre el medio ambiente. La diferencia entre ambas radica, especialmente, en su ámbito de aplicación. Mientras la EIA aplica las actividades, obras o proyectos, la EAE tiene un alcance más amplio y permite evidenciar las oportunidades, riesgos, amenazas y potencialidades, basándose en la sostenibilidad (ver cuadro 4.2). 


\section{Cuadro 4.2 Comparación entre los alcances de la EAE y la EIA}

\begin{tabular}{|l|l|l|}
\hline Objeto & EAE & EIA \\
\hline $\begin{array}{l}\text { Responsable de } \\
\text { Ilevarla a cabo } \\
\text { mas }\end{array}$ & A cargo de la administración pública & $\begin{array}{l}\text { A cargo del titular, propietario o repre- } \\
\text { sentante legal de una actividad, obra o } \\
\text { proyecto }\end{array}$ \\
\hline Alcance & $\begin{array}{l}\text { Permite visualizar impactos a nivel } \\
\text { macro y acumulativos }\end{array}$ & $\begin{array}{l}\text { Permite visualizar los impactos única- } \\
\text { mente en el área de influencia del pro- } \\
\text { yecto }\end{array}$ \\
\hline $\begin{array}{l}\text { Momento dentro del } \\
\text { proceso de escala- } \\
\text { miento de la AbE }\end{array}$ & Planificación para la AbE & Implementación de la AbE \\
\hline
\end{tabular}

La EAE es un instrumento de apoyo en la toma de decisiones, en forma de proceso, y que se aplica a decisiones de naturaleza estratégica, típicamente conocidas como políticas, planes y programas. Informa a los planeadores, decisores y público afectado acerca de la sustentabilidad de las decisiones estratégicas, facilitando la búsqueda de mejores alternativas y asegurando un proceso de decisión democrático (Lobos, 2015).

La EIA es una herramienta preventiva sobre mediante la cual se evalúan los impactos negativos y positivos que los proyectos generan sobre el medio ambiente, y se proponen alternativas para ajustarlos a niveles de aceptabilidad. El impacto ambiental es "toda alteración significativa de los sistemas naturales y transformado y de sus recursos, provocada por acciones humanas (...) Los impactos se expresan en las diversas actividades y se presentan tanto en ambientes naturales, como en aquellos que resultan de la intervención de y creación humana". Dicho impacto debe interpretarse en sentido amplio, incluyendo los posibles efectos sociales y económicos negativos y positivos, así como los efectos sobre el patrimonio cultural y paisajístico (Aguilar \& Iza, 2009).

La EAE y la EIA son instrumentos similares y complementarias. El carácter estratégico de la primera le permite considerar los impactos indirectos, acumulados y sinérgicos de las actividades en un ámbito espacial y temporal que las EIA no logran considerar puesto que su objeto es únicamente actividades, obras y proyectos concretos (Lobos, 2015). Por su parte, la EIA analiza los impactos en un espacio mucho más definido de lo que las EAE logran estudiar.

La EAE tiene siete fases, según las recomendaciones de la Comisión Económica para América Latina y el Caribe (CEPAL, 2009):

Fase 1. Establecimiento del Marco Ambiental Estratégico. Esta fase tiene como objetivo fundamental definir las bases de la EAE y sus objetivos específicos.

Fase 2. Alcance de EAE. En esta fase se inician las consultas con los agentes sociales (las autoridades con competencia en el plan y otros grupos de interés), con el fin de acordar el alcance de la EAE y su nivel de detalle.

Fase 3. Modelo de Evaluación. En esa fase se realiza un diagnóstico ambiental estratégico del ámbito de política que está siendo sujeto de una planificación y se evalúan las opciones alternativas que se van elaborando en el proceso de planificación. 
Fase 4. Análisis y Diagnóstico Ambiental. Esta fase se trata de describir con el mayor grado de precisión deseable la dimensión ambiental estratégica del plan para sentar esa visión como eje de evaluación del plan. El objetivo es disponer de una visión muy clara de las dinámicas ambientales sectoriales más relevantes, y de su comportamiento pasado y comprender los retos ambientales más importantes para el plan.

Fase 5. Evaluación Ambiental de Opciones Alternativas. La fase de evaluación ambiental de opciones es un proceso iterativo, en el cual se evalúan las opciones consideradas en diferentes momentos de elaboración del plan. La CEPAL considera tres momentos relevantes de cara a la EAE: i) el de definición de los objetivos operativos del plan, ii) el de definición de las opciones estratégicas y iii) el del desarrollo de opciones operativas.

Fase 6. Prevención y Seguimiento. En esta fase la EAE se recapitula y se generan recomendaciones al proceso de implementación del plan que se hayan derivado del ejercicio llevado a cabo. Se proponen las medidas ambientales o instrumentos de gestión ambiental directa que deberá incorporar el plan y las medidas o instrumentos para su seguimiento ambiental.

Fase 7. Elaboración y Consulta de Informes Finales. El proceso de EAE finaliza con la fase de elaboración y consulta de informes finales. Tras las consultas se debe informar sobre el alcance de los comentarios en la formulación final del plan, tanto de los resultados de las fases previas del proceso de evaluación, como del proceso final de consultas. En las fases anteriores se han llevado a cabo procesos de participación, por lo que esta no comienza, sino que se cierra en esta última fase.

Las EAE son procesos clave para la incorporación de la AbE en las políticas, planes y programas de desarrollo y sectoriales, por ello, la UNEP propone que se integren los servicios ecosistémicos como una variable más dentro de lo que se debe de evaluar (UNEP, 2014). Al llevar la recomendación a la práctica se puede establecer el contexto del ecosistema, determinar y evaluar los servicios ecosistémicos prioritarios, identificar alternativas y evaluar los impactos en los servicios de los ecosistemas; y dar seguimiento de los servicios ecosistémicos. Ello es igualmente aplicable a las EIA.

Además de la integración de los servicios ecosistémicos, es importante integrar la variable del cambio climático como una capa más de información en estos procesos de toma de decisiones. Para ello, es importante incluir un estudio de impacto y vulnerabilidad climática, diseñar medidas de gestión de los posibles impactos ambientales y climáticos, así como medidas de adaptación, preferiblemente de AbE.

\subsection{Instituciones y procesos para la AbE}

Entre las funciones de la Ley se encuentra también crear instituciones, definir sus funciones, competencias y facultades, así como los procesos que deben implementar para garantizar el cumplimiento de sus funciones. Las instituciones para la adaptación se tratan en detalle en el capítulo 5.

\subsubsection{Mecanismos de coordinación institucional}

El primer mecanismo para la coordinación institucional para la AbE que se puede encontrar en una ley consiste en una clara distribución de funciones entre las distintas instituciones sectoriales y los diversos niveles de gobierno, junto con un mandato para cooperar en asuntos específicos. 


\section{Ejemplo: Distribución de competencias en la Ley de Cambio Climático de México}

- La Federación tiene atribución para "establecer, regular e instrumentar las acciones para la adaptación al cambio climático" en materia de "preservación, restauración, conservación, manejo y aprovechamiento sustentable de los recursos naturales, los ecosistemas terrestres, acuáticos, marinos, costeros, islas, cayos, arrecifes y los recursos hídricos" (Art. 7).

- Las entidades federativas tienen facultades para "formular, conducir, dirigir e instrumentar acciones para la adaptación en materia de "preservación, restauración, manejo y aprovechamiento sustentables de los ecosistemas y recursos hídricos de su competencia” (Art. 8).

- Los municipios tienen atribución para formular e instrumentar políticas y acciones para la adaptación, en congruencia con las políticas y leyes nacionales y estatales en materia de "recursos naturales y protección al ambiente de su competencia" (Art. 9).

Por tanto, ciertos ecosistemas han quedado únicamente en manos de la Federación, mientras que, para aquellos recursos donde hay facultades concurrentes entre los distintos niveles de gobierno, se instruye a las autoridades a firmar acuerdos de coordinación con la federación, entidades federativas y los municipios para la implementación de las acciones de adaptación (Art. 8, VII).

El caso mexicano ejemplifica la distribución de competencias y la disponibilidad de arreglos de cooperación interinstitucional cuando existen competencias que de algún modo se sobreponen.

Otros mecanismos de coordinación institucional se relacionan con el apoyo o el desarrollo de capacidades. Por ejemplo, la Ley de Cambio Climático de Honduras establece un mandato a diversas autoridades nacionales (Instituto de Desarrollo y Conservación Forestal, Áreas Protegidas y Vida Silvestre, a la Secretaría de Estado en el Despacho de Agricultura y Ganadería, la Secretaría de Estado en los Despachos de Recursos Naturales y Medio Ambiente, y la Secretaría Técnica de Planificación y Cooperación Externa) a prestar colaboración a las Municipalidades que requieran adecuar sus planes de ordenamiento territorial para estar alineados con los planes nacionales (Art. 24).

\subsubsection{Coherencia normativa multinivel}

La necesidad de garantizar la coherencia del sistema jurídico a distintos niveles de gobierno no es un asunto nuevo para el derecho, ya que forma parte su propia teoría y que se resumen en la pirámide de Kelsen (figura 4.4).

De acuerdo con la pirámide de Kelsen, la Constitución es la norma fundamental que establece el contenido que determina la validez sustantiva de toda norma de jerarquía inferior. Es decir, toda ley, reglamento, convenio o uso y costumbre debe ajustarse a los preceptos constitucionales. Esto se podría resumir como "nada por encima de la Constitución y nada fuera de la Constitución". Actualmente, muchas constituciones conceden rango Constitucional a los tratados internacionales en materia de derechos humanos que han sido ratificados por el Estado.

En materia de cambio climático hay una tendencia a la formulación de leyes generales o leyes marco que establecen principios y disposiciones básicas. Al mismo tiempo dichas leyes dejan suficiente espacio para que las regulaciones regionales, locales y sectoriales sean desarrolladas en mayor detalle de acuerdo con las realidades locales, siempre siguiendo los límites de las normas superiores. 


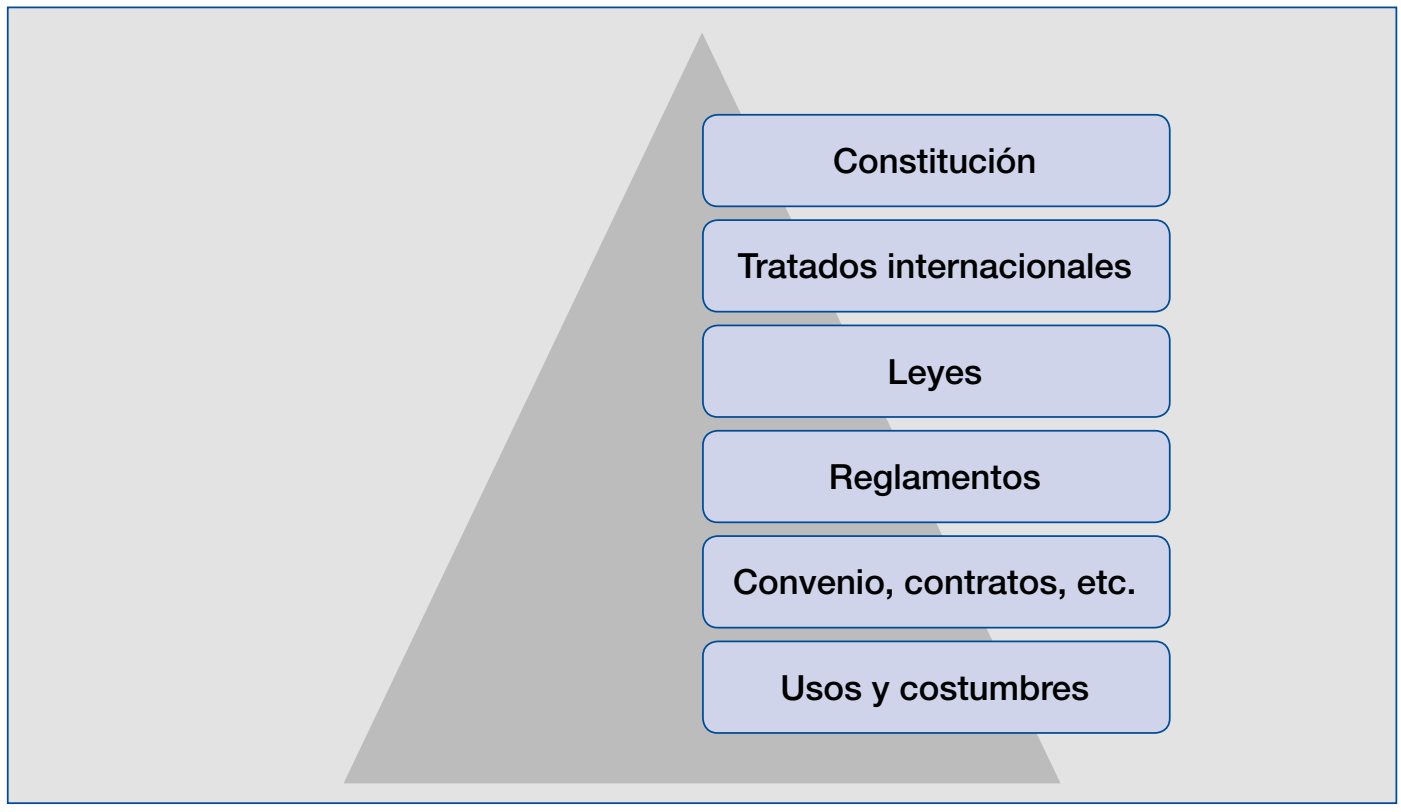

Figura 4.4 Pirámide de Kelsen

Fuente: Adoptado de Hans Kelsen

El reto, entonces no consiste en alcanzar una coherencia inicial entre las normas a distintos niveles, sino mantener dicha coherencia en un contexto dinámico y cambiante. En este sentido, la gestión adaptativa requiere de una evaluación y ajuste periódico de las leyes, en una realidad donde las autoridades de gobierno en distintos niveles y sectores, no operan a un mismo ritmo.

\subsubsection{Monitoreo y evaluación}

El monitoreo, evaluación y ajuste constituye la piedra angular de la nueva forma de adoptar políticas públicas. La Ley debe incluir estos procesos en todos los instrumentos de política y los mecanismos regulatorios analizados. Por ejemplo, las leyes deben incluir los mecanismos necesarios para que los planes de gestión de las áreas protegidas y los planes de ordenamiento territorial se revisen periódicamente a la luz de las vulnerabilidades climáticas. De esta manera, los mecanismos específicos que se vuelven obligatorios obtienen flexibilidad para hacer frente a las incertidumbres asociadas al cambio climático.

Dado que la adaptación es específica para cada contexto territorial, es necesario que las leyes prescriban los procesos de evaluación basados en la información científica y el conocimiento local y tradicional (Boer \& Clarke, 2012).

Asimismo, las leyes necesitan incluir disposiciones para los procesos de enmienda de mecanismos regulatorios, pues el monitoreo y evaluación perderían gran parte de su valor sin la posibilidad de hacer ajustes. Dichos procesos necesitan encontrar un equilibrio entre, por un lado, la simplicidad y la flexibilidad, y por el otro, la transparencia y el debido proceso. La Ley también debe incluir disposiciones que indiquen claramente las instituciones encargadas de llevar a cabo la evaluación.

Todo proceso de enmienda de los mecanismos regulatorios debería establecer oportunidades de participación de las personas afectadas, siguiendo los estándares mínimos acordados en los 
acuerdos internacionales para la participación pública en asuntos ambientales y las legislaciones nacionales en la materia.

\subsubsection{Participación pública}

La participación pública en asuntos relacionados con el medio ambiente constituye un principio fundamental del derecho ambiental, una condición necesaria de las políticas ambientales y un derecho humano.

La participación pública ha ganado protagonismo en el derecho internacional gracias a los múltiples beneficios que reporta, entre otros:

- Fomenta la concienciación ambiental.

- Permite identificar los problemas ambientales y posibles soluciones. En el caso de la AbE, la participación permite identificar vulnerabilidades al cambio climático y diseñar medidas para la adaptación.

- Promueve la democracia, evitando que las decisiones se tomen únicamente tomando en cuenta factores o información técnica (tecnocracia).

- Facilita llegar a decisiones que favorezcan la justicia distributiva y por tanto reconoce el interés de diversos actores y, al permitirles participar en los procesos de toma de decisiones y defender sus derechos, también favorece que sus derechos sean tomados en cuenta para el acceso a los beneficios y distribución de costos de las decisiones adoptadas (favorece la equidad).

- Permite que las personas tomen responsabilidad por el cuidado del ambiente y se conviertan en agentes de cambio.

- Facilita la vigilancia del cumplimiento de la legislación ambiental, lo cual significa que cuando las personas presentan denuncias ante las autoridades o acuden a las Cortes para reclamar la reparación de daños ambientales, se convierten en vigilantes de la legislación ambiental.

Los derechos de participación se reconocieron por primera vez en el ordenamiento internacional en el Principio 10 de la Declaración de Río sobre Medio Ambiente y Desarrollo en el año 1992. Desde entonces se han ido incorporando en las Constituciones de los Estados como parte del derecho a un ambiente sano, en las legislaciones nacionales sobre transparencia, acceso a la información y medio ambiente y en tratados internacionales ambientales y de derechos humanos. Asimismo, tribunales internacionales de derechos humanos han reconocido la dimensión ambiental de los derechos civiles y políticos.

Actualmente se encuentran consagrados de manera especial en dos tratados internacionales específicos:

- La Convención sobre el acceso a la información, la participación del público en la toma de decisiones y el acceso a la justicia en asuntos ambientales (en adelante, Convención de Aarhus); y

- El Acuerdo regional sobre el acceso a la información, la participación pública y el acceso a la justicia en asuntos ambientales en América Latina y el Caribe (en adelante, Acuerdo de Escazú). ${ }^{10}$

10 Al cierre de la elaboración de este libro, el Acuerdo de Escazú contaba con 16 ratificaciones, pero aún no se había cumplido el plazo del artículo 22 para su entrada en vigor. 
Estos tratados reconocen tres derechos inter-relacionados e inseparables:

- El derecho al acceso a la información;

- El derecho a la participación pública en asuntos ambientales; y

- El derecho al acceso a la justicia.

Se considera que la información accesible es un pre-requisito para que los actores interesados puedan formar una opinión y participar en la dirección de los asuntos relacionados con el ambiente. La existencia de recursos administrativos o judiciales es una condición necesaria para garantizar el derecho al acceso a la información y para hacer efectivo el derecho a la participación pública en asuntos ambientales.

Los tres derechos mencionados imponen algunas obligaciones comunes a cargo de las autoridades públicas:

a) Legislar para hacer efectivos los derechos de acceso. La legislación debe cumplir con algunos estándares mínimos internacionales.

b) Fortalecer capacidades y educar a la población y a los funcionarios públicos sobre el ejercicio de estos derechos.

c) Remover obstáculos que dificulten el pleno goce y disfrute de los derechos de acceso (por ejemplo, las autoridades públicas deben garantizar la seguridad de las personas defensoras del ambiente).

d) Establecer recursos eficaces contra violaciones a los derechos de acceso (por ejemplo, la posibilidad de ir a una corte o tribunal para demandar la reparación o compensación por las violaciones a los derechos).

Los derechos procedimentales ambientales son de suma importancia para la efectividad de la AbE, toda vez que son el medio a través del cual los ciudadanos pueden ejercer un rol como agentes de cambio. Por un lado, los ciudadanos pueden promover la integración de la AbE en planes, programas y proyectos y, por otro lado, pueden vigilar el cumplimiento de la ley para defender los ecosistemas $y$, en consecuencia, contribuir a su propia adaptación. Un ejemplo de su importancia se puede visualizar en un caso reciente decidido en Colombia.

\section{Sentencia C-035/16 de febrero 8, 2016 del Tribunal Constitucional de Colombia}

La sentencia C-035/16 el Tribunal Constitucional anuló las disposiciones de dos leyes nacionales (Ley No. 1450 de 2011 y Ley No. 1753 de 2015) porque amenazaba a los páramos, ecosistemas sensibles de altura. El tribunal hizo notar varias características de los páramos, entre ellas su fragilidad, la falta de protección jurídica y su rol para la provisión del $70 \%$ del agua potable en el país, así como la capacidad de sus suelos y vegetación para capturar $\mathrm{CO}_{2}$. El Tribunal resaltó que los páramos son "sistemas de captura de carbono" y explicó que estos ecosistemas llegan a superar la capacidad de captura de los bosques tropicales de las mismas dimensiones, motivo por el cual merecen especial protección.

En vista de ello, el tribunal consideró inconstitucionales ambas leyes (1450 y 1753), en especial, dos disposiciones de la Ley No. 1753 de 2015. Una, porque autorizaba a la Comisión de Infraestructura Intersectorial y Proyectos Estratégicos a declarar algunos proyectos como de "interés estratégico nacional”, declaración que los eximía de cierta vigilancia regulatoria local. La otra disposición prohibía varias actividades en los páramos como la agricultura, la minería, las exploraciones de petróleo y gas, y otras, pero sólo si los propietarios de los proyectos habían obtenido sus licencias 
ambientales en fecha posterior a Febrero 9 de 2010, y para las operaciones de gas e hidrocarburos después del 16 de junio de 2011.

El Tribunal declaró que ambas disposiciones eran inconstitucionales porque, entre otras cosas, ponían en riesgo el derecho al agua potable de la población y porque las autoridades gubernamentales no habían cumplido con su obligación de justificar decisiones que resultarían en una degradación de áreas y ecosistemas sensibles y de alto valor social.

Otros tratados internacionales de derechos humanos reconocen el derecho a participación de personas o grupos específicos, por ejemplo, pueblos indígenas, mujeres, niños, personas con discapacidades, entre otros, por los mismos motivos que ya se han descrito. Sin embargo, los tratados dan un tratamiento especial al derecho a participar de estas personas con el fin de eliminar los obstáculos de facto para el ejercicio de sus derechos que comúnmente encuentran.

De especial referencia es el Convenio No. 169 de la Organización Internacional del Trabajo sobre Pueblos Indígenas y Tribales y la Declaración de las Naciones Unidas sobre los Derechos de los Pueblos Indígenas reconocen el derecho de los pueblos indígenas al consentimiento libre, previo e informado (CLPI) en las decisiones que afectan sus territorios y los recursos naturales que en ellos se encuentran. El CLPI tiene un valor intrínseco de reivindicación de los pueblos indígenas, pues reconoce y promueve el respeto a su autonomía y su derecho a la autodeterminación, es decir, tiene un valor de justicia social porque les permite determinar su modelo de desarrollo, el uso y distribución de sus recursos naturales y les permite, en teoría, negociar una distribución equitativa de los beneficios de la utilización de dichos recursos y la biodiversidad. Más allá de ello, se reconoce que los pueblos indígenas tienen conocimientos ancestrales y prácticas armoniosas con la naturaleza de gran valor en búsqueda de soluciones ante el cambio climático, por lo que su participación en los procesos de decisiones enriquece la calidad de las decisiones en este tema.

En la actualidad, la mayoría de las leyes ambientales y de cambio climático incluyen disposiciones para el acceso a la información y la participación pública en relación al cambio climático.

\subsection{Mecanismos de financiamiento para la AbE}

Desde el momento que la $\mathrm{AbE}$ se convierte en un objetivo social incorporado en planes y estrategias públicas, se debe acompañar con mecanismos financieros adecuados para la implementación de las acciones detalladas en dichos planes y estrategias.

Las leyes tienen un rol fundamental en el financiamiento de la $\mathrm{AbE}$, ya sea para dirigir directamente fondos públicos para acciones de adaptación o para crear mercados específicos u otros mecanismos económicos.

\section{Ejemplo: Destinación de presupuesto público para acciones de AbE en Guatemala}

La ley marco para regular la reducción de la vulnerabilidad, la adaptación obligatoria ante los efectos del cambio climático y la mitigación de gases de efecto invernadero de Guatemala otorga un mandato a los Consejos de Desarrollo Urbano y Rural de incorporar en sus políticas, planes, programas y proyectos de desarrollo al cambio climático, lo cual debe coordinarse con la planificación de la inversión pública a nivel sectorial, público y territorial. Asimismo, la Secretaría de Planificación y Programación de la Presidencia está a cargo de garantizar la inclusión de los proyectos en el Sistema Nacional de Inversión Pública). 
La Ley identifica áreas prioritarias para el desarrollo de planes estratégicos y operativos para la reducción de vulnerabilidad y la adaptación al cambio climático, mismos que sirven de puntos de partida para el desarrollo de prácticas de AbE en los planes sectoriales. Las áreas prioritarias son: salud humana; zonas marino costeras; agricultura, ganadería y seguridad alimentaria; recursos forestales, ecosistemas y áreas protegidas; e infraestructura. Se incluye, como medida de refuerzo, la obligación a cargo de personas individuales o jurídicas, públicas o privadas del país, a adoptar nuevas prácticas, incluidas las provenientes del conocimiento tradicional y ancestral, que minimice los procesos de degradación de los suelos. Asimismo, se instruye los Ministerios de Agricultura, Ganadería y Alimentación -MAGA- y de Ambiente y Recursos Naturales -MARN- a establecer políticas y programas para evitar la degradación, mejorar la conservación del suelo y establecer las recomendaciones para el uso productivo del mismo.

Finalmente, se establece un Fondo Nacional de Cambio Climático, a cargo del MARN, con el objetivo de financiar "el pago por servicios naturales por fijación de carbono, producción y protección del agua, protección de ecosistemas, belleza escénica y otros". Las fuentes de financiamiento del Fondo son diversas, entre ellas se destacan "un aporte determinado por el presupuesto de Ingresos y Egresos del Estado en forma anual", "el pago de las compensaciones por las emisiones de gases de efecto invernadero que sean requeridas por el Ministerio de Ambiente y Recursos Naturales según la normativa que para el efecto de esta ley se emita"; "fondos provenientes de las negociaciones de Canje por Adaptación y Mitigación al Cambio Climático" y "fondos provenientes de la cooperación nacional o internacional". Los fondos se emplearán especialmente en la adaptación.

La Ley también tiene la función de crear fondos para la captación y canalización de recursos económicos para la implementación de la $\mathrm{AbE}$, y pueden crear mecanismos económicos para la $\mathrm{AbE}$, entre ellos esquemas de pagos por servicios ambientales, concesiones, bonos verdes, el cobro de entradas a los parques de áreas naturales protegidas, los seguros climáticos, etc. (Boer \& Clarke, 2012).

Las medidas de AbE deben responder a las condiciones de cada contexto en particular (el riesgo climático, el ecosistema, la escala geográfica de la medida y el nivel de implementación), por lo que no existe un único mecanismo que resulte adecuado para financiar todo tipo de acciones de $\mathrm{AbE}$ aplicable a todos los casos (GIZ, 2018). Así, permitir que la creación de mecanismos económicos dependa del ecosistema, servicio específico y condiciones de las poblaciones locales parece ser la mejor opción. Por ejemplo, la Ley General de Cambio Climático de México deja abierta la elección y/o creación de mecanismos adecuados en manos de la Federación y de las Entidades Federativas para incentivar el cumplimiento de los objetivos de la política nacional en materia de cambio climático (art. 91). Ello no obstante, la apuntada flexibilidad debería ir acompañada de un cuidadoso trabajo de ingeniería jurídica para garantizar el funcionamiento efectivo de cualquiera que sea el mecanismo elegido, puesto que este depende de marcos jurídicos apropiados y acuerdos claros y equitativos entre las partes.

\subsection{Aplicación y cumplimiento de la Ley}

La aplicación y el cumplimiento de la Ley depende de la existencia de instituciones sólidas y eficientes (Iza \& Stein (eds.), 2011), así como del establecimiento de procesos de inspección y vigilancia, medidas de seguridad y sanciones. 
Actualmente la mayoría de los países cuenta con un órgano de control del cumplimiento de la legislación ambiental, por lo que a pesar de que la regulación de la AbE es dispersa (en leyes generales ambientales, leyes relativas a los recursos naturales y otras leyes indirectamente relacionadas) los procedimientos de aplicación y cumplimiento no necesariamente están dispersos. Por ejemplo, en México la Procuraduría Federal de Protección al Ambiente (PROFEPA) se encarga de vigilar el cumplimiento de la Ley General del Equilibrio Ecológico y la Protección al Ambiente (LGEEPA), así como todas otras leyes generales y federales relacionadas con los recursos naturales. Así, la PROFEPA también es la encargada de realizar actos de inspección y vigilancia a las personas físicas o morales sujetas a reporte de emisiones.

Esta coherencia normativa e institucional es fundamental para optimizar recursos y capacidades para el control de las leyes para la AbE. La falta de un adecuado control de cumplimiento podría tener como consecuencia el aumento de las presiones sobre los ecosistemas (por ejemplo, más actividades que emiten gases a la atmósfera u otras sustancias contaminantes, la explotación ilegal de recursos forestales, el comercio ilegal de especies, entre otros) y, por tanto, amenaza la capacidad de dichos ecosistemas y de las personas a adaptarse al cambio climático.

\subsection{Resolución de controversias}

La gobernanza va más allá del gobierno, atañe también a toda otra forma de organización entre distintos miembros o sectores de la sociedad. Incluye relaciones autoridad pública-comunidad, autoridad pública-empresa (sector privado), empresa-comunidad, entidad financiera-comunidad, entre muchas otras posibles, entre las cuales pueden surgir controversias.

Las cuestiones sobre las que pueden versar las controversias son innumerables, por poner unos ejemplos: actividades que degradan los ecosistemas de los que dependen las comunidades, la aplicación o interpretación de una ley ambiental o sectorial que tiene efectos sobre el equilibrio de los ecosistemas, la propiedad o tenencia de la tierra, la aplicación o interpretación de un contrato de pagos por servicios ambientales, la aplicación o interpretación de un contrato de co-gestión de ecosistemas, la distribución interna dentro de una comunidad de los beneficios de un esquema de financiamiento de $\mathrm{AbE}$, entre otros.

Normalmente, estas controversias se resuelven ante las cortes o el poder judicial nacional, ya sea juzgados civiles, administrativos o penales, según corresponda. Sin embargo, zanjar conflictos puede tomar años e incluso décadas, por lo que es importante buscar formas de agilizar los procedimientos judiciales que tienen relación con la adaptación y la gestión de ecosistemas.

Aunado a ello, la incertidumbre del cambio climático puede ser un detonante adicional de conflictos, no sólo por cambiar las condiciones físicas sobre los que se diseñaron y establecieron los marcos normativos, le mecanismos de implementación, los contratos (y todo lo que ya se ha mencionado en este capítulo), sino también por una competencia cada vez mayor por recursos cada vez más escasos, por ejemplo, el agua.

Por eso resulta también importante considerar además de los mecanismos judiciales los mecanismos alternativos de resolución de conflictos que, por lo general, son más ágiles y flexibles. La conveniencia de su uso, en lugar de los judiciales, se debe ponderar en cada caso en particular.

La resolución alternativa de conflictos importa el uso de diversas técnicas y enfoques para lograr una solución de las diferencias entre las personas (físicas y jurídicas) de común acuerdo, de un modo que se eviten los costos, la demora y lo imprevisible de los procesos de adjudicación tradicionales. 
Son procesos que emplean terceros neutrales, con autoridad sustantiva y de decisión. Las entidades de resolución alternativa de conflictos pueden incluir a tribunales o divisiones de la autoridad judicial.

Dentro de estas técnicas de resolución de conflictos se destacan las siguientes:

- Arbitraje: Es un proceso que emplea a un tercero neutral de carácter privado con poder de decisión, cuya autoridad es sustantiva. Las partes explícitamente acuerdan utilizar este mecanismo para terminar una controversia. Típicamente las partes tienen mayor control sobre el procedimiento.

- Asesoría con poder de decisión: Se trata de un proceso que emplea a un tercero neutral con poder de decidir, de carácter público o privado, cuya autoridad puede ser vinculante respecto al procedimiento, pero no a la sustancia. Es una categoría de técnicas que incluyen el arbitraje no vinculante.

- Mediación: Constituye un proceso que emplea a un tercero neutral comunicador, sea de carácter público o privado, quien tiene poder de decisión con el objetivo de lograr un acuerdo sustantivo entre las partes. La posibilidad de resolver asuntos sustantivos pasa enteramente a las partes.

- Facilitación: En este mecanismo se emplea a un tercero neutral comunicador, sea de carácter público o privado, quien tiene poder de decisión con el objetivo de lograr un acuerdo sustantivo entre las partes. Los facilitadores son los últimos neutrales en el universo de técnicas de resolución de conflictos y, por sobre ellos, las partes negocian directamente. Con esta técnica el actor neutral pude lograr un acuerdo entre todas las partes, aun por decisiones procesales.

\subsection{Desafíos y oportunidades para la Política}

El cambio climático y sus efectos requieren una nueva forma de entender y de elaborar las políticas y las leyes. La centralización y concentración de las decisiones ya no resulta adecuada, la confianza en una sola fuente o tipo de información es insuficiente, y la certeza y estabilidad de una ley rígida se revela, en muchos casos como problemática.

El holismo, la coordinación, la descentralización, la participación de todos los sectores, la integración de distintos tipos de conocimientos e información y la flexibilidad son las términos claves que definen el proceso de adaptación planificada y la gobernanza para la AbE.

Hacer frente a estas cuestiones constituye un desafío y a la vez una oportunidad. El cambio climático nos hace conscientes de las interrelaciones entre los sistemas socio-ambientales, nos invita a reformular la manera en la cual concebimos la relación ser humano con la naturaleza y a redefinir en última instancia dicha relación desde todos los aspectos de la organización social y en especial, desde la política y la legislación. 


\title{
5 Instituciones
}

\author{
Mauricio Luna Rodríguez
}

\subsection{Introducción}

En términos generales, las instituciones son las condiciones establecidas por el ser humano que estructuran sus interacciones sociales, económicas y políticas. A lo largo de la historia las instituciones han sido establecidas para reducir la incertidumbre en las interacciones humanas y han evolucionado para responder a las crecientes necesidades en un mundo cada vez más interconectado (North, 1991; O’Riordan \& Jordan, 1999). El fenómeno del cambio climático aumenta la incertidumbre en la toma de decisiones por lo que las instituciones juegan un papel fundamental para gestionar las respuestas a los retos del calentamiento global (Sanchez \& Roberts, 2013).

Las instituciones pueden ser clasificadas en informales y formales; asimismo, estas pueden pertenecer al ámbito público, privado o civil (North, 1991; Wang et al., 2013). Las instituciones son, por un lado, las "reglas del juego" no codificadas (informales) como los valores y tradiciones que dictan el comportamiento en sociedad y, por otro lado, son las organizaciones de gobernanza tangibles (formales), como por ejemplo: asociaciones de desarrollo (ámbito civil), empresas (ámbito privado) o estructuras de gobierno (ámbito público) (O’Riordan \& Jordan, 1999; Mubaya \& Mafongoya, 2017).

En tiempo reciente y en respuesta al cambio climático han surgido una serie de instituciones formales que integran actores de múltiples ámbitos. Para efectos de una clasificación conceptual que ayude a identificar diferentes tipos instituciones formales, en el presente capítulo aquellas que integran actores de más de un ámbito a nivel de gobernanza serán llamadas multidimensionales.

Muchas veces las instituciones son vistas como sinónimos de organizaciones. Sin embargo, las organizaciones son solamente aquellas instituciones que han formalizado sus patrones de regulación y toma de decisiones (Gupta et al., 2010).

El presente capítulo se centra en el análisis de las instituciones formales (organizaciones o estructuras multidimensionales) identificadas en las políticas como parte del sistema institucional para dar respuesta al cambio climático y con particular atención en los siguientes países: Guatemala, Honduras, Costa Rica y México; en este último caso, en lo que respecta al Estado de Chiapas.

\subsection{Institucionalidad para la adaptación}

Los retos que plantea la adaptación al cambio climático requieren de un abordaje institucional multi-sectorial y multinivel (Vignola et al., 2009). La adaptación al cambio climático es un tema vinculado con el desarrollo; de ahí que hayan surgido una serie de arreglos institucionales formales cuya finalidad es brindar respuestas de carácter multidimensional, esto es, de forma multinivel y multisectorial, a los retos que presenta la adaptación (Chaudhury et al., 2016; Sanchez \& Roberts, 2013). Por lo tanto, analizar y comprender las dimensiones institucionales de la adaptación es fundamental en el proceso de ajuste al cambio climático que se necesita para gestionar y procurar reducir la incertidumbre (Cuevas, 2018).

Los retos de la adaptación requieren nuevos arreglos institucionales formales que van más allá de la forma "sectorial" en la que se han organizado los Estados. Aunque no existe una fórmula que defina el ideal de institución para enfrentar los retos del cambio climático, si la dimensión institucional no 
es atendida, frecuentemente se desperdician recursos (Bolman \& Deal, 2013). En consecuencia, brindarles una mayor atención a las instituciones resulta de fundamental importancia para una efectiva implementación de acciones de adaptación (Chaudhury et al., 2016).

En este capítulo se pretende, por un lado, analizar las instituciones formales que son parte de las políticas nacionales de adaptación al cambio climático y, por otro, examinar las instituciones multidimensionales emergentes en materia de cambio climático en Mesoamérica. Esto último, a través de una descripción y el análisis de la institucionalidad formal para la adaptación en las políticas públicas de México, Guatemala, Honduras y Costa Rica, mismas que incorporan diversos sectores, actores y niveles gobierno.

\subsection{Tipología de las instituciones para la adaptación}

La literatura sobre cambio climático reconoce la importancia de la participación de los sectores público, privado y civil en la gobernanza para la adaptación (Fröhlich \& Knieling, 2012; Mubaya \& Mafongoya, 2017; Sanchez \& Roberts, 2013; Wang et al, 2013). Asimismo, se enfatiza la necesidad de un abordaje multinivel, desde lo local hasta lo internacional (Girard et. al., 2015; Sanchez \& Roberts, 2013). En el siguiente cuadro se incluye una propuesta de tipología de instituciones formales (multinivel y miltisector) para la adaptación, donde se enfatiza un enfoque multidimensional.

Cuadro 5.1 Tipología de instituciones para la adaptación.

\begin{tabular}{|c|c|c|c|c|}
\hline \multirow{2}{*}{ NIVEL } & \multicolumn{4}{|c|}{ SECTOR } \\
\hline & Público & Privado & Civil & Multidimensional \\
\hline Global & $\begin{array}{l}\text { Instituciones } \\
\text { globales } \\
\text { conformados por } \\
\text { los Estados }\end{array}$ & $\begin{array}{l}\text { Instituciones } \\
\text { globales de } \\
\text { carácter privado }\end{array}$ & $\begin{array}{l}\text { Instituciones de la } \\
\text { sociedad civil }\end{array}$ & \multirow{5}{*}{$\begin{array}{c}\text { Estructuras } \\
\text { que Integran } \\
\text { simultáneamente } \\
\text { a organizaciones } \\
\text { de más de un } \\
\text { sector y/o más } \\
\text { de un nivel (de } \\
\text { gobernanza para } \\
\text { la adaptación) }\end{array}$} \\
\hline Regional & $\begin{array}{l}\text { Instituciones } \\
\text { regionales } \\
\text { conformados por } \\
\text { Estados }\end{array}$ & $\begin{array}{l}\text { Instituciones de } \\
\text { carácter privado a } \\
\text { nivel regional }\end{array}$ & $\begin{array}{l}\text { Instituciones } \\
\text { regionales de la } \\
\text { sociedad civil }\end{array}$ & \\
\hline Nacional & $\begin{array}{l}\text { Instituciones de } \\
\text { carácter estatal } \\
\text { rectoras de la } \\
\text { agenda climática a } \\
\text { nivel nacional }\end{array}$ & $\begin{array}{l}\text { Instituciones } \\
\text { privadas a nivel } \\
\text { nacional }\end{array}$ & $\begin{array}{l}\text { Instituciones } \\
\text { nacionales de la } \\
\text { sociedad civil }\end{array}$ & \\
\hline Subnacional & $\begin{array}{l}\text { Instituciones de } \\
\text { carácter estatal } \\
\text { subnacionales y } \\
\text { municipales }\end{array}$ & $\begin{array}{l}\text { Instituciones } \\
\text { privadas a nivel } \\
\text { subnacional }\end{array}$ & $\begin{array}{l}\text { Instituciones } \\
\text { subnacionales de } \\
\text { la sociedad civil }\end{array}$ & \\
\hline Local & - & $\begin{array}{l}\text { Instituciones } \\
\text { locales de carácter } \\
\text { privado }\end{array}$ & $\begin{array}{l}\text { Instituciones } \\
\text { locales de la } \\
\text { sociedad civil }\end{array}$ & \\
\hline
\end{tabular}

Fuente: Elaboración propia a partir de Chaudhury et al., 2016; Fröhlich \& Knieling, 2012; Iza \& Stein, 2011; Mubaya \& Mafongoya, 2017

En el presente capítulo el análisis de la institucionalidad para la adaptación se centra en aquellas de ámbito nacional y subnacional de los países anteriormente mencionados, incluyendo ejemplos 
de instituciones de carácter transfronterizo que atienden cuencas compartidas. Debido al reciente surgimiento de estructuras multidimensionales para hacer frente al cambio climático, se prestará especial atención a este tipo de estructuras emergentes.

\section{México}

El país cuenta con un Sistema Nacional de Cambio Climático (SINACC) establecido por la Ley General de Cambio Climático (artículos 38-57). El objetivo principal del SINACC es "fungir como un mecanismo permanente de concurrencia, comunicación, colaboración, coordinación y concertación sobre la política nacional de cambio climático" (Congreso de la Unión de los Estados Unidos Mexicanos, 2012, Art. 38, I).

EI SINACC está conformado por la Comisión Intersecretarial de Cambio Climático; el Consejo de Cambio Climático; el Instituto Nacional de Ecología y Cambio Climático; gobiernos de las Entidades Federativas; representantes de las Asociaciones de Autoridades Municipales y representantes del Congreso de la Unión (Congreso de la Unión de los Estados Unidos Mexicanos, 2012), como se ilustra en la figura 5.1 .

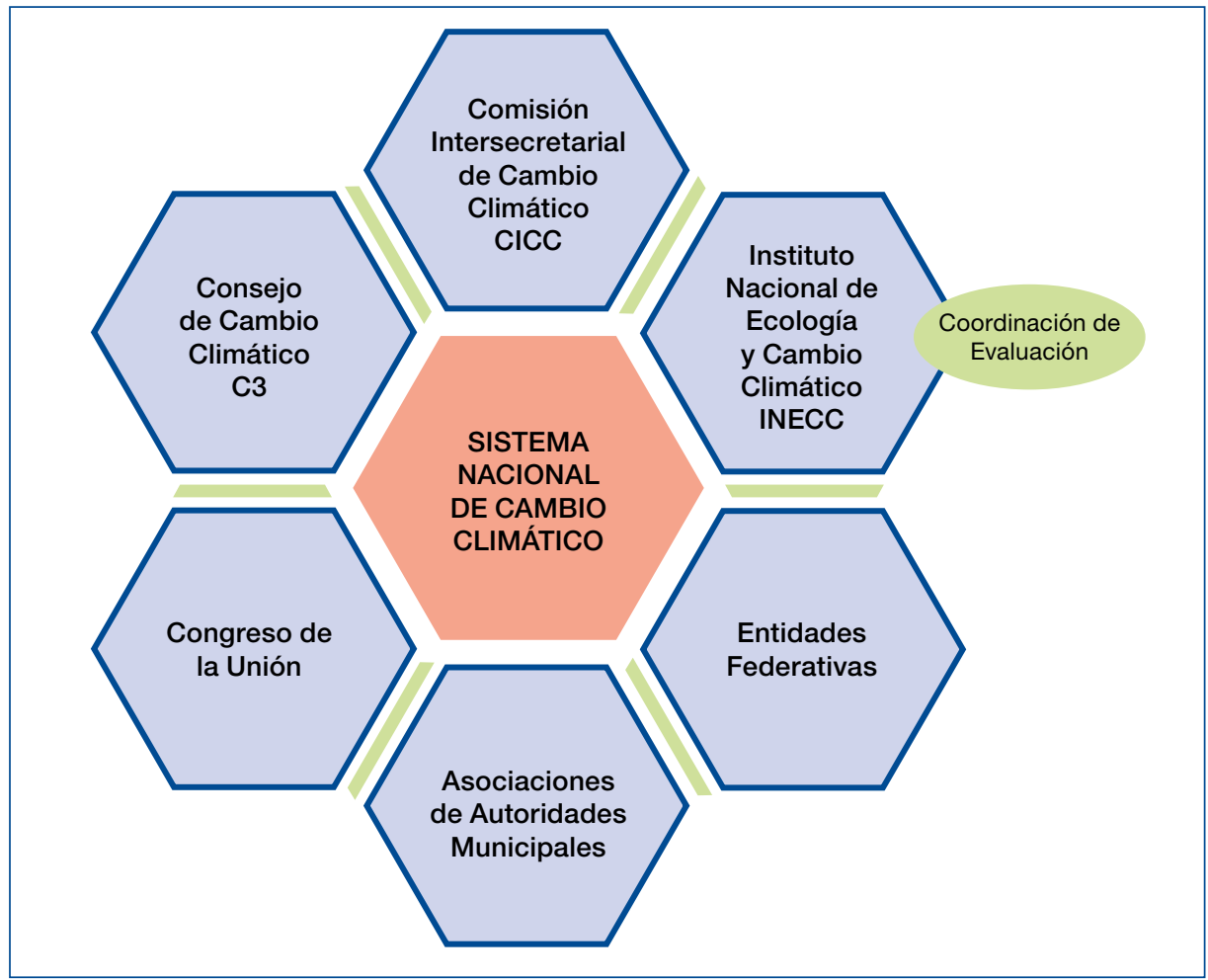

Figura 5.1 Marco Institucional del Sistema Nacional de Cambio Climático de México Fuente: SEMARNAT, 2018

Una de las fortalezas del sistema mexicano es que está amparado en la legislación marco de cambio climático del país, misma que brinda un sólido sustento legal en una región donde los países comúnmente carecen de políticas públicas que van más allá de los ciclos electorales y los 
cambios de gobierno (Delamaza et al., 2017). Además, el sistema integra de manera coherente la institucionalidad existente (por ejemplo, al Congreso y a las Entidades Federativas) con la creación de nuevos arreglos institucionales que buscan brindar una mayor coherencia de carácter multisectorial y multinivel. A continuación, se describen las instituciones que conforman el Sistema Nacional de Cambio Climático de México:

\section{Comisión Intersecretarial de Cambio Climático (CICC)}

Es un órgano público de carácter nacional permanente conducido por el presidente de la República, quien podrá delegar la función en el titular de la Secretaría de Gobernación o al titular de la Secretaría de Medio Ambiente y Recursos Naturales. Su naturaleza es multisectorial al estar integrada por los titulares de 14 Secretarías: Medio Ambiente y Recursos Naturales; Agricultura, Ganadería, Desarrollo Rural, Pesca y Alimentación; Salud; Comunicaciones y Transportes; Economía; Turismo; Desarrollo Social; Gobernación; Marina; Energía; Educación Pública; Hacienda y Crédito Público; Relaciones Exteriores; y Desarrollo Agrario, Territorial y Urbano. (Congreso de la Unión de los Estados Unidos Mexicanos, 2012).

\section{El Consejo de Cambio Climático (C3)}

El Consejo de Cambio Climático es el órgano multidimensional y permanente de consulta de la CICC. Está integrado por miembros provenientes de los sectores de la sociedad civil, el sector privado y académico que cuenten con reconocidos méritos y experiencia en la temática de cambio climático. Entre sus funciones se destacan: 1) asesorar a la CICC y recomendarle la realización de estudios, políticas y acciones, así como fijar metas tendientes a adaptarse a los afectos adversos del cambio climático, y 2) promover la participación social, informada y responsable, mediante la realización de consultas públicas (Congreso de la Unión de los Estados Unidos Mexicanos, 2012).

\section{Instituto Nacional de Ecología y Cambio Climático}

El Instituto Nacional de Ecología y Cambio Climático (INECC) es una institución pública federal establecida por la Ley General de Cambio Climático en su Artículo 13. El INECC es la entidad de investigación del Estado mexicano enfocada en la realización de estudios y proyectos de ciencia y tecnología con instituciones académicas, de investigación (públicas o privadas, nacionales o extranjeras) en la temática de cambio climático, protección al ambiente y preservación y restauración del equilibrio ecológico (Congreso de la Unión de los Estados Unidos Mexicanos, 2012).

\section{Congreso de la Unión}

México tiene un sistema parlamentario bicameral compuesto por una Cámara de Senadores y una Cámara de Diputados, las cuales conforman el Congreso de la Unión. Ambas cámaras tienen comisiones encargadas de promover o modificar leyes que contribuyan a la mitigación y adaptación al cambio climático. En la Cámara de Senadores, este trabajo está a cargo de la Comisión Especial de Cambio Climático en conjunto con la Comisión de Medio Ambiente y Recursos Naturales, en tanto que, en la Cámara de Diputados, este trabajo lo realiza la Comisión de Cambio Climático y la Comisión de Medio Ambiente (SEMARNAT, 2018).

\section{Entidades federativas y municipios}

México es un Estado Federal compuesto por los gobiernos de los Estados federados (32 en total) y los gobiernos municipales (2457 municipios en todo el país). Estas instancias tienen diversas atribuciones y responsabilidades en el tema de cambio climático, las cuales se resumen a continuación (SEMARNAT, 2018): 
Estados federados:

- Formular, conducir y evaluar la política estatal de cambio climático e implementar acciones de adaptación y mitigación.

- Elaborar e integrar la información de las categorías de fuentes emisoras de su jurisdicción, para su incorporación al Inventario Nacional de Emisiones en colaboración con el INECC.

- Gestionar y administrar fondos estatales.

- Promover la investigación científica y tecnológica, el desarrollo, transferencia y desarrollo de tecnologías.

- Desarrollar proyectos de reducción de emisiones de gases de efecto invernadero.

- Publicar y actualizar el atlas estatal de riesgo de desastres.

- Diseñar y promover el establecimiento e implementación de incentivos.

Municipios:

- Conducir y evaluar la política municipal de cambio climático.

- Desarrollar políticas y acciones para enfrentar al cambio climático e instrumentar acciones de mitigación y adaptación.

- Elaborar e integrar la información de las categorías de fuentes emisoras que se originan en su territorio, para su incorporación al Inventario Nacional de Emisiones en colaboración con el INECC.

- Fomentar la investigación científica y tecnológica, el desarrollo y transferencia de tecnologías.

- Desarrollar proyectos de reducción de emisiones de gasees de efecto invernadero.

- Realizar campañas de educación y concientización.

- Participar en el diseño e implementación de incentivos.

\section{Asociaciones de Autoridades Municipales}

El país cuenta con asociaciones de autoridades municipales las cuales tienen un representante por cada una de las asociaciones de gobiernos municipales legalmente reconocidas (Congreso de la Unión de los Estados Unidos Mexicanos, 2012).

\section{Guatemala}

Guatemala cuenta con una ley general de cambio climático que establece una nueva institucionalidad en este tema. Dicha ley establece una serie de arreglos institucionales, que denotan importantes avances en la articulación multidimensional entre distintos sectores, ministerios y niveles de gobierno.

Las principales instituciones formales para hacer frente al cambio climático se describen a continuación:

\section{Ministerio de Ambiente y Recursos Naturales (MARN)}

El Ministerio de Ambiente y Recursos Naturales es la institución de gobierno que posee la rectoría en materia de cambio climático. Entre sus múltiples tareas como ministerio regente, el artículo 12 de la ley marco de cambio climático determina la articulación con el Ministerio de Agricultura, Ganadería y Alimentación (MAGA) y la Secretaría de Planificación y Programación de la Presidencia (SEGEPLAN) 
con el objeto de promover la colaboración con las municipalidades del país para adecuar sus planes de ordenamiento territorial (Congreso de la República de Guatemala, 2013). Este artículo de la ley establece un mandato de articulación multidimensional entre los distintos ministerios y niveles de gobierno.

\section{Dirección Nacional de Cambio Climático (DNCC)}

La DNCC del MARN es responsable del diseño e implementación de planes, programas, proyectos y estrategias en concordancia con la ley marco de cambio climático, en los ámbitos local, subnacional y nacional. Asimismo, la DNCC debe estar conformada por grupos técnicos de trabajo que dan seguimiento a los ejes de adaptación y mitigación al cambio climático (MARN, 2018). La DNCC, como parte del MARN, tiene entre sus responsabilidades la articulación entre distintos niveles y actores en el país.

\section{Consejo Nacional de Cambio Climático}

La aprobación de la ley marco de cambio climático de Guatemala dio origen al Consejo Nacional de Cambio Climático. Dicha institución formal de gobernanza tiene una conformación multidimensional con la participación de representantes de los sectores público, privado y de la sociedad civil (Congreso de la República de Guatemala, 2013). Esta estructura de gobernanza es presidida por el MARN y será analizada en mayor de detalle en el siguiente apartado, mismo en el que se consideran las estructuras de gobernanza multidimensionales para hacer frente al cambio climático.

\section{Secretaria de Planificación y Programación de la Presidencia (SEGEPLAN)}

Esta Secretaría juega un papel de carácter articulador en el engranaje de gobernanza del cambio climático establecidos por la ley marco (Congreso de la República de Guatemala, 2013). Entre sus funciones se destacan la de facilitar el funcionamiento del Consejo Nacional de Cambio Climático (el cual cómo se indico es precedido por el MARN) (Art. 8). Además, tiene la tarea de integrar el cambio climático en los Consejos de Desarrollo Urbano y Rural y en la coordinación de los procesos planificación y programación de la inversión pública (Art. 10). Finalmente, la SEGEPLAN, en conjunto con el Consejo Nacional, tiene la responsabilidad de formular el Plan Nacional de Acción de Cambio Climático (Art. 11).

\section{Sistema Nacional de Información sobre Cambio Climático (SNICC)}

Fue establecido por medio de la ley marco de cambio climático en su artículo 9. El SNICC está inscrito al Ministerio de Ambiente y Recursos Naturales (Congreso de la República de Guatemala, 2013). Dicha legislación establece que todas las entidades públicas y privadas "deberán proporcionar información directamente relacionada con cambio climático" que solicite el Ministerio (Art. 9), lo que busca garantizar el acceso a la información pública para la toma de decisiones.

\section{Honduras}

El país posee una ley marco de cambio climático aprobada por el Congreso en el año 2014. sus alcances en lo que respecta a la institucionalidad son mucho más limitados en comparación con los países antes descritos. El marco institucional para dar respuesta al cambio climático es complejo, toda vez que existen una serie de decretos ejecutivos dan origen a estructuras que complementan a las instituciones establecidas por la ley. 


\section{Secretaría de Energía, Recursos Naturales, Ambiente y Minas (SERNA)}

La Secretaría de Energía, Recursos Naturales, Ambiente y Minas (SERNA) ${ }^{1}$ es el ente rector en la materia, según se establece en la Ley de Cambio Climático. Entre las responsabilidades de la SERNA, el artículo 3 de la apuntada ley establece la "gestión, creación y el establecimiento de medidas de prevención, adaptación y mitigación dirigidas a contrarrestar las amenazas" (Congreso Nacional de Honduras, 2014). Esto implica que, al igual que en el caso de los países previamente mencionados, las soluciones asociadas al cambio climático siguen siendo vistas como un problema principalmente de carácter ambiental.

\section{Dirección Nacional de Cambio Climático (DNCC)}

La Dirección Nacional de Cambio Climático (DNCC) de Honduras está adscrita a la Secretaría de Energía, Recursos Naturales, Ambiente y Minas (SERNA). La DNCC fue creada por el Decreto Ejecutivo PCM-022-2010 y es el ente que lidera la implementación de las acciones en materia de cambio climático, como las Comunicaciones Nacionales, las Contribuciones Nacionalmente Determinadas y las evaluaciones de necesidades tecnológicas del país para enfrentar el cambio climático (SERNA, 2018b). Entre sus acciones destaca la formulación e implementación de la política pública en la materia, como el Plan Nacional de Adaptación (PNA), oficializado en el 2018.

\section{Comité Interinstitucional de Cambio Climático (CICC)}

El artículo 8 de la Ley de Cambio Climático establece la creación del Comité Interinstitucional de Cambio Climático (Congreso Nacional de Honduras, 2014). De acuerdo con la ley, es un "órgano permanente, consultivo, deliberativo y de asesoría para formular políticas, monitoreo y control social" (Art. 10).

EICICC es una institución de carácter multidimensional que está integrada por catorce representantes.

\section{Cuadro 5.2 Miembros del Comité Interinstitucional de Cambio Climático de Honduras}

1. Presidente de la República (quien lo preside) y puede delegar esta función.

2. Secretaría de Recursos Naturales y Ambiente (SERNA).

3. Secretaría de Finanzas.

4. Instituto Nacional de Conservación Forestal, Áreas Protegidas y Vida Silvestre (ICF).

5. Instituto Hondureño de Turismo (IHT).

6. Empresa Nacional de Energía Eléctrica (ENEE).

7. Comisión de Medio Ambiente y Cambio Climático del Congreso Nacional.
8. Consejo Hondureño de la Empresa Privada (COHEP).

9. La Asociación de Municipios de Honduras (AMHON).

10. Consejo de Educación Superior (CES).

11. Fundación de Iniciativas de Cambio Climático de Honduras.

12. Consejo Nacional de Desarrollo Sostenible

13. Comité Permanente de Contingencia (COPECO).

14. Integrantes de la sociedad civil organizada afines al tema que a criterio del Comité deban ser convocados.

\section{Comité Técnico Interinstitucional de Cambio Climático (CTICC)}

Este órgano multidimensional establecido por la Ley de Cambio Climático de Honduras (Congreso Nacional de Honduras, 2014) es una instancia permanente de consulta y apoyo a la DNCC y al CICC

1 Actualmente denominado MiAmbiente+, por Decreto Ejecutivo Número PCM-009-2018, publicado en La Gaceta, Diario Oficial de la República de Honduras, 23 de marzo de 2018. 
en aquellos casos que ameriten una amplia participación (Art. 13). Está compuesto por al menos dieciséis representantes de los sectores público, privado y de la sociedad civil lo que lo convierte en la plataforma de consulta más amplia del país en la materia. Más detalles sobre la conformación de este Comité se brindan en el apartado siguiente, dónde se analizan en mayor detalle algunas de las estructuras multidimensionales emergentes en la región.

\section{Secretaría de la Presidencia CLIMA+}

La Secretaría Presidencial de Cambio Climático Clima Plus (CLIMA+) fue establecida mediante el Decreto Ejecutivo PCM 017-2016. Entre sus objetivos se destaca la armonización de la Agenda Climática del país. Esta oficina coordina la política nacional denominada Plan Maestro Agua, Bosque y Suelos (Gobierno de la Republica de Honduras, 2017).

La agenda climática de Honduras "establece un vínculo entre la DNCC y CLIMA+ para la coordinación de actividades conjuntas entre los programas que desarrollan ambas instancias" (SERNA, 2018a). Es una oficina de reciente creación, cuya articulación práctica con el resto del sistema institucional de cambio climático del país está por definirse.

\section{Observatorio Nacional de Cambio Climático y Desarrollo Sostenible (ONCCDS)}

Esta es una iniciativa de la Secretaría de Energía, Recursos Naturales, Ambiente y Minas (SERNA) destinada a facilitar el monitoreo climático y gestionar información sobre variables ambientales para mejorar la toma de decisiones frente a los retos del cambio climático. Entre sus tareas se destacan:

- Interpretar indicadores de cambio climático y su relación con el desarrollo sostenible.

- Fomentar investigación aplicada a través de su vinculación con la Mesa de Monitoreo Biológico.

- Mantener bases de datos del estado de los recursos naturales.

- Producir publicaciones técnicas

- Apoyar a las instituciones públicas y privadas en la gestión del conocimiento sobre cambio climático y el desarrollo sostenible.

- Desarrollar un programa de educación sobre cambio climático para el desarrollo sostenible (ONCCDS, s.a.).

\section{Costa Rica}

El país no cuenta con una legislación marco en materia de cambio climático que establezca una relación sistémica entre instituciones del Estado en esta temática. Por el contrario, Costa Rica ha optado por realizar una serie de ajustes en su estructura institucional, valiéndose de la legislación ambiental existente, recientes decretos ejecutivos y políticas públicas, como la Política Nacional de Adaptación (2018). Esta política resume el marco institucional para la adaptación de la siguiente manera:

\section{El Consejo Nacional Ambiental}

El Consejo Nacional Ambiental fue establecido mediante el Art. 77 de la Ley Orgánica del Ambiente (Asamblea Legislativa de Costa Rica, 1995). Este Consejo está conformado por: 1) El Presidente de la República o, en su representación, el ministro de la Presidencia, quien lo presidirá, además de los siguientes ministros: 2) de Planificación Nacional y Política Económica; 3) de Ambiente y Energía; 
4) de Salud; 5) de Agricultura y Ganadería; 6) de Educación Pública; 7) de Ciencia, Tecnología y Telecomunicaciones (Art 79).

A través del Decreto Ejecutivo 38536-PLAN se designa al Ministro de Ambiente y Energía como Rector del Sector Ambiente, Energía, Mares y Ordenamiento Territorial. Dicho sector se articula por medio de la Secretaría de Planificación del Sector Ambiental (SEPLASA).

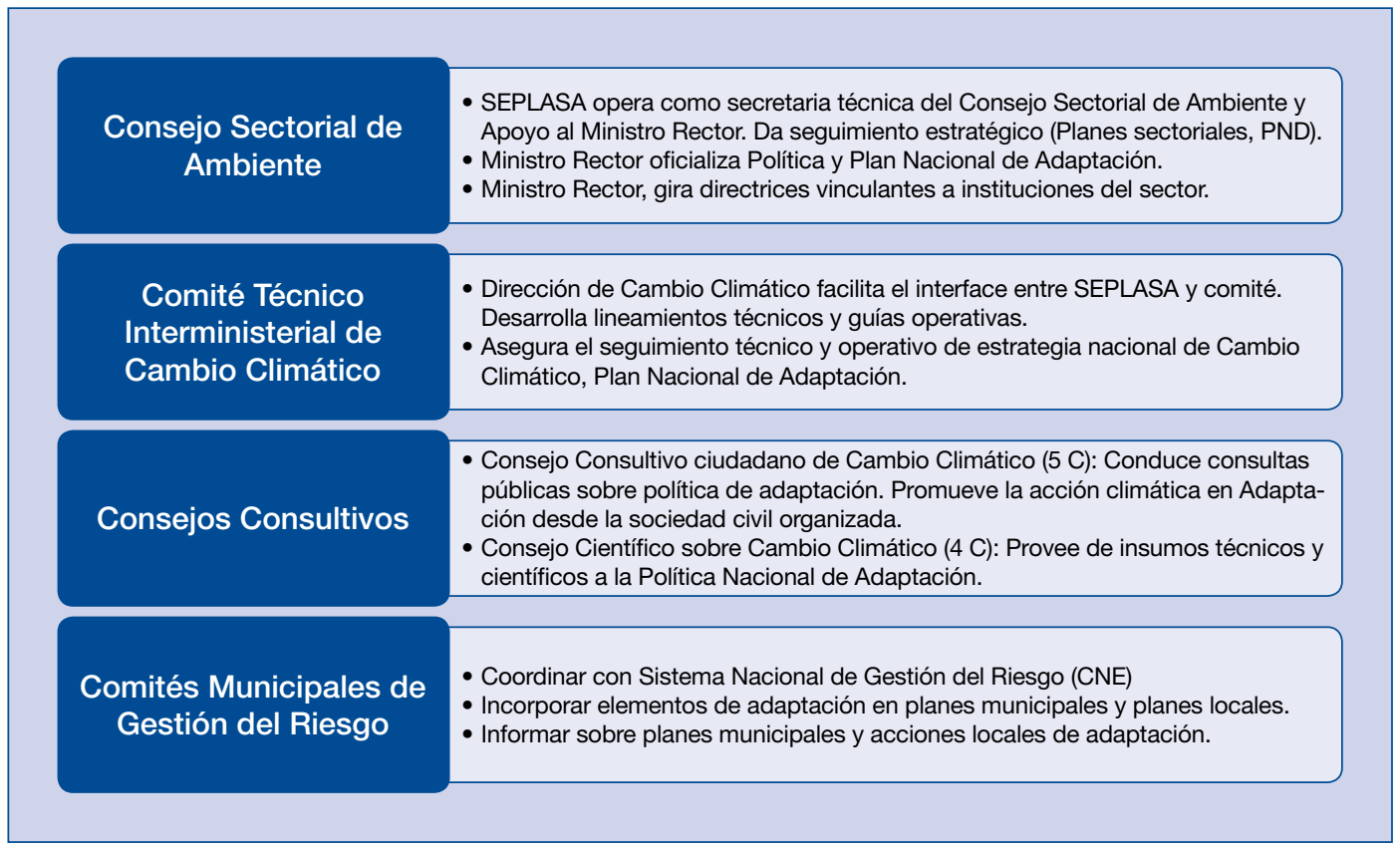

Figura 5.2 Marco institucional de cambio climático en Costa Rica Fuente: MINAE, 2018

La SEPLASA se rige por medio del Consejo Sectorial de Ambiente, un ente multisectorial conformado por una amplia gama de instituciones: el Ministerio de Ambiente y Energía (MINAE); el Ministerio de Vivienda y Asentamientos Humanos (MIVAH); el Ministerio de Agricultura y Ganadería (MAG); el Ministerio de Obras Públicas y Transportes (MOPT); el Instituto Costarricense de Turismo (ICT); el Instituto Costarricense de Electricidad (ICE); el Instituto Costarricense de Acueductos y Alcantarillados (AyA); el Instituto Nacional de Vivienda y Urbanismo (INVU); el Instituto de Desarrollo Rural (INDER); el Instituto Costarricense de Pesca y Acuicultura (INCOPESCA); la Refinadora Costarricense de Petróleo S.A. (RECOPE); la Comisión Nacional de Prevención de Riesgos y Atención de Emergencias (CNE); el Servicio Nacional de Guardacostas de la Fuerza Pública del Ministerio de Seguridad Pública; y el Servicio Nacional de Aguas Subterráneas, Riego y Avenamiento (SENARA) (Gobierno de la República de Costa Rica, 2014).

\section{Comité Técnico Interministerial de Cambio Climático (CTICC)}

Establecido mediante Decreto Ejecutivo No.36823-MINAET, el Comité Técnico Interministerial de Cambio Climático es un órgano asesor y de apoyo del Ministerio de Ambiente y Energía (MINAE) para dar seguimiento a la política de cambio climático. El Comité está integrado por un representante titular y un suplente de las siguientes instituciones: 1) Ministerio de Ambiente y Energía (representado 
por la Dirección de Cambio Climático, en calidad de coordinador y secretaría técnica); 2) Ministerio de Obras Públicas y Transportes; 3) Ministerio de Agricultura y Ganadería; 4) Ministerio de Ciencia y Tecnología; 5) Ministerio de Hacienda; 6) Ministerio de Planificación Nacional y Política Económica.

\section{Dirección de Cambio Climático (DCC)}

La Dirección de Cambio Climático fue establecida mediante el Decreto Ejecutivo 35669 como una entidad adscrita al Ministerio del Ambiente y Energía (Gobierno de la República de Costa Rica, 2011). A pesar de estar anclada en el ministerio de la cartera de ambiente, su objetivo es coordinar, gestionar y formular la política pública de cambio climático, promoviendo la integración de una agenda interinstitucional (DCC, 2018).

\section{Consejos Consultivos de Cambio Climático}

Como parte de los compromisos en su Contribución Nacionalmente Determinada (NDC, por sus siglas en inglés) el gobierno de Costa Rica ha establecido dos Consejos Consultivos.

El Consejo Científico de Cambio Climático (4C), creado mediante Decreto Ejecutivo 40615-MINAE, tiene como objetivo "fortalecer la captación de información y la capacidad científica del país en materia de cambio climático, integrando mejor los esfuerzos que ya se vienen realizando de manera aislada". El 4C es un órgano de consulta independiente conformado por 8 académicos, investigadores y expertos nacionales o extranjeros (incluyendo criterios de paridad de género) designados por el MINAE. De manera informal ha sido socializado como el "IPCC costarricense".

Por otro lado, por medio del Decreto Ejecutivo 40616-MINAE se oficializa el Consejo Consultivo Ciudadano de Cambio Climático (5C) que tiene como finalidad "Deliberar de forma independiente acerca del diseño, aplicación y evaluación de las políticas de cambio climático que proponga y opere el gobierno, por medio de sus diferentes instituciones" (Art. 3). El 5C está conformado por 21 representantes de organizaciones sociales, sectoriales y productivas inscritas en el Registro Público. Estas organizaciones representan a la sociedad civil y al sector productivo. En el siguiente apartado se brindan mayores detalles sobre esta estructura de carácter multidimensional.

\section{Comités Municipales de Emergencia (CME)}

Creados mediante Decreto Ejecutivo No. 34361-MP (Gobierno de la República Costa Rica, 2007) los Comités Municipales de Emergencia (CME) se hallan constituidos por el alcalde municipal (quien lo coordina), los vicealcaldes, el jefe o jefa del Depto. de la Unidad Técnica de Gestión Vial, del Depto. de Ingeniería u Obras y cualquier miembro que se halle legitimado por el Concejo Municipal (Apartado c.ii). Según el Reglamento de Organización y Funcionamiento de los Comités Regionales, Municipales y Comunales de Emergencia (CNE, 2009) los CME "se articulan a partir de la participación de representantes de organizaciones, directores o jefes de las instituciones públicas, organizaciones no gubernamentales y empresas privadas con actividad propia en el cantón” (capítulo 2).

\subsection{Avances y retos en las instituciones}

Como se anotara previamente, México posee una estructura federal que integra tres niveles que gobierno: federal, estatal y municipal (algunos autores que consideran la organización comunitaria ejidal posee elementos para ser considerada un cuarto nivel de gobierno, ver por ejemplo, Lozano Moheno (2012). Debido a su menor extensión territorial los demás países previamente analizados poseen estructuras de gobernanza territorial de menor complejidad, primordialmente nacional y municipal. Aunque los restantes países tienen divisiones provinciales (Costa Rica) o departamentales 
(Guatemala y Honduras), en términos prácticos el nivel de incidencia en la toma de decisiones de los departamentos y provincias es limitado, o inexistente por ejemplo en el caso de Costa Rica (González Jacobo, 2008).

Todos los países han realizado esfuerzos por establecer estructuras nacionales de carácter público. Asimismo, han establecido estructuras multidimensionales de variada naturaleza, como lo son el Consejo de Cambio Climático de México, el Consejo Nacional de Cambio Climático de Guatemala, el Comité Interinstitucional de Cambio Climático de Honduras y el Consejo Consultivo Ciudadano de Cambio Climático de Costa Rica.

México se destaca por poseer un engranaje de instituciones a múltiples niveles amparadas en la legislación marco y que conforman su Sistema Nacional de Cambio Climático (SINACC). En el caso de Guatemala y Honduras, aunque han realizado grandes esfuerzos para proponer una nueva institucionalidad por medio de la legislación marco, no tienen un sistema institucional de cambio climático tan articulado como el del caso anterior.

En este ámbito, el caso de Costa Rica es singular, toda vez que, aunque no posee una legislación general de cambio climático ha realizado esfuerzos por lograr una mayor articulación institucional a través del uso de decretos ejecutivos. Uno de los retos de este país es poder brindar mayor seguridad jurídica a la institucionalidad nacional relativa al cambio climático por medio de la actualización de su marco normativo; por ejemplo, a través de una legislación marco de cambio climático. La aprobación de una legislación marco "blindaría" los esfuerzos hasta ahora realizados de potenciales cambios abruptos en el poder ejecutivo como ha sucedido en otros países.

Por otra parte, en Mesoamérica la rectoría de la temática de cambio climático recae en la responsabilidad de los ministerios o secretarias de ambiente. Por lo tanto, la agenda climática de la región continúa estando circunscrita a la temática ambiental, a pesar de los llamados desde la academia para que el cambio climático sea abordado como un problema de desarrollo (Parry, 2009) y, como tal, liderado por los ministerios de desarrollo o planificación.

Finalmente, como se ha mencionado, una de las semejanzas más sobresalientes en los arreglos institucionales en los países analizados, es la creación de estructuras multidimensionales, mismas que se describen en mayor detalle en la sección siguiente.

\subsection{Estructuras multidimensionales emergentes}

Una de las respuestas para enfrentar el cambio climático desde la perspectiva de la gobernanza ha sido la conformación de nuevos arreglos institucionales (Fröhlich \& Knieling, 2013).

En la medida en que los países transitan de la formulación de políticas públicas, a la implementación surgen novedosas estructuras de gobernanza (Chaudhury et al., 2016). Dichas estructuras reconocen que los retos del cambio climático superan la capacidad y la legitimidad de las organizaciones individuales y emplean un abordaje multisectorial y multinivel (Girard et. al., 2015).

En adelante, dichas estructuras emergentes compuestas por diversas organizaciones independientes una de la otra, serán catalogadas como "multidimensionales". En el cuadro 3 se presentan las estructuras multidimensionales seleccionadas y las variables que serán analizadas en esta sección. 


\section{Cuadro 5.3 Estructuras multidimensionales para la gobernanza del cambio climático y variables de análisis}

\begin{tabular}{|ll|ll|}
\hline \multicolumn{1}{|c|}{ Estructuras multidimensionales } & \multicolumn{2}{|c|}{ Variables de análisis } \\
\hline a. Consejo Consultivo de Cambio Climático del & 1. & Estatus legal \\
Estado de Chiapas & 2. & Participantes y roles \\
b. Consejo Nacional de Cambio Climático de & 3. & Funciones \\
& Guatemala & 4. Financiamiento \\
c. Comité Técnico Interinstitucional de Cambio & 5. & Procesos internos y toma de decisiones \\
d. Climático de Honduras & Consejo Consultivo Ciudadano de Cambio & & \\
Climático (5C) de Costa Rica & & \\
\hline
\end{tabular}

Del análisis que realizan Chaudhury et al. (2016), respecto de los nuevos arreglos institucionales para la adaptación al cambio climático corresponde destacar (p. 244) que "Estas estructuras tienen muchos de los elementos que caracterizan a las organizaciones formales, como objetivos, reglas, sistemas de reporte, procedimientos de monitoreo y evaluación para alinear todas sus actividades. Aun así, dependen de actores autónomos (normalmente otras organizaciones) para poder implementar sus propias iniciativas mientras que cada una tiene su propio alcance organizacional, agenda, mediciones de éxito, lenguaje, y abordaje".

\subsubsection{Consejo Consultivo de Cambio Climático del Estado de Chiapas}

Esta estructura fue establecida por medio de la Ley para la Adaptación y la Mitigación ante el Cambio Climático en el Estado de Chiapas que en su Art. 67 dicha ley establece:

"Se crea el Consejo Consultivo de Cambio Climático del Estado de Chiapas, que es el órgano permanente de consulta de la Comisión ${ }^{2}$, se constituirá con un mínimo de quince integrantes provenientes de los sectores social, privado y académico, con reconocidos méritos y experiencia en cambio climático, que serán designados por el Presidente de la Comisión, a propuesta de sus integrantes, y conforme a lo que al efecto se establezca en el Reglamento Interno del Consejo, debiendo garantizarse el equilibrio entre los sectores e intereses respectivos."

La conformación del Consejo Consultivo en el año 2018 era de 12 integrantes del sector civil, 4 integrantes del sector académico y ninguno del sector privado.

La Ley establece que el Consejo debe estar encabezado por un presidente y un secretario, elegidos a través por mayoría de sus integrantes, quienes permanecerán en el cargo por un periodo de tres años y podrán ser reelectos por un periodo adicional (Art. 68). Uno de los aspectos sobresalientes de la conformación de este Consejo es que sus integrantes ejercen su puesto a título personal "con independencia de la institución, empresa u organización de la que formen parte o en la cual presten sus servicios" (Art. 69).

El Consejo tiene las siguientes funciones:

I. Asesorar a la Comisión en los asuntos de su competencia.

II. Recomendar a la Comisión realizar estudios y adoptar políticas, acciones y metas tendientes a enfrentar los efectos adversos del Cambio Climático.

2 Comisión de Coordinación Intersecretarial de Cambio Climático del Estado de Chiapas, órgano responsable de coordinar la formulación e instrumentación de la política estatal de Cambio Climático. 
III. Promover la participación social, informada y responsable, a través de las consultas públicas que determine en coordinación con la Comisión.

IV. Dar seguimiento a las políticas, acciones y metas previstas en la presente Ley, evaluaciones del Programa Estatal de Cambio Climático, la Estrategia Estatal de REDD+; así como formular propuestas en materia de Cambio Climático a la Comisión, la Secretaría y la Subsecretaría.

V. Integrar Grupos de Trabajo especializados que coadyuven con las atribuciones de la Comisión y las funciones del Consejo.

VI. Integrar, publicar y presentar a la Comisión, a través de su Presidente, el informe anual de sus actividades, a más tardar en el mes de febrero de cada año.

VII. Las demás que se establezcan en el Reglamento Interno o las que le otorgue la Comisión.

Lamentablemente la norma que crea el Consejo no hace mención respecto de su financiamiento. En lo que respecta a los procedimientos internos estos son consensuados por sus miembros (la aprobación de un reglamento interno ha sido un engorroso proceso de negociación para poner a las diversas partes de acuerdo). Entre los resultados alcanzados por Consejo hasta la fecha se destaca el afianzamiento de un espacio de deliberación de expertos en el tema a nivel estatal. Además, el Consejo constituye una plataforma en la que se presentan experiencias diversas que pueden ser transmitidas a la Comisión Intersecretarial de Cambio Climático para ser consideradas en la formulación de la política pública.

\subsubsection{Consejo Nacional de Cambio Climático de Guatemala (CNCC)}

Esta estructura fue creada mediante la Ley Marco para Regular la Reducción de la Vulnerabilidad, la Adaptación Obligatoria ante los Efectos del Cambio Climático y la Mitigación de Gases de Efecto Invernadero (Congreso de la República de Guatemala, 2013). Está encabezada por el Presidente de la República de Guatemala y conformada por los siguientes actores representantes de tres distintos sectores (Art. 8) (ver cuadro 5.4).

\section{Cuadro 5.4 Representación en el Consejo Nacional de Cambio Climático}

\begin{tabular}{|c|c|c|c|}
\hline & Público & Privado & Civil \\
\hline 1. & Presidente de la República & $\begin{array}{l}\text { 1. Un representante del } \\
\text { Comité de Asociaciones } \\
\text { Comerciales, Industriales y } \\
\text { Financieras }\end{array}$ & $\begin{array}{l}\text { Un representante de } \\
\text { organizaciones indígenas }\end{array}$ \\
\hline 2. & $\begin{array}{l}\text { Ministro de Ambiente y } \\
\text { Recursos Naturales }\end{array}$ & $\begin{array}{l}\text { 2. Un representante de la } \\
\text { Cámara de Industria }\end{array}$ & $\begin{array}{l}\text { 2. Un representante de } \\
\text { organizaciones campesinas }\end{array}$ \\
\hline 3. & $\begin{array}{l}\text { Ministro de Agricultura, } \\
\text { Ganadería y Alimentación }\end{array}$ & $\begin{array}{l}\text { 3. Un representante de la } \\
\text { Cámara del Agro }\end{array}$ & $\begin{array}{l}\text { 3. Un representante de } \\
\text { autoridades indígenas } \\
\text { (AGAAl) }\end{array}$ \\
\hline
\end{tabular}




\begin{tabular}{|c|c|c|}
\hline Público & Privado & Civil \\
\hline 4. Ministro de Energía y Minas & $\begin{array}{l}\text { 4. Un representante de las } \\
\text { universidades privadas del } \\
\text { país }\end{array}$ & $\begin{array}{l}\text { 4. Un representante de } \\
\text { la Asociación Nacional } \\
\text { de Organizaciones No } \\
\text { Gubernamentales de } \\
\text { Recursos Naturales y Medio } \\
\text { Ambiente, (ASOREMA), } \\
\text { avalado por la Mesa } \\
\text { Nacional de Cambio } \\
\text { Climático }\end{array}$ \\
\hline $\begin{array}{l}\text { 5. Ministro de Comunicaciones, } \\
\text { Infraestructura y Vivienda }\end{array}$ & & \\
\hline $\begin{array}{l}\text { 6. Secretario Ejecutivo de la } \\
\text { Coordinadora Nacional para } \\
\text { la Reducción de Desastres } \\
\text { (CONRED) }\end{array}$ & & \\
\hline $\begin{array}{l}\text { Un representante de la } \\
\text { Asociación Nacional de } \\
\text { Municipalidades (ANAM) }\end{array}$ & & \\
\hline $\begin{array}{l}\text { 8. Un representante de la } \\
\text { Universidad de San Carlos } \\
\text { de Guatemala }\end{array}$ & & \\
\hline
\end{tabular}

De acuerdo con la ley, las funciones del Consejo Nacional son "la regulación, la supervisión de la implementación de acciones y resolución de conflictos, para dar seguimiento a la puesta en ejecución de las acciones derivadas de esta ley, incluyendo la política nacional de cambio climático, el fondo de cambio climático, las estrategias y los planes y programas de acción en mitigación (reducción de emisiones) y la adaptación a los impactos del cambio climático” (Art. 8).

La normativa no hace mayor referencia a las funciones del Consejo Nacional ni al financiamiento para su funcionamiento. En la práctica los procesos internos del Consejo Nacional han sido complejos dada la diversidad de posiciones que convergen en esta plataforma. En cuanto a los resultados alcanzados hasta la fecha se destaca la aprobación del Plan de Acción Nacional de Cambio Climático.

\subsubsection{Comité Técnico Interinstitucional de Cambio Climático de Honduras (CTICC)}

El Comité Técnico Interinstitucional de Cambio Climático de Honduras fue establecido por la Ley de Cambio Climático (Congreso Nacional de Honduras, 2014). Según se desprende de dicha ley, el comité fue creado "como un órgano permanente de apoyo y consulta a la Dirección de Cambio Climático y al Comité Interinstitucional de Cambio Climático en aquellos casos en que amerite un amplio análisis y participación" (Art. 13).

El comité es una estructura de apoyo y consulta. La ley no establece que las recomendaciones tengan un carácter vinculante ni tampoco hace referencia al financiamiento del comité.

El Artículo 13 de la apuntada ley establece que el CTICC debe estar conformado por las siguientes organizaciones: 


\section{Cuadro 5.6 Representantes del Comité Técnico Interinstitucional de Cambio Climático de Honduras}

\begin{tabular}{|c|c|c|}
\hline Público & Privado & Civil \\
\hline $\begin{array}{l}\text { 1. Secretaría de Estado en } \\
\text { el Despacho de Recursos } \\
\text { Naturales y Ambiente } \\
\text { (coordinación a través } \\
\text { de Dirección de Cambio } \\
\text { Climático) }\end{array}$ & $\begin{array}{l}\text { 1. Consejo Hondureño de la } \\
\text { Empresa Privada (COHEP) }\end{array}$ & $\begin{array}{l}\text { 1. Fundación de Iniciativas } \\
\text { de Cambio Climático de } \\
\text { Honduras }\end{array}$ \\
\hline $\begin{array}{l}\text { 2. Secretaría de Estado en el } \\
\text { Despacho de Educación }\end{array}$ & & $\begin{array}{l}\text { 2. Integrantes de la Sociedad } \\
\text { Civil organizada, afines } \\
\text { al tema y que a criterio } \\
\text { del Comité puedan ser } \\
\text { convocados. }\end{array}$ \\
\hline $\begin{array}{l}\text { 3. Secretaría de Estado en el } \\
\text { Despacho de Finanzas }\end{array}$ & & \\
\hline $\begin{array}{l}\text { 4. Secretaría de Estado en } \\
\text { el Despacho de Obras } \\
\text { Públicas, Transporte y } \\
\text { Vivienda }\end{array}$ & & \\
\hline $\begin{array}{l}\text { 5. Secretaría de Estado en el } \\
\text { Despacho de Agricultura y } \\
\text { Ganadería }\end{array}$ & & \\
\hline $\begin{array}{l}\text { 6. Secretaría de Estado en el } \\
\text { Despacho de Defensa }\end{array}$ & & \\
\hline $7 \begin{array}{l}\text { Secretaría Técnica } \\
\text { de Planificación y de } \\
\text { Cooperación Externa }\end{array}$ & & \\
\hline $\begin{array}{l}\text { 8. Instituto Nacional de } \\
\text { Conservación Forestal Áreas } \\
\text { Protegidas y Vida Silvestre } \\
\text { (ICF) }\end{array}$ & & \\
\hline $\begin{array}{l}\text { 9. Instituto Hondureño de } \\
\text { Turismo (IHT) }\end{array}$ & & \\
\hline $\begin{array}{l}\text { 10. Empresa Nacional de } \\
\text { Energía Eléctrica (ENEE) }\end{array}$ & & \\
\hline $\begin{array}{l}\text { 11. Comisión de Medio } \\
\text { Ambiente y Cambio } \\
\text { Climático del Congreso } \\
\text { Nacional }\end{array}$ & & \\
\hline $\begin{array}{l}\text { 12. Asociación de Municipios de } \\
\text { Honduras (AMHON) }\end{array}$ & & \\
\hline $\begin{array}{l}\text { 13. Consejo de Educación } \\
\text { Superior (CES) }\end{array}$ & & \\
\hline $\begin{array}{l}\text { 14. Comité Permanente de } \\
\text { Contingencia (COPECO) }\end{array}$ & & \\
\hline
\end{tabular}


EI CTICC ha sido convocado una cantidad limitada de veces desde su conformación, restringiéndose a dar el visto bueno a las políticas públicas a nivel nacional relativas al cambio climático. En lo relativo a los procesos internos del CTICC, estos han sido cordiales a pesar de su diversa representación. Entre los resultados alcanzados por el CTICC a la fecha está el de brindar insumos a política pública, tales como el Plan Nacional de Adaptación. Una de las principales limitaciones ha sido la de la carencia de recursos para convocar a sus miembros en forma periódica, toda vez que esta estructura no cuenta con fondos propios.

\subsubsection{Consejo Consultivo Ciudadano de Cambio Climático (5C) de Costa Rica}

Esta estructura de gobernanza (conocida como el " $5 \mathrm{C}$ ") fue inicialmente propuesta en la Contribución Prevista Nacionalmente Determinada (INDC por sus siglas en inglés) de Costa Rica ante la Conferencia de las Partes (COP21) de la CMNUCC. Una vez ratificado el Acuerdo de París en 2016, los compromisos presentados en la INDC pasaron a ser Contribuciones Nacionalmente Determinadas (NDCs, por sus siglas en inglés). En el año 2017 el Gobierno de Costa Rica afirmó el 5C mediante el Decreto Ejecutivo 40616- MINAE.

Esta plataforma de consulta y control ciudadano se encuentra conformada por organizaciones sociales, sectoriales y productivas (asociaciones, fundaciones, cooperativas, cámaras). Estas organizaciones deben estar legalmente inscritas ante el Registro Nacional, contar con más de tres años de existencia, estar interesadas en la acción climática y ser capaces de aportar al proceso de carácter nacional. Forman parte de esta estructura además el Ministro de Ambiente y Energía (o el representante que este designe) y el director o directora de la Dirección de Cambio Climático, quienes tendrán derecho de voz, pero no de voto, y no pueden ocupar puestos en el comité directivo (Art. 4).

El Artículo 6 del Decreto Ejecutivo establece que el 5C estará conformado por un total de 21 miembros plenos, designados por un periodo de dos años representando a una diversidad de sectores como se refleja en el cuadro 6.

\section{Cuadro 5.6 Representantes del Consejo Consultivo Ciudadano de Cambio Climático (5C)}

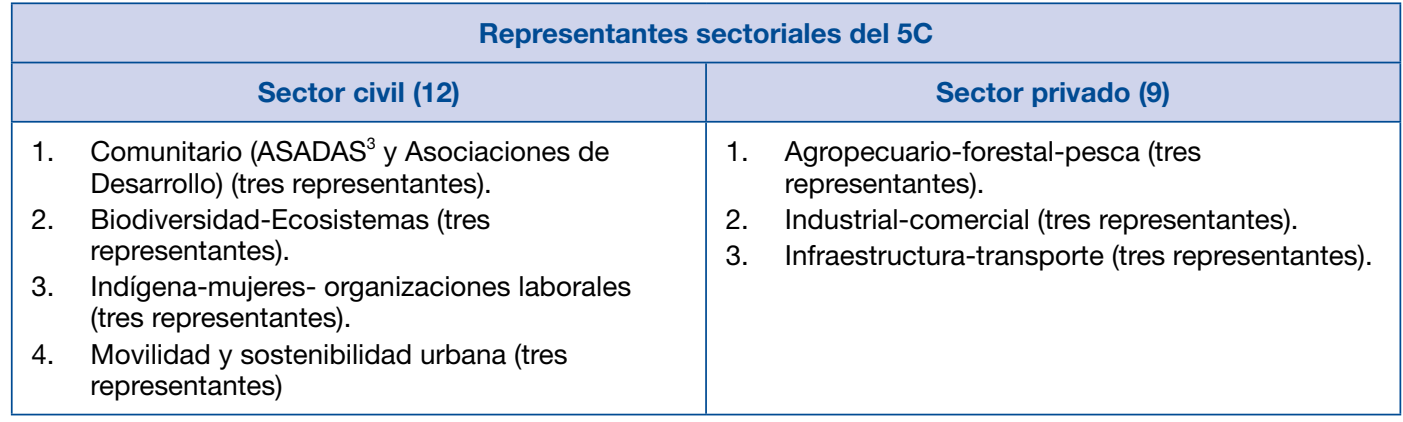

Además, el Decreto determina que la diferencia entre la representación de hombres y mujeres no puede ser superior a uno (Ley No. 8901 y voto 004630-2014 de la Sala Constitucional). Asimismo, se

3 ASADAS: Asociaciones Administradoras de Sistemas de Acueductos y Alcantarillados Comunales de Costa Rica. 
insta a los distintos sectores a integrar a jóvenes menores de 35 años en sus representaciones ante el 5C (Art. 6) El plenario elegirá a un comité directivo compuesto por un presidente, un vicepresidente y un secretario (Art. 7 y 8 ).

El 5C es una plataforma de deliberación, consulta, sensibilización, coordinación, auditoria, y relación con el Objetivo de Desarrollo Sostenible número 13 "Acción por el Clima". Específicamente, entre sus atribuciones el Artículo 3 establece:

1. Deliberar de forma independiente acerca del diseño, aplicación y evaluación de las políticas de cambio climático que proponga y opere el gobierno, por medio de sus diferentes instituciones.

2. Responder las consultas que presente el MINAE u otras instancias públicas sobre el diseño, aplicación y evaluación de sus políticas, programas y métricas climáticas.

3. Generar las actividades que se consideren necesarias para aumentar el nivel de información y sensibilización de la ciudadanía en relación al Cambio Climático.

4. Mejorar los niveles de coordinación y comunicación entre la administración pública y la ciudadanía.

5. Servir de espacio de auditoría ciudadana a cargo de analizar, discutir y apoyar la implementación de la Contribución Prevista y Determinada a Nivel Nacional presentada por Costa Rica ante la Conferencia de las Partes 21 celebrada en París en diciembre 2015.

6. Interactuar con las instancias de gobernanza establecidas para los Objetivos de Desarrollo Sostenible de las Naciones Unidas (Decreto No. 40203-PLAN-MINAE), generando insumos sobre los avances en el cumplimiento del Objetivo 13 (sobre el combate al cambio climático y sus efectos), de los Objetivos de Desarrollo Sostenible en el marco de la Agenda 2030, brindándoles una retroalimentación para las instituciones correspondientes.

El decreto de creación del 5C no hace referencia al financiamiento para el funcionamiento de este, aunque deja en claro que la participación de los representantes de los distintos sectores en el 5C será voluntaria y ad-honorem (Art. 5).

El 5C es una plataforma emergente de muy reciente formación. El proceso de conformación del reglamento interno brinda algunas señales de los complejos procesos de negociación que se dan en estructuras de naturaleza multidimensional.

\subsubsection{Análisis comparativo de las estructuras multidimensionales}

Aunque no existe una conformación ideal para las estructuras multidimensionales (Chaudhury et al., 2016) el análisis de la institucionalidad emergente brinda algunas lecciones relevantes. A continuación, se analizan en forma comparada las estructuras multidimensionales descritas en este capítulo (ver cuadro 5.3) siguiendo las variables de análisis previamente citadas: 1) estatus legal; 2) participantes; 3) funciones; 4) financiamiento; 5) procesos internos; y 6) resultados y retos.

\section{Estatus legal}

En lo que respecta al estatus legal de estas estructuras, la mayoría derivan de legislación parlamentaria. Tres de estas están estipuladas en leyes marco de cambio climático (Chiapas, Guatemala y Honduras) y una de un decreto ejecutivo (Costa Rica). Las diferencias en lo relativo al asidero legal están en la falta de una ley marco de cambio climático en Costa Rica. Esto lleva a concluir que el $5 \mathrm{C}$ podría ser eliminado por medio un decreto presidencial, a diferencia de las otras estructuras que se sustentan en leyes aprobadas por los respectivos parlamentos. 


\section{Participantes y responsabilidades}

Aunque la membresía en las estructuras comparte generalidades, existen detalles importantes que las diferencian. Las cuatro estructuras multidimensionales analizadas integran actores de la sociedad civil y del sector privado, mientras que dos de estas también incorporan plenamente a actores del sector público (Honduras y Guatemala). Más allá de estas generalidades en su conformación, estas varían sustancialmente en cuando a la representación por sector y en la forma de elegir a los representantes (ver cuadro 5.7).

A manera de ejemplo, en el Consejo Consultivo de Cambio Climático de Chipas los miembros ejercen el puesto a título personal (con independencia institucional) mientras que en las restantes estructuras las personas representan instituciones formales a cuáles pertenecen. Asimismo, en Chipas se incorpora a representantes del "sector académico" junto a representantes del sector civil y privado, "debiendo garantizarse el equilibrio entre los sectores e intereses respectivos" lo cual, en términos prácticos, realza la participación de la academia. Por otro lado, como se indicó anteriormente, en la conformación actual de este Consejo no hay representación del sector privado, lo cual va en contraposición del espíritu con que los legisladores conformaron dicha estructura.

\section{Funciones}

Entre las funciones comunes de las estructuras de gobernanza analizadas destaca la de fungir como órganos de consulta y supervisión de políticas públicas. Tres de las cuatro estructuras analizadas incluyen dicha función en forma explícita, mientras que el Consejo Nacional de Cambio Climático de Guatemala funge como ente de "regulación, la supervisión de la implementación de acciones y resolución de conflictos", como se resume en el cuadro 5.9. Sin embargo, las consultas hasta ahora realizadas a estas organizaciones han sido más de carácter formal para la aprobación de políticas públicas ya establecidas. Por ejemplo, solicitud de ajustes para la aprobación del Plan de Acción Nacional de Cambio Climático de Guatemala por parte del Consejo Nacional de Cambio Climático, como se mencionará anteriormente.

\section{Financiamiento}

Ninguno de los instrumentos que dan origen a estas estructuras hace mención al financiamiento propio Esto representa una de las mayores omisiones y, al mismo tiempo, uno de los mayores retos que comparten para enfrentar el cambio climático. La falta de recursos económicos propios sin duda alguna limita sus acciones y es un aspecto que debe de ser solucionado en el corto plazo si se desea lograr su sostenibilidad.

\section{Procesos internos}

Las estructuras multidimensionales de cambio climático enfrentan varios retos en sus procesos internos. Entre los principales desafíos identificados por los miembros de las estructuras que fueron consultados se destacan los múltiples intereses de los actores involucrados. Aunque en teoría esas plataformas están pensadas para lograr consensos con un objetivo común, la realidad es que sus miembros representan intereses tan disímiles como los que están presentes en la sociedad misma.

Aunado a lo anterior, los representantes en estas estructuras provienen de múltiples experiencias de trabajo, contextos socioculturales y disciplinas académicas. En primera instancia esto no debería tener mayor relevancia dado que la diversidad de estas estructuras es conocida de antemano por los distintos actores que las conforman. En la práctica, la realidad es mucho más compleja, por lo que tareas básicas como el establecimiento de reglas internas de procedimiento ha sido lento y engorroso dada la diversidad de perspectivas que confluyen en estos espacios. 


\section{Resultados}

Las estructuras multidimensionales analizadas tienen finalidades diversas dentro del ámbito del cambio climático. Aunque comparten algunos rasgos comunes que permiten incluirlas dentro de una categoría de institución formal con características multidimensionales (ver cuadro 5.1), cada país ha ido ajustando sus organizaciones conforme a la institucionalidad formal existente y a su propia visión de la gobernanza para el cambio climático.

Esto tiene como consecuencia que cada organización posee metas diferenciadas de acuerdo con la finalidad con la que fue establecida. Así, por ejemplo, existen estructuras de consulta que poseen una conformación más general como el Consejo Consultivo Ciudadano de Cambio Climático de Costa Rica, mientras otras poseen una orientación más técnica y especializada, como se intuye del nombre del Comité Técnico Interinstitucional de Cambio Climático de Honduras.

Cualquiera que sea la finalidad de estas estructuras de gobernanza, lo cierto es que al ser instituciones de reciente formación es limitado todavía el análisis que se puede realizar de sus resultados. Por otro lado, una característica común (y a la vez uno de los mayores retos que enfrentan este tipo de organizaciones) es la dificultad para reunir a una diversidad de actores ubicados en distintas partes del país o del Estado y que poseen otras responsabilidades que emanan de sus agendas de trabajo en sus respectivos ámbitos de acción.

\section{Cuadro 5.7 Resumen de caracterización de las estructuras multidimensionales}

\begin{tabular}{|c|c|c|c|c|c|}
\hline & $\begin{array}{l}\text { Organización/ } \\
\text { Variables }\end{array}$ & $\mathrm{CCCH}$ & CN & CTICC & $5 C$ \\
\hline a. & Estatus legal & $\begin{array}{l}\text { Ley Marco de CC } \\
\text { de Chiapas }\end{array}$ & $\begin{array}{l}\text { Ley Marco de CC } \\
\text { de Guatemala }\end{array}$ & $\begin{array}{l}\text { Ley Marco de CC } \\
\text { de Honduras }\end{array}$ & $\begin{array}{l}\text { Decreto Ejecutivo } \\
\text { Costa Rica }\end{array}$ \\
\hline b. & $\begin{array}{l}\text { Participantes } \\
\text { (sectores) }\end{array}$ & $\begin{array}{l}\text { Civil, privado } \\
\text { y académico } \\
\text { (mínimo } 15 \text { con } \\
\text { balance entre } \\
\text { miembros) }\end{array}$ & $\begin{array}{l}\text { Público (7), priva- } \\
\text { do (4) y civil (4) }\end{array}$ & $\begin{array}{l}\text { Público (4), priva- } \\
\text { do (1) y civil }(1+)\end{array}$ & $\begin{array}{l}\text { Privado (9) y civil } \\
\text { (12) }\end{array}$ \\
\hline c. & Funciones & $\begin{array}{l}\text { "Órgano perma- } \\
\text { nente de consulta } \\
\text { de la Comisión" } \\
\text { (Art. 67) }\end{array}$ & $\begin{array}{l}\text { "regulación, la } \\
\text { supervisión de } \\
\text { la implementa- } \\
\text { ción de acciones } \\
\text { y resolución de } \\
\text { conflictos" (Art. 8) }\end{array}$ & $\begin{array}{l}\text { "como un órgano } \\
\text { permanente de } \\
\text { apoyo y consulta } \\
\text { a la Dirección de } \\
\text { Cambio Climático } \\
\text { y al Comité Inter- } \\
\text { institucional de } \\
\text { Cambio Climático } \\
\text { en aquellos casos } \\
\text { en que amerite } \\
\text { un amplio análisis } \\
\text { y participación" } \\
\text { (Art. 13). }\end{array}$ & $\begin{array}{l}\text { Plataforma de } \\
\text { deliberación, } \\
\text { consulta, sensibi- } \\
\text { lización, coordi- } \\
\text { nación, auditoria, } \\
\text { y relación el ODS } \\
13 \text { de Acción por } \\
\text { el Clima } \\
\text { (Artículo 3) }\end{array}$ \\
\hline d. & $\begin{array}{l}\text { Financiamiento } \\
\text { propio }\end{array}$ & No & No & No & No \\
\hline & $\begin{array}{l}\text { Procesos } \\
\text { internos }\end{array}$ & $\begin{array}{l}\text { Complejos dada } \\
\text { la diversidad de } \\
\text { actores }\end{array}$ & $\begin{array}{l}\text { Problemas para } \\
\text { reunirse periódi- } \\
\text { camente }\end{array}$ & $\begin{array}{l}\text { Problemas para } \\
\text { reunirse periódi- } \\
\text { camente }\end{array}$ & $\begin{array}{l}\text { Complejos dada } \\
\text { la reciente forma- } \\
\text { lización }\end{array}$ \\
\hline
\end{tabular}




\begin{tabular}{|l|l|l|l|l|}
\hline \multicolumn{1}{|c|}{$\begin{array}{l}\text { Organización/ } \\
\text { Variables }\end{array}$} & \multicolumn{1}{|c|}{ CCCH } & \multicolumn{1}{|c|}{ CN } & \multicolumn{1}{c|}{ CTICC } & 5C \\
\hline f. Resultados & $\begin{array}{l}\text { Reactivación de } \\
\text { la plataforma } \\
\text { después de un } \\
\text { periodo de inacti- } \\
\text { vidad (2017) }\end{array}$ & $\begin{array}{l}\text { Aprobación del } \\
\begin{array}{l}\text { Plan de Acción } \\
\text { Nacional de } \\
\text { Cambio Climático } \\
\text { (2016) }\end{array}\end{array}$ & $\begin{array}{l}\text { Aprobación del } \\
\begin{array}{l}\text { Plan Nacional de } \\
\text { Adaptación (2018) }\end{array}\end{array}$ & $\begin{array}{l}\text { Aprobación de } \\
\text { su reglamento } \\
\text { interno (2018) }\end{array}$ \\
\hline
\end{tabular}

\section{Retos en el funcionamiento de las estructuras multidimensionales}

Uno de los principales desafíos deriva de la naturaleza misma de las estructuras multidimensionales las cuales están integradas por organizaciones autónomas. Esto implica que cada uno de los representantes posee agendas de trabajo diversas con intereses y visiones muchas veces divergentes. Aunque la pluralidad de actores es una de las razones de ser de estas estructuras como se mencionó, en la práctica, esta diversidad de voces hace que los procesos internos sean complejos debido a la variedad de perspectivas que convergen en ellas.

Sin duda otro de los retos más sobresalientes constituye la necesidad de consolidar los mecanismos de rendición de cuentas sobre la política pública de cambio climático. Al ser estructuras de gobernanza no vinculantes, y más bien tener un carácter consultivo o de rendición de cuentas, la maduración de estos procesos será fundamental. Como se ha reiterado, estos mecanismos de consulta son novedosos en cuanto a su conformación, pero además lo son en términos de formas de control de las políticas del sector público de parte de actores no estatales. Esto implica una transformación en la forma de rendir cuentas, ya que estos representantes tienen un acceso más directo a los tomadores de decisión en el gobierno.

Al mismo tiempo, estas estructuras carecen de financiamiento propio y de otros recursos necesarios para su funcionamiento. Dado que estas estructuras generalmente están conformadas por actores diversos de distintos ámbitos sociales y zonas geográficas, los recursos económicos, humanos, físicos y tecnológicos resultan clave para su sostenibilidad. Irónicamente ninguna de las políticas públicas que respalda la creación de estas estructuras brinda los recursos necesarios para materializar su funcionamiento básico. En la práctica se amparan en partidas específicas de recursos de la cooperación internacional lo cual ensancha la dependencia de la agenda climática de la región en recursos externos como ya se ha subrayado.

Otro de los principales desafíos de estas estructuras de gobernanza es la poca capacidad de diálogo y de negociación. A manera de ejemplo, todas las plataformas multidimensionales analizadas han presentado serios retos para alcanzar acuerdos acerca de su funcionamiento interno. Pareciera ser que los participantes de estas estructuras tienen dificultades para llegar a consensos que les permita avanzar en agendas multisectoriales de desarrollo frente a los retos del cambio climático.

Por otro lado, uno de los mayores beneficios de estas estructuras es que han transmitido los temas de la agenda de adaptación (y la acción climática en general) a actores que tradicionalmente no forman parte de estas discusiones. Este proceso permite, por un lado, concientizar a diversos actores sobre los desafíos y oportunidades del cambio climático y, por otro lado, contar con múltiples perspectivas sobre las posibles soluciones. Como se ha señalado, esto es un imperativo, ya que los retos de adaptación a los impactos del cambio climático requieren del trabajo conjunto de diversos sectores y actores de la sociedad a múltiples niveles (Fröhlich \& Knieling, 2012; Girard et. al., 2015). 
Finalmente, no se debe pasar por alto que todas estas estructuras son de reciente formalización. Por lo tanto, el proceso de adaptación al que está expuesto cualquier institución apenas comienza. Esto lleva a destacar que el análisis efectuado de las estructuras multidimensionales antes citadas resulta preliminar, y será necesario que dar tiempo a que este tipo de instituciones maduren para poder llegar conclusiones más concretas respecto a su funcionamiento y efectividad.

\subsection{Otras estructuras de gobernanza}

Con el objeto de precisar aún más el papel de las instituciones para la adaptación dos estructuras de gobernanza son analizadas, una de ellas de carácter transnacional como la Comisión Binacional de la Cuenca del Río Sixaola (Costa Rica-Panamá) y otra de carácter local, la Coordinadora Departamental de Recursos Naturales y Ambiente de San Marcos (Guatemala).

\subsubsection{Comisión Binacional de la Cuenca del Río Sixaola (CBCRS)}

Esta es una estructura de gobernanza de carácter binacional ubicada en la cuenca transfronteriza del Río Sixaola compartida entre Costa Rica y Panamá. La CBCRS fue establecida en el año 2009 para la implementación del proyecto Gestión Integrada de Ecosistemas en la Cuenca Binacional del Río Sixaola, conocido como Proyecto Binacional Sixaola, el cual estuvo amparado en el Convenio para el Desarrollo Fronterizo Costa Rica-Panamá. En el año 2012 se conformó una alianza estratégica entre las Secretarías Ejecutivas del Convenio para el Desarrollo Fronterizo Costa Rica-Panamá, el Proyecto Binacional Sixaola y la UICN, con el objetivo de contribuir al fortalecimiento de la CBCRS como instancia de promoción y liderazgo de la buena gobernanza y el desarrollo sostenible en la cuenca una vez concluido el Proyecto Binacional Sixaola.

La CBCRS está adscrita el Convenio para el Desarrollo Fronterizo Costa Rica-Panamá y su objetivo es "la coordinación y desarrollo de las acciones necesarias para la gestión integrada de la cuenca binacional del Río Sixaola, la conservación de los recursos naturales y la biodiversidad, la promoción de una producción sostenible y el fortalecimiento del marco institucional binacional, al amparo del Convenio Fronterizo y de la legislación nacional en materia de gestión de cuencas de ambos países" (Reglamento de la CBCRS, Art. 6).

Actualmente, la CBCRS tiene 35 integrantes de Costa Rica y Panamá.

Para consolidar los avances en materia de gobernanza para la adaptación al cambio climático de la CBCRS es importante reforzar las inversiones en la cartera de proyectos de su Plan Estratégico de Desarrollo Territorial Transfronterizo 2017-2021. Para el escalamiento de las acciones de AbE se debe fortalecer el objetivo estratégico de fomentar la diversificación agropecuaria a nivel binacional. Además, es preciso apoyar las acciones de protección y conservación de la cuenca por medio de la conectividad ecológica transfronteriza como medida de adaptación al cambio climático, así como la gestión del recurso hídrico en la cuenca de forma conjunta (Luna \& Cruz, 2018). 


\section{Cuadro 5.8 Integrantes de la CBCRS}

\section{INTEGRANTES COSTA RICA}

1) Ministerio de Ambiente y Energía

2) Ministerio de Salud

3) Ministerio de Obras Públicas y Transporte

4) Ministerio de Planificación y Política Económica

5) Ministerio de Agricultura y Ganadería

6) Comisión Nacional de Prevención de Riesgos y Atención de Emergencias

7) Instituto Costarricense de Turismo

8) Dirección General de Migración y Extranjería

9) Dirección General de Aduanas

10) Municipio de Talamanca

11) Secretaria Ejecutiva del Convenio

Sociedad Civil organizada, un representante de:

a) Asociaciones de productores

b) Organizaciones o asociaciones de desarrollo comunal

c) Asociaciones de turismo

Representantes Indígenas de:
a) ADITIBRI
b) ADITICA
c) Keköldi

Proyectos y programas de la cuenca binacional del río Sixaola, desarrollados en el marco del Convenio Fronterizo en el entendido de que dichos representantes no contribuyen a la formación del quórum.

\section{INTEGRANTES PANAMÁ}

1) Ministerio de Ambiente

2) Ministerio de Salud

3) Ministerio de Obras Públicas

4) Ministerio de Economía y Finanzas

5) Ministerio de Desarrollo Agropecuario

6) Sistema Nacional de Protección Civil

7) Autoridad Nacional de Turismo

8) Servicio Nacional de Migración

9) Autoridad Nacional de Aduanas

10) Municipio de Changuinola

11) Municipio de Bocas del Toro

12) Secretaria Ejecutiva del Convenio

Sociedad Civil organizada, un representante de:

a) Asociaciones de productores

b) Organizaciones o asociaciones de desarrollo comunal

c) Asociaciones de turismo

Representantes Indígenas de:
a) Ngäbe
b) Naso
c) Bribri

Fuente: UICN (2017)

\subsubsection{Coordinadora Departamental de Recursos Naturales y Ambiente de San Marcos (CORNASAM)}

La CORNASAM fue establecida en el año 2004 como una iniciativa de las organizaciones internacionales UICN, CARE International, así como del Instituto Nacional de Bosques (INAB) de Guatemala ante la necesidad de articular los esfuerzos de las instituciones relacionadas con la gestión de recursos naturales a nivel departamental. La CORNASAM es una estructura de coordinación técnico-política, sin constitución legal, compuesta por instituciones gubernamentales y no gubernamentales del departamento de San Marcos, ubicado en la zona fronteriza con el Estado de Chiapas, México.

El objetivo de esta estructura subnacional y multidimensional es facilitar la cooperación y apoyar a la gestión integral de los recursos naturales y el medio ambiente a través de la elaboración de propuestas conjuntas que promuevan el desarrollo sostenible en el departamento de San Marcos. La CORNASAM está conformada por una asamblea general y una junta directiva; esta última integrada por un coordinador general, una secretaria y tres coordinadores de comisiones interinstitucionales: 
la Comisión de la cuenca El Naranjo, la Comisión de la cuenca Coatán-Suchiate y la Comisión de la cuenca Cuilco. Cada comisión de cuenta a su vez con una estructura similar para las microcuencas que las conforman.

Para la consolidación de la CORNASAN es necesario fortalecer el proceso a múltiples niveles. A nivel local se debe de continuar fortaleciendo capacidades de las comunidades y los municipios con el fin de facilitar la conformación de una estrategia común de adaptación. Además, es necesario crear un centro de información climática subnacional que ayude a la toma de decisiones y el involucramiento del sector privado.

A nivel departamental, se debe continuar el fortalecimiento de la CORNASAM para recopilar información de los Planes de Desarrollo Municipal e incluirlos en su Plan de Operación Anual. Asimismo, es importante que el Presupuesto Departamental contemple la asignación de una partida para la implementación efectiva del Plan de Operación Anual.

A nivel nacional, se debe promover la reactivación del Grupo de Coordinación Interinstitucional para el manejo sustentable de los recursos naturales, como una plataforma de coordinación intersectorial y multinivel. Finalmente, se debe reforzar el enlace entre la CORNASAM y el Consejo Nacional de Cambio Climático con el objeto de facilitar el escalamiento de las acciones de adaptación y el enfoque de AbE del nivel subnacional al nivel nacional (Martínez \& Navarro, 2019).

La CORNASAM posee la siguiente membresía:

\section{Cuadro 5.9 Integrantes de la CORNASAM}

\section{Líderes locales}

- Representantes comunitarios

- Representantes municipales

- Representantes de mancomunidades

Delegaciones del gobierno nacional

- Ministerio de Ambiente y Recursos Naturales (MARN)

- Instituto Nacional de Bosques (INAB)

- Consejo Nacional de Áreas Protegidas (CONAP)

- Ministerio de Agricultura y Ganadería (MAGA)

- Secretaria de Planificación y Programación de la Presidencia (SEGEPLAN)

\section{Organizaciones internacionales}

- Organización de las Naciones Unidas para la Alimentación y la Agricultura (FAO)

- Programa de las Naciones Unidas para el Desarrollo (PNUD)

ONGs y organizaciones intergubernamentales

- Care International

- UICN, entre otras 


\subsection{Implementación de la AbE: características fundamentales de las instituciones}

A continuación, se exponen las condiciones necesarias para que las instituciones puedan facilitar la AbE.

\subsubsection{Flexibles}

La flexibilidad es una característica fundamental de la gobernanza para hacer frente a la incertidumbre y a la complejidad del cambio climático. Por tanto, las instituciones formales de gobernanza para el cambio climático deben ser lo suficientemente flexibles para adaptarse a los retos del calentamiento global.

La flexibilidad institucional es la capacidad de las organizaciones de adaptarse a cambios constantes, incluidos aquellos derivados del calentamiento global. Las instituciones formales tienden a ser conservadoras y poco flexibles, por lo que adaptarse a los impactos del cambio climático implica un gran reto (Gupta et al. 2010; Sánchez \& Roberts, 2013). Algunos interrogantes importantes de efectuar en este espacio serían ¿Cómo reaccionan las instituciones del Estado ante fenómenos hidrometeorológicos extremos cómo sequías o inundaciones, que se ven exacerbados por el cambio climático? ¿Cómo se preparan las instituciones ante eventos de evolución lenta como el aumento del nivel mar y sus efectos en el corto, mediano y largo plazo?

Las instituciones formales existentes y emergentes deberían evolucionar para incorporar la flexibilidad en la toma de decisiones. Esto se logra por medio de procesos que les permitan incorporar la mejor información disponible para la toma de decisiones por medio de una gestión adaptativa (Gupta et al. 2010). La gestión adaptativa requiere un cambio de paradigma que supere la visión de estacionalidad en el comportamiento del clima e incorpore elementos de incertidumbre, así como la mejor información y modelos disponibles en el proceso de toma decisiones (Sanchez \& Roberts, 2013).

La flexibilidad institucional deriva del reconocimiento de la complejidad de los sistemas climáticos y humanos, así como de la necesidad de establecer mecanismos que incorporen nueva información para la toma de decisiones de manera constante. Dentro de los sistemas institucionales de cambio climático de los países analizados existen organizaciones que cumplen - en mayor o menor medida de acuerdo con su naturaleza y sus capacidades - el papel de generadores de información científica para la toma de decisiones, con el fin de reducir las incertidumbres asociada al cambio climático. Algunas de estas instituciones se destacan en el cuadro siguiente. 


\section{Cuadro 5.10 Instituciones formales de generación de información científica} para la toma de decisiones frente al cambio climático

\begin{tabular}{|l|l|l|l|l|}
\hline \multicolumn{1}{|c|}{ País } & \multicolumn{1}{|c|}{ México } & \multicolumn{1}{c|}{ Guatemala } & \multicolumn{1}{c|}{ Honduras } & \multicolumn{1}{c|}{ Costa Rica } \\
\hline Institución & INECC & SNICC & ONCCDS & 4 C \\
\hline $\begin{array}{l}\text { Tipo de } \\
\text { institución }\end{array}$ & Pública-Nacional & Pública-Nacional & Pública-Nacional & $\begin{array}{l}\text { Multidimensional- } \\
\text { Nacional }\end{array}$ \\
\hline Asidero legal & $\begin{array}{l}\text { Ley marco de } \\
\text { cambio climático }\end{array}$ & $\begin{array}{l}\text { Ley marco de } \\
\text { cambio climático }\end{array}$ & $\begin{array}{l}\text { Iniciativa } \\
\text { de SERNA } \\
\text { (financiamiento } \\
\text { de proyectos de } \\
\text { cooperación) }\end{array}$ & $\begin{array}{l}\text { Decreto Ejecutivo } \\
\text { 40616-MINAE }\end{array}$ \\
\hline
\end{tabular}

Estas instituciones presentan retos importantes en la generación de información para la toma de decisiones. Entre estas instituciones, el INECC de México y el SNICC de Guatemala son parte del sistema nacional de cambio climático (figura 5.1) y fueron creadas por la legislación marco de cambio climático de los respectivos países. Por su parte la ONCCDS de Honduras y el 4C de Costa Rica fueron creados por medio de iniciativas del poder ejecutivo. EI ONCCDS de Honduras no ha sido muy activo hasta el momento y el 4C de Costa Rica fue recientemente ratificado a finales de 2018.

\subsubsection{Multidimensionales}

En Mesoamérica se han conformado instituciones con una diversa participación de diversos sectores a través de mecanismos que permitan una mayor coordinación horizontal entre instituciones de gobierno. Ejemplos de este tipo de plataformas son la Comisión Intersecretarial de Cambio Climático (CICC) de México y el Consejo Sectorial de Ambiente de Costa Rica.

La gobernanza para la adaptación al cambio climático promueve además la integración vertical. Esta se da a través de la creación de instituciones en donde participan representantes de entes nacionales y subnacionales (así como autoridades de diversos sectores) a fin de establecer diálogos para la elaboración de políticas y acciones de adaptación. Mesoamérica ha asistido a la creación de una serie de instituciones formales que promueven la participación de actores en múltiples niveles. Entre este tipo de estructuras se encuentran Consejo de Cambio Climático (C3) de México; el Consejo Nacional de Cambio Climático de Guatemala; el Comité Técnico Interinstitucional de Cambio Climático (CTICC) de Honduras y el Consejo Consultivo Ciudadano de Cambio Climático (5C) de Costa Rica.

\subsubsection{Participativas}

La participación amplia de actores interesados es otra de las características deseadas de las instituciones de gobernanza para hacer frente al cambio climático. Las últimas décadas han asistido al surgimiento de instituciones formales como respuesta al cambio climático (Chaudhury et al., 2016). Mesoamérica no es la excepción tal y como quedó ejemplificado en este capítulo con la creación de organizaciones multidimensionales para dar respuesta al cambio climático. Entre este tipo de estructuras organizativas en los países analizados se destaca la participación de actores no gubernamentales: el Consejo de Cambio Climático (C3) de México; el Consejo Nacional de Cambio Climático de Guatemala; el Comité Técnico Interinstitucional de Cambio Climático (CICC) de Honduras; y el Consejo Consultivo Ciudadano de Cambio Climático (5C) de Costa Rica. Las 
estructuras participativas facilitan la incorporación del enfoque de ecosistemas para la adaptación, al incorporar las experiencias de diversos actores que trabajan con los ecosistemas en el territorio.

\subsubsection{Enfoque ecosistémico}

A los impactos del cambio climático se le suman una sería de efectos acumulados derivados de la sobreexplotación de los ecosistemas naturales por parte del ser humano (Millennium Ecosystem Assessment, 2005). Es así como, a los impactos esperados por el aumento de la temperatura promedio y el consecuente cambio climático, hay que añadirle una serie de presiones relacionadas con el consumo excesivo y que estimulan la expansión de la frontera agrícola y urbana en forma descontrolada a nivel global (Steffen et al., 2015).

Como se mencionara anteriormente, en Mesoamérica existen instituciones formales cuyo objetivo principal es incorporar la ciencia en la toma de decisiones (ver cuadro 5.10). Al ser informadas por la generación de ciencia, estas estructuras pueden servir de agentes en la incorporación de la información que permita conservar la integridad de los ecosistemas como medida de adaptación al cambio climático por medio de los múltiples servicios de apoyo, aprovisionamiento, regulación y culturales que ellos bridan (Millennium Ecosystem Assessment, 2005).

\subsubsection{Formalidad}

En este apartado se detalló el respaldo jurídico que las ampara y del cual emana su sustento legal. De los distintos casos analizados, aunque todos están formalmente constituidos, debe destacarse que varían en lo que a su sustento legal se refiere.

Los arreglos institucionales con mayor soporte legal son los de México, Guatemala y Honduras, respectivamente, ya que su andamiaje institucional se ampara en leyes marco de cambio climático que integran la institucionalidad existente (como los ministerios de ambiente) con la institucionalidad nueva (como las estructuras multidimensionales), así como a través de decretos ejecutivos que los complementan.

En el caso de Costa Rica, si bien el sistema de gobernanza climática ha sido formalizado, al no contar con una ley marco de cambio climático, el sustento legal tiene menor fortaleza jurídica. Aunque el sistema se ampara en institucionalidad existente por ley (como los ministerios), las estructuras multidimensionales emergentes que forman parte del sistema (por ejemplo, el Comité Técnico Interministerial de Cambio Climático y los Consejos Consultivos conocidos como el 4C y 5C) están amparados en decretos ejecutivos que pueden ser modificados en forma relativamente sencilla por el poder ejecutivo.

\subsection{Desafíos y oportunidades de las institucionales para la AbE}

Los desafíos de las instituciones para la adaptación en Mesoamérica son de variada índole, como se fue puesto de manifiesto a lo largo de este capítulo.

\section{Escaso financiamiento}

Uno de los principales desafíos de la institucionalidad para enfrentar al cambio climático es la falta de financiamiento.

Este reto es particularmente agudo en las estructuras locales, multidimensionales, como así también en las direcciones nacionales y estatales de cambio climático. Por ejemplo, las direcciones de cambio 
climático de los tres países centroamericanos y del Estado de Chiapas tienen un limitado número de personal contratado si se tienen en cuenta los desafíos de la agenda climática. En los países de Centroamérica en particular, esto ha generado una dependencia respecto de la cooperación internacional que limita generación de las capacidades institucionales necesarias para dar respuesta a la adaptación al cambio climático en el corto, mediano y largo plazo.

\section{Limitaciones de la agenda de los ecosistemas}

En Mesoamérica, las respuestas para hacer frente al cambio climático utilizando los ecosistemas siguen siendo vistas como un enfoque anclado en la institucionalidad ambiental. Irónicamente esta es una realidad que limita el potencial de los ecosistemas para la adaptación, ya que muchas de las instituciones necesarias para una exitosa implementación de la AbE (ministerios de finanzas, infraestructura, industria, o turismo, entre otros) continúan percibiéndola como una estrategia para la adaptación de los ecosistemas. Esta visión restringe el salto cuantitativo necesario para que la AbE formen parte de estrategias integrales de adaptación de múltiples sectores económicos.

\section{Limitada capacidad de negociación}

Tal y como se señalará, uno de los principales retos de la institucionalidad emergente es la limitada capacidad de negociación en la puesta en práctica de espacios multidimensionales. Por un lado, los múltiples ministerios de gobierno históricamente han trabajado con agendas independientes, las cuales en algunos casos presentan posiciones que se perciben como antagónicas (minería extractiva vis-à-vis protección ambiental). Por otro lado, la articulación de múltiples niveles de gobierno (gobierno nacional y municipal) enfrenta rezagos históricos como la falta de claridad de competencias o el limitado presupuesto municipal lo que limita una adecuada articulación y puesta en marcha de las políticas de adaptación al cambio climático.

\section{Escasa flexibilidad institucional}

Como se expuso, las instituciones formales requieren de una serie de reglas para la efectiva toma de decisiones (Gupta et al., 2010). Por lo tanto, incorporar una mayor flexibilidad a estructuras que tradicionalmente buscan incrementar la certeza implica un cambio de paradigma que reconoce la creciente incertidumbre del contexto que impone el cambio climático. En este escenario, uno de los mayores retos es como lograr la flexibilidad institucional sin olvidar la certeza necesaria de los procesos políticos, legales e institucionales. Este balance pasa por mejorar la incorporación de la más adecuada información disponible para la toma de decisiones en las políticas públicas (Vij et. al. 2017). Este es sin lugar a dudas uno de los mayores retos en una región como Mesoamérica con limitadas capacidades institucionales para generar información que permita la adopción de sólidas políticas públicas.

\section{Limitada participación efectiva}

Los actuales procesos que buscan incrementar la participación por medio de las estructuras de gobernanza novedosas representan un avance, aunque su alcance sigue siendo restringido. Partiendo de la escalera de participación propuesta por Arnstein (1969)4, las estructuras consultivas creadas recientemente en la región Mesoamericana se podrían clasificar dentro de la categoría Colaboración, Delegación de poder, y Control ciudadano). 
intermedia de participación denominada "formulismo", ya que los alcances del involucramiento de sus miembros se limitan a "informar", "consultar" o "apaciguar". Estos niveles de colaboración si bien dan un sentido de "participación" en la toma de decisiones, no brindan a los miembros de estas estructuras poder de decisión sustantivo en la formulación de políticas públicas sobre cambio climático.

\section{Integridad de los ecosistemas}

Por último, el actual modelo de desarrollo enfrenta la paradoja de ser la principal causa de la degradación de los ecosistemas (Buscher, Dressler \& Fletcher 2014). Esta, como el cambio climático, son externalidades que deben de ser internalizados por el modelo imperante de desarrollo en Mesoamérica y en el mundo. Dicha ecuación enfrenta un sinnúmero de retos, ya que las promesas de "desacople" en que han venido trabajando las instituciones del Estado no han tenido el nivel de efectividad que se pensaba. Testimonio de ello es el traslado de las emisiones de Europa hacia China (Pan et. al., 2017) lo cual ha permitido a los habitantes del continente europeo "reducir" sus emisiones de forma artificial. Por lo tanto, las instituciones (entendidas en su aserción más amplia como las reglas de organización de las sociedades) deben ser objeto de una profunda transformación si lo que se pretende es que las soluciones al cambio climático sean exitosas. 


\section{Negociación}

\section{Pascal Girot}

\subsection{Introducción}

El cambio climático sigue su curso inexorable y constituye sin duda unos de los retos más importantes que enfrentarán los países y, entre ellos, los de Mesoamérica, generando impactos en la disponibilidad de recursos naturales como el agua e incidiendo en la productividad primaria de ecosistemas terrestres, dulceacuícolas y marino costeros (IPCC, 2014). Sin embargo, la magnitud, frecuencia y extensión de estos impactos continúan siendo marcados por la incertidumbre; asimismo son inciertas las consecuencias que tendrán dichos impactos sobre sistemas humanos dependientes de estos ecosistemas. Mesoamérica ya ha experimentado los impactos negativos de la variabilidad climática, al registrar pérdidas económicas por eventos hidrometeorológicos extremos, incluyendo episodios de El Niño o La Niña (ENOS).

Ante esta incertidumbre, la toma de decisiones en materia de adaptación debe privilegiar soluciones naturales basadas en los ecosistemas. Esta premisa parte del principio de In Dubio Pro Natura, o el Principio de Precaución, que plantea que, ante la incertidumbre sobre posibles impactos sobre el ambiente, se debe privilegiar a la naturaleza. En lo que a la toma de decisiones relacionada con la AbE respecta, la creación de condiciones para la gobernanza de los ecosistemas a largo plazo, se vuelve crítica para la provisión de bienes y servicios ambientales.

La AbE presenta múltiples retos para las sociedades y, entre ellas, para las mesoamericanas. Los países de Mesoamérica han realizado importantes esfuerzos de conservación in-situ de la biodiversidad. Las áreas protegidas cubren hoy aproximadamente un $25 \%$ de los ecosistemas terrestres y $14 \%$ de los ecosistemas marinos de Centroamérica (Proyecto Estado de la Nación, 2016). Muchas áreas protegidas son establecidas por vía legal con linderos y delimitaciones fijas. Debido a los efectos adversos del cambio climático, los ecosistemas y los sistemas productivos humanos requerirán de ajustes y cambios respecto de su cobertura y de las categorías de manejo. En este sentido, la AbE requiere de flexibilidad y de la creación de espacios y opciones de ajustes a futuro en materia de conservación in situ y de uso sostenible de la biodiversidad.

Toda acción climática debe brindar oportunidades a las comunidades humanas y a los sistemas productivos de adaptarse al cambio climático dentro de los límites impuestos por la provisión de servicios ambientales y la protección de fuentes de agua. Entre los retos de la AbE se encuentra, por un lado, la permanencia de esquemas de conservación in situ, parques nacionales con linderos y categorías de manejo establecidos legalmente y, por otro, por la flexibilidad necesaria para garantizar que estos valores de conservación y los bienes y servicios ambientales que proveen puedan seguir brindándose de cara al cambio climático.

La apuntada flexibilidad pasa por aprovechar una amplia gama de esquemas de conservación y uso sostenible de la biodiversidad y de gestión integrada de recursos hídricos ya existentes tales como los corredores biológicos, las cuencas hidrográficas, las áreas marino-costeras (zona marítimo terrestre), las servidumbres ecológicas, los esquemas de manejo comunitario de bosques y de zonas de recarga hídrica y zonas de pesca responsable, entre otros. 


\subsection{Integración vertical y horizontal}

\subsubsection{Descentralización y desconcentración}

La AbE está determinada territorialmente y requiere, por ende, de un enfoque multi-nivel, multisectorial, inter-ministerial.

La división territorial administrativa de los países mesoamericanos se ha definido con criterios demográficos y electorales y no corresponde a la configuración espacial de los ecosistemas y a las regiones climáticas de un país en particular. En varios países existe una alta concentración del poder de decisión en gobiernos nacionales y escasa participación efectiva de gobiernos locales en temas relevantes a las políticas de cambio climático. El Acuerdo de París de la CMNUCC así como el Marco de Acción de Sendai sobre la reducción del riesgo de desastres señalan, sin embargo, el carácter esencialmente local de la gestión del riesgo y de la adaptación al cambio climático. Asimismo, las potestades de los gobiernos locales en materia de ordenamiento territorial y planificación urbana están claramente definidas en la mayoría de los países del istmo. La implementación de instrumentos normativos internacionales, como el Acuerdo de París de la CMNUCC requiere de una adecuada desconcentración y descentralización del Estado. También necesitan una integración horizontal entre ministerios y una integración vertical entre niveles de gobierno (Federal, Estatal, Provincial, Regional, Municipal, Local).

Entre los principales desafíos de la gestión desconcentrada y descentralizada del territorio quizás el más importante sea la débil transferencia de recursos desde el Gobierno Nacional y la limitada recaudación fiscal por parte de los gobiernos locales. Esto, a su vez, limita la capacidad de inversión pública, de provisión de funcionarios locales para garantizar tareas de prevención del riesgo, manejo y administración de parques nacionales, manejo integrado de recursos hídricos, la planificación de cuencas hidrográficas y de paisajes forestales y agro-productivos. La integración vertical continúa siendo un desafío importante ya que la coordinación entre instituciones nacionales y municipales es limitada e ineficaz en muchos de los países de la región. Esto debilita las acciones colectivas y la aplicación de la normativa en materia de ordenamiento territorial y conservación in situ de la biodiversidad. Ante la ausencia de mecanismos formales de coordinación, existen múltiples ejemplos de mesas de trabajo, tanto nacionales como subnacionales, que buscan una mayor integración horizontal y vertical en la gobernanza climática de los países de la región.

La integración horizontal permite mejorar la coordinación entre diferentes instituciones con mandatos y competencias distintas. Dicha integración requiere de una instancia rectora que pueda asegurar las labores de coordinación o secretariado para convocar a las partes, articular acciones y escalar prácticas de adaptación basada en la comunidad hasta abarcar territorios más amplios (Rossing, T. et al., 2014). En términos pragmáticos, la adaptación debe partir de los esfuerzos ya realizados en materia de planificación territorial, de conservación in situ de la biodiversidad, manejo forestal, gestión de cuencas y recursos marino-costeros. La adaptación puede potenciar estos instrumentos de planificación bio-regional y permitir a distintos actores comprender los riesgos climáticos actuales y futuros y responder preventivamente ante esas amenazas.

Esta gestión prospectiva del riesgo es parte de la adaptación y demanda un fortalecimiento en la articulación entre los niveles de gobierno nacional, regional y local. Las estructuras de gestión descentralizadas constituyen un espacio idóneo para canalizar los esfuerzos en materia de planificación territorial a nivel local para la adaptación al cambio climático en tanto busquen fortalecer 
la participación de actores de la sociedad civil, el sector privado, los gobiernos locales a la par de las instituciones nacionales responsables de aplicar no solo las políticas sino también la ley en materia ambiental y los instrumentos de política de desarrollo económico y de planificación territorial.

\subsubsection{Articulación entre Nación, Región y Municipio}

La adaptación requiere involucrar diferentes niveles de la administración del Estado (provincias, regiones, departamentos, municipios y comunidades), cada uno de ellos con sus complejas relaciones entre autoridades locales y nacionales, actores públicos y privados, muchas veces con mandatos legales diferentes e intereses divergentes.

De allí la necesidad de negociar. Aquí se propone la siguiente tipología de negociaciones, misma que tiene por objeto servir para analizar las instancias de coordinación y negociación existentes y definir mejoras en la gobernanza.

- Entre Estados y organismos internacionales

- Entre Estados sobre ecosistemas compartidos (cuencas transfronterizas, etc.)

- Entre sectores (por ejemplo, agricultura, transporte, energía, ambiente, economía y comercio)

- Entre el Estado y el sector privado

- Entre el Estado nacional y los gobiernos regionales y municipales

- Entre el Estado nacional, los gobiernos municipales y las comunidades

- Entre el Estado y la sociedad civil organizada

Corresponde destacar que esta tipología no es exhaustiva. El tipo de negociación varía de un país a otro, de una situación particular a otra. Existen ejemplos de negociaciones imbricadas, por ejemplo, que parten de un acuerdo entre Estados limítrofes para el manejo de áreas de protección de régimen internacional tales como las Reservas de la Biósfera y los Sitios del Patrimonio Mundial (ambas categorías de manejo administradas por la UNESCO con apoyo de la UICN). La experiencia del Río Yorkín en la frontera entre Costa Rica y Panamá, es una acción de adaptación local que se inscribe en un marco de cooperación binacional más amplio. Ejemplos similares se pueden encontrar tanto en el Golfo de Fonseca entre Honduras y El Salvador, o en el área del Trifinio entre Guatemala, Honduras y El Salvador, o en la Reserva de la Biósfera Maya entre Guatemala, Belice y México.

La naturaleza de la negociación es dictada, en buena medida, por el tipo de recurso a ser gestionado en función de la adaptación, de su escala geográfica y del número de instituciones y actores involucrados. La negociación directa entre el Estado y la sociedad civil se ha dado, por ejemplo, en temas de concesiones forestales comunitarias, como en el caso de Asociación de Comunidades Forestales del Petén (ACOFOP). También en Guatemala, los programas de pago por incentivos forestales (Programa Nacional de Incentivos Forestales-PINFOR-Programa de Incentivos Forestales para Poseedores de Pequeñas Extensiones de Tierra de Vocación Forestal o Agroforestal, PINPEP) a cargo del Instituto Nacional de Bosques (INAB), reconoce un régimen diferenciado de financiamiento hacia pequeños productores, sin títulos de propiedad pero con el usufructo y manejo efectivo de tierras forestales. Existen importantes lecciones aprendidas de estas experiencias comunitarias en términos del reconocimiento por parte del Estado de actores locales como interlocutores válidos en procesos de gobernanza local (en este caso del recurso forestal). Finalmente, hay espacios ya institucionalizados para la negociación entre sectores económicos y el Estado, sea a través de cámaras u otras organizaciones gremiales, o mediante la figura de Uniones de Cámaras o Consejo 
Superiores de la Empresa Privada, que pueden servir de puente para negociar arreglos en materia de legislación sobre recursos hídricos o en materia de zonificación costera.

Estos ejemplos de negociación no tienen lugar en términos abstractos, sino que a menudo se dan a través de procesos de consulta formal o de participación ciudadana y multi-sectorial local o nacional para la definición de políticas públicas relevantes para la adaptación. Dicha negociación debe estar anclada en términos territoriales y referirse a ecosistemas y cuencas específicos. Hay muchas acciones relevantes para la adaptación que no son etiquetadas como adaptación en sí (gestión de zonas de recarga para la provisión de agua potable, reconocimiento de los servicios ambientales provistos por esquemas privados de conservación de la biodiversidad, delimitación de áreas de pesca responsable) pero no por ello menos relevantes.

Al territorializar las negociaciones en materia de adaptación se aprovechan los espacios existentes de participación ciudadana a nivel local y bioregional. Instancias de coordinación inter-institucional existen en varios países de Centroamérica. En Costa Rica, por ejemplo están los Consejos Regionales de Áreas de Conservación (CORAC), los territorios establecidos por el Instituto de Desarrollo Rural (INDER), los Comités de Coordinación Cantonales Inter-institucionales (CCCl) a nivel municipal. Dichos espacios de participación inciden directamente en las tomas de decisiones en materia de administración local, inversión pública y asignación de recursos para la AbE.

\subsubsection{Coordinación intersectorial}

En aquellos países en donde existen políticas públicas y marcos legales en materia de biodiversidad, manejo forestal, gestión de cuencas hidrográficas, manejo de la zona marítima terrestre, se dan amplias oportunidades para aprovechar dichos instrumentos y transversalizar la AbE. Muchos instrumentos legales en materia de biodiversidad y recursos hídricos requieren para su adecuada implementación de los aportes de otros sectores y actores. Varios de estos instrumentos (Leyes Forestales, de Agua, de Conservación de la Biodiversidad) carecen de instancias de gobernanza, tales como los consejos interministeriales o inter-sectoriales, y de claros espacios de coordinación y participación de la sociedad civil. Sería necesario aprovechar los arreglos institucionales existentes, fortaleciendo la trama institucional al servicio de la adaptación al cambio climático y la gestión del riesgo. Esto se debería lograr sin duplicar funciones o crear instituciones especializadas que puedan contribuir a dispersar los esfuerzos y gastar los escasos fundos públicos de forma poca efectiva. Hay instancias de coordinación inter-sectorial en varios países mesoamericanos, tales como el Consejo Consultivo de Sociedad Civil del Sistema de Integración Centroamericano. La Ley de Cambio Climático tanto en Honduras como en Guatemala crean cada una de ellas un Consejo Nacional de Cambio Climático, presidido por el Presidente de la República y atendido por los jerarcas de ministerios e instituciones relevantes (ver capítulo 5). Por ejemplo, Costa Rica tiene una Ley de Biodiversidad (1998), una Política Nacional y Estrategia Nacional de Biodiversidad (2015), una Ley Forestal (1997), una Estrategia de Adaptación para el sector Biodiversidad (2015) y una Política Nacional de Adaptación (2018). La creación en el 2010 del Consejo Técnico Inter-ministerial de Cambio Climático (CTICC) reúne más de 15 instituciones y permite una mayor coordinación de la acción climática y la implementación de políticas públicas en materia de cambio climático. 


\subsection{La planificación territorial y la AbE}

\subsubsection{La prospectiva climática y la planificación territorial}

La adaptación al cambio climático se apoya en la provisión de información climática oportuna y fidedigna. La prospectiva climática se basa en la generación de escenarios climáticos futuros y ofrece una visión de las condiciones del clima en distintas partes de un territorio. Permite prever cambios en la distribución de la precipitación y en la temperatura promedio y brindar así elementos científicos importantes para la toma de decisiones y la planificación territorial.

Corresponde destacar que dicha prospectiva debe entender no sólo la multiplicación de amenazas atribuibles al cambio climático, sino también las condiciones de vulnerabilidad y exposición de la población como generadores de escenarios locales de riesgo.

La planificación territorial ofrece ventajas para identificar zonas potenciales de exposición y riesgo y evitar los riesgos futuros. Tiene también la virtud de contribuir a la gestión del riesgo por medio de sistemas de alerta temprana, medidas de adaptación que permiten lidiar mejor con la variabilidad climática (sequías prolongadas, huracanes etc.) y restringir la inversión pública en zonas potenciales de riesgo, para garantizar la eficiencia del gasto público y la continuidad de servicios y negocios.

\subsubsection{La incorporación de la AbE en instrumentos de ordenamiento territorial}

Una forma de orientar la planificación territorial en función de la adaptación al cambio climático sería por medio de la aplicación de las herramientas de análisis bioregional y bioclimático. Dichas herramientas guiaron varios esfuerzos de planificación territorial de Mesoamérica en materia de áreas protegidas y corredores biológicos a partir de la década de los 80 s.

El enfoque bioregional analiza cómo los cambios en el clima generarán transformaciones en los ecosistemas terrestres, dulceacuícolas y marinos, y cómo estos afectarán a las sociedades y grupos humanos que dependen directa o indirectamente de los bienes y servicios que proveen. Permite identificar aquellos ecosistemas críticos para la sociedad y los que requieren medidas de gestión especial.

La planificación territorial bio-regional se basa en el análisis de la cobertura, estructura y función de los ecosistemas, y permite delimitar áreas protegidas actuales y futuras, diseñar corredores biológicos y ubicar paisajes productivos que contribuyen a la generación de bienes y servicios ambientales esenciales para la AbE. Evitar daños en infraestructura vial, por ejemplo, muchas veces pasa por la gestión de microcuencas, taludes y diseños hidráulicos adaptados. La AbE requiere de mecanismos que permitan garantizar la provisión de bienes y servicios ambientales y que potencien la reducción del riesgo a nivel local.

Una buena planificación territorial en base a criterios bio-regionales contribuye a la creación de las condiciones de resiliencia necesaria ante los impactos futuros del cambio climático. La experiencia de planificación territorial resulta particularmente compleja cuando se trata de áreas de frontera, donde existen ecosistemas o cuencas hidrográficas que atraviesan dos o más jurisdicciones nacionales. La experiencia recogida y analizada en este libro muestra que se pueden establecer espacios de coordinación y mesas de diálogo sobre la AbE en zonas de frontera. En Mesoamérica, una parte significativa de la biodiversidad y de los recursos hídricos se ubican en zonas fronterizas entre dos 0 más países. La gama de bienes y servicios que proveen (o pueden proveer) estas áreas pueden ser una clave para la adaptación al cambio climático, siempre y cuando sean manejados adecuadamente. 
Y para esto se requiere acordar estructuras de gobernanza que faciliten esta gestión local, nacional y binacional. Hay ejemplos en los ríos Coatán y Suchiate entre México y Guatemala, de encuentros multiniveles ("Soluciones Naturales \& Gobernanza Local para la Adaptación al Cambio Climático"). Existen además estructuras comunales como los Ejidos, que ofrecen arreglos básicos de gobernanza local de bienes públicos como el agua y los recursos forestales. En la microcuenca del Río Esquichá en Guatemala, por ejemplo, existe una gestión compartida en los diferentes niveles: a) comunitario, a través de la suscripción de actas comunitarias en las cuales las comunidades manifiestan su interés de ingresar al programa de incentivos forestales; b) municipal, a través del acompañamiento de consejo municipal presidido por el alcalde municipal y Oficina Forestal Municipal en las gestiones de los incentivos; y c) institucional a través del acompañamiento y apertura del proceso de ingreso de incentivos forestales del Instituto Nacional de Bosques. Dichos niveles anidados de gobernanza, acompañados con el desarrollo de capacidades locales y recursos financieros a través de incentivos forestales, pueden fortalecer la acción climática local.

\subsection{Negociación: ¿la trama o el desenlace?}

En tanto que la negociación respecto a las diferentes opciones de AbE no opera en el vacío sino que deriva de la existencia de fuerzas opuestas que buscan conjugar sus intereses y resolver sus diferencias, corresponde plantear algunos de los interrogantes siguientes:

- ¿Quién determina la agenda de negociación?

- ¿Qué capacidades son necesarias para la negociación?

- ¿Quién es el árbitro de la negociación?

- ¿Cómo se sabe cuándo hay acuerdo?

- ¿Cómo se les da seguimiento a los acuerdos?

- ¿Cómo se monitorean los efectos del cambio climático y sus repercusiones sobre la AbE?

- ¿Existen salvaguardas contra la maladaptación?

- ¿Cómo se ajustan o se actualizan los acuerdos en materia de AbE a la luz de lo anterior?

Los interrogantes precedentes no son preguntas retóricas, sino que constituyen una guía preliminar para orientar procesos de negociación.

Esta sección no pretende responder a todos estos interrogantes aunque valdría la pena arriesgarse a formular preguntas como las anteriores, ya que teniendo claras las respuestas se podrán evitar los escollos típicos de iniciativas de la gestión ambiental o de los proyectos de campo con actores reales.

La AbE requiere de ajustes entre la oferta ambiental de un sitio en particular y la demanda local de la población por bienes y servicios ambientales. Necesita además conocer el complejo entramado entre redes viales, fluviales, dinámicas geomorfológicas y procesos propiamente biológicos (conectividad, corredores biológicos, zona costera). En cuanto a los actores locales de la adaptación, existe una amplia gama de ellos que son relevantes para la adaptación, quienes muchas veces no participan en la planificación, o en la toma de decisiones y en las negociaciones que conducen a ella. En estos contextos, las preguntas de quien determina la agenda de la negociación, quién es el árbitro y como se materializan los acuerdos que derivan de la negociación en materia de AbE, se tornan cruciales. Cada situación dictará quiénes participan en la negociación y cómo las autoridades nacionales 
- locales contribuyen a crear las condiciones adecuadas para la misma. Un primer paso sería el reconocimiento de los interlocutores como actores sociales válidos para forjar acuerdos que luego puedan cumplirse y así fortalecer la gobernanza.

Una condición previa que, sin duda, determina una gobernanza efectiva es el Estado de Derecho y el acceso a los procedimientos legales y la adecuada administración de justicia. Estas condiciones subyacen a muchos de los acuerdos que se derivan de una negociación.

Reunidas estas condiciones, se propone entonces organizar las lecciones derivadas las negociaciones necesarias para la AbE de acuerdo con grandes principios y tipos de instrumentos.

\subsubsection{Aspectos de la gobernanza ex ante}

\section{La negociación como punto de partida de la AbE}

\section{1) Consentimiento Libre, Previo e Informado (CLPI)}

El principio de consentimiento libre, informado y previo refleja el desarrollo del derecho ambiental e indígena y se encuentra amparado en el Convenio 169 de la OIT. Este principio requiere que el Estado o la empresa que desarrolla grandes obras de infraestructura, mega proyectos hidroeléctricos o de minería, realice consultas previas con las comunidades directamente afectadas por dichas obras. En los países de Mesoamérica existe una amplia gama de estructuras de gobernanza con pueblos indígenas desde la autonomía territorial de las Comarcas en Panamá a los ejidos comunitarios en Chiapas. Costa Rica publicó recientemente un reglamento oficial para la realización de consultas con pueblos indígenas, lo que permitirá definir un procedimiento único para todas las instituciones de gobierno. El CLPI permite nivelar las reglas de juego en las negociaciones, posibilitando a poblaciones con desventajas estructurales tener voz y voto respecto de las decisiones que afectan directamente el acceso a los recursos naturales y a la tierra.

\section{2) Estructuras ad hoc}

Para la conducción de programas y estrategias resulta necesario establecer estructuras temporales de gobernanza que reúnan diferentes actores (gubernamentales y no gubernamentales, nacionales o locales) para tomar decisiones, darle seguimiento a planes y proyectos y facilitar los espacios de auditoría social de proyectos de conservación, desarrollo o adaptación al cambio climático. Dichas estructuras, que pueden ser entre representantes comunales y funcionarios municipales, permiten otorgarle coherencia a las políticas públicas y, a la vez, darle un espacio de participación a distintos actores locales en las soluciones naturales ante el cambio climático. En México, existe un Grupo de Trabajo de Adaptación del Consejo Consultivo de Cambio Climático del Estado de Chiapas. En Costa Rica, en el Río Yorkín, los comités locales, amparados a asociaciones de desarrollo indígena, le han dado continuidad a las acciones locales de adaptación impulsadas por proyectos específicos y más allá de su vida útil.

\section{3) Estructuras formales}

En muchos países de Mesoamérica existe una gama amplia de instancias institucionales creadas por ley. En el caso de México, por ejemplo, la Ley de Cambio Climático crea el Consejo Consultivo de Cambio Climático que ofrece a nivel federal y estatal la posibilidad de establecer espacios de consulta y concertación en torno a políticas públicas. Es un marco normativo nacional que rige la gestión climática y el establecimiento de estructuras formales, como consejos consultivos estatales, que facilitan la coordinación necesaria entre actores para poder implementar acciones de AbE. 
En Costa Rica, el Consejo Consultivo Ciudadano de Cambio Climático, conformado por 21 representantes de distintos sectores de la sociedad civil, constituye un espacio deliberativo emergente para acompañar la política pública en materia de acción climática. Si bien no es un órgano oficial del gobierno, el Consejo Consultivo Ciudadano de Cambio Climático fue creado por Decreto Ejecutivo 40615-MINAE y ofrece una oportunidad única para fortalecer la gobernanza climática dentro del país.

\section{4) Otros mecanismos de coordinación/articulación/participación}

La experiencia también señala la importancia de contar con mecanismos ad hoc de coordinación/ articulación/participación que permitan sensibilizar y motivar a los actores locales a actuar en materia de AbE. Por ejemplo, en la cuenca del Río Goascorán, entre Honduras y El Salvador, los encuentros sobre soluciones naturales frente al cambio climático permitieron concientizar a actores locales respecto de los beneficios derivados de la $\mathrm{AbE}$, así como acerca de los marcos legales y políticos existentes en ambos países que facilitan la participación y la articulación multidimensional (multinivel y multisectorial) para hacer frente al cambio climático.

Otro espacio de coordinación transfronteriza participativa y multidimensional es el que se establece a partir del acercamiento entre el Consejo de Cuenca del Río Goascorán (Honduras) y la reinstauración de las Mesas Técnicas Ambientales (El Salvador).

En el caso del Río Sixaola (Costa Rica-Panamá) se logró alcanzar una mayor coordinación multidimensional a través del fortalecimiento de la Comisión Binacional de la Cuenca del Río Sixaola (CBCRS) como plataforma de coordinación multinivel a través de acciones tales como la actualización y socialización de un reglamento interno entre sus miembros y la elaboración de un Plan Estratégico de Desarrollo Territorial Transfronterizo (PEDTT) 2017-2021.

\subsubsection{Aspectos de la gobernanza ex post}

\section{La negociación como punto de llegada de la AbE}

\section{1) Las dinámicas de gobernanza local y el rol de la negociación}

Existe amplia literatura detallando ejemplos de negociaciones que desembocan en arreglos de gobernanza sobre recursos naturales (IISD-IUCN, 2002; McNeely, 1995; Borrini-Feyerabend, G. et al., 2007).

Dichos arreglos permiten, muchas veces, resolver conflictos duraderos entre actores locales y otros actores institucionales o externos respecto de la tenencia, derechos de acceso a recursos naturales y extracción minera o forestal. Al igual que la conservación de la biodiversidad in situ, la adaptación busca manejar recursos desde una perspectiva precautoria, de manera tal de permitir que futuras generaciones puedan gozar de los mismos recursos que las presentes. En este sentido, comparten, en esencial el compromiso inter-generacional y la preocupación por dejar un mundo en mejor estado para las generaciones venideras.

Entre los desenlaces más comunes de los conflictos socio-ambientales se encuentra la creación de comisiones o grupos de trabajo ad hoc. Dichas comisiones, que son coordinadas por gobiernos nacionales o locales y, muchas veces, involucran a representantes de los principales actores en el conflicto, presentan opciones de soluciones y salidas a un conflicto que, a menudo, deriva en nuevos arreglos de gobernanza a nivel local. En este sentido, el desenlace de la negociación es el nuevo 
arreglo o arreglo complementario, cuyo éxito dependerá, en buena medida, de la legitimidad de las decisiones tomadas en base a procesos participativos.

\section{2) La legitimidad de las decisiones de adaptación con base a procesos participativos \\ a) Acceso a información oportuna y libre}

Una de las características de la adaptación al cambio climático es que requiere de un acceso libre y oportuno a información adecuada sobre condiciones climáticas futuras. Los casos que se presentan a continuación son ilustrativos de ello.

En el caso del citado Río Sixaola, la mejora de conocimientos de los agricultores respecto de las medidas de AbE para fincas integrales piloto permitió el establecimiento de espacios de intercambio y coordinación multisectorial y multinivel para la organización de eventos tales como una feria de agro-biodiversidad y una jornada de reforestación binacional.

En Guatemala, las comunidades de la microcuenca del Río Esquichá incorporaron acciones de adaptación dentro de su territorio y actualmente apoyan su implementación. Ello, gracias a la participación social en procesos de diagnóstico de vulnerabilidad, diseño e implementación de medidas de AbE.

En el caso de Chiapas, herramientas destinadas a mejorar el conocimiento y la evidencia sobre la AbE, fueron presentadas ante el Grupo de Trabajo de Adaptación del Consejo Consultivo de Cambio Climático del Estado de Chiapas en mayo de 2018 con la intención de que dichas herramientas fueran utilizadas por dicho Consejo en el ejercicio de sus funciones.

Como queda plasmado en los ejemplos anteriores, no se trata de crear nuevas estructuras sino de dotarlas con las capacidades y los recursos necesarios para que puedan ejercer sus funciones y, consecuentemente, potenciar los arreglos de gobernanza ya existentes en un territorio en particular.

\section{b) La búsqueda del consenso y la concertación}

Los arreglos de gobernanza climática son principalmente el resultado de procesos de búsqueda de consensos y concertación entre las partes involucradas. En muchos casos, la solución de conflictos en torno al agua, la tierra o los recursos forestales refleja la necesidad de compartir visiones y alcanzar soluciones consensuadas. A menudo también requiere de alianzas estratégicas entre actores o iniciativas que sirvieron de vehículo para una colaboración que no se hubiera dado de no existir dichas iniciativas. En el caso del río Goascorán por ejemplo, los esfuerzos mancomunados de proyectos como AVE, BRIDGE, ICWL o Nuestra Cuenca Goascorán, permitieron la colaboración entre una amplia gama de actores tales como productores agrícolas, comités de microcuenca, juntas de agua, municipalidades, mancomunidades de municipios, instituciones de gobierno, líderes comunitarios, mujeres y jóvenes de ambos países (Honduras y El Salvador). En Guatemala, el Municipio de Tacaná actualmente apoya medidas de adaptación y se encuentra en proceso de actualización de su Plan de Desarrollo Municipal que incluye medidas de AbE y asigna una partida presupuestaria específica para la adaptación al cambio climático. Lo anterior, como resultado de la labor de acompañamiento técnico desde 2003 de parte de la UICN a la Oficina Forestal Municipal de Tacaná en campañas de reforestación en zonas de recarga y la aprobación de incentivos forestales.

\section{c) Arreglos institucionales como desenlace}

Los arreglos de gobernanza más duraderos son, a menudo, los que demuestran sobrevivir a las crisis en torno al manejo de los recursos naturales de bien común (Ostrom, E. 2000). Este libro incluye 
algunos ejemplos de arreglos de gobernanza cuya solidez se medirá dentro de algunos años o décadas cuando el impacto del cambio climático se haga sentir con mayor intensidad. Dejar procesos en marcha y encaminados es uno de los aspectos más relevantes de los mencionados ejemplos.

En Chiapas, por ejemplo, los esfuerzos de acompañamiento a las estructuras de gobernanza local permitieron desarrollar una estrategia de desarrollo sostenible en el contexto del cambio climático en el ejido El Azteca. En la cuenca del Río Sixaola, como producto de un extenso proceso de participación multisectorial se pudo elaborar un Plan Estratégico de Desarrollo Territorial Transfronterizo (PEDTT) para el periodo 2017-2021 que incluye apoyar acciones para la protección y conservación de la cuenca por medio de una propuesta de conectividad ecológica transfronteriza como medida de adaptación al cambio climático.

\section{3) El reconocimiento de instituciones/instancias locales}

El reconocimiento de estructuras o instancias locales emergentes es muchas veces una etapa clave del proceso de negociación. Una vez reconocidos como interlocutores válidos ante autoridades locales y nacionales, estas instancias pueden contribuir a legitimar decisiones basadas en una amplia participación ciudadana. Por ejemplo, en el multicitado Río Sixaola los procesos locales fueron reconocidos y condujeron a la formulación de un proyecto binacional implementado por la CBCRS sobre fincas integrales para la adaptación al cambio climático. Dicho proyecto es una iniciativa a cargo de la CBCRS e impulsada por la Estrategia Centroamericana de Desarrollo Rural Territorial (ECADERT) del Sistema de Integración Centroamericana (SICA). Las diez fincas incluidas en este proyecto se han sumado a la red de fincas integrales impulsada con instituciones de gobierno en conjunto con la UICN. En Honduras, los esfuerzos de los socios locales del proyecto AVE brindaron insumos técnicos para la formulación del Plan Nacional de Adaptación (PNA), mismo que incorpora el enfoque de $\mathrm{AbE}$ como uno de sus ejes estratégicos y la gobernanza adaptativa como uno de los transversales.

\section{4) Elementos constitutivos de instituciones locales sólidas para la AbE}

Como ha podido apreciarse a lo largo de este capítulo, las negociaciones son a la vez punto de partida y punto de llegada de los sistemas o arreglos de gobernanza. Comparando las distintas experiencias en los sitios de intervención del Proyecto AVE, se advierte que muchas de ellas tienen varios elementos en común. Como lo documentó Ostrom (2000) los elementos constitutivos de instituciones locales robustas para la gestión de recursos de bien común son, en buena medida, los mismos que para la adaptación al cambio climático. Por ejemplo, la delimitación de los territorios de intervención en materia de AbE y la identificación de fuentes de agua críticos ante los efectos adversos del cambio climático, permite definir prioridades comunes para su protección entre actores locales, reduciendo la incidencia de conflictos locales por escasez de agua. El reconocimiento de instancias y estructuras locales a nivel nacional y regional también permite legitimar las decisiones tomadas en forma colegiada.

Aunque los arreglos de gobernanza en materia de AbE son aún incipientes y todavía queda por ver si pasarán la prueba de fuego de los impactos adversos del cambio climático, existen co-beneficios directos que derivan de una buena gobernanza, sobre todo en un contexto como el que existe en muchos lugares de Mesoamérica donde la inseguridad y la violencia constituyen una realidad y una amenaza constante para los países de la región y sus poblaciones.

Una comunidad organizada para hacer frente a estos problemas puede también luchar contra los desafíos que impone el cambio climático respecto de la seguridad hídrica y la seguridad alimentaria, 
por ejemplo. La AbE requiere de acuerdos y soluciones naturales a largo plazo, y sin duda los acuerdos que se puedan forjar y las soluciones derivadas de ellos serán el resultado de complejos y continuos procesos de negociación que desemboquen, en definitiva, en una adecuada gobernanza climática.

\subsection{Brechas en materia de gobernanza}

A continuación se exponen algunos de los principales condicionantes de una gobernanza efectiva para la AbE en Mesoamérica. Dichos condicionantes, que no son exclusivos de los países de esta región, se pueden predicar también respecto de otros países en vías de desarrollo en otras regiones del mundo. De no ser correctamente ponderados pueden comprometer la viabilidad y efectividad de cualquier estrategia o medida orientada a promover la AbE.

\subsubsection{Limitaciones para la participación ciudadana}

Los países de Mesoamérica han forjado instituciones democráticas a lo largo de los últimos 50 años. Sin embargo, en muchos de ellos la cultura de participación ciudadana sigue siendo limitada y la transparencia y las prácticas de rendición de cuentas por parte de las instituciones públicas continúan siendo imperfectas.

Las decisiones en materia de $\mathrm{AbE}$ requerirán de una negociación compleja para permitir crear las condiciones apropiadas de gobernanza a nivel local conducentes a un manejo sostenible y a largo plazo de los ecosistemas frente al cambio climático.

Los sistemas democráticos representativos de los países de la región depositan en el poder ejecutivo la responsabilidad de ejecutar las políticas públicas y velar por su implementación dentro de un marco normativo establecido y legítimo. Si bien las instituciones públicas tienen esta responsabilidad, la gobernanza requiere de una amplia participación de actores de la sociedad civil. Los espacios de participación y de coordinación multi-sectorial varían de un país a otro, y sin duda presentan diferentes grados de legitimidad y representatividad. Sin embargo, como lo han podido ilustrar los capítulos anteriores, existen lecciones importantes en materia de gobernanza para facilitar la AbE. El gran interrogante sería entonces como establecer las condiciones favorables para una gobernanza efectiva dadas estas condiciones.

\subsubsection{Fallas en la comunicación}

El acceso a información oportuna, libre y fidedigna es un aspecto fundamental de la gobernanza. Para ser aplicada, la AbE requiere ser comunicada de manera sencilla y asequible. ¿Cómo, por ejemplo, contribuye un área protegida y/o el manejo de una microcuenca en asegurar la provisión de agua para consumo humano o para uso agrícola de una comunidad? ¿Cómo las medidas de adaptación que se adopten hoy pueden garantizar la provisión de bienes y servicios ambientales a largo plazo? ¿Cuál es la mejor forma de comunicar escenarios futuros que permitan presentar las opciones de forma amena y fácil de entender?

\subsubsection{Legitimidad, reconocimiento y liderazgo}

Detrás de toda experiencia exitosa de gestión comunitaria de la biodiversidad y de la AbE están los líderes locales que han permitido darle legitimidad a una gestión cuyos resultados y beneficios palpables le dan reconocimiento. 
Existen múltiples ejemplos de liderazgo local en Mesoamérica, varios de ellos basados en la organización y el empoderamiento de estructuras de gobernanza local. Muchas de estas experiencias refuerzan la importancia de entender y fortalecer la vida cívica y la participación de organizaciones de la sociedad civil en procesos de toma de decisiones a nivel nacional y local. Son signos vitales de una democracia participativa. Varias de las experiencias de gestión local (forestal, conservación, gestión de recursos hídricos, pesca responsable) parten del reconocimiento y el reforzamiento mutuo entre instituciones del Estado, autoridades locales y organizaciones comunitarias. El reconocimiento estimula el compromiso, la participación ciudadana, el fortalecimiento de la transparencia y habilita la rendición de cuentas en una sociedad.

La legitimidad de los procesos de gobernanza local parte del reconocimiento del liderazgo comunitario. La importancia de este liderazgo no puede ser subestimada en un contexto signado en muchos aspectos, entre otros, falta de transparencia de los gobiernos, tráfico de influencias, políticas polémicas y delincuencia. No pueden existir arreglos de gobernanza local duraderos, condición sine qua non de la $\mathrm{AbE}$, sin un sólido liderazgo comunitario y local, legítimo y reconocido por la institucionalidad local y nacional.

\subsubsection{Tierras y tenencia}

Muchos de los ecosistemas terrestres de Mesoamérica son parte de paisajes productivos con los cuales han co-existido. La inmensa mayoría de las áreas protegidas han sido creadas a partir de tierras en manos privadas o baldíos públicos. Los conflictos agrarios y la tensión entre tierras comunales, minifundios y haciendas y latifundios son parte de la historia de Mesoamérica. A pesar de los esfuerzos de reforma agraria de los años 20's y 30's en México y en los años 60's y 70's en Centroamérica, sigue habiendo múltiples situaciones de conflictos por tierras y por reconocimientos de títulos comunales sobre recursos como el agua y bosques.

En los últimos veinte años Mesoamérica asiste a un incremento en la presencia en zonas costeras y áreas de frontera de organizaciones vinculadas a actividades delictivas. Esto constituye un reto creciente para autoridades locales, tanto en México como en Centroamérica, toda vez que estas actividades erosionan las capacidades de organizaciones locales de defender sus intereses y socavan las bases de la gobernanza.

\subsubsection{Debilidad institucional nacional y local}

Muchos países cuentan con políticas públicas y marcos legales que contemplan, refuerzan y habilitan la AbE. Aun así, ello no es garantía de que la AbE vaya a implementarse a la escala o en los niveles de gobernanza adecuados. En muchos países de Mesoamérica, la aplicación de instrumentos de planificación regional y ordenamiento territorial siempre se ha topado con las limitaciones de la institucionalidad pública y las dificultades de regular la utilización de los recursos naturales, de reglamentar el uso del suelo urbano y de evaluar el impacto ambiental de proyectos de desarrollo. La adaptación, al igual que la gestión del riesgo, requiere de una gestión prospectiva que presupone la buena fe de parte de actores en juego en cuanto a los escenarios climáticos o al análisis de riesgos que justifican los ajustes necesarios para la adaptación, y de un acceso sin obstáculos a datos y escenarios climáticos que sean robustos, confiables y fácilmente disponibles. 


\subsubsection{Falta de financiamiento}

Si bien no todos los eventos hidrometeorológicos extremos son atribuibles en su totalidad a los efectos adversos del cambio climático, la tendencia descrita en los últimos informes del IPCC es hacia un incremento paulatino en la magnitud y frecuencia de estos eventos.

El cúmulo de daños y pérdidas registradas por eventos hidrometeorológicos en Mesoamérica no refleja los costos indirectos que implican las perturbaciones e interrupciones en la vida diaria de la población (por ejemplo, la suspensión de clases en escuelas públicas) causada por estos eventos. Adicionalmente, los daños a los ecosistemas, con afectaciones en la vida silvestre y en el hato ganadero y las pérdidas asociadas a ellos (directas e indirectas) no se miden de forma sistemática, lo que sugiere un sub-registro del impacto de los citados eventos. Sumados a las condiciones de exposición y vulnerabilidad en las que viven amplios segmentos de la sociedad, dichos eventos generan conflictos sociales y una erosión permanente de los activos del desarrollo.

Con el impacto del cambio climático, las pérdidas podrían aumentar en el futuro y ocasionar severas repercusiones en el desarrollo económico y social de los países, al erosionar en forma recurrente sus propios recursos. Aunque dichas pérdidas tendrían impactos diferenciados entre sectores, territorios, comunidades y grupos vulnerables, lo cierto es que la mayoría de los países no cuenta con los recursos fiscales necesarios para hacer frente a estas erogaciones periódicas para atender emergencias y la reconstrucción tras los desastres.

La adaptación al cambio climático pretende reducir esta carga financiera, contribuyendo a la reducción de pérdidas y daños por eventos hidrometeorológicos. La evidencia muestra que los sistemas humanos están expuestos no solo a las limitaciones de los recursos naturales, sino también a las financieras del Estado. ¿De dónde provendrán los recursos para financiar la adaptación? Existen varios instrumentos internacionales multilaterales (Fondo Verde del Clima, Fondo para el Medio Ambiente Mundial, Fondo Adaptación) y bilaterales (Internationale Klimatschutzinitiative (IKI), Agencia Española de Cooperación Internacional al Desarrollo (AECID), Unión Europea (UE)) que apoyan acciones de adaptación. Existen también importantes recursos nacionales que financian la conservación in situ de la biodiversidad, o la provisión de agua potable a comunidades que pueden constituir una fuente significativa de co-financiamiento para la AbE.

La UICN publicó un inventario donde se demuestra que al 2017 se estaban ejecutando un total de USD 716718262 en 173 proyectos de adaptación al cambio climático en Centroamérica. Los Estados deben invertir tempranamente en la adaptación de manera tal de proteger sus activos y operaciones; de lo contrario verán incrementarse los costos derivados de pérdidas y daños.

\subsection{Desafíos y oportunidades para la negociación}

A lo largo de este capítulo se propusieron algunos elementos de análisis respecto de las condiciones necesarias para la negociación de arreglos de gobernanza habilitantes de la AbE e identificaron las principales brechas en la materia en Mesoamérica, además de señalarse algunos pasos conducentes a la mejora de la integración vertical y horizontal entre instituciones nacionales y locales, entre actores locales, agentes y liderazgos comunitarios para permitir una mejor planificación y gestión del territorio en aras de la adaptación al cambio climático. 
Entre los principales desafíos identificados se encuentra la erosión paulatina de los principios de convivencia democrática que obedece, en parte, a la pérdida de credibilidad en las instituciones públicas respecto a su capacidad de resolver los problemas que enfrenta la ciudadanía en materia de seguridad física, seguridad hídrica y seguridad alimentaria. Dichos problemas de seguridad se verán agravados como producto de los efectos adversos derivados del cambio climático. El debilitamiento de la legitimidad de las instituciones también es reflejo de una falta de liderazgo local y nacional y de una incapacidad de proponer, a través de los mecanismos de representación existentes, soluciones viables y duraderas a los retos apremiantes del desarrollo.

Otro desafío significativo tiene que ver con la incongruencia entre atender necesidades apremiantes actuales del desarrollo humano (empleo de calidad, acceso a educación, servicios de salud, seguridad alimentaria) con la necesidad de prever condiciones futuras frente al cambio climático y tomar decisiones cuyos réditos no son inmediatos ni cortoplacistas, pero que garantizarán un mínimo de calidad de vida para las generaciones futuras. ¿Cómo reconciliar entonces lo que es urgente con lo importante? Este es un reto para toda organización, toda instancia, actor o comunidad dedicada a la gestión ambiental en general y a la adaptación al cambio climático en particular.

Una de las enseñanzas derivadas del análisis propuesto en este libro es que la negociación puede partir de un orden institucional dado o puede desembocar en nuevos arreglos institucionales que promuevan una gobernanza más robusta y legítima. Esto constituye, sin lugar a dudas, una oportunidad, ya que facilita la toma de decisiones a nivel local y, sobre todo, permite discernir entre la necesidad de cambio y de continuidad. Resta entonces determinar cuándo es menester aprovechar las instituciones y arreglos de gobernanza existentes y cuándo proponer nuevas figuras que respondan más adecuadamente a las necesidades de las partes interesadas.

Otra oportunidad existente en los procesos de negociación tiene que ver con la identificación y el reconocimiento de co-beneficios entre políticas públicas, ya que la adaptación al cambio climático puede verse potenciada o limitada por otros instrumentos de política no-climáticos. Por ejemplo, una decisión de aprovechar las aguas servidas por parte del sector pecuario para reducir la contaminación de cuerpos de agua puede derivar en una oportunidad de adaptación ya que reduce el consumo de agua, fomentando el reciclaje y el re-uso de un recurso finito, frágil y sujeto a cambios en su disponibilidad. Ello refuerza la idea de mejorar la comunicación y la coordinación inter-institucional para identificar estas oportunidades y fomentar las sinergias entre acciones de desarrollo y la AbE.

Finalmente, otra ventaja derivada de los procesos de negociación es cómo estos permiten construir instituciones más sólidas y transparentes. En muchos países de la región existe un marco legal amplio y complejo, cuya interpretación y aplicación es a veces aleatoria y poco eficaz. Una oportunidad que emerge de las lecciones aprendidas vertidas en este libro es cómo fortalecer la convivencia con los impactos adversos del clima mejorando las condiciones de gobernanza efectiva. Los nuevos arreglos que emerjan de los procesos de negociación aquí mencionados serán sin duda un camino de esperanza para quienes habían perdido la fe en las instituciones públicas, puesto que responden directamente a las aspiraciones y necesidades de la población local y así contribuyen a la transparencia y a la legitimidad del orden institucional de los países de Mesoamérica. 


\section{Conclusiones y recomendaciones: calibrando}

\section{En torno al ajuste}

La gobernanza efectiva para la AbE debe permitir la articulación entre el mantenimiento de los servicios de los ecosistemas, el desarrollo económico y la equidad social garantizando a la vez la convivencia pacífica de las personas. Asimismo deberá adecuarse a contextos y zonas geográficas específicas con diversos grados de vulnerabilidad a fin de transformarse en un vehículo que asegure la sostenibilidad de las medidas de la AbE no obstante las incertidumbres del clima.

Las políticas, leyes y regulaciones relacionadas con la AbE no ser vistas como instrumentos cuyas transformaciones, ajustes y reformas son inalcanzables. Por el contrario, deberán ser vigilados, aprehendidos e internalizados por la sociedad civil en su conjunto y en particular los grupos más vulnerables. La reforma de los marcos legales e institucionales para la AbE si bien constituye una tarea compleja puesto que demanda tiempo y esfuerzo, será posible en tanto y cuanto los actores se comprometan a incidir en su formulación e implementación. La consolidación y el fortalecimiento de las capacidades para la negociación y la incidencia política de estos actores son condiciones imperativas para una gobernanza eficiente, efectiva, justa y equitativa para la $\mathrm{AbE}$.

Resulta indispensable una gestión del conocimiento coherente, continua e innovadora, que contemple el conocimiento tradicional y esté científicamente respaldada (evidencia) para demostrar que la AbE opera efectivamente. Si no se cuenta con evidencia y cifras concretas que persuadan a tomadores de decisión y a los sectores económicamente influyentes, las medidas de AbE y su no podrán subsistir en el tiempo.

La gobernanza (efectiva) del cambio climático es un tema primordial de la agenda local, nacional e internacional a ser resuelto en la actualidad, toda vez que la prueba de fuego vendrá dentro de los próximos 30 años cuando los impactos del cambio climático se hagan sentir más intensamente y sea por tanto necesario contar con instituciones sólidas capaces de hacer frente a la escasez y de gobernar en un contexto de emergencia y crisis. Para ello será ineludible reforzar los espacios, todavía imperfectos, de transparencia de la gestión pública y de participación ciudadana. En caso contrario, las estructuras de gobernanza no tendrán la resistencia ni resiliencia necesaria para hacer frente a dichos impactos.

Los ecosistemas pueden transformarse en seguros de vida para la sociedad ante los impactos del cambio climático. Muchos de los bienes y servicios que brindan sostienen a una amplia gama de actividades productivas: desde la agricultura, la ganadería, la pesca hasta buena parte de la vida urbana. No obstante, su conservación y uso sostenible requieren de políticas claras, leyes efectivas e instituciones sólidas que faciliten la participación de todos los actores y partes interesadas.

La AbE requiere una integración horizontal entre ministerios y una vertical entre niveles de gobierno (federal, estatal, provincial, regional, municipal y local). En términos pragmáticos, debe partir de esfuerzos concretos en materia de planificación territorial, gestión de cuencas, manejo de recursos marino-costeros y articular los distintos niveles de gobierno nacional, regional, provincial, departamental y local en materia de planificación territorial, ambiental y de desarrollo económico. 


\section{En torno a la capacidad}

En relación con la adaptación al cambio climático, la capacidad es una noción pluriconceptual que abarca la capacidad para la adaptación, la capacidad para la gobernanza y la capacidad para la gobernanza para la AbE.

Dado que los países más vulnerables al cambio climático son también aquellos que cuentan con menor capacidad para la adaptación es imperativo priorizar programas de formación de capacidades no solamente para enfrentar los impactos del cambio climático sino también para incidir en el establecimiento de estructuras de gobernanza efectivos en esta materia.

La capacidad para la gobernanza para la AbE requiere considerar temas que van desde la sensibilización en la materia de distintos grupos de actores hasta la construcción de marcos políticos, legales e institucionales que permitan su gestión efectiva en el largo plazo. Dichas capacidades deben ser ponderadas desde los niveles más locales hasta los Estados nacionales y en su cooperación con los vecinos.

Las limitaciones en términos de capacidades para la gobernanza para la AbE deben ser consideradas en forma prioritaria, holística e integral de manera tal de asegurar que se tomen en cuenta los diferentes intereses y necesidades de los actores y los ecosistemas en el contexto de incertidumbre propia del cambio climático.

Las capacidades resultan indispensables para alcanzar el objetivo de una gobernanza para la AbE que tenga la virtud de ser multidimensional, flexible, participativa y ecosistémica.

Teniendo en cuenta que la vulnerabilidad se compone de tres elementos distintivos, a saber, la exposición, la sensibilidad y la capacidad para la adaptación, en definitiva es con el fortalecimiento de esta última que se puede operar una reducción de la vulnerabilidad y aumentar la resiliencia de las poblaciones y ecosistemas ante el cambio climático. Las capacidades para la AbE y su gobernanza son por tanto indispensables para mejorar, en el largo plazo, los medios de vida sostenibles de las poblaciones humanas y los ecosistemas de los que estas dependen.

\section{En torno a la evidencia}

Resulta necesario contar con la evidencia que sea evaluada en forma periódica y que permita modificar las acciones en materia de AbE teniendo en cuenta la complejidad de los procesos ecosistémicos y sociales involucrados. Para ello se requerirá profundizar la investigación en cuanto a la relación costo-beneficio y costo-efectividad de la implementación de medidas de AbE y los arreglos de gobernanza necesarios para ello. Se podrían aprovechar experiencias existentes y lecciones derivadas de estas así como mecanismos de financiamiento para la adaptación que tienen lugar a nivel global para elaborar y evaluar proyectos, políticas, instituciones, leyes y procesos vinculados con la AbE y continuar mejorándolos en el tiempo.

La gobernanza para la AbE está condicionada por la existencia de una base de datos de evidencia integral, rigurosa y sólida. La implementación de la AbE debe incluir el levantamiento de información sobre servicios ecosistémicos y co-beneficios que generan y pueden generar así como la vulnerabilidad ambiental y social; un sistema de gestión del conocimiento que permita recopilar información y analizarla; la elaboración de un sistema de monitoreo y evaluación con indicadores realistas; planes de capacitación en materia de AbE y la comunicación y transferencia del conocimiento clara y oportuna. Todo ello con la participación de todos los grupos interesados. 
El fortalecimiento de capacidades para generar evidencia, analizarla e interpretarla a la luz de las incertidumbres climáticas, establecer redes de diseminación de información y finalmente, transmitir de manera clara la evidencia a tomadores de decisión, resulta fundamental para retroalimentar la gobernanza para la AbE y asegurar resultados positivos y sostenibles en el tiempo de los proyectos y medidas en esta materia.

Es preciso contar con evidencia respecto a la efectividad de la AbE con el objeto de mejorar su gobernanza y, a la vez, evidencia respecto de la efectividad de la gobernanza para la AbE para poder garantizar la sostenibilidad de las acciones de adaptación.

Los marcos de gobernanza para la AbE deben tener la capacidad de influir iniciativas y proyectos en la materia. Asimismo, en la medida en que los responsables de la aplicación de las políticas y leyes implementen efectivamente estas, se generará confianza en los referidos marcos. Para ello, es importante la transparencia, la rendición de cuentas, el cumplimiento de la ley y la capacidad institucional con el fin de construir participativamente y de manera inclusiva arreglos de gobernanza efectivos.

\section{En torno a la política}

La integración de la $\mathrm{AbE}$ en políticas relativas al cambio climático permite guiar su progresiva integración en las políticas sectoriales y en los distintos niveles de la administración del Estado. Con ello se podría asegurar que la AbE permeara las políticas de desarrollo, en donde la conservación, restauración y uso sostenible de ecosistemas dejara de ser considerado como un objetivo exclusivo de la política ambiental.

Las políticas que integren la AbE deberían ser lo suficientemente precisas para dirigir las reformas legislativas necesarias. Dichas reformas deberían realizarse sobre la base de una evaluación holística de los vacíos y las posibles sinergias entre los marcos normativos sectoriales para la AbE.

Las reformas legislativas requieren ser integrales de manera tal de reducir los posibles factores de estrés sobre los ecosistemas derivados de otras fuentes distintas al cambio climático (por ejemplo, la sobre-explotación de recursos naturales, la contaminación). Dichas reformas deberían potenciar las acciones de conservación, restauración y uso sostenible de los ecosistemas, y remover incentivos perversos que contribuyan al agotamiento de los recursos naturales y la biodiversidad.

En tanto que la política y la ley son inherentes a la gobernanza, la segunda es necesaria para asegurar la continuidad de la primera evitando así que, ante posibles cambios de gobierno y de administraciones, se puedan perder los avances logrados en materia de AbE. Asimismo, la ley es relevante para garantizar la coherencia de la política y promover la coordinación institucional entre múltiples niveles y sectores. El cambio climático impone la necesidad de ponderar, cuando así corresponda, la flexibilización de la ley en particular en lo que respecta a mecanismos regulatorios para, por ejemplo, hacer lugar a cambios en patrones de conducta de especies, modificaciones en límites espaciales de áreas protegidas, etc.

Habida cuenta de que la efectiva implementación de la AbE depende de la existencia, entre otros, de recursos económicos adecuados, se recomienda que la política y la ley detallen la fuentes de financiamiento para la AbE y consecuentemente dirijan los recursos necesarios para implementar acciones en la materia, como así también para la investigación y el fortalecimiento de capacidades.

En atención a que la adaptación al cambio climático y la conservación de los ecosistemas, es decir, la $\mathrm{AbE}$ requiere, para su implementación efectiva, un involucramiento de la sociedad en su conjunto, 
se revela como necesario fortalecer las capacidades de esta y del papel de la ciudadanía como agente de cambio. Para esto se recomienda la capacitación y el empoderamiento de ellos de manera tal que puedan cumplir el papel de vigilantes de la salud de los ecosistemas y así contribuir a la efectividad y sostenibilidad de la AbE.

La política (s) y la ley (es) relativas a la AbE debe proveer las medidas necesarias para asegurar la participación de los grupos indígenas, comunidades locales, jóvenes, mujeres y otros grupos vulnerables y marginados, de manera tal que se contribuya a mejorar sus capacidades de incidencia en esta materia y reconozca la función esencial que tienen en la custodia, restauración y gestión sostenible de los ecosistemas.

Frente a las amenazas que derivan del cambio climático resulta imperioso mejorar implementación de los marcos legales relativos a la conservación de los ecosistemas y sus servicios de manera tal de reducir su vulnerabilidad, aumentar su resiliencia y, consecuentemente asegurar que la AbE pueda lograr su cometido de manera efectiva.

Mientras que a nivel nacional, subnacional y local, la política y la ley constituyen los instrumentos adecuados para asegurar una gobernanza efectiva de la AbE, a nivel global y transfronterizo corresponde insistir en la celebración e implementación de acuerdos entre Estados que sean conducentes no solo a asegurar la conservación y el uso sostenible de los ecosistemas compartidos sino también de promover la colaboración entre Estados en temas conexos tales como el intercambio de información y experiencias, el fortalecimiento de capacidades y la investigación en esta materia.

\section{En torno a las instituciones}

El principal reto de la institucionalidad para el cambio climático y ciertamente para la AbE consiste en reconciliar la incertidumbre derivada de dicho fenómeno y sus efectos con la rigidez inherente a toda institución, estructura u organización encargada de la gestión del territorio y los recursos naturales.

La institucionalidad emergente para hacer frente al cambio climático y sus consecuencias asiste a la aparición de estructuras de carácter multidimensional, multiactores (públicos y privados) y de carácter consultivo que operan en forma paralela y complementaria a las instituciones tradicionales para la gestión del ambiente, la biodiversidad y los recursos naturales.

En tanto que dichas estructuras emergentes presentan una serie de debilidades (entre ellas, el inadecuado financiamiento, la necesidad de fortalecer liderazgos internos para promover el diálogo y la negociación, o el carácter no vinculante de sus decisiones) mismas que deben ser atendidas para no comprometer su efectividad, han traído aparejados una serie de beneficios en materia de participación social, concienciación e internalización de la agenda climática a actores que tradicionalmente no formaban parte de las discusiones en materia de cambio climático y AbE.

La multidimensionalidad de las instituciones emergentes debe entenderse como una de carácter horizontal (entre distintos sectores) y de carácter vertical (entre distintos entes locales, subnacional y nacionales). La primera requiere reconciliar el trabajo de ministerios, agencias y entes del Estados que trabajan con agendas distintas, en tanto que la segunda requiere promover una interacción que fomente el diálogo entre distintos niveles y se establezca el ambiente propicio para la definición de acciones, la elaboración de políticas y la adopción de normas en materia o relacionadas con la AbE. Las instituciones multiactores que involucran a un amplio grupo de ellos del sector público, la sociedad civil y el sector privado sirven como espacios para facilitar el diálogo y la negociación respecto a las opciones de adaptación al cambio climático. 
En atención a que muchos de los ecosistemas clave para la adaptación son compartidos entre dos o más Estados, y habida cuenta de que gran parte de las comunidades y poblaciones más vulnerables al cambio climático, sobre todo en países en vías de desarrollo y que dependen de dichos ecosistemas viven en zonas de frontera, es importante recalcar la necesidad de promover la internalización de la AbE en el diálogo político entre Estados con el fin de incorporarla a las acciones, proyectos e iniciativas de carácter multinacional, como así también a las estructura de gobernanza de carácter transfronterizo/transnacional. La AbE podría, en este sentido, ser vista como un vehículo para promover la cooperación entre Estados.

La incertidumbre y complejidad de los sistemas y la variabilidad climática y sus efectos imponen la necesidad de una evolución paulatina de las instituciones tradicionales de manera tal que permita incorporar un elemento de flexibilidad necesario para incorporar la información más adecuada disponible y los elementos de incertidumbre propias de este fenómeno. Así la gestión adaptativa aparece como un nuevo paradigma o como una tendencia que impone un cambio de paradigma de la gestión de los recursos naturales.

Una debilidad significativa del marco institucional para la AbE deriva de una limitada capacidad de las mismas instituciones de comprender que la AbE no constituye una herramienta solo para la adaptación de los ecosistemas y que impide que la misma AbE pueda ser vista como parte de estrategias integrales de adaptación que promueve beneficios para toda la sociedad e incluye a todos los sectores económicos relevantes (no solo al ambiental).

La efectividad del marco institucional para el cambio climático está condicionado, en última instancia, por la capacidad de las instituciones, órganos, agencias y de los mismos funcionarios y tomadores de decisión respecto a los temas inherentes a la adaptación al cambio climático. De allí que sea necesario trabajar en pos del fortalecimiento de las capacidades de gobernanza en múltiples niveles y con una multiplicidad de actores de manera de contribuir a una implementación y gestión efectiva de la AbE.

\section{En torno a la negociación}

La negociación en materia de AbE es polifacética. La toma de decisiones en esta materia requiere de una compleja serie de transacciones para establecer el ambiente propicio a nivel local y nacional conducente a la gestión sostenible de los ecosistemas en el largo plazo en un contexto de cambio e incertidumbre.

El tipo de negociación varía de un país al otro, de una región a otra, de una situación particular a otra y pueden ir desde un acuerdo entre Estados vecinos para la gestión de áreas de protección como Reservas de la Biósfera o Sitios del Patrimonio Mundial, hasta procesos de diálogo y consulta a nivel local entre autoridades, gremios, cámaras y asociaciones de carácter comunitario para definir los alcances y la gestión de un proyecto de reforestación o de restauración de riberas o manglares.

La naturaleza de la negociación en materia de AbE es dictada por el tipo de recurso que pretende ser gestionado en función de la adaptación, de su escala geográfica y territorial y del número de instituciones y actores involucrados. Tiene lugar en términos concretos a través de procesos de consulta formal o de participación ciudadana o multisectorial en la definición de políticas públicas relevantes para la adaptación o de manera ad hoc para una iniciativa o un proyecto en particular.

La negociación para la $\mathrm{AbE}$ debe ser anclada en términos territoriales y referirse a espacios, ecosistemas o cuencas hidrográficas específicas. Esta "territorialización" de la negociación requiere 
aprovechar espacios existentes a nivel local o bioregional, mismos que inciden directamente en la toma de decisiones en materia de administración local, inversión pública y asignación de recursos en temas vinculados con la AbE.

En tanto que la AbE implica conocer y ajustar un complejo entramado de ofertas y demandas de bienes y servicios, dinámicas de carácter biológico y geomorfológico y de interrelaciones entre actores nacionales y locales de diversa índole que participan (o no) en la toma de decisiones y en la planificación, la definición de una agenda, sus términos, la facilitación y la toma de decisiones en una negociación resultan cruciales para la adopción de acuerdos efectivos, que puedan cumplirse $y$, en definitiva, que sirvan para fortalecer la gobernanza para la $\mathrm{AbE}$.

El cambio climático requiere de compromisos de largo plazo en materia de adaptación, y esto sólo se logra mediante instituciones que puedan evolucionar y reinventarse. Este proceso de transformación institucional es, en última instancia, el mayor reto de la adaptación. Para hacer frente a los impactos del cambio climático no hay opciones de adaptación basada en la continuidad (business as usual), sino que se requiere de una capacidad permanente de construir y reinventar los arreglos de gobernanza. 


\section{Bibliografía}

\section{Ajuste}

Abell, R., Asquith, N., Boccaletti, G., Bremer,L., Chapin, E., Erickson-Quiroz, A., Higgins, J., Johnson, J., Kang, S., Karres,N., Lehner, B., McDonald,R., Raepple, J., Shemie, D., Simmons, E., Sridhar, A., Vigerstøl, K., Vogl, A. y Wood, S. (2017). Beyond the Source: The Environmental, Economic and Community Benefits of Source Water Protection. Arlington, VA, EE.UU.: The Nature Conservancy.

Aguilar, G. y Iza, A.O. (2009). Gobernanza de Aguas Compartidas. Aspectos Jurídicos e Institucionales. Gland, Suiza: UICN. https://portals.iucn.org/library/node/9421

Adger, W.N., Brown I. y Surminski, S. (2018). 'Advances in risk assessment for climate change adaptation policy'. Philosophical Transactions of the Royal Society 376: 20180106. http://dx.doi. org/10.1098/rsta.2018.0106

Andrade, A., Córdoba, R., Dave, R., Girot, P., Herrera-F, B., Munroe, R., Oglethorpe, J., Paaby, P., Pramova, E., Watson, J., Vergara, W. y Suarez, I. (2012). Principles and Guidelines for Integrating Ecosystem-based Approaches to Adaptation in Project and Policy Design. Turrialba, Costa Rica: IUCN-CEM, CATIE.

Bai, X. (2018). 'Advance the ecosystem approach in cities'. Nature 559: 7. https://doi.org/10.1038/ d41586-018-05607-x

Burhenne-Guilmin, F. y Scanlon, J. (eds.) (2004). International Environmental Governance. An International Regime for Protected Areas. IUCN Environmental Policy and Law Paper No. 49. Gland, Suiza y Cambridge, G.B.: UICN.

Convention on Biological Diversity (CBD) (2010). Convention on Biological Diversity 2010: Decision adopted by the Conference of the Parties to the Convention on Biological Diversity at its 10th Meeting. X/33. Biodiversity and climate change. UNEP/CBD/COP/DEC/X/33.

CBD (2018). Voluntary Guidelines for the design and effective implementation of ecosystem-based approaches to climate change adaptation and disaster risk reduction. CBD/SBSTTA/22/INF/1. Vigésimo segunda reunión. Montreal, Canadá. 2-7 de Julio de 2018. Disponible en: https://www. cbd.int/doc/c/3f7a/4589/5cc1b7058bf52427fa9bae84/sbstta-22-inf-01-en.pdf

CBD (2018a). COP 14. Marco mundial de la diversidad biológica posterior a 2020. Decisión: CBD/ COP/DEC/14/34. Disponible en: https://www.cbd.int/doc/decisions/cop-14/cop-14-dec-34-es. pdf

Convenio sobre la Diversidad Biológica (CDB) (1992). Convenio de Diversidad Biológica. Disponible en: https://www.cbd.int/doc/legal/cbd-es.pdf

CDB (2000). Enfoque de Ecosistemas. (Decisión V/6. UNEP/CBD/COP/5/23).

CDB (2009 a). COP 10, Decisión X/33

CDB (2009 b). Relación entre la diversidad biológica y la mitigación y adaptación al cambio climático. Montreal, Canadá. Disponible en: https://www.cbd.int/doc/publications/ahteg-brochure-es.pdf 
CDB (2010). Plan Estratégico para la Diversidad Biológica 2011-2020 y las Metas de Aichi. Disponible en: https://www.cbd.int/doc/strategic-plan/2011-2020/Aichi-Targets-ES.pdf

CDB (2011). Protocolo de Nagoya sobre acceso a los recursos genéticos y participación justa y equitativa en los beneficios que se deriven de su utilización al Convenio sobre la Diversidad Biológica.

CDB (2019). Marco Mundial de la Diversidad Biológica posterior a 2020: Documento para el Debate. CBD/POST2020/PREP/1/.

Colloff, M.J., Martín-López, B., Lavorel, S., Locatelli, B., Gorddard, R., Longaretti, P.Y., Walters, G., van Kerkhoff, L., Wyborn, C., Coreau, A., Wise, R.M., Dunlop, M., Degeorges, P., Grantham, H., Overton, I.C., Williams, R.D., Doherty, M.D., Capon, T., Sanderson, T. y Murphy, H.T. (2017). 'An integrative research framework for enabling transformative adaptation'. Environmental Science and Policy 68: 87-96. Disponible en: https://www.sciencedirect.com/science/article/pii/ S1462901116301289

CMNUCC (1992). Convenio Marco de las Naciones Unidas para el Cambio Climático.

CMNUCC (2015). Convenio Marco de las Naciones Unidas sobre el Cambio Climático. Acuerdo de París.

Costanza, R., de Groot, R., Braat, L., Kubiszewski, I., Fioramonti, L., Sutton, P., Farber, S. y Grasso, M. (2017). 'Twenty years of ecosystem services: How far have we come and how far do we still need to go?' Ecosystem Services 28: 1-16. https://doi.org/10.1016/j.ecoser.2017.09.008

Chong, J. (2014). 'Ecosystem-based approaches to climate change adaptation: progress and challenges'. International Environment Agreements 14: 391-405. https://doi.org/10.1007/s10784014-9242-9

Cohen-Shacham, E., Walters, G., Janzen, C. y Maginnis, S. (eds.) (2016). Nature-based Solutions to address global societal challenges. Gland, Suiza: UICN. https://portals.iucn.org/library/ $\underline{\text { node/46191 }}$

Cosens, B.A., Craig, R.K., Hirsch, S., Arnold, C.A.(T.), Benson, M.H, DeCaro, D.A, Garmestani, A.S., Gosnell, H, Ruhl, J. y Schlager, E. (2017). 'The role of law in adaptive governance'. Ecology and Society 22(1): 30. https://doi.org/10.5751/ES-08731-220130

Creed I.F. y van Noordwijk, M. (eds.) (2018). Forest and Water on a Changing Planet: Vulnerability, Adaptation and Governance Opportunities. A Global Assessment Report. Volume 38. Viena, Austria: IUFRO World Series.

Department for International Development (DFID) (1999). Sustainable livelihoods guidance sheets. Londres, G.B.: DFID. Disponible en: https://www.ennonline.net/dfidsustainableliving

Evaluación de los Ecosistemas del Milenio. (2005). Ecosistemas y Bienestar Humano. Informe de Síntesis. Disponible en: https://www.millenniumassessment.org/documents/document.439. aspx.pdf 
Friends of Ecosystem-based Adaptation (FEBA) (2017). Making Ecosystem-based Adaptation Effective: A Framework for Defining Qualification Criteria and Quality Standards (FEBA technical paper developed for UNFCCC-SBSTA 46). Bertram, M., Barrow, E., Blackwood, K., Rizvi, A.R., Reid, H., y von Scheliha-Dawid, S.5 (authors). Bonn, Alemania: GIZ, IIED; Londres, G.B.: IIED y Gland, Suiza: UICN.

Gobierno de Costa Rica (2015). Contribución Prevista y Determinada a Nivel Nacional.

Gobierno de El Salvador (2015). Contribución Prevista y Determinada a Nivel Nacional.

Gobierno de Guatemala (2015). Contribución Prevista y Determinada a Nivel Nacional.

Gobierno de México (2015). Intended Nationally Determined Contribution.

Gobierno de Nicaragua (2018). Contribución Nacionalmente Determinada a la Mitigación del Cambio Climático (NDC) de la República Nicaragua ante la Convención Marco de Naciones Unidas sobre Cambio Climático (CMNUCC).

Gobierno de la República de Honduras (2015). Contribución Prevista y Determinada a Nivel Nacional.

Gobierno de la República de Panamá (2016). Contribución Nacionalmente Determinada a la Mitigación del Cambio Climático (NDC) de la Republica Panamá ante la Convención Marco de Naciones Unidas sobre Cambio Climático (CMNUCC).

Government of Belize (2015). Intended Nationally Determined Contribution.

Guerrero, E., de Keizer, O. y Córdoba, R. (2006). La Aplicación del Enfoque Ecosistémico en la Gestión de los Recursos Hídricos. Quito, Ecuador: UICN. https://portals.iucn.org/library/node/8806

Instituto Internacional para el Medio Ambiente y el Desarrollo (IIED) y Unión Internacional para la Conservación de la Naturaleza (UICN) (2016). Adaptación basada en ecosistemas ¿una fórmula beneficiosa para la sostenibilidad frente al cambio climático? Producto del conocimiento. Disponible en: http://pubs.iied.org/17364SIIED

Grupo Intergubernamental de Expertos sobre el Cambio Climático (IPCC) (2007). Cambio climático 2007: Informe de síntesis. Contribución de los Grupos de trabajo I, II y III al Cuarto Informe de evaluación del Grupo Intergubernamental de Expertos sobre el Cambio Climático Equipo de redacción principal: Pachauri, R.K. y Reisinger, A. (directores de la publicación). Ginebra, Suiza: IPCC.

IPCC (2014). Glosario. Planton, S. (ed.). Cambio Climático 2013. Bases físicas. Contribución del Grupo de trabajo I al Quinto Informe de Evaluación del Grupo Intergubernamental de Expertos sobre el Cambio Climático. Stocker, T.F., Qin, D., Plattner, G.K., Tignor, M., Allen, S.K., Boschung, J., Nauels, A., Xia, Y., Bex, V. y Midgley, P.M. (eds.). Cambridge, Reino Unido y Nueva York, NY, EE.UU: Cambridge University Press.

Iza, A. y Stein, R.(eds.) (2011). NORMAR-Reformando la gobernanza del agua. Gland, Suiza: UICN. https://portals.iucn.org/library/node/10047

Lausche, B. (2011). Directrices para la legislación relativa a áreas protegidas. Bonn, Alemania: UICN. https://portals.iucn.org/library/node/10204

Layke, C. (2009). Measuring Nature's Benefits: A Preliminary Roadmap for Improving Ecosystem Service Indicators. WRI Working Paper. Washington DC, EE.UU.: World Resources Institute. Disponible en: https://www.wri.org/publication/measuring-natures-benefits. 
MacKinnon, K., Dudley, N. y Sandwith, T. (2011). Natural solutions: protected areas helping people to cope with climate change. Fauna \& Flora International, Oryx, 45(4): 461-462. doi:10.1017/ S0030605311001608

Mann, M., Rahmstorf, S. Kornhuber, K., Steinman, B.A., Miller S.K. y Coumou, D. (2017). 'Influence of Anthropogenic Climate Change on Planetary Wave Resonance and Extreme Weather Events'. Scientific Reports 7, 45242. Disponible en: https://www.nature.com/articles/srep45242. https:// doi.org/10.1038/srep46822

Martínez, L. y Luna, M. (2019). 'Gobernanza para la Adaptación basada en Ecosistemas'. Catálogo de Adaptación basada en Ecosistemas. Serie Gobernanza. San José, Costa Rica: UICN.

Mumby, P.J., Flower, J., Chollett, I., Box, S.J., Bozec, YM., Fitzsimmons, C., Forster, J., Gill, D., Griffith-Mumby, R., Oxenford, H.A., Peterson, A.M., Stead, S.M., Turner, R.A., Townsley, P., van Beukering, P.J.H., Booker, F., Brocke, H.J., Cabañillas-Terán, N., Canty, S.W.J., Carricart-Ganivet, J.P., Charlery, J., Dryden, C., van Duyl, F.C., Enríquez, S., den Haan, J., Iglesias-Prieto, R., Kennedy, E.V., Mahon, R., Mueller, B., Newman, S.P., Nugues, M.M., Cortés Núñez, J., Nurse, L., Osinga, R., Paris, C.B., Petersen, D., Polunin, N.V.C., Sánchez, C., Schep, S., Stevens, J.R., Vallès, H., Vermeij, M.J.A., Visser, P.M., Whittingham, E., y Williams, S.M. (2014). Towards Reef Resilience and Sustainable Livelihoods: A handbook for Caribbean coral reef managers. Exeter: University of Exeter.

Organización para la Cooperación y el Desarrollo Económicos (OCDE) (2015). Principios de Gobernanza del Agua de la OCDE. París, Francia.

Organisation for Economic Co-operation and Development (OECD) (2018). Implementing the OECD Principles on Water Governance: Indicator Framework and Evolving Practices. OECD Studies on Water. París, Francia: OECD Publishing. http://dx.doi.org/10.1787/9789264292659-en.

Organización de las Naciones Unidas (ONU) (2016). Agenda 2030 y los Objetivos de Desarrollo Sostenible. Una oportunidad para América Latina y el Caribe. Comisión Económica para América Latina y el Caribe (CEPAL). Santiago, Chile.

Programa de las Naciones Unidas para el Desarrollo (PNUD) (2015). Objetivos de Desarrollo Sostenible. Disponible en: https://www.undp.org/content/undp/es/home/sustainable-develop ment-goals.html

Programa de Naciones Unidas para el Medio Ambiente (PNUMA) (2011). Hacia una economía verde: Guía para el desarrollo sostenible y la erradicación de la pobreza - Síntesis para los encargados de la formulación de políticas. Disponible en: https://www.unenvironment.org/explore-topics/ green-economy

Programa Mundial de las Naciones Unidas de Evaluación de los Recursos Hídricos/ONU-Agua (WWAP) (2018). Informe Mundial de las Naciones Unidas sobre el Desarrollo de los Recursos Hídricos 2018: soluciones basadas en la naturaleza para la gestión del agua. París, Francia: UNESCO.

Potschin, M., Jax, K., Görg, C y Haines-Young, R. (2014). OpenNESS Project Deliverable 1.1.: preliminary conceptual frameworks for the analysis of ES and NC in relation to the 4 challenges, and how these issues can be communicated and resolved in difference place based-contexts. European Commission FP7. 
Reid, H., Seddon, N., Barrow, E., Hicks, C., Hou-Jones, X., Kapos, V., Rizvi, A. R., Roe, D. y Wicander, S. (2017). Adaptación basada en Ecosistemas: Guía de preguntas para evaluar la efectividad. Londres, G.B.: IIED.

Rubio Scarano, F. (2017). 'Ecosystem-based adaptation to climate change: concept, scalability and a role for conservation science'. Perspectives in Ecology and Conservation 15: 65-73. https:// doi.org/10.1016/j.pecon.2017.05.003

Sánchez, J.C. y Roberts, J. (eds.) (2014). Transboundary Water Governance. Adaptation to Climate Change. Gland, Suiza: UICN. https://portals.iucn.org/library/node/44675

Sieber, I.M., Biesbroek, R. y de Block, D. (2018). 'Mechanism-based explanations of impasses in the governance of ecosystem-based adaptation'. Regional Environmental Change 18(8): 23792390. https://doi.org/10.1007/s10113-018-1347-1

Sistema Nacional de Áreas de Conservación (SINAC) (2013). Análisis de vulnerabilidad al cambio climático de las áreas silvestres protegidas terrestres. San José, Costa Rica.

Tickner, D., Parker, H., Moncrieff, C.R., Oates, N.E.M., Ludi, E. y Acreman, M. (2017). 'Managing Rivers for Multiple Benefits-A Coherent Approach to Research, Policy and Planning'. Frontiers in Environmental Science 5:4, 1-8. https://doi.org/10.3389/fenvs.2017.00004

Unión Internacional para la Conservación de la Naturaleza (UICN) (2006). Plan Estratégico de Incidencia Centroamérica 2006-2010. Costa Rica: UICN. https://portals.iucn.org/library/node/9303

UICN (2016). Programa Intersesional 2016-2020. Disponible en: https://portals.iucn.org/library/sites/ library/files/documents/WCC-6th-001-Es.pdf

UNEP-DHI Partnership/IUCN/TNC (2014). Green Infrastructure Guide for Water Management: ecosystem-Based Management Approaches for Water- Related Infrastructure Projects. PNUMA. Disponible en: https://portals.iucn.org/library/node/44769

Oficina de las Naciones Unidas para Reducción de Riesgo de Desastres (UNISDR) (2015). Marco de Sendai para la Reducción del Riesgo de Desastres 2015-2030.

United Nations System Task Team on the Post-2015 UN Development Agenda (UNSTT) (2012). Governance and development: thematic think piece. Nueva York, EE.UU.: Naciones Unidas Disponible en: http://www.un.org/millenniumgoals/pdf/Think\%20Pieces/7 governance.pdf

Williams, G.D., Andrews, K., Tolimieri, N., Samhouri, J.F. y Levin, P.S. (2012). Ecological Integrity. CCIEA. Reporte de la Fase II.

Wood, S.L.R., Jones, S.K., Johnson, J.A., Brauman, K.A., Chaplin-Kramer, R., Fremier, A. y DeClerck, F.A. (2018). 'Distilling the role of ecosystem services in the Sustainable Development Goals'. Ecosystem Services 29, 70-82. https://doi.org/10.1016/j.ecoser.2017.10.010

\section{Capacidades}

Arrevillaga, F. y López, D. (2019). 'Protección de ecosistemas, seguridad alimentaria e hídrica en ejidos: Cuenca del río Cahoacán, Chiapas, México'. Catálogo de Adaptación basada en Ecosistemas. Serie Comunidades con Inteligencia Natural. San José, Costa Rica: UICN. 
Cumming, G. S., Cumming, D. H. M. y Redman, C.L. (2006). 'Scale mismatches in social-ecological systems: causes, consequences, and solutions'. Ecology and Society 11(1): 14. Disponible en: http://www.ecologyandsociety.org/vol11/iss1/art14/

Gupta, J., Termeer, C., Klostermann, J., Meijerink, S., van den Brink, M., Jong, P., Nooteboom, S. y Bergsma, E. (2010). 'The Adaptive Capacity Wheel: a method to assess the inherent characteristics of institutions to enable the adaptive capacity of society'. Environmental Science \& Policy 13: 459-471. https://doi.org/10.1016/j.envsci.2010.05.006

Intergovernmental Panel on Climate Change (IPCC)(2014). 'Summary for policymakers'. In: Field, C.B., V.R. Barros, D.J. Dokken, K.J. Mach, M.D. Mastrandrea,T.E. Bilir, M. Chatterjee, K.L. Ebi, Y.O. Estrada, R.C. Genova, B. Girma, E.S. Kissel, A.N. Levy, S. MacCracken,P.R. Mastrandrea, and L.L. White (eds.) Climate Change 2014: Impacts, Adaptation, and Vulnerability. Part A: Global and Sectoral Aspects. Contribution of Working Group II to the Fifth Assessment Report of the Intergovernmental Panel on Climate Change, pp. 1-32. Cambridge, G.B. y Nueva York, NY, EE.UU.: Cambridge University Press.

Ministerio de Ambiente y Recursos Naturales (MARN) (2016). Acuerdo Ministerial 335-2016. Guatemala: Ministerio de Ambiente y Recursos Naturales.

Martínez, L. y Luna, M. (2019). ‘Gobernanza para la Adaptación basada en Ecosistemas’. Catálogo de Adaptación basada en Ecosistemas. Serie Gobernanza. San José, Costa Rica: UICN.

Narvaez-Marulanda, B.L. (2018). 'Communities perception of their adaptive capacities related to water availability in El Aguacate microwatershed - Paz River, El Salvador'. Tesis. Bonn, Alemania: United Nations University, Institute for Environment and Human Security (UNU - EHS).

Newborne, P. y Dalton, J. (2016). Water Management and Stewardship: Taking stock of corporate water behaviour. Gland, Suiza: UICN y Londres G.B.: ODI. https://doi.org/10.2305/IUCN. $\underline{\mathrm{CH}} .2016 .16 . \mathrm{en}$

Pérez de Madrid, M. (2019). Fortalecimiento de la gobernanza comunitaria para la restauración de manglares y la seguridad alimentaria del río Paz, El Salvador. Disponible en: https://panorama. solutions/es/node/3502.

Pérez de Madrid, M. y Navarro, M. (2019). Seguridad alimentaria e hídrica de las comunidades indígenas en Guatemala. Disponible en: https://panorama.solutions/es/node/3502.

Reid, H., Seddon, N., Barrow, E., Hicks, C., Hou-Jones, X., Kapos, V., Rizvi, A. R., Roe, D. y Wicander, S. (2017). Adaptación basada en Ecosistemas: Guía de preguntas para evaluar la efectividad. Londres, G.B: IIED.

Smit, B. y Pilifosova, O. (2001). 'Adaptation to climate change in the context of sustainable development and equity'. En: McCarthy, J.J., Canzianni, O.F., Leary, N.A., Dokken, D.J. y White, K.S. (eds.), Climate Change 2001: Impacts, Adaptation, and Vulnerability, pp. 876-912. -Contribution of Working Group II to the Third Assessment Report of the Intergovernmental Panel on Climate Change-. Cambridge, G.B.: Cambridge University Press.

World Economic Forum (WEF) (2016). The Future of Jobs. Employment, Skills and Workforce Strategy for the Fourth Industrial Revolution. Global Challenge Insight Report. World Economic Forum. 


\section{Evidencia}

Albert, C., Schröter, B., Haase, D., Brillinger, M., Henze, J., Herrmann, S., Gottwald, S., Guerrero, P., Nicolas, C., y Matzdorf, B. (2019). 'Addressing societal challenges through nature-based solutions: How can landscape planning and governance research contribute?'. Landscape and Urban Planning 182: 12-21. https://doi.org/10.1016/j.landurbplan.2018.10.003

Bennett, N.J. y Satterfield, T. (2018). 'Environmental governance: A practical framework to guide design, evaluation, and analysis'. Conservation Letters. https://doi.org/10.1111/conl.12600

Calliari, E., Staccione, A. y Mysiak, J. (2019). 'An assessment framework for climate-proof nature-based solutions'. Science of the Total Environment 656: 691-700. https://doi.org/10.1016/j. scitotenv.2018.11.341

CDB. (2010). Convenio sobre la Diversidad Biológica: ABS Tema Conocimiento tradicional. Disponible en: https://www.cbd.int/abs/infokit/factsheet-tk-es.pdf

Convenio sobre la Diversidad Biológica (CBD) (2018). Voluntary Guidelines for the design and effective implementation of ecosystem-based approaches to climate change adaptation and disaster risk reduction. CBD/SBSTTA/22/INF/1. Vigésimo Segunda Reunión. Montreal, Canadá, 2-7 de Julio de 2018. Disponible en: https://www.cbd.int/doc/publications/cbd-ts-93-en.pdf

Chong, J. (2014). 'Ecosystem-based approaches to climate change adaptation: progress and challenges'. International Environment Agreements 14:391-405. https://doi.org/10.1007/s10784014-9242-9

Collins, A., Coughlin, D., Miller, J., Kirk, S. (2015). The Production of Quick Scoping Reviews and Rapid Evidence Assessments: A How To Guide. Department for Environment, Food and Rural Affairs. Natural Environment Research Council and Environment Agency. G.B.

Comas, D. (2015). ‘¿Qué es la evidencia científica y cómo utilizarla? EMPIRIA'. Revista de Metodología de Ciencias Sociales 31: 211-214. https://doi.org/10.5944/empiria.31.2015.14560

Cvitanovic, C., McDonald, J. y Hobday, A.J. (2016). 'From science to action: Principles for undertaking environmental research that enables knowledge exchange and evidence-based decision-making'. Journal of Environmental Management 183: 864-874. https://doi.org/10.1016/j. jenvman.2016.09.038

Departamento Administrativo Nacional de Estadística (DANE) (2013). Guía para diseño, construcción e interpretación de indicadores: Estrategia para el Fortalecimiento Estadístico Territorial. Herramientas estadísticas para una gestión territorial más efectiva. Número 2. Colombia.

Davenport, T.H. y Prusak, L. (1998). Working knowledge: how organizations manage what they know. Disponible en: https://books.google.co.cr/books?hl=en\&lr=\&id=-4-7vmCVG5cC\&oi=fnd\&pg=PR7\&dq=Thomas+H.+Davenport+\&ots=mzkaX 9IL6\&sig=dOu8VAOjfnslcUThRGqSdi4MidE\&redir esc=y\#v=onepage\&q=Thomas\%20H.\%20Davenport\&f=false

Dendoncker, N., Turkelboom, F., Boeraeve, F., Boerema, A., Broekx, S., Fontaine, C., Demeyer, R., De Vreese, R., Devillet, G., Keune, H., Janssens, L., Liekens, I., Lord-Tarte, E., Popa, F., Simoens, I., Smeets, N., Ulenaers, P., Van Herzele, A., Van Tichelen, K. y Jacobs, S. (2018). 'Integrating Ecosystem Services values for sustainability? Evidence from the Belgium Ecosystem Services community of practice'. Ecosystem Services 31: 68-76. https://doi.org/10.1016/j.ecoser.2018.03.006 
Doswald, N., Munroe, R., Roe, D., Giuliani, A., Castelli, I., Stephens, J., Möller, I., Spencer, T., Vira, B. y Reid, H. (2014). 'Effectiveness of ecosystem-based approaches for adaptation: review of the evidence-base'. Climate and Development. http://dx.doi.org/10.1080/17565529.2013.867247

Encalada, M. A. (2005). Comunicación sobre el cambio climático. Manual para su planificación y práctica en América Latina. Ecuador: OIKOS y Kenia: PNUMA. Disponible en: https://www.oei. es/historico/decada/manual.htm

Hills, T. (2015). The State of Ecosystem-based Adaptation (EbA) to Climate Change in 2015 -EbA. Policy Analysis-. Informe técnico. Conservación Internacional. Disponible en: https://www.conservation.org/publications/Documents/EbA-Synthesis-28-July-2015.pdf

Iza, A. y Stein, R. (eds.) (2011). NORMAR - Reformando la gobernanza del agua. Gland, Suiza: UICN.

Marín, M. y Navarro, M. (2019). Adaptación basada en Ecosistemas y seguridad alimentaria en la subcuenca del río Esquichá, Guatemala. Catálogo de Adaptación basada en Ecosistemas. Serie Comunidades con Inteligencia Natural. San José, Costa Rica: UICN.

Marín, M., Pérez de Madrid, M. y Cruz, E. (2019). Tendencias, enfoques y oportunidades de los proyectos sobre cambio climático y adaptación en Mesoamérica. Catálogo de Adaptación basada en Ecosistemas. Serie Evidencia. San José, Costa Rica: UICN. Disponible en: http://iucn. cr/arcgis/apps/webappviewer/index.html?id=202a718c741e498aad091b39ee93508f

McKinnon, M.C., Cheng, S.H., Dupre, S., Edmond, J., Garside, R., Glew, L., Holland, M.B., Levine, E., Masuda, Y.J., Miller, D.C., Oliveira, I., Revenaz, J., Roe, D., Shamer, S., Wilkie,D. Wongbusarakum, S. y Woodhouse, E. (2016). 'What are the effects of nature conservation on human well-being? A systematic map of empirical evidence from developing countries'. Environmental Evidence 5:8. DOI 10.1186/s13750-016-0058-7

Mehvar, S., Filatova, T., Sarker, M.H. y Ranasinghe, R. (2019). 'Climate change-driven losses in ecosystem services of coastal wetlands: A case study in the West coast of Bangladesh'. Ocean and Coastal Management 169: 273-283. https://doi.org/10.1016/j.ocecoaman.2018.12.009

Montaña, T. (2015). Gobernanza para el Cambio Climático Estudio del caso gobierno local de Mendoza-Argentina. Banco Interamericano de Desarrollo. Disponible en: http://www.mendoza.gov. ar/wp-content/uploads/sites/14/2016/05/Gobernanza-para-el-CC-en-gobiernos-locales-VF. $\underline{\mathrm{pdf}}$

Munroe, R., Roe, D., Doswald, N., Spencer, T., Möller, I., Vira, B., Reid, H., Kontoleon, A., Giuliani, A., Castelli, I. y Stephens, J. (2012). 'Review of the evidence base for ecosystem-based approaches for adaptation to climate change'. Environmental Evidence 1:13. Disponible en: http://www.environmentalevidencejournal.org/content/1/1/13. https://doi.org/10.1186/2047-2382-1-13

Nalau, J. y Becken, S. (2018). Ecosystem-based Adaptation to Climate Change: Review of Concepts. Griffith Institute for Tourism. Research Report No 15. Queensland, Australia.

Organization for Economic Co-operation and Development (OECD) (2018). Implementing the OECD Principles on Water Governance: Indicator Framework and Evolving Practices. OECD Studies on Water. París, Francia: OECD Publishing. http://dx.doi.org/10.1787/9789264292659-en

Pérez de Madrid, M. y Guillén, R. (2019). Seguridad alimentaria e hídrica en la cuenca del río Goascorán (Honduras, El Salvador). Catálogo de Adaptación basada en Ecosistemas. Serie Comunidades con Inteligencia Natural. San José, Costa Rica: UICN. 
PNUD-INECC (2017). Experiencias internacionales en el desarrollo de sistemas de indicadores para el seguimiento de políticas de cambio climático. Proyecto 00085488: "México: Sexta Comunicación Nacional ante la Convención Marco de Naciones Unidas sobre Cambio Climático". Ciudad de México. Disponible en: https://www.gob.mx/inecc/documentos/experiencias-internacionales-desarrollo-de-un-sistema-de-indicadores-que-oriente-la-evaluacion-de-la-politi-

ca-nacional-de-cambio-climatico

Programa Mundial de las Naciones Unidas de Evaluación de los Recursos Hídricos)/ONU-Agua (WWAP) (2018). Informe Mundial de las Naciones Unidas sobre el Desarrollo de los Recursos Hídricos 2018: Soluciones basadas en la naturaleza para la gestión del agua. París, Francia: UNESCO.

Raum, S. (2018). 'A framework for integrating systematic stakeholder analysis in ecosystem services research: Stakeholder mapping for forest ecosystem services in the UK'. Ecosystem Services 29: 170-184. https://doi.org/10.1016/j.ecoser.2018.01.001

Raymond, C.M., Frantzeskaki, N., Kabisch,N., Berry, P., Breil, M., Razvan Nita, M., Geneletti, D. y Calfapietra, C. (2017). 'A framework for assessing and implementing the co-benefits of nature-based solutions in urban areas'. Environmental Science \& Policy 77:15-24. https://doi. org/10.1016/i.envsci.2017.07.008

Real Academia Española (RAE) (2018). Diccionario de la lengua española. Disponible en: https://dle. rae.es/?w=diccionario.

Reid, H., Bourne, A., Mulle, H., Podvin, K., Scorgie, S., y Orindi, V. (2018). 'A Framework for Assessing the Effectiveness of Ecosystem-Based Approaches to Adaptation'. En: Zommers, Z. y Alverson, K. (eds.) Resilience: The Science of Adaptation to Climate Change, pp. 207-216. Amsterdam, Países Bajos. doi: 10.1016/B978-0-12-811891-7.00016-5

Reid, H., Pérez de Madrid, M. y Ramírez, O. (2018). Ecosystem-based approaches to adaptation: strengthening the evidence and informing policy. Research results from the Adaptation,Vulnerability and Ecosystems (AVE) project, Costa Rica and Panama. IIED-NUAmbiente-UICN-WCMC. Disponible en: http://pubs.iied.org/17627IIED.

Reid, H., Pérez de Madrid, M., Ramírez, O. y Hicks, C. (2019a). Ecosystem-based approaches to adaptation: strengthening the evidence and informing policy. Research results from the Adaptation,Vulnerability and Ecosystems (AVE) project, Costa Rica and Panama. Disponible en: http:// pubs.iied.org/17627IIED/

Reid, H., Pérez de Madrid, M., Ramírez, O. y Hicks, C. (2019b). Ecosystem-based climate adaptation: building on the positives in El Salvador. Disponible en: http://pubs.iied.org/17496IIED/

Reid, H., Seddon, N., Barrow, E., Hicks, C., Hou-Jones, X., Kapos, V., Rizvi, A.R., Roe, D. y Wicander. S. (2017). Adaptación basada en Ecosistemas: Guía de preguntas para evaluar la efectividad. Londres, G.B.: IIED.

Seddon, N., Reid, H., Barrow, E., Hicks, Ch., Hou-Jones, X., Kapos, V., Rizvi, A.R. y Roe, D. (2016). Ecosystem-based approaches to adaptation: strengthening the evidence and informing policy. Research overview and overarching questions. Londres, G.B.: IIED.

Sieber, I.M., Biesbroek, R. y de Block, D. (2018). 'Mechanism-based explanations of impasses in the governance of ecosystem-based adaptation'. Regional Environmental Change. https://doi. org/10.1007/s10113-018-1347-1. 
SINAC-PNUD-GEF (2018). Proyecto Humedales. Herramientas para mejorar la gestión en Sitios Ramsar de Costa Rica y otros ecosistemas de humedal. Reporte 2014-2018 del Proyecto Humedales. SINAC/PNUD/GEF. San José, Costa Rica.

United Nations System Task Team on the Post-2015 UN Development Agenda (UNSTT) (2012). Governance and development: thematic think piece. Nueva York, EE.UU.: Naciones Unidas Disponible en: http://www.un.org/millenniumgoals/pdf/Think\%20Pieces/7 governance.pdf

Vignola, R., Otárola, M., Alpízar, F., Rivera, P. (2019). ‘Gobernanza para la Adaptación basada en Ecosistemas (AbE) para pequeños caficultores de América Central'. Agronomía Mesoamericana 30 (1): 19-32. https://doi.org/10.15517/am.v30i1.32615

\section{Política}

Acuerdo de París, firmado el 12 de diciembre de 2015 y entrada en vigor el 4 de noviembre de 2016.

Aguilar, G. y Iza, A.O (2009). Gobernanza de Aguas Compartidas. Aspectos Jurídicos e Institucionales. IUCN Environmental Policy and Law Paper No. 58 rev. Gland, Suiza: UICN. https://portals. iucn.org/library/node/9421

Amaya, O. (2002). La Constitución ecológica de Colombia. Análisis comparativo con el sistema constitucional latinoamericano. Bogotá: Universidad Externado de Colombia

Andrade A., Arguedas S. y Vides R. (2011). Guía para la aplicación y monitoreo del Enfoque Ecosistémico. CEM-UICN, CI-Colombia, ELAP-UCI, FCBC, UNESCO-Programa MAB.

Andrade, A., Córdoba, R., Dave, R., Girot, P., Herrera-F, B., Munroe, R., Oglethorpe, J., Paaby, P., Pramova, E., Watson, J., Vergara, W. y Suarez, I. (2012). Principles and Guidelines for Integrating Ecosystem-based Approaches to Adaptation in Project and Policy Design. Turrialba, Costa Rica: IUCN-CEM, CATIE

Austin, E., Ford, J.D., Berrag-Ford, L., Biesbroek, R. y Ross, N.A. (2019). 'Enabling local public health adaptation to climate change'. Social Science \& Medicine vol. 220, pp. 236-244. https://doi. org/10.1016/j.socscimed.2018.11.002

Boer, B. y Clarke, P. (2012). Legal frameworks for ecosystem-based adaptation to climate change in the Pacific Islands. Apia, Samoa: SPREP.

Burhenne-Guilmin, F. y Scanlon, J. (eds.) (2004). International Environmental Governance. IUCN Environmental Policy and Law Paper No. 49. Gland, Suiza: UICN. https://portals.iucn.org/library/ node/8377

Convention on Biological Diversity (CBD) (2006). Decision VIII/30. Biodiversity and climate change: guidance to promote synergy among activities for biodiversity conservation, mitigating or adapting to climate change and combating land degradation, Curitiba, Brazil, 20-31 March, UN Doc. UNEP/CBD/COP/DEC/VIII/30

CDB (2009). Connecting Biodiversity and Climate Change Mitigation and Adaptation: Informe del Segundo Grupo Ad Hoc de Expertos Técnicos sobre Biodiversidad y Cambio Climático. Montreal, Serie Técnica No. 41. 
CBD (2014). Decision XII/20. Biodiversity and climate change and disaster risk reduction, 6-17 October, UN Doc. UNEP/CBD/COP/DEC/XII/20.

CDB (2018). Decision 14/5. Biodiversity and Climate Change. COP14. Sharm El-Sheikh, Egypt. CBD/ COP/DEC/14/5

Comisión Económica Para América Latina (CEPAL) (2009). Guía de evaluación ambiental estratégica. NU.

Convention on the Conservation of Migratory Species of Wild Animals (CMS) (2017). Decisiones 12/72 a 12/74. Cambio climático y especies migratorias. 23-28 octubre, UN Doc. UNEP/CMS/ COP12/Decisiones.

CMS (2017b). Resolución 12/21. Cambio Climático y Especies Migratorias. 23-28 de octubre. UN Doc. UNEP/CMS/Resolución 12.21.

Constitución Política de Colombia (1991).

Convención Relativa a los Humedales de Importancia Internacional Especialmente como Hábitat de Aves Acuáticas (Convención de Ramsar) (2015). Resolución XII.2. El Cuarto Plan Estratégico para 2016 - 2024, 1 a 9 de junio.

Convención de Ramsar (2015b). Resolución XII.13. Humedales y reducción del riesgo de desastres, 1 a 9 de junio.

Cosens, B., Craig, R., Hirsch, S.L., Craig, A. A., Benson, M., De Caro, A., Garmestani, A. S., Gosnell, H., Ruhl, J.B. y Schlager, E. (2017). 'The Role of Law in Adaptive Governance'. Ecology and Society 22(1):30. https://doi.org/10.5751/ES-08731-220130

Craig, R. K. (2010). "'Stationary is dead"- Long live transformation: Five Principles for Climate Change Adaptation Law'. Harvard Environmental Law Review 34:10-73.

Flatt, V. (2012). 'Adapting Laws for a Changing World: A Systemic Approach to Climate Change Adaptation'. Florida Law Review 64)1): 280.

Gesellschaft für Internationale Zusammenarbeit (GIZ) (2018). Finance options and instruments for Ecosystem-based Adaptation. Overview and compilation of ten examples. Authors: Kiran Hunzai, Thiago Chagas, Lieke 't Gilde, Tobias Hunzai, Nicole Krämer. Bonn, Alemania: Deutsche Gesellschaft für Internationale Zusammenarbeit (GIZ) GmbH.

Greiber, T. (ed.) (2010). Pagos por servicios ambientales. Marcos jurídicos e institucionales. Gland, Suiza: UICN. https://portals.iucn.org/library/node/9609

Greiber, T. y Schiele, S. (2011). Governance of Ecosystem Services. Lessons learned from Cameroon, China, Costa Rica and Ecuador. Gland, Suiza: UICN. https://portals.iucn.org/library/node/10078

Intergovernmental Panel on Climate Change (IPCC) (2014). Cambio climático 2014: Impactos, adaptación y vulnerabilidad. Resúmenes, preguntas frecuentes y recuadros multicapítulos. Contribución del Grupo de trabajo II al Quinto Informe de Evaluación del Grupo Intergubernamental de Expertos sobre el Cambio Climático. Field, C.B., Barros, V.R., Dokken, D.J., Mach, K.J., Mastrandrea, M.D., Bilir, T.E., Chatterjee, M., Ebi, K.L.,Estrada, Y.O.,Genova, R.C., Girma, B., Kissel, E.S., Levy, A.N., MacCracken, A.N., Mastrandrea, P.R. y White, L.L. (eds.). Ginebra, Suiza: Organización Meteorológica Mundial. Disponible en: https://www.ipcc.ch/site/assets/uploads/2018/03/WGIIAR5-IntegrationBrochure_es-1.pdf 
Iza, A. y Stein, R. (eds.) (2011). NORMAR - Reformando la gobernanza del agua. Gland, Suiza: UICN. https://portals.iucn.org/library/node/10047

Lausche, B. (2012). Directrices para la legislación relativa a áreas protegidas. Bonn, Alemania: UICN. https://portals.iucn.org/library/node/10204

Lausche, B., Farrier, D., Verschuuren, J., La Viña, A. G. M., Trouwborst, A., Born, C.H. y Aug, L. (2013). The Legal Aspects of Connectivity Conservation. A Concept Paper. Bonn, Alemania: UICN. https://portals.iucn.org/library/node/30283

Lausche, B. (2018). Integrated Planning. Policy and law tools for biodiversity conservation and climate change. Gland, Suiza: UICN. https://doi.org/10.2305/IUCN.CH.2019.EPLP.88.en

Ley de Cambio Climático de Honduras.

Ley de Cambio Climático del Estado de Chiapas.

Ley General de Cambio Climático de México.

Ley Marco para regular la reducción de la vulnerabilidad, la adaptación obligatoria ante los efectos del cambio climático y la mitigación de gases de efecto invernadero de Guatemala.

Lobos, V. (2015). 'La Evaluación Ambiental Estratégica (EAE) como instrumento de gestión ambiental: conceptos, evolución y práctica'. En: Carmona-Lara, M.C. y Acuña-Hernández, A.L. (coord.) La Constitución y los derechos ambientales. Instituto de Investigaciones Jurídicas de la Universidad Nacional Autónoma de México. Disponible en: https://archivos.juridicas.unam.mx/www/ bjv/libros/9/4089/12.pdf

Martin, P., Boer, B. y Slobodian, L. (eds.) (2016) Framework for Assessing and Improving Law for Sustainability. Gland, Suiza y Bonn, Alemania: IUCN. https://doi.org/10.2305/IUCN.CH.2016. EPLP.87.en

Millenium Ecosystem Assessment. (2005). Ecosystem and Human Wellbeing: Synthesis. Washington: Island Press.

Organization for Economic Co-operation and Development (OECD) (2015). National Climate Change Adaptation Framework: emerging practices in monitoring and evaluation. París. Francia: OECD Publishing

Plan Nacional de Adaptación al Cambio Climático (2006). Marco para la coordinación entre administraciones públicas para las actividades de evaluación de impactos, vulnerabilidad y adaptación al cambio climático. Oficina Española de Cambio Climático. S.G. para la prevención de la contaminación y del cambio climático. Ministerio de Medio Ambiente.

Proyecto "Adaptation and Blue Carbon in Mexico". (SF) Disponible en: https://www.youtube.com/ watch? $v=$ AyovXQIVKQM\&t=11s

Proyecto Ecovalor. (SF) Soluciones Económico-Ambientales. Incorporando soluciones ambientales múltiples y sus implicaciones económicas, en el manejo de los paisajes, bosques y sectores productivos en Cuba. Consultar con Oficina de Implementación Nacional. Centro Nacional de Áreas Protegidas. Disponible en: www.snap.cu

Ramsar Convention on Wetlands (2002). Resolution VIII.3 Climate change and wetlands: impacts, adaptation, and mitigation. 18-26 November. 
Ramsar Convention on Wetlands (2008). Resolution X.24 Climate change and wetlands. 28 October-4 November.

Rozas-Vásquez, D., Fürst, C., Geneletti, D. y Almendra, O. (2018). 'Integration of ecosystem services in strategic environmental assessment across spatial planning scales'. Land Use Policy 71: 303310. https://doi.org/10.1016/j.landusepol.2017.12.015

Ruhl, J.B. (2010). 'Climate Change Adaptation and the Structural Transformation of Environmental Law'. Environmental Law 40.

Sanchez, J.C. y Roberts, J. (eds.) (2013). Transboundary Water Governance: Adaptation to Climate Change. IUCN Environmental Policy and Law Paper No. 75. Bonn, Alemania: UICN. https:// portals.iucn.org/library/node/44675

Sands, F. (1995). Principles of International Environmental Law. Frameworks, standards and implementation. Manchester, G.B.: Manchester University Press.

Tanner-McAllister, S., Rhodes, J. y Hockings, M. (2017). 'Managing for climate change on protected areas: An adaptive management decision making framework'. Journal of Environmental Management 204. https://doi.org/10.1016/j.jenvman.2017.09.038

The Economics of Ecosystems and Biodiversity (TEEB)-Russia (2018). Ecosystem Services of Russia. Prototype National Report. Vol. 1. Terrestrial Ecosystem Services. Moscow. Disponible en: http://www.biodiversity.ru/programs/ecoservices/first-steps/Ecosystem-Services-Russia_V1_ eng_web.pdf

Unión Internacional para la Conservación de la Naturaleza (IUCN) (2017). 'El Desafío de Bonn: Catalizando liderazgo en América Latina'. Forest Brief 14.

United Nations Convention to Combat Desertification in those Countries Experiencing Drough and/ or Desertification, Particularly in Africa (UNCCD) (2017a). Decision 21/COP.13: Work programme of the Science-Policy Interface for the biennium 2018-2019, (12 October 2017), (UN Doc. ICCD/ $\operatorname{COP}(13) / 21)$

UNCCD (2017b). Decision 4/COP.13: Report on progress in the implementation of the comprehensive communication strategy and on the United Nations Decade for Deserts and the Fight against Desertification (2010-2020), (6-16 September 2017), (UN Doc. ICCD/COP(13)/4)

United Nations Economic Commission for Europe (UNECE) (2018). DRAFT Words into Action. Implementation Guide for Addressing Water-Related Disasters and Transboundary Cooperation: Integrating disaster risk management with water management and climate change adaptation. 28-30 May. UN Doc. ECE/MP.WAT/WG.2/2018/INF.8

UNECE. Task Force on Water and Climate Change. https://www.unece.org/env/water/water_and_climate.html. Consultada: el 20 de julio de 2018.

United Nations Environment Programme (UNEP) (2014). Integrating Ecosystem Services in Strategic Environmental Assessment: A guide for practitioners. A report of Proecoserv. Geneletti, D.

UNEP (2019). Environmental Rule of Law. First Global Report. Nairobi,Kenia: United Nations Environment Programme.

United Nations Framework Convention on Climate Change (UNFCCC) (2013). Report on the technical workshop on ecosystem-based approaches for adaptation to climate change, 28th SABSTA session, Bonn, 3-14 June. UN Doc FCCC/SBSTA/2013/2. 
Vallejo, L. (2017). Insights from national adaptation monitoring and evaluation systems. Climate Change Expert Group. Paper No. 2017(3), OECD. Disponible en: https://www.oecd.org/environment/cc/Insights\%20from\%20national\%20adaptation\%20monitoring\%20and\%20evaluation\%20systems.pdf

Vasseur, L., Horning, D., Thornbush, M., Cohen-Schacham, E., Andrade, A., Barrow, E., Edwards, S.R., Wit, P., Jones, M. (2017). Complex problems and unchallenged solutions: Bringing ecosystem governance to the forefront of the UN. https://doi.org/10.1007/s13280-017-0918-6

Verschuuren, J. (2013). 'Legal Aspects of Climate Change Adaptation'. En: Hollo, E., Kulovesi, K., Mehling, M. (eds.) Climate Change and the Law. Amsterdam, Países Bajos: Springer Netherlands. https://doi.org/10.1007/978-94-007-5440-9 11

Verschuuren, J. (ed.) (2013a) Research Handbook on Climate Change Adaptation. Cheltenham, G.B. y Northampton, EE.UU. : Edward Elgar Publishing Limited.

Yazykova, S., Bruch, C. (2018). 'Incorporating Climate Change Adaptation into Framework Environmental Laws'. Environmental Law Reporter 48.

\section{Instituciones}

Asamblea Legislativa de Costa Rica. (1995). Ley Orgánica del Ambiente No. 7554.

Buscher, B., Dressler, W., y Fletcher, R. (eds.) (2014). Nature Inc.: Environmental Conservation in the Neoliberal Age, p.304. Tucson, EE.UU.: University of Arizona Press.. https://doi.org/10.2307/j. ctt183pdh2

Bolman, L.G. y Deal, T.E. (2013). Reframing Organizations: Artistry, Choice and Leadership. Jossey-Bass.

Chaudhury, A., Ventresca, M., Thornton, T., Helfgott, A., Sova, C., Baral, P., Rasheed, T., y Ligthart, J. (2016). 'Emerging meta-organisations and adaptation to global climate change: Evidence from implementing adaptation in Nepal, Pakistan and Ghana'. Global Environmental Change 38: 243-257. https://doi.org/10.1016/j.gloenvcha.2016.03.011

Comisión Nacional de Prevención de Riesgos y Atención de Emergencias (CNE) (2009). Reglamento de Organización y Funcionamiento de los Comités Regionales, Municipales y Comunales de Emergencia. Acuerdo No. 123-2009

Congreso Nacional de Honduras (2014). Ley de Cambio Climático. Decreto 297-2013.

Congreso de la República de Guatemala (2013). Ley Marco para regular la reducción de la vulnerabilidad, la adaptación obligatoria ante los efectos del climático y la mitigación de gases de efecto invernadero. Decreto 7-2013.

Congreso de la Unión de los Estados Unidos Mexicanos (2012). Ley General de Cambio Climático. Nueva Ley DOF 06-06-2012.

Congreso del Estado de Chiapas. (2014). Ley para la Adaptación y Mitigación ante el Cambio Climático en el Estado de Chiapas. Decreto 228.

Cuevas S.C. (2018). 'Institutional dimensions of climate change adaptation: insights from the Philippines'. Climate Policy 18(4): 499-511. https://doi.org/10.1080/14693062.2017.1314245 
Dirección de Cambio Climático de Costa Rica (DCC) (2018). ¿Quiénes somos?. Página web de la DCC. Disponible en: http://www.cambioclimaticocr.com/2012-05-22-19-42-06/quienes-somos. (Consultada: 02 de agosto de 2018)

Delamaza Escobar, G. y Flores, L. (2017). ‘El Estado en América Latina: un análisis desde las políticas públicas'. Polis (Santiago), 16(48): 5-10. https://dx.doi.org/10.4067/S0718-65682017000300005 (Consultado: 10 de agosto de 2018).

Fröhlich J. y Knieling J. (2013). 'Conceptualising Climate Change Governance’. En: Jörg Knieling y Walter Leal Filho. Climate Change Governance. Berlín y Heidelberg, Alemania: Springer-Verlag https://doi.org/10.1007/978-3-642-29831-8

Girard C., Pulido-Velazquez, M., Rinaudo, J., Pagé, C. y Caballero, Y. (2015). 'Integrating top-down and bottom-up approaches to design global change adaptation at the river basin scale'. Global Environmental Change 34: 132-146. https://doi.org/10.1016/j.gloenvcha.2015.07.002

Gobierno de la República de Costa Rica. (2007). Decreto Ejecutivo 34361-MP.

Gobierno de la República de Costa Rica. (2011). Decreto Ejecutivo 35669-MINAET.

Gobierno de la República de Costa Rica. (2011). Decreto Ejecutivo 36823-MINAET.

Gobierno de la República de Costa Rica. (2014). Decreto Ejecutivo 38536-PLAN.

Gobierno de la República de Costa Rica. (2017). Decreto Ejecutivo 40615- MINAE.

Gobierno de la República de Costa Rica. (2017). Decreto Ejecutivo 40616-MINAE.

Gobierno de la República de Honduras. (2017). Plan Maestro Agua, Bosque y Suelo. Tegucigalpa, Honduras.

González Jacobo, J.A. (2008). El Desafío de la descentralización en Centroamérica. Ciudad de Guatemala, Guatemala: Estado de la Región.

Gupta, J., Termeer, C., Klostermann, J., Meijerink, S., van den Brink, M., Jong, P, Nooteboom, S., y Bergsma, E. (2010). 'The Adaptive Capacity Wheel: a method to assess the inherent characteristics of institutions to enable the adaptive capacity of society'. Environmental Science and Policy 13: 459-471. https://doi.org/10.1016/j.envsci.2010.05.006

Iza, A. y Stein, R. (Eds) (2011). NORMAR - Reformando la gobernanza del agua. Gland, Suiza: UICN.

Lozano Moheno, I. (2012). Ejidos y comunidades: ¿cuarto nivel de gobierno?: exploración sobre las facultades legales de ejidos y comunidades en materia ambiental. México DF, México: Centro de Investigación y Docencia Económicas, División de Administración Pública.

Luna, M. y Cruz, E. (2019). Gobernanza para la Adaptación basada en Ecosistemas: Cuenca del Río Sixaola. San José, Costa Rica: UICN.

Martínez, L. y Navarro, M. (2019). Gobernanza para la Adaptación basada en Ecosistemas: Cuenca del Río Caotán, Guatemala. San José, Costa Rica: UICN.

Millennium Ecosystem Assessment (2005). Ecosystems and Human Well Being: Synthesis. Washington D.C., EE. UU.: Island Press

Ministerio de Ambiente y Energía (MINAE) (2018). Política Nacional de Adaptación. San José, Costa Rica: MINAE. 
Ministerio de Ambiente y Recursos Naturales de Guatemala (MARN) (2018). Dirección de Cambio Climático. Disponible en: http://www.marn.gob.gt/paginas/Direccin de Cambio Climtico. (Consultada: 10 de agosto de 2018)

Mubaya, C.P. y Mafongoya, P. (2017). 'The role of institutions in managing local level climate change adaptation in semi-arid Zimbabwe'. Climate Risk Management 16: 93-105. https://doi. org/10.1016/j.crm.2017.03.003

North, C.N. (1991). 'Institutions'. Journal of Economic Perspectives 5: 97-112. https://doi.org/10.1257/ jep.5.1.97

Observatorio Nacional de Cambio Climático para el Desarrollo Sostenible (ONCCDS) (s.a.). Secretaría de Energía, Recursos Naturales, Ambiente y Minas (SERNA). Tegucigalpa, Honduras.

O'Riordan, T. y Jordan, A. (1999). 'Institutions, climate change and cultural theory: towards a common analytical framework'. Global Environmental Change 9: 81-93. https://doi.org/10.1016/ S0959-3780(98)00030-2

Pan, C., Peters, G., Andrew, R., Korsbakken, J., Li, S., Zhou, D. and Zhou, P. (2017). 'Emissions embodied in global trade have plateaued due to structural changes in China'. Earth's Future 5:9; 934-46. https://doi.org/10.1002/2017EF000625

Sánchez, J.C. y Roberts, J. (eds.) (2014). Transboundary Water Governance. Adaptation to Climate Change. Gland, Suiza: UICN. https://portals.iucn.org/library/node/44675

Secretaría de Medio Ambiente y Recursos Naturales (SEMARNAT) (2018). Sistema Nacional de Cambio Climático (SINACC) 2018. Disponible en: https://www.gob.mx/inecc/acciones-y-programas/sistema-nacional-de-cambio-climatico-sinacc. (Consultada: 02 de agosto de 2018).

Secretaría de Recursos Naturales y Ambiente (SERNA) (2018a). Plan Nacional de Adaptación al Cambio Climático. Tegucigalpa, Honduras: SERNA.

SERNA (2018b). ¿Quiénes Somos?. Disponible en: http://www.miambiente.gob.hn/dncc/quiensomos/. (Consultada: 10 de agosto de 2018).

Steffen, W., Biggs, R., Richardson, K., de Wit, C., Gerten, D., Mace, G., Publist, C., Fetzer, I., Rockstrom, J., Rockstrom, J., Cornell, S., Fetzer, I., Biggs, R., Folke, C., Reyers, B., Richardson, K., Bennett, E., Carpenter, S., de Vries, W., de Wit, C., Gerten, D., Heinke, J., Mace, G., Persson, L., Ramanathan, V., y Sorlin, S. (2015). 'Planetary boundaries: Guiding human development on a changing planet'. Science 347: 6223. https://doi.org/10.1126/science.1259855

Unión Internacional para la Conservación de la Naturaleza (UICN) (2017). Reglamento de la Comisión Binacional de la Cuenca del Río Sixaola (CBCRS). San José, Costa Rica.

Vignola, R., Locatelli B., Martínez C., y Imbach P. (2009). 'Ecosystem-based adaptation to climate change: what role for policy-makers, society and scientists?'. Mitigation and Adaptation Strategies for Global Change 14: 691-696. https://doi.org/10.1007/s11027-009-9193-6

Vij, S., Moors, E., Ahmad, B., Arfanuzzaman, M., Bhadwal, S., Biesbroek, R., Gioli, G., Groot, A. Mallick, D., Regmi, B., Saeed, B.A., Ishaq, S., Thapa, B., Werners, S.E. and Wester, P. (2017). 'Climate adaptation approaches and key policy characteristics: Cases from South Asia'. Environmental Science and Policy 78: 58-65. https://doi.org/10.1016/i.envsci.2017.09.007 
Wang , J., Brown, D.G. y Agrawal, A. (2013). 'Climate adaptation, local institutions, and rural livelihoods: A comparative study of herder communities in Mongolia and Inner Mongolia, China'. /* 23: 1673-1683. https://doi.org/10.1016/j.gloenvcha.2013.08.014

\section{Negociación}

Borrini-Feyerabend, G., Farvar, M. T., Nguinguiri, J. C. y Ndangang, V. A. (2007). Comanagement of Natural Resources: Organising, Negotiating and Learning-by-Doing. Reimpresión 2007. Kasparek Verlag, Heidelberg, Alemania: GTZ y IUCN.

IISD-IUCN (2002). Conserving the Peace: Resources, Livelihoods and Security. Ginebra, Suiza: IISD.

Intergovernmental Panel on Climate Change (IPCC) (2014). Climate Change 2014: Synthesis Report. Contribution of Working Groups I, II and III to the Fifth Assessment Report of the Intergovernmental Panel on Climate Change [Core Writing Team, Pachauri, R.K. y Meyer, L.A. (eds.)]. Ginebra. Suiza: IPCC

McNeely, J. (1995). Expanding Partnerships in Conservation. Segunda edición. New York: Island Press.

Ostrom, E. (2000). El gobierno de los bienes comunes. La evolución de las instituciones de acción colectiva. México: UNAM-CRIM-FCE.

Proyecto Estado de la Nación (2016). Quinto Informe Estado de la Región en Desarrollo Humano Sostenible. San José, Costa Rica.

Rossing, T., Otzelberger, A. y Girot, P. (2014). Scaling- up the use of tools for community-based adaptation: Issues and challenges. In: Community Based Adaptation to Climate Change: Scaling it up, J. Ayers et al (eds.), Londres. G.B.: Earthscan. 
